INTERNATIONAL MONETARY FUND

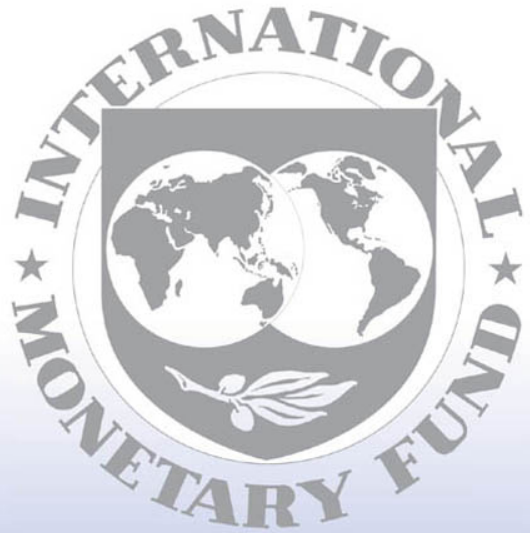

Staff

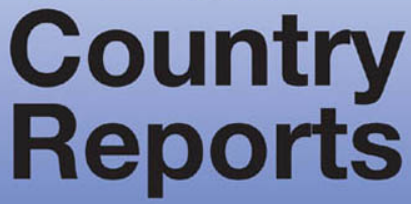




\section{Nicaragua: Poverty Reduction Strategy Paper}

This poverty reduction strategy paper on Nicaragua was prepared by a staff team of the International Monetary Fund as background documentation for the periodic consultation with the member country. It is based on the information available at the time it was completed on September 2009. The views expressed in this document are those of the staff team and do not necessarily reflect the views of the government of Nicaragua or the Executive Board of the IMF.

The policy of publication of staff reports and other documents by the IMF allows for the deletion of market-sensitive information.

Copies of this report are available to the public from

International Monetary Fund • Publication Services

$70019^{\text {th }}$ Street, N.W. • Washington, D.C. 20431

Telephone: (202) 623-7430 • Telefax: (202) 623-7201

E-mail: publications@imf.org Internet: http://www.imf.org

\section{International Monetary Fund Washington, D.C.}




\section{Gobierno de Reconciliación}

y Unidad Nacional

El Pusblo, Presidente!

\section{UPDATED NATIONAL HUMAN DEVELOPMENT PLAN 2009-2011}

\section{TECHNICAL SUMMARY}

(Moving Forward Despite the International Economic Crisis)

SEPTEMBER 2009 
CHAPTER IV. NHDP STRATEGIC POLICIES AND PROGRAMS.

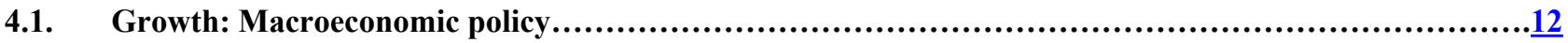

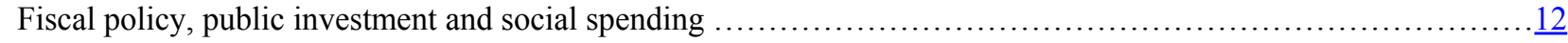

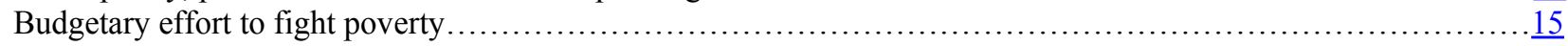

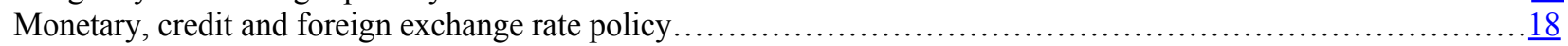

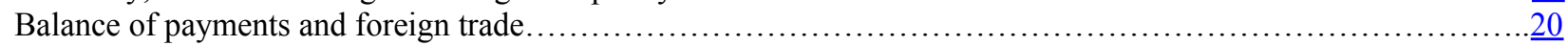

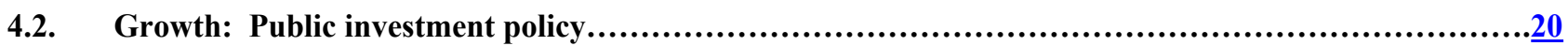

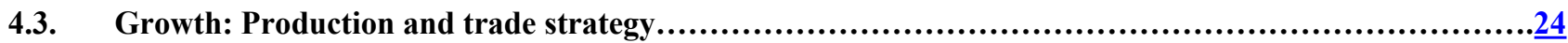

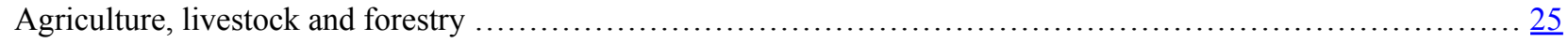

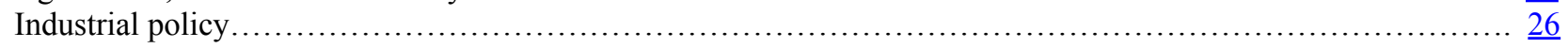

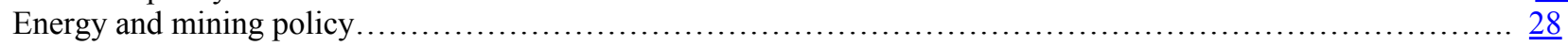

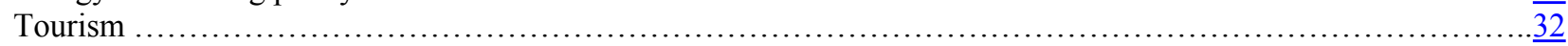

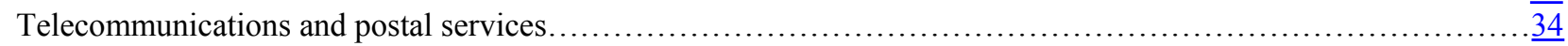

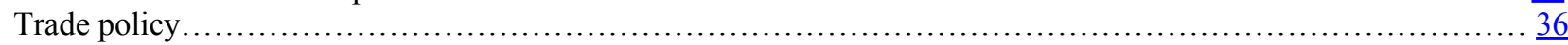

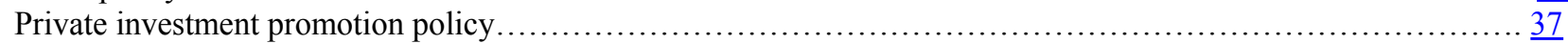

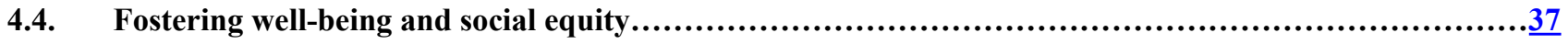

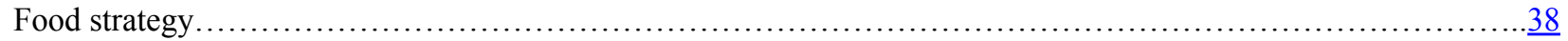

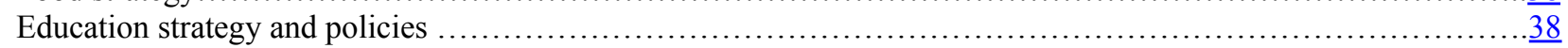

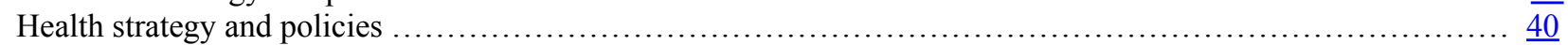

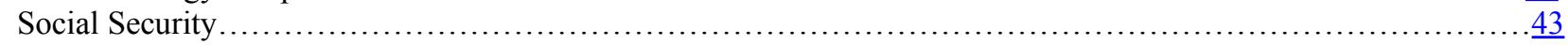

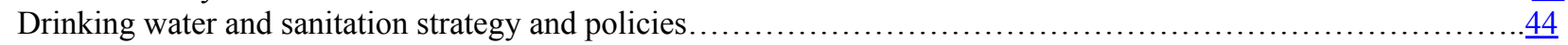

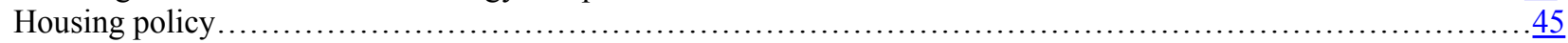

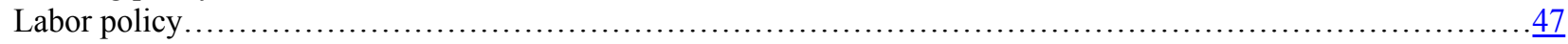

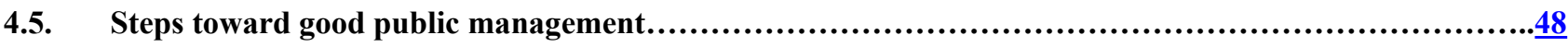

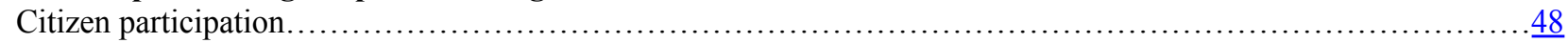

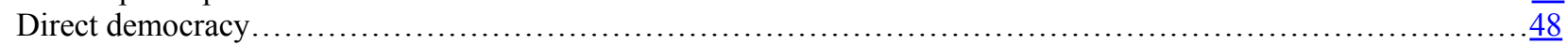

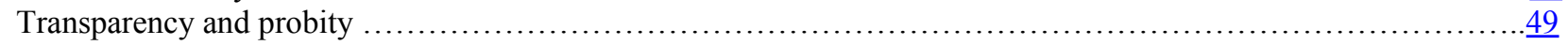

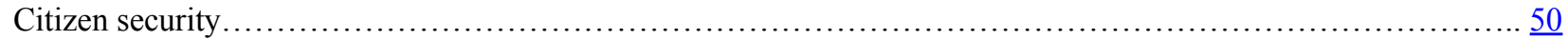

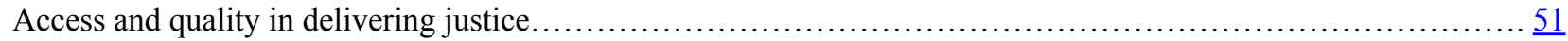

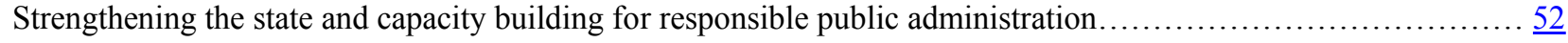

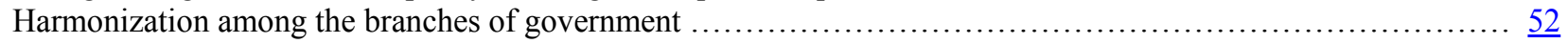

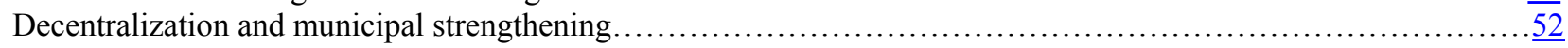

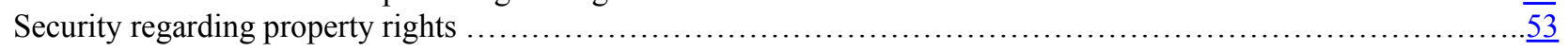

4.6. Environmental sustainability and forestry development............................................5

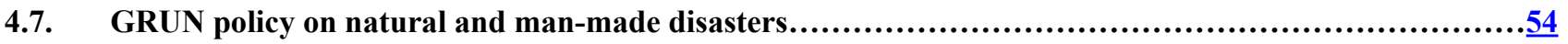

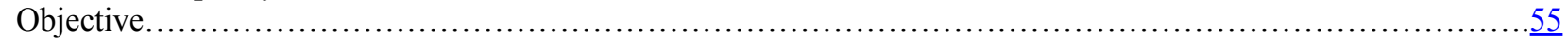


Disaster prevention, mitigation and relief strategy .$\underline{.55}$

4.8. Caribbean Coast Development Strategy

Development objective

. .56

Specific objectives

Goals and results expected by 2012 .

Expected results...

Pillars and programs

Pillar 1: Socioeconomic well-being of the population living on the Nicaraguan Caribbean coast

Pillar 2: Equitable and sustainable economic transformation, humans and nature live in harmony

Pillar 3: Autonomous institutions are strengthened and lead human development on the Nicaraguan

Caribbean coast

CHAPTER V. NHDP STRATEGIC FRAMEWORK AND GOALS $\underline{59}$

5.1. Perspectives, strategic objectives, results indicators and goals.................................... $\underline{60}$

5.2. Reduce extreme poverty and chronic child malnutrition............................................

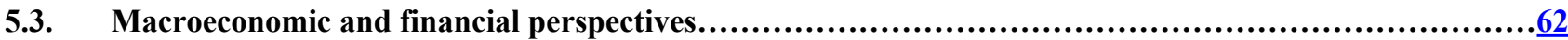

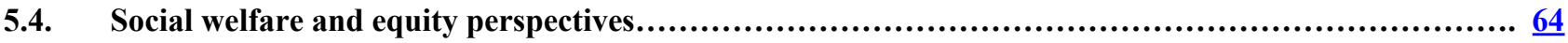

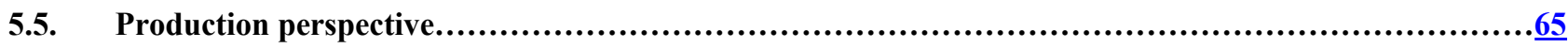

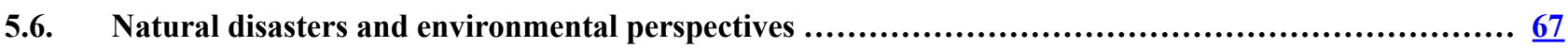

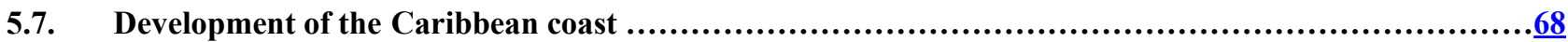

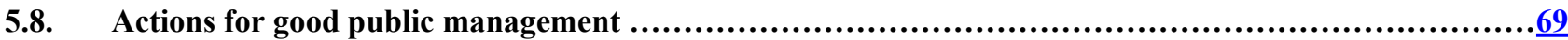

\section{CHAPTER VI. IMPACT OF THE INTERNATIONAL ECONOMIC CRISIS, BUDGET

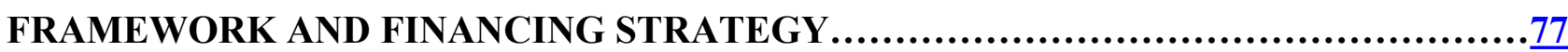

6.1. Impact of the international economic crisis and changes in the macroeconomic context ................. $\underline{78}$

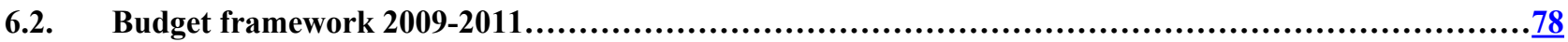

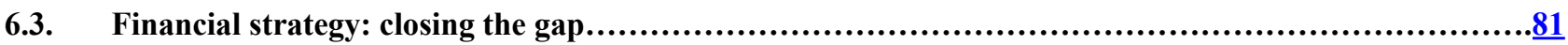

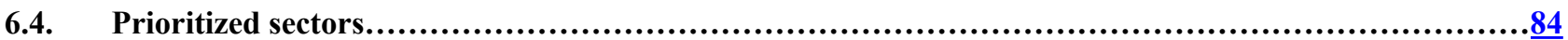

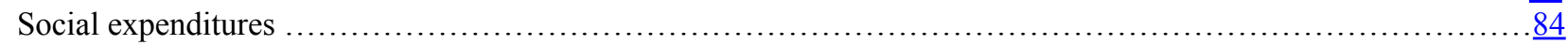

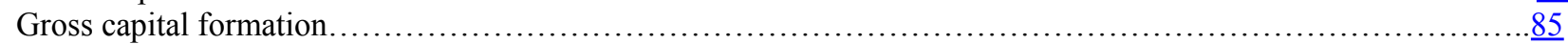

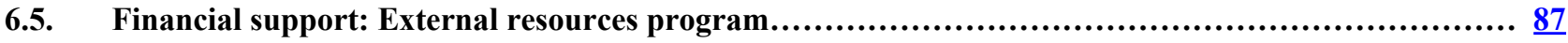

CHAPTER VII. RISKS AND THREATS............................................

CHAPTER VIII. IMPLEMENTATION, FOLLOW-UP AND EVALUATION................91 


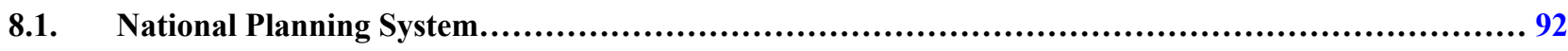

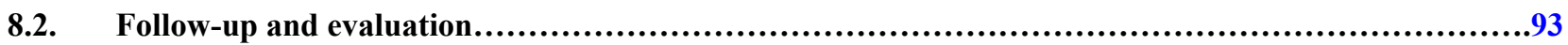

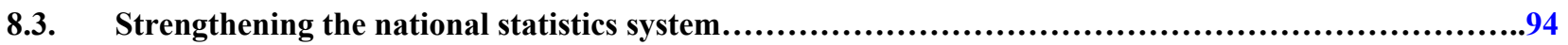

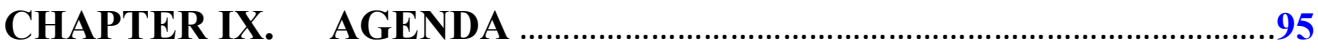

\section{ANNEXES}

ANNEX No. 1: MACROECONOMIC STATISTICS

ANNEX No. 2: ECONOMIC AND SOCIAL MANAGEMENT 2007-2008

ANNEX No. 3: DETERMINING BUDGET EFFORTS TO FIGHT POVERTY

ANNEX NO. 4: ACTION FURTHERANCE MATRIX

ACRONYMS

CInternational Monetary Fund. Not for Redistribution 


\section{CHAPTER I. INTRODUCTION}

1. Despite the various programs, policies and large amount of resources allocated to poverty reduction between 1990 and 2008, poverty remains high throughout Nicaragua. Economic growth, although key, has not been effective in reducing poverty. First, public policy in Nicaragua has not been traditionally pro-poor, and has not been aimed at sustained growth with social responsibility. Second, in an effort to protect the economy's productive sectors, the benefits to privileged groups in the form of tax shelters have outweighed the fiscal resources allocated to social protection. Third, low levels of technological progress have implied low levels of labor productivity.

2. The main obstacles to poverty reduction are related to culture, historical, and structural factors, as well as weak public policy. The increase in illiteracy rates over the past 16 years, the absence of a tradition of disease prevention, and appropriate natural resource management, have all contributed to the inter-generational transmission of poverty in the country. Likewise, the lack of proper physical infrastructure, the weaknesses in the energy matrix, the flaws in the health, education and potable water systems, and the precarious presence of state institutions in the territory, have all contributed to the lack of success in poverty reduction.

3. The outcomes indicate that the quality, intensity and continuity of the public policies of past poverty reduction strategies have not been effective. The superficial and assistance-oriented approach, coupled with limited fiscal resources and fragmented social programs, resulted in temporary poverty alleviation, yet failed to address the structural causes of poverty in Nicaragua.

4. Other factors that have hindered the fight against poverty include natural disasters and the behavior of international commodity prices. The effects of the El Niño and La Niña, hurricanes (Mitch and Felix), droughts, tsunamis and earthquakes have undermined poverty reduction in many communities. Likewise, the drop in coffee prices earlier in the decade, and more recently the rise in oil prices and the international economic crisis, are all phenomena that have weighed heavily against efforts to reduce poverty.

5. In 2007, the Government of Reconciliation and National Unity (GRUN) launched its economic growth and poverty reduction strategy, which medium-term profile can be found in the National Human Development Plan (NHDP). A draft of the NHDP was made public officially in April 2008, and the final version was disseminated in October 2008.

6. The main premise behind this plan is that markets are imperfect and that to correct such imperfections the state must intervene through an appropriate regulatory framework. Further, the NHDP is based on the premise that the market can produce socially-undesirable outcomes in terms of inequality, the correction of which again requires state intervention.

7. The NHDP was structured following the macroeconomic framework established under the IMF program. It was based on certain assumptions regarding foreign investment and cooperation that signaled favorable economic growth. However, during the implementation of the program, difficulties arose due in part to increases in oil and food prices, but also as a result of the international financial crisis. Taken together, these factors hindered the process of meeting the goals 
set for the first two years and changed the economic outlook for the remainder of the five-year period. It therefore became necessary to update the NHDP strategy.

8. Even though oil prices fell in 2009 , the international financial crisis exacerbated other problems, especially in the real economy. The slowdown initially caused by higher oil prices was further deepened in 2009 because of the international financial crisis. Fiscal resources linked to domestic economic activity contracted, and foreign direct investment and international cooperation flows were also reduced. Likewise, international liquidity available for credit dropped considerably, constraining the economy even further. It is estimated that nominal GDP will drop by approximately US\$4.8 billion between 2009 and 2011, and cumulative growth rates for this period are now estimated at $2.5 \%$ instead of the $15.3 \%$ projected before the crisis. This represents an accumulated loss in growth (relative to the pre-crisis projections) of approximately $12.8 \%$.

9. Given this setting, GRUN has decided that the most prudent course under the current circumstances is to implement an updated strategy, which is wider in scope than that of the original NHDP, but with a narrower order of priorities than those originally projected for the 2008-2012 period. The revised strategy takes the uncertainty of the global economy as its point of departure, and its main objective is to mitigate the effects of the crisis on the most vulnerable. It foresees actions to encourage production and employment, and keep citizens united around the most essential tasks. To that end the government has prepared this document, titled "Updated National Human Development Plan 2009-2011 - Technical Summary", in which policies and goals to be achieved, and resource to be allocated, are determined by the constraints brought about by the international financial crisis.

10. The main pillars of this updated version are described in the main NHDP document. The struggle to keep them in place gains greater relevance during this period of international crisis. Among these are: (i) the renewed role of the state in direct economic, social, environmental and cultural activities; (ii) a social policy that favors the poor more directly; (iii) a social response reflected in a prioritized infrastructure policy; (iv) the capitalization of the poor through programs very much focused on food production; (v) continuation of the energy policy, prioritizing renewable energy; (vi) security guarantees for private investors and a commitment to coordinate with the private sector; (vii) an ongoing dialogue with the international community in search of consensus and solidarity in commercial and financial support; and (viii) the strengthening of the democratic process.

11. The horizon for achieving the Millennium Development Goals (MDGs) has also been severely affected by the adverse effects of world oil prices, and more recently by the international financial and economic crisis, as well as natural disasters. The foregoing makes it necessary to change the approach of poverty reduction policies. The state must play a more relevant role, external cooperation needs to be more structural and less assistance-oriented, and the population must participate directly in national, sectoral and territorial decision-making processes.

12. In this document, the Nicaraguan Government of Reconciliation and National Unity presents a human development and poverty reduction strategy designed to address the international crisis. The text is organized as follows: chapter II contains a brief description of the evolution of poverty in Nicaragua over the past few years. Chapter III depicts the process of citizen participation process in 
the NHDP. Chapter IV details the various programs and policies that constitute the essential NHDP scaffold. Based on that structure, chapter V outlines the plan's strategic framework. Chapter VI is critical in the sense that it scrutinizes the NHDP budget framework and strategy, lending realism to both the investment program and large portions of the policies. Chapter VII analyzes the risks posed to implementation of the NHDP and possible actions that might mitigate those risks. Chapter VIII is an account of the follow-up and evaluation systems, as well as actions needed to strengthen the National Statistics System. Finally, Chapter IX closes with a description of the agenda to be followed. 


\section{CHAPTER II. SITUATION REGARDING POVERTY 1993-2005}

13. According to the 2007 World Development Indicators published by the World Bank (WB), Nicaragua is the second poorest country in Latin America and the Caribbean, with a per capita income of US $\$ 1,022.00$, ahead only of Haiti. Therefore it should not come as a surprise that approximately half the population lives beneath the poverty line, with almost one out of every five Nicaraguans in conditions of extreme poverty. Perhaps even more worrisome is that these levels of poverty have proven to be highly persistent. This is patently obvious when analyzing the home surveys taken in Nicaragua, which show that general poverty decreased by only $2 \%$ between 1993 and 2005 (from $50.3 \%$ to $48.3 \%$ ), despite an increase of $33 \%$ in per capita income for this same period. Further, although there was a 7\% increase in per capita income between 2001 and 2005, poverty also grew by $2.5 \%$. The situation is similar among the poorest population groups. Extreme poverty rates only improved from $19.4 \%$ in 1993 to $17.2 \%$ in 2005 , of which $2.1 \%$ occurred during 2001-2005.

\begin{tabular}{|c|c|c|c|c|c|c|c|c|c|c|}
\hline \multicolumn{11}{|c|}{ Table No. 1: Evolution of the Impact of Poverty by Area and Region of Residence } \\
\hline \multirow[b]{2}{*}{ Geographic Area } & \multicolumn{5}{|c|}{ Overall Poor } & \multicolumn{5}{|c|}{ Extremely Poor } \\
\hline & 1993 & 1998 & 2001 & 2005 & $\begin{array}{c}\text { Change } \\
2001-2005\end{array}$ & 1993 & 1998 & 2001 & 2005 & $\begin{array}{l}\text { Change } \\
2001-2005\end{array}$ \\
\hline National & 50.3 & 47.8 & 45.8 & 48.3 & 2.5 & 19.4 & 17.3 & 15.1 & 17.2 & 2.1 \\
\hline Urban & 31.9 & 30.5 & 30.1 & 30.9 & 0.8 & 7.3 & 7.6 & 6.2 & 6.7 & 0.5 \\
\hline Rural & 76.1 & 68.5 & 67.8 & 70.3 & 2.5 & 36.3 & 28.9 & 27.4 & 30.5 & 3.1 \\
\hline Managua & 29.9 & 18.5 & 20.2 & 21.2 & 1 & 5.1 & 3.1 & 2.5 & 3.6 & 1.1 \\
\hline Pacific Urban & 28.1 & 39.6 & 37.2 & 37.7 & 0.5 & 6.4 & 9.8 & 5.9 & 6.4 & 0.5 \\
\hline Pacific Rural & 70.7 & 67.1 & 56.8 & 61.5 & 4.7 & 31.6 & 24.1 & 16.3 & 20.8 & 4.5 \\
\hline Central Urban & 49.1 & 39.4 & 37.6 & 39.3 & 1.7 & 15.3 & 12.2 & 11.1 & 12.8 & 1.7 \\
\hline Central Rural & 84.7 & 74 & 75.1 & 76.8 & 1.7 & 47.6 & 32.7 & 38.4 & 37.1 & -1.3 \\
\hline Atlantic Urban & 35.5 & 44 & 43 & 37.8 & -5.2 & 7.9 & 17 & 13.1 & 9.8 & -3.3 \\
\hline Atlantic Rural & 83.6 & 79.3 & 76.7 & 76.6 & -0.1 & 30.3 & 41.4 & 26.9 & 34.2 & 7.3 \\
\hline
\end{tabular}

Source: 1998-2005 LSMS and data from World Bank with 1993 LSMS.

14. The poverty map shows that poverty is more severe in rural areas and the Caribbean coast, notwithstanding their economic potential. Likewise, general poverty increased by $2.5 \%$ in rural areas and $3.2 \%$ on the Caribbean coast. This outcome stands in contrast with rural areas in western Nicaragua, which experienced poverty reduction in the years between 1993 and 2005 as a result of benefits deriving from staple foods production programs and investments in the rebuilding of infrastructure damaged by Hurricane Mitch of September 2007. The Caribbean coast, however, displayed a sustained slippage toward deeper poverty.

15. During the last five years there has been a generalized increase in poverty throughout the country, including those areas in which there are public services, public investment, social policies and economic policy incentives. For example, the capital city Managua experienced an $8.7 \%$ reduction in general poverty between 1993 and 2005, followed by a 1\% increase, according to the most recent survey taken.

16. In many aspects the gaps between poor and non-poor are determined by an inadequate distribution of income and consumption. The 2005 survey shows that at national level, the wealthiest $20 \%$ of the population accounted for $47.2 \%$ of total consumption, while the poorest $20 \%$ 
consumed only $6.2 \%$. Nicaragua finds itself in the upper quartile among world countries with the widest disparity in consumption. For its part, income distribution is more uneven than consumption. The income structure shows a 24:1 income ratio between the first and last decile, compared to a 12:1 ratio for consumption. If a comparison is drawn by decile between average income and consumption (in córdobas, the national currency), the former is lower than the latter for the first three deciles. Starting with the fourth decile, the ratio becomes growingly inverted (see table 1, above).

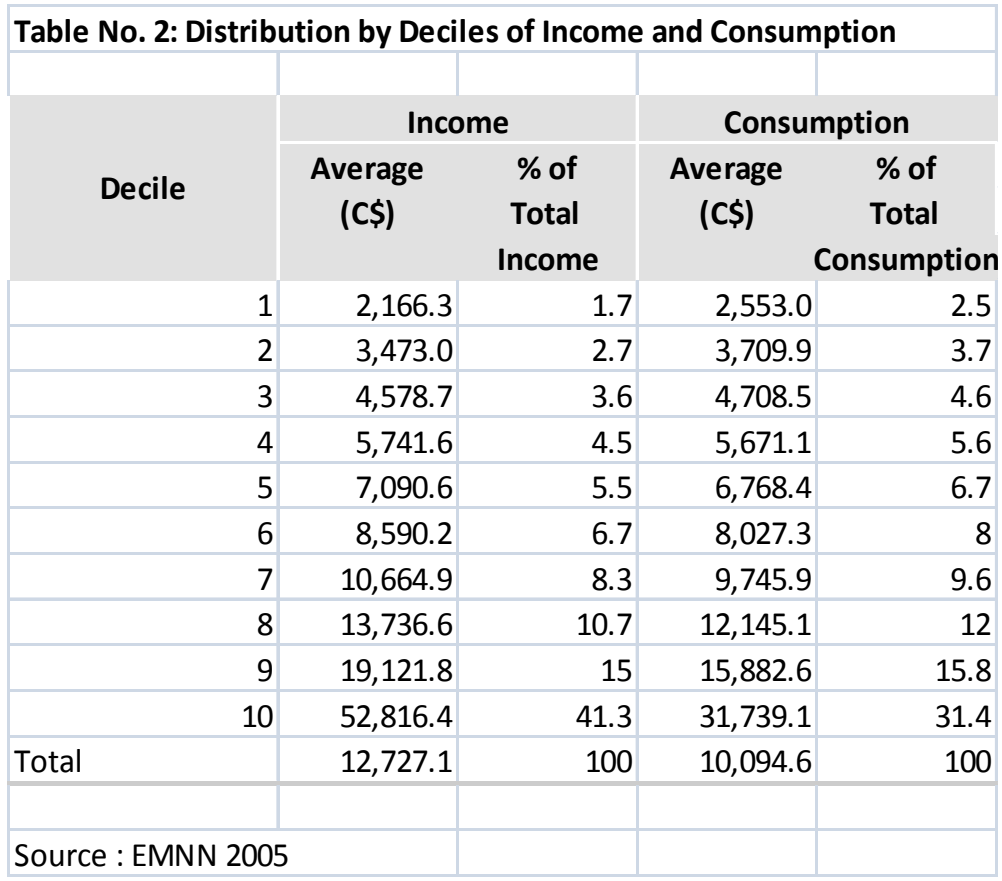

17. There can be no question that poverty reduction is a high priority problem in Nicaragua and success in this area is largely determined by the capacity of government policies to address the issues of (i) low income, by accelerating sustained economic growth; and (ii) the high degree of inequality in consumption and income distribution, through a set of social policies that both expand opportunities to the most disadvantaged population groups and take into account the needs of the poorest sectors of the population. 


\section{CHAPTER III. CITIZEN PARTICIPATION: CONSULTATIVE PROCESS}

18. The national consultation process surrounding the NHDP began during the electoral campaign of 2006 and concluded with broad-based sectoral and community consensus. The Sandinista National Liberation Front (FSLN) platform during the 2006 presidential race planted the strategic seed in this process. It had been discussed previously at the regional councils, where community leadership facilitated the dissemination and ownership of NHDP priorities. The Financial-Economic Program (FEP) was another step in the process, and was broadly consulted with social and economic sectors. Once an overall view of the NHDP was obtained, the National Economic and Social Planning Council (CONPES) became an organized space at which to consolidate the consultation process throughout the country. In practice, CONPES activated a double consultation and consultant mechanism, given its sectoral makeup. This allowed for greater interaction and direct contact with the various sectors and citizens in the territory.

19. This process led to the holding of meetings with communities nationwide with a view toward determining local priorities. These meetings were held with individual citizens, trade associations and civil society organizations. Debates were held and participants put forth feasible proposals that were included in a socioeconomic source document. These meetings between the highest authorities in the territory and central government representatives were coordinated with the aim of ensuring that the proposed objectives would be achieved. State institutions charged with carrying out sectoral policies were directly involved in the consultative process.

20. The government's consultation effort took place with the collaboration and contribution of organized sectors. A number of organizations that play a role in national life participated, either to discuss the material (sectoral plans, NHDP draft, territorial proposals, etc.) and state their point of view, or to contribute a specialized opinion on a subject of their interest. Among these sectors were the political parties with benches in the National Assembly (parliament), private sector associations, unions, federations and confederations, citizen associations and organizations, churches, universities and research centers.

21. The international community had its specific space in the consultation process, with a draft of the NHDP being sent ahead of the deadline established by Budget Support Group. In April 2008, President Ortega called a meeting with the donor community to officially deliver a draft of the report. Sectoral roundtables were subsequently established between GRUN and donors, in order to hear opinions in an organized manner by sector. This exercise led to the formulation of recommendations and suggestions that were used to strengthen the Plan. It must be acknowledged that the global donor roundtable (in existence since 2004) was crucial in coordinating relations between the government and the international community, and has become a space for dialogue between government institutions, branches of government, financial organizations, cooperation agencies and civil society. ${ }^{1}$

22. A number of factors contributed to a situation in which the consolidation and preparation of the NHDP had to be interrupted, in order to reevaluate priorities and the Plan's operation mechanisms.

\footnotetext{
${ }^{1}$ The roundtables formed and active are: electrical energy, health, education, production and competitiveness, infrastructure, governance and social protection.
} 
Now GRUN has found it necessary to update the Plan, giving rise to the current document, which includes: (i) the strategy announced in January 2009 to ensure production, growth and employment; (ii) an estimate of the effects of the crisis on the economy, development assistance, and investment; and (iii) a new profile for the public sector budget. Albeit in a less extensive fashion, this document too has undergone a process of consultation with the main sectors in the country.

\section{Chapter IV. NHDP STRATEGIC POLICIES AND PROGRAMS}

23. The NHDP was structured around the central goal of improving the living conditions of all Nicaraguans, especially those living in poverty. Thus the policies and strategies launched to date include substantive changes intended to achieve results with the widest possible scope and greater celerity than has been the case thus far. New strategies and a different way of dealing with poverty are accompanied by a more decisive role to be played by the state, citizens and the international community.

24. Notwithstanding, faced by the international financial and economic crisis, the government has had to prioritize a contingency plan intended to defend the medium and long-term NHDP objectives announced in 2008. While standing by the fundamental principles and spirit of those policies, the Government of Reconciliation and National Unity (GRUN) has taken into account the results of the 2007-2008 Implementation Plan, the evolution of world oil prices, and the international financial and economic crisis. As a consequence, it has aligned policies and resources in such a way as to protect the socially most vulnerable population groups.

\section{The NHDP strategy is based on the following priorities:}

- Economic growth:

- Macroeconomic policy

- Public investment policy

- Productive and commercial strategy

- Well-being and social equity

- Measures leading to good public management

- Environmental sustainability and forestry

- GRUN policy on natural and man-made disasters

- Caribbean coast development strategy

There follows a detailed description of each priority. 


\subsection{Growth: Macroeconomic policy}

26. The objective of GRUN macroeconomic policy continues to be a stable economy that stimulates economic growth with greater social benefits for the poorest sectors of society. This is even more pertinent in the context of the current international economic crisis. The economic policy incorporated to the NHDP is structured as to guarantee stability in the provision of public goods and services and financial markets, as well as to minimize the cost of inflation for families. The ultimate aim is to overcome poverty.

27. Macroeconomic stability is a necessary but not sufficient condition to reach this objective. In order to arrive at sustained economic recovery with a redistributive effect on income, it is necessary to effect change over the medium term in public policies and restore the productive potential of the poor, increase human capital and improve competitiveness. It is also required to work towards public spending that reflects a social rate of return higher than that achieved thus far. This increased effectiveness can be furthered by both a correct prioritization of programs and projects, and the coordination of citizen power.

28. Due to the effects of the international financial crisis and the structural difficulties inherent to the Nicaraguan economy, GRUN considers 2009 to be a year of resistance to the effects brought about by the crisis. Therefore the government has taken contingency measures intended to preserve employment and reduce the impact on social sectors. The main pillars of the measures are:
i) financial stability;
ii) prioritized public investment;
iii) support to production and private investment;
iv) employment solidarity; and
v) fiscal austerity.

29. It has been estimated that GDP will decrease by $1 \%$ in 2009 , accompanied by a low $2.6 \%$ inflation rate (the outcome of the significant drop in oil prices on the international market; the GRUN Production, Growth and Employment Protection Plan; and the government's reduction of expenditures (austerity measures).

30. This stable macroeconomic setting will be buttressed by a level of international reserves that guarantees at least twice the monetary base, under a crawling peg exchange rate system that operates with a constant $5 \%$ per annum devaluation.

\section{Fiscal policy, public investment and social spending}

31. Fiscal policy constitutes the government's main instrument as it seeks to play a more active role in guiding the economy and reducing poverty. GRUN is introducing changes to the design and administration of fiscal policy, in an effort to achieve a greater impact on infrastructure and social / productive programs. 
32. In this setting, prudent fiscal deficit management within a sustainable framework will be crucial to maintaining medium- and long-term stability. The government seeks to generate a spending policy that has a lasting impact, moving beyond superficial and relief-oriented programs, which rather than creating capabilities among the poor have led to an unsustainable situation of dependency.

33. Counter to the practice of increasing budget item lines in general, GRUN in 2007 began a process of structural changes to its spending policy that implies better resource allocations in line with NHDP objectives. In order to create fiscal spaces that favor social spending, it has been necessary to discard non-priority item lines, regulate public employee wages, renegotiate the internal public debt and implement of an anti-crisis program.

34. Along the same lines, GRUN seeks to generate additional resources by reforming the tax system and encouraging greater efficiency in tax administration. These efforts are complemented with negotiations for external resources intended to finance programs prioritized by the NHDP.

35. GRUN has already set into motion a fiscal austerity plan as part of its strategy to keep spending under control in the adverse international scenario. By means of a presidential decree measures were taken in 2009 that led to a $\mathrm{C} \$ 1.312$ billion adjustment to the budget. These measures included:

i) reduce current expenditures for the procurement of goods and services by $20 \%$;

ii) reduce the amount budgeted for the procurement of vehicles, office and computer equipment, as well as travel abroad by $50 \%$;

iii) freeze public sector job openings for three-months;

iv) postpone until April, without retroactivity, the implementation of budgeted salary adjustments;

v) recalculate allocations guaranteed by the Constitution and the law based on new income and expenditure forecasts; and

vi) consider as exceptions only those investments linked to infrastructure and furtherance of production.

36. The government has proposed an important change in its public investment policy, acknowledging that structural changes to the economy are a long-term task that cannot be adjusted depending on how the political winds might be blowing. Thus an order of priorities has been established in the NHDP, within which three levels of action are defined: ${ }^{2}$ primary and immediate, stabilization and growth. The objective is to increase the impact of investments upon economic growth and poverty reduction. The strategy adopts a sectoral and national approach that goes beyond the microeconomic and institutional vision currently in place. It includes a policy for targeting investment in strategic productive and social sectors, as well as the formation of fixed capital as a generator of productive capacity and social response. Part of the strategy is to guide resources to pre-investment as a planning instrument, while eliminating the improvisation factor from projects.

\footnotetext{
${ }^{2}$ The primary immediate level reflects the investment necessary to avoid the collapse of services; the stabilization level is one at which investments needed to align the supply of a service to current demand are available; and the growth level refers to investments that increase the productive or generation capacity needed for predicable future consumption and the enhancement of preventive reserves.
} 
37. It is pertinent to acknowledge that despite aforementioned budget adjustments, the 2009 fiscal policy is countercyclical, with real public spending growing by $10 \%$. The GRUN program includes an increase in the consolidated public sector of $1.5 \%$ of GDP in 2008 to $4.9 \%$ of GDP in 2009. However, this expansion is temporary only, and it is expected that in 2010 a process of fiscal consolidation will get underway that returns to the path of sustainability.

38. In order to improve the effect of public spending on poverty reduction, the government has introduced changes to the allocation criteria, as follows:

i) augmentation of productive capabilities among the poorest population groups;

ii) implementation of a food security strategy in rural areas;

iii) ensuring the gratuity of heath and education services;

iv) introduction of a new National Social Welfare System; and

v) creation of anti-poverty programs.

39. GRUN seeks a long-term outlook as regards fiscal policy, and is thus abandoning the shortterm management of taxes and the emphasis placed on tax collection. This implies a process that implies freeing tax policy from tax expenditures, a function that was insistently assigned to it during the last few administrations. In practical terms, this means:

i) gradually changing the system's regressive nature;

ii) adjusting tax rates to competitive levels;

iii) increasing the efficiency of tax collection;

iv) reducing still existing levels of discretion; and

v) increase the tax base by incorporating sectors currently outside the system.

40. In this setting, the government intends to assign tax policy a relevant role in the attainment of economic development and poverty reduction objectives. The tax plan launched in 2007 includes a review of taxpayer standing, in order to clear the arrears accumulated by certain sectors; the implementation of legal or administrative mechanisms to reduce all types of tax evasion and to increase the transparency of the system; rationalize the tax exemption policy and preferential treatment regarding taxes; increase administrative efficiency; and fight corruption in tax and public funds management.

41. In early 2009 the government began a process of reaching "tax consensus", meaning agreement on the system most suitable for Nicaragua. To that end, four general areas were put up for discussion, with a view toward achieving passage in September of this year:

i) reduction in costs of production and financing of productive activities;

ii) financing fiscal stimuli through generalized measures and rationalization;

iii) achieving neutrality in tax revenue collection; and

iv) improving the current tax legislation. ${ }^{3}$

\footnotetext{
${ }^{3}$ Ministry of Finance and Public Credit (MHCP), Tax Consensus Proposal, February 2009.
} 


\section{Budgetary effort to fight poverty}

42. The need to determine the budget adjustments necessary in the struggle against poverty emerged in the late nineties and became part of the conditionality for obtaining debt relief under the Highly Indebted Poor Countries (HIPC) initiative. In contrast to previous governments, GRUN decided to shift away from the concept of "spending on poverty" to that of "budgetary effort to fight poverty", with a political approach toward a new classification in resource allocation and budgetary quality, as reflected in the NHDP and keyed to:

i) upholding the new strategic vision of the social program;

ii) implementing public policies that reflect a preference for furthering the productive capabilities of the poorest population groups, making them subjects and beneficiaries of economic and social development;

iii) prioritizing the inclusion of programs with activities whose linkage to the Millennium Development Goals is clearly established; and

iv) increasing program efficiency by means of citizen power participation.

43. The new criteria used in the social program and productive strategy, and the consolidation of citizen power in the struggle against poverty, have established a different framework for classifying antipoverty policies and programs. Based on the foregoing, three expenditure groups were drawn up:

i) public spending with direct bearing on the standard of living among poor population groups;

ii) expenditures that restore and strengthen the productive capacities of the poor and increase their income; and

iii) public spending geared toward creating the institutional capacity needed to increase coverage of services.

44. In order to ensure achievements in the social sphere, GRUN gave high priority to a budgetary effort intended to reduce poverty. This led to the creation of a new generation of programs aimed fundamentally at exerting direct influence upon the reduction of poverty and hunger, which in turn generated a significant change in the pattern of current expenditures and spending. Such spending focuses on restoring the right of Nicaraguans to health and education and to expand both the coverage and quality of basic services that have the most impact on improving the well-being of the population, mainly the lowest income groups. This process led to rapid growth of current spending, for three reasons:

i) the creation and implementation of the antipoverty programs now in place;

ii) the impact of reverting the privatization of health and education services; and

iii) the process of streamlining public investments begun in 2007 and concluded in 2009 implied transferring significant budget item lines from capital expenditures to current expenditures. During 2008-2009 alone this cost US\$185 million, resources that in large measure now classify as current expenditures earmarked for the fight against poverty. 
45. In addition to increasing its participation in public spending, current expenditures are achieving medium-term stability, regardless of any particular political or economic situation. There follows a description of policy efforts and measures taken that use current expenditures geared toward the NHDP top priority, which is the fight against poverty.

i) In public health, services have been made available to populations living in poverty and extreme poverty, as well as to those facing serious difficulties concerning access, through progress made in the implementation of the Family and Community Health Model (MOSAFC); the provision of outpatient and hospital medical care to anyone who needs it; support for carrying out diagnoses; treatment of patients, including services requiring state-of-the-art technology; free medication; timely identification of risks and complications among pregnant women; and oversight of the growth and healthy development of children less than one year of age, including vaccines.

ii) In education, the gratuity of schooling is guaranteed; thoroughgoing reforms via education policies; building the Global and Comprehensive Model for Inclusion to Basic and Middle Education; the "From Martí to Fidel" national literacy campaign, which reduced illiteracy among the population over 15 years of age from $22.8 \%$ in 2007 to $4.06 \%$ in 2009 , an achievement for which Nicaragua was declared territory free of illiteracy; contribution to closing inequity gaps in the education system; real solutions and strategies in response to problems concerning coverage, efficiency and efficacy that exist in the education sector.

iii) In the struggle against hunger, innovative policies and strategies in the area of food security, improving food supply through the Hambre Cero (Zero Hunger) program and providing food assistance to families affected by disasters, drought and floods.

iv) Production is being promoted in both urban and rural areas, through programs that promote the growing of staple foods, certified seeds and in general agriculture and livestock development. In urban areas, micro, small and medium enterprises (MIPYMES) are receiving support, in particular by capitalizing urban women with credit and technical assistance programs such as the Usura Cero (Zero Usury) microcredit program and giving credits to small tourist enterprises and small farmers. Support is also made available for environmental management and care, and the real salary of low-income workers is being protected via subsidies to urban collective transport.

v) With current resources, teachers and health staff have received pay raises of up to $16 \%$, and additional teachers and health staff have been hired. These were made retroactive starting in January 2009. These wage adjustments are worth US\$ 32.7 million per year and benefited 74,117 employees in these two sectors.

46. The change described in the budget effort to fight poverty, as well as the streamlining of public investments and increase in current expenditures for new generation programs used in the struggle against poverty are reflected in table 3. For purposes of comparison, expenditures on the same budget items for the 2002-2006 period, as shown in two columns, the first without and the second with adjustments. The result shows that the budget effort to fight poverty as a proportion of GDP went from $9.2 \%$ during $2002-2006$, to $13.2 \%$ for 2007 2011, notwithstanding the world financial and economic crisis. This increase in the budget 
effort to fight poverty between the two periods is a result of the change in current expenditures from $4.6 \%$ to $7.1 \%$, and in capital expenditures from $4.6 \%$ to $6.1 \%$, respectively.

47. Budget coverage measured as the relation between the budget effort to fight poverty as compared to total budget spending remains the same during the two periods. The share of domestic resources of the total budget effort to fight poverty rose from $33.1 \%$ to $51.2 \%$, while the share of external resources used for that purpose dropped from $66.9 \%$ to $48.8 \%$. This latter figure is still excessive and reflects the high degree of dependence on foreign resources for use in the struggle against poverty. However, under the current circumstances of international financial and economic crisis it is a complement that rather needs to be increased.

Table No. 3: NICARAGUA: Budget Effort to Fight Poverty

\begin{tabular}{|c|c|c|c|c|c|c|c|c|c|c|}
\hline \multirow{3}{*}{ Item } & \multicolumn{2}{|c|}{ Avg. 2002-06 } & \multirow{3}{*}{2007} & \multirow{3}{*}{2008} & \multirow{3}{*}{2009} & \multirow{3}{*}{2010} & \multirow{3}{*}{2011} & \multirow{3}{*}{$\begin{array}{c}\text { Avg. } \\
2007-11 \\
(3)\end{array}$} & \multicolumn{2}{|c|}{ Difference } \\
\hline & $\mathbf{w} / \mathbf{0}$ & with adj & & & & & & & \multirow{2}{*}{$\begin{array}{c}(4)= \\
(3-1)\end{array}$} & \multirow{2}{*}{$\begin{array}{c}(5)= \\
(3-2)\end{array}$} \\
\hline & $(1)$ & $\quad(2)$ & & & & & & & & \\
\hline & \multicolumn{10}{|c|}{ Ratio to GDP } \\
\hline Total Spending NFPS (TS) & 28.5 & 23.9 & 28.8 & 29.7 & 32.2 & 32.2 & 32.6 & 31.1 & 2.6 & 7.1 \\
\hline Current & 18.9 & 18.9 & 20.3 & 22.1 & 24.2 & 23.5 & 24.5 & 22.9 & 4.0 & 4.0 \\
\hline Capital & 9.6 & $5.0^{1}$ & 8.5 & 7.5 & 7.9 & 8.7 & 8.1 & 8.2 & -1.5 & 3.1 \\
\hline Total Prim ary Spending (TPS) ${ }^{2 /}$ & 26.3 & 21.7 & 27.3 & 28.5 & 30.7 & 30.7 & 31.1 & 29.7 & 3.4 & 8.0 \\
\hline Budget Effort (BE) & 11.8 & 9.2 & 13.1 & 13.2 & 13.2 & 13.2 & 13.4 & 13.2 & 1.4 & 4.0 \\
\hline Current Spending (CS) & 4.6 & 4.6 & 6.4 & 7.4 & 7.3 & 7.1 & 7.1 & 7.1 & 2.5 & 2.5 \\
\hline Capital Spending (KS) & 7.2 & $4.6^{11}$ & 6.6 & 5.8 & 5.9 & 6.1 & 6.3 & 6.1 & -1.0 & 1.5 \\
\hline Central Government & 11.0 & - & 12.3 & 12.5 & 12.0 & 11.9 & 11.8 & 12.1 & 1.1 & - \\
\hline Autonomous Entities & 0.8 & - & 0.7 & 0.6 & 1.2 & 1.3 & 1.6 & 1.1 & 0.3 & - \\
\hline \multicolumn{11}{|l|}{ Ratios } \\
\hline$\overline{\text { Budgetary Coverage (BE/TPS) }}$ & 44.7 & 44.7 & 47.9 & 46.2 & 42.9 & 42.9 & 43.2 & 44.6 & -0.1 & -0.1 \\
\hline Structural Coefficient (KS/TPS) & 27.4 & 21.4 & 24.3 & 20.4 & 19.1 & 19.9 & 20.3 & 20.8 & -6.6 & -0.6 \\
\hline Fiscal Management (Internal Res./BE) & 33.1 & 33.1 & 47.3 & 46.8 & 54.6 & 53.9 & 53.3 & 51.2 & 18.1 & 18.1 \\
\hline External Dependency (Ext. Res/BE) & 66.9 & 66.9 & 52.7 & 53.2 & 45.4 & 46.1 & 46.7 & 48.8 & -18.1 & -18.1 \\
\hline \multicolumn{11}{|c|}{ V: Capital spending adjusted for the current spending component included in the Public Investment Program. } \\
\hline \multicolumn{11}{|c|}{ 2/: Excludes payment of interest on the public debt. } \\
\hline Source: SEPRES. & & & & & & & & & & \\
\hline
\end{tabular}




\begin{tabular}{|c|c|c|c|c|c|c|c|c|c|c|c|c|c|c|}
\hline Programs & Avg. 02- & 2007 & 2008 & 2009 & 2010 & 2011 & Avg. 07- & Avg. 02 & 2007 & 2008 & 2009 & 2010 & 2011 & Avg. 07. \\
\hline & \multicolumn{7}{|c|}{ Millions of dollars } & \multicolumn{7}{|c|}{ Ratio to GDP } \\
\hline Total & 101.7 & 121.3 & 143.2 & 147.2 & 151.6 & 157.6 & 144.2 & 2.2 & 2.1 & 2.2 & 2.3 & 2.3 & 2.3 & 2.2 \\
\hline Production and food security ${ }^{1 /}$ & - & 10.0 & 8.3 & 12.0 & 14.0 & 15.0 & 11.9 & - & 0.2 & 0.1 & 0.2 & 0.2 & 0.2 & 0.2 \\
\hline Support to small and medium production ${ }^{2 /}$ & 10.8 & 21.9 & 27.1 & 21.0 & 22.0 & 22.0 & 22.8 & 0.3 & 0.4 & 0.4 & 0.3 & 0.3 & 0.3 & 0.4 \\
\hline Basic social services & 76.7 & $86.3^{\prime}$ & 96.8 & 103.0 & 106.6 & 110.6 & 100.7 & 1.7 & 1.5 & 1.5 & 1.6 & 1.6 & 1.6 & 1.6 \\
\hline Education & 50.5 & 62.5 & 59.7 & 63.0 & 64.8 & $66.1 P$ & 63.2 & 0.5 & 1.1 & 0.9 & 1.0 & 1.0 & 1.0 & 1.0 \\
\hline Health & 22.7 & 21.7 & 32.6 & 35.0 & 35.0 & $37.0^{\prime}$ & 32.3 & 0.2 & 0.4 & 0.5 & 0.5 & 0.5 & 0.5 & 0.5 \\
\hline Water and Sanitation & 1.9 & 2.1 & 3.9 & 4.0 & 5.0 & $5.0^{r}$ & 4.0 & - & 0.0 & 0.1 & 0.1 & 0.1 & 0.1 & 0.1 \\
\hline Housing & 1.5 & - & 0.6 & 1.0 & 1.8 & 2.5 & 1.5 & - & - & 0.0 & 0.0 & 0.0 & 0.0 & 0.0 \\
\hline Vulnerable groups & 4.9 & 3.0 & 6.8 & 7.0 & 8.0 & $8.0^{\circ}$ & 6.6 & 0.1 & 0.1 & 0.1 & 0.1 & 0.1 & 0.1 & 0.1 \\
\hline Environmental protection & 0.8 & - & 0.2 & 0.5 & 1.0 & 2.0 & 0.9 & - & - & 0.0 & 0.0 & 0.0 & 0.0 & 0.0 \\
\hline Others $^{31}$ & 8.4 & 0.0 & 4.0 & 3.7 & 0.0 & 0.0 & 1.5 & 0.3 & 0.0 & 0.1 & 0.1 & 0.0 & 0.0 & 0.0 \\
\hline \multicolumn{15}{|c|}{\begin{tabular}{|l|l|l|l|l|l|l} 
V: Includes Food Production Package of Zero Hunger Program & &
\end{tabular}} \\
\hline \multicolumn{15}{|c|}{ 2/: Include Zero Usury M icro credit, P roperty Regularization and Rural Develo pment Programs, among others. } \\
\hline \multicolumn{15}{|c|}{\begin{tabular}{|l|l|l} 
3/:Includes municipal infrastructure, Caribbean Coast develo pment projects, and others. &
\end{tabular}} \\
\hline Source: SEPRES. & & & & & & & & & & & & & & \\
\hline
\end{tabular}

\section{Monetary, credit and foreign exchange rate policy}

49. The monetary program is one of the fundamental pillars of the GRUN economic program, and is keyed to providing the macroeconomic framework necessary to the struggle against poverty. In this regard, monetary policy focuses on guaranteeing there is confidence in the currency and stability of the financial system, which are basic conditions for promoting the efficient allocation of resources to the economy, as they encourage savings, investment and economic growth. The agreement entered into with the IMF by the government in its first year and subsequent compliance therewith, has been fundamental to maintaining stability despite difficult conditions caused by the oil shock and the international financial and economic crisis.

50. The Nicaragua Central Bank $(\mathrm{BCN})$ has continued to use the rate of exchange as a nominal anchor of price levels, and no substantive alterations are foreseen in the medium term. GRUN has considered it prudent to maintain the crawling peg regime, while advancing on the fiscal front despite the impact of the international financial and economic crisis. Under current circumstances, an increase in the rate of crawl would in the short term fuel inflation (considering the economy's high level of indexation) and contribute to the recession that is emerging in the various sectors. To ensure the stability of the exchange rate system, monetary policy will be based on an accumulation of international reserves sufficient to cover the monetary base twice over.

51. The Central Bank's main instruments are open market operations, which concentrate on neutralizing surplus liquidity and reducing the volatility of reserves. Debt acquisition through the placement of central bank paper is only a short-term measure taken for the purposes set forth in the organic law. The Ministry of Finance and Public Credit (MHCP) is responsible for placing longerterm instruments to cover the government's budget gap. The attainment of international reserve goals will continue to be supported by fiscal policy, mainly through the build up of government deposits in the BCN.

52. Credit policy plays an important role in achieving the macroeconomic objectives. The BCN will continue its current neutral or contractive credit policy with the public sector, to which end the 
government will continue to maintain deposits at the monetary institution and comply with the mandatory schedule of transfers for servicing the external public debt. Public enterprises and autonomous entities are also targets of this monetary regulation. The sustainability of the exchange rate regime is based on the strength of this policy. For the banking system, the Central Bank will continue to be a last recourse source of credit. The $\mathrm{BCN}$ is to be strengthened by means of a set of sensible regulations that facilitate access to credit for productive sectors and strengthen the banking system and intermediation mechanisms.

53. In order to expand the supply of credit to the productive sector, GRUN will encourage private and public investment in new banking institutions. The incorporation to the financial system of foreign banks is being promoted, including savings and loans companies. For its part, the government has created Banco Produzcamos by means of Law 640, the goal of which is to directly favor small and medium producers. This bank will operate with state resources and development assistance. Likewise, the government will strengthen microfinance institutions, including those operating within the Bank Superintendency regulatory framework.

54. Notwithstanding the foregoing, scarce liquidity on the international market as a consequence of the crisis has introduced new risk elements to the national financial system, causing the $\mathrm{BCN}$ to take measures. The reduction of liquidity in the national system as a result of the drop in exports, family remittances and foreign direct investment has also had repercussions, notably a slowdown in banking system credit, and a weakening of tax revenues. The BCN goal has been to maintain confidence in the monetary authorities and the financial system in general. For this purpose a contingency credit line has been signed with the Central American Bank for Economic Integration $(\mathrm{CABEI})^{4}$, new sources of financing for the private sector have been promoted, and an Extraordinary Financial Assistance Line (LAFEX) has been approved for the national financial system as part of GRUN's anti-crisis plan. ${ }^{5}$ Likewise, the government has agreed with the Inter-American Development Bank (IADB) that the banking system can make use of credit liquidity originated by the international economic crisis, meaning that commercial banks operating in Nicaragua may go directly to IADB to mitigate liquidity needs arising from the contraction of external credit lines.

\section{Balance of payments and foreign trade}

55. The structural weaknesses inherent to the Nicaraguan economy are reflected in the country's current account deficit. Weakness of the export sector and the high degree of dependence on raw materials and imported consumer goods are in part the outcome of policies favoring private sector consumption and investment supported by increased foreign indebtedness. The already unfavorable situation regarding the balance of payments has grown worse during the current crisis, as reflected in the decrease of exports, credit, foreign direct investment and family remittances, all of which have affected the domestic economy. In addition, due to structural and external factors, Nicaragua has had to significantly increase import levels, leading to a sustained expansion of the trade gap.

\footnotetext{
${ }^{4}$ This was approved in April 2009 for the amount of US\$200 million, of which US\$ 100 million are intended for the Deposit Guaranty Fund (FOGADE) in case of bank failures. The other US\$100 million are for the BCN to cover its international reserves, should this become necessary.

${ }^{5}$ Production, Growth and Employment Protection Program, BCN, January 2009.
} 
56. During 2008, Nicaragua obtained total debt relief of US\$ 59.1 million. The ongoing negotiations to reduce debt resulted in that nominal debt relief granted in the framework of HIPC and the Multilateral Debt Relief Initiative (MDRI) now stands at US\$ 6.8064 billion (equivalent to $84 \%$ of the total nominal relief foreseen for Nicaragua under these initiatives). Relief came mainly from commercial creditors that participated in the External Commercial Debt Repurchase Operation (the most salient participants were Beogradska Banka AD of Serbia, with US 18.2 million, and Bulgargeomin LTD of Bulgaria, with US\$ 14.1 million).

57. Negotiations regarding debt relief will continue with bilateral creditors such as Costa Rica, Libya, Iran, Honduras, Taiwan and Peru. It is foreseen that nominal relief may reach an additional US\$ 1 billion.

58. Foreign public debt reached US\$ 3.5115 billion by end-December 2008, equivalent to $55 \%$ of GDP (59.5\% in 2007) and 156.5\% of total exports of goods and services (175.8\% in 2007).

59. The NHDP seeks to reduce long-term balance of payments vulnerability through, (i) promoting a change in the structure of exports; (ii) strengthening the infrastructure needed to increase the potential of international trade; and, (iii) developing tourism. A prudent foreign indebtedness policy and the creation of conditions leading to a greater flow of direct foreign investment are actions that will improve the country's balance of payments. GRUN also considers it important to facilitate foreign trade transactions by eliminating superfluous bureaucratic procedures, creating one-stop service windows, establishing the Central American Customs union, improving services at customs and diversifying markets. Taken together, these will encourage foreign trade.

\subsection{Growth: Public investment policy}

60. The overall GRUN public investment policy aims to increase efficiency, yield and impact of investments on economic growth and poverty reduction. The overall policy framework is keyed to:

i) Use pre-investments as an instrument by which to reduce improvisation in investments and the adoption of a sectoral and national approach in lieu of institutional projects;

ii) Target investments at strategic productive and social sectors;

iii) Form fixed capital as a capacity generator; and

iv) Adopt a more efficient physical and financial follow-up system.

61. The Government of Reconciliation and National Unity continues to prioritize infrastructure in the energy sector, drinking water, health, social housing, land transport and seaports. In view of the international financial and economic crisis this priority has been reaffirmed by the measures described in the January 2009 GRUN Production, Growth and Employment Protection Plan. This priority is in keeping with the population's demands and in line with efforts to improve social indicators.

62. Timely and immediate investment in the aforementioned sectors will avoid increases in the number of children left out of school each year and the maternal-child mortality rate. The latter, for instance, may be caused by lack of clean drinking water in the most impoverished communities and neighborhoods. It is also crucial to avoid allowing a further slowdown of the economy due to rationing of the electrical energy supply or chaotic situations in the transport sector. 
63. The strategic approach taken by the public investment policy also works to achieve a more efficient institutional organization. The government has begun a process to overcome the institutional weakness shown at all levels of the public investment process (policy formulation, resource management, strategic planning, budgeting and evaluation and follow-up). Likewise, a qualitative leap has been taken in the follow-up to the Public Investments Program (PIP) at both the physical and financial levels, by the establishment of a Central Commission lodged at the Presidency. It coordinates work on a weekly basis with the planning and projects units at the ministries and public enterprises. This makes for greater efficiency in the implementation of PIP.

64. Table 5 reflects the main GRUN public investment efforts (Productive and Social Infrastructure Goals, see p. 23, below). Even amidst the international financial and economic crisis these prioritize the maintenance and in some cases expansion of public services, due to their relevance to the formation of gross capital, multiplier effect on the economy and contribution to the preservation and growth of the economic and social infrastructure.

65. The following physical infrastructure goals are scheduled for the 2009-2011 period:

i) Roads and highways: $350 \mathrm{~km}$. expansion of the highway network; $131 \mathrm{~km}$ of highway rehabilitation; $377 \mathrm{~km}$ of road rehabilitation and improvements; and 216 meters of bridge construction.

ii) Energy: construction of six electrical substations; extension of one electrical substation; construction of one hydroelectricity plant; $1,450 \mathrm{~km}$ extension of the electricity grid; 46,750 homes connected; construction of twenty small hydroelectricity plants; and the installation of 214 solar and hybrid systems.

iii) Education: 2,108 classrooms repaired, replaced and/or extended; 328 schools with additional spaces added.

iv) Health: rehabilitation of 16 hospitals; rehabilitation of 8 health centers; rehabilitation of health posts; construction of 16 health posts; construction of 8 health centers; rehabilitation of 2 childbearing shelters; construction of 2 childbearing shelters.

v) Water and sanitation: drilling and rehabilitation of 143 wells; 69,042 home connection to the drinking water pipeline system; 25,334 connections to the sewage system; installation of $73 \mathrm{~km}$ of drinking water piping.

vi) Housing: construction and delivery of 26,389 new houses and home improvement to 7,950 units. 


\begin{tabular}{|c|c|c|c|c|}
\hline Description & 2009 & 2010 & 2011 & TOTAL \\
\hline \multicolumn{5}{|l|}{ Production } \\
\hline \multicolumn{5}{|l|}{ Roads and Highways } \\
\hline Rehabilitated highways (kilometers) & 27 & 56 & 48 & 131 \\
\hline Widening of paved highways (kilometers) & 80 & 146 & 124 & 350 \\
\hline Improved and repaired roads (kilometers) & 182 & 90 & 105 & 377 \\
\hline Bridge construction (linear meters) & 101 & & 115 & 216 \\
\hline \multicolumn{5}{|l|}{ Energy } \\
\hline Construction of electric sub-station & & 5 & 1 & \\
\hline Construction of hydroelectric plant & & & 1 & 1 \\
\hline Expansion of electric sub-station & & & 1 & 1 \\
\hline Installation of transformers to increase capacity & & & 16 & 16 \\
\hline Reactivation of sub-stations (units) & & & 10 & 10 \\
\hline Electric installations in homes (units) & 12,525 & 13,358 & 20,867 & 46,750 \\
\hline Expansion of grid (kilometers) & 526 & 435 & 489 & 1,450 \\
\hline Construction of small hydroelectric plant (units) & 12 & 7 & 1 & 20 \\
\hline Installation of solar and hybrid systems (systems) & 204 & 8 & 2 & 214 \\
\hline \multicolumn{5}{|l|}{ Social } \\
\hline \multicolumn{5}{|l|}{ Education } \\
\hline Classrooms repaired, replaced and/or expanded (units) & 582 & 678 & 848 & 2,108 \\
\hline \multicolumn{5}{|l|}{ Schools with exterior works built (units) } \\
\hline Sports fields refurbished (units) & 0 & 0 & & 0 \\
\hline Schools with complementary environments built (units) & 207 & 29 & 92 & 328 \\
\hline \multicolumn{5}{|l|}{ Health } \\
\hline Hospitals refurbished (units) & 5 & 7 & 4 & 16 \\
\hline Health Centers refurbished (units) & 5 & 1 & 2 & 8 \\
\hline Health Posts refurbished (units) & & 1 & & 1 \\
\hline Health Posts built (units) & 11 & 1 & 4 & 16 \\
\hline Health Centers built (units) & 2 & 4 & 2 & \\
\hline Maternity Houses Refurbished (units) & & & 2 & 2 \\
\hline Maternity Houses built (units) & & 1 & 1 & 2 \\
\hline \multicolumn{5}{|l|}{ Water and Sanitation } \\
\hline Drilling and refurbishing of wells (units) & 47 & 87 & 9 & 143 \\
\hline Increase of storage (cubic meters) & 5,347 & 12,301 & 666 & 18,314 \\
\hline Household drinking water connections (units) & 36,056 & 26,674 & 6,312 & 69,042 \\
\hline Household waste water connections (units) & 2,075 & 2,075 & 21,184 & 25,334 \\
\hline Installation of pipes for drinking water (kilometers) & & & 73 & 73 \\
\hline \multicolumn{5}{|l|}{ Housing } \\
\hline New houses (units) & 3,709 & 10,940 & 11,740 & 26,389 \\
\hline Houses improved (units) & 1,450 & 3,000 & 3,500 & 7,950 \\
\hline
\end{tabular}




\subsection{Growth: Production and trade strategy}

66. The GRUN productive strategy is based on Nicaragua's comparative advantages, donor support and private investment. The country's potential in agriculture and natural resources are the main areas of opportunity regarding economic growth and poverty reduction. Private investment can grow more quickly in these sectors with support from appropriate public policies and international cooperation, in the framework of NHDP strategies. In the medium term this effort is geared toward stepping up food production, boosting the agro-industrial process, the rational exploitation of natural resources and investment in production.

67. In the context of the Bolivarian Initiative for the Americas (ALBA), Venezuelan cooperation entered the country unconditionally and was invested in substantive areas of the national economy, such as electrical energy and the supply of oil and oil derivatives. The immediate effect was to mitigate the impact of the rise in fuel prices, expand the generation of electricity and reduce the rationing of electrical services. In 2008, Venezuelan cooperation reached US\$ 457 million, of which 98.5 million went to investments that generated 100 MW of electricity. In the framework of the PETROCARIBE agreement, cooperation was of US\$ 293 million, between non-reimbursable financing (US\$ 99 million) and loans (US\$ 194 million). These funds continue to be made available through ALBACARUNA and were used to finance productive activities of rural cooperatives (mainly in agriculture), subsidies to electrical energy and collective/selective transport, social infrastructure and food security, among others. The assistance was channeled through the private sector and does not imply contracting public debt. It is also relevant to point out that the commercial relation between ALBA member countries has made it possible avoid a more serious drop in national exports as a consequence of the world economic crisis, mainly by way of trade with Venezuela, which in 2008 quintupled its demand for Nicaraguan products in relation to 2007.

68. The government is building a productive model that includes the rescue of impoverished small farmers. This is an integral part of the national development strategy. While the rights of private investors are respected, and conditions are created for the continued growth of large farmers and enterprises, GRUN is also taking the lead in the creation of a package intended to favor small and medium farmers, with the aim that in the medium term they be less poor, more self-sustaining, inserted to economies of scale and in a position to benefit from fair trade, alongside large farmers. The policy includes anti-monopoly measures that facilitate access to markets by small and medium producers.

69. The industrialization of agriculture is an essential part of the productive strategy, insofar as it contributes to expanding the value chain, generates greater value added and benefits mainly farmers. However, to increase competitiveness and raise levels of production also requires the efficient use of production factors, diversification and strengthening of productive and commercial chains, as well as the use of modern marketing techniques. Along these lines, coordinated participation of the government and private sector, research at universities, and technical assistance from the donor community will be critical to magnifying the country's agro-industrial capacity to produce goods for foreign markets.

70. In the medium term the main focus will be on solving the country's energy needs, expanding the coverage of drinking water and protecting the environment. Given the large sums necessary to 
achieve structural change in the energy matrix, the government has invited the international community to finance programs in the sector, is negotiating with private investors and has introduced a policy of openness with regards to the generation of electrical energy using renewable resources, all with a view toward encouraging the private sector to join the process. Rural areas will be prioritized for the purpose of furthering food production.

71. In order to accelerate the implementation of the productive strategy, a road map has been drawn up. GRUN has advanced in its discussions with large producers at the coordination roundtables, as well as with trade associations and other groups that bring together micro-, small and medium producers. It has also coordinated activities with the donor community and independent organizations that support the productive sector, and programs are being formulated that are consistent with this strategy. Consensus has been reached on the need to act in the medium term on the following critical needs:

i) Direct policies in support of the private sector (micro-, small and medium producers in the countryside and the towns).

ii) Strategic agreements with the private sector (large farmers).

iii) Stimuli for national and foreign investment, in a framework of adequate incentives; in exchange, investors will commit to fiscal, labor, environmental and cultural responsibility.

iv) Speed up effective commitments of cooperation in the framework of new agreements with friendly countries (such as the members of ALBA).

v) Speed up the public investments program in infrastructure associated directly to production.

vi) Overcome the energy crisis and stabilize the sector, thus paving the way for improved yields.

vii) Maintain macroeconomic stability and a timetable for reaching consensus on a tax reform that encourages agricultural production.

viii) Ensure respect and introduce guarantees for private property, with a view toward strengthening both the market economy and fair trade.

ix) Remain in the framework of the trade agreements entered into by previous governments (mainly CAFTA-DR) and bilateral treaties.

x) Promote technical and higher education aimed at the transformation of the productive process.

\section{Agriculture, livestock and forestry}

72. The principles that underpin the agriculture, livestock and forestry strategy and are being shouldered by the Agriculture, Livestock and Forestry System (SPAR) are as follows:

i) Reach food sovereignty and promote agricultural exports. Poor decapitalized small farmers and small landowners are the active subjects of development. They are the pillar upon which the government's planning and public management strategy toward rural areas is based. 
ii) Regulate land tenure, update the physical cadastre and proceed with delimitation, (political sphere) demarcation (technical sphere), titling (legal sphere) and physical planning.

iii) Encourage a shift from the use of groundwater to surface water by building reservoirs, dams and micro-dams. By adding adequate irrigation systems it will become possible to produce food during the dry season as well. The groundwater is to be left as a strategic reserve and be used only for human consumption.

iv) Promote the association of small and medium producers in rural and coastal areas, so as to accelerate capitalization in these places and advance with the transfer of technology.

v) Ensure access by small producers to financial services, guaranteeing the expansion and deepening of credit and continuing with the revolving fund for women beneficiaries of the Food Production Program (Hambre Cero).

vi) Work to revolutionize the agricultural technology used by small and medium food producers, as well as their socioeconomic and environmental conditions. Place emphasis on the Food Production Program by means of technical assistance and training. Stress also the Agricultural Foodstuff Seeds Program.

vii) Bring the agricultural sector into productive reactivation. The policy of collaborating with top Nicaraguan business leaders is to be maintained and deepened, in order to facilitate the operation of large farms, agribusinesses and service providers under conditions of economic, social, labor and environmental responsibility. Conventional private businesses have sufficient space to facilitate the rapid insertion of the country to the regional economic dynamics (ALBA, CAFTA and alternative markets).

viii) Protect the environment and foster production, conservation, development and life. Promote sustainable management of land and water resources and forests by improving practices and designing instruments by which to deal with climate change and the vulnerability of agriculture and livestock to natural disasters. Human beings are conceived of as part of a complex environmental and living system, with which they are to be brought into harmony.

73. The four programs of the strategy are:

i) Productive Rural Development Sector Program

ii) National Food Program

iii) Rural Agro-Industry Program

iv) National Forestry Program

\section{Industrial policy}

74. In the sphere of public policy, GRUN is taking a more active role in its support to industrial development, for the purpose of adding greater value to the primary production that makes up the value chains. The industrial strategy is conceived of from a short, medium and long-term perspective. Many of these changes depend not only on government policy, but on the process of regional and extra-regional integration, productive integration within the country itself, the evolution and opportunities that may arise in the international economy, and the international community. 
75. The Ministry of Industry, Development and Commerce (MIFIC) is the institutional organ that governs policy towards industrial development and the micro-, small and medium enterprises (MIPYMEs). Its executing bodies are the Institute of Small and Medium Enterprises (INPYME), the Institute of Tourism (INTUR) and the National Technological Institute (INATEC).

76. GRUN industrial policy has for its goal to create a setting that propitiates the growth of businesses already existing in the country, as well as the establishment of new industries. This translates into the creation of the mechanisms necessary to improve the investment climate, strengthen the legal framework, expand opportunities for technical education and support technological change. From this point of departure the government has begun a process to review the regulatory framework in the sector, as well as identify and eliminate unnecessary procedures and formalities that make doing business cumbersome or expensive.

77. Priority is afforded to an infrastructure investment policy linked directly to cost reduction for the companies' production processes. For this reason, GRUN has placed maximum emphasis on the stabilization and development of the energy sector, as one of the central pillars in the country's development. Transport, communications and the water supply, among other services, are vital to industrial development. These are precisely the areas on which the government has focused in its public investment program.

78. For the large companies, ${ }^{6}$ much as in other sectors, the government is gearing its policy towards creating conditions that attract investment, propitiate opening to the world, and promote integration with the primary sector. The modernization and expansion of installed capacity at large companies rests upon their ability to obtain investment capital and penetrate new markets. Most have the capacity to borrow for short and long-term maturity investments, as well as access to joint investments.

79. Small and medium enterprises ${ }^{7}$ have also been prioritized by the NHDP, again for the purpose of reducing poverty, as many low-income families work at or own these. Such companies have only scarce capital, their access to conventional credit is extremely limited and little skilled labor is available to them. The policy toward MIPYMES is based on improving their capacity to provide goods and services, mainly for the local market. The industrial policy instrument is the Micro, Small and Medium Enterprise Development Program (PROMIPYME).

80. The implementation of PROMIPYME is underway as a MIPYME sector development strategy. Its development objective is to "contribute to increase and consolidate the competitiveness of the MIPYME, so they are able to operate in the national and international markets with improved advantages, become a source of quality employment and additional resources for their owners and workers, and contribute to substantially reduce poverty levels among the Nicaraguan population."

81. This program will be operated through the following ten sub-programs:

\footnotetext{
${ }^{6}$ In Nicaragua, a large company is one that generates over 100 jobs. Overall, the sector provides jobs to approximately $25 \%$ of the total industrial workforce.

${ }^{7}$ Small and medium enterprises are defined as those with anywhere from 6 to 99 employees. Such enterprises generate around $30 \%$ of all jobs in the industrial sector.
} 
i) Furtherance of cooperation among entrepreneurs;

ii) Training and updating of human resources and business promotion;

iii) Improvement in quality, productivity and marketing;

iv) Technological development and innovation;

v) Export promotion;

vi) Improvement of access to financial systems;

vii) Improvement of access to infrastructure and basic services;

viii) Development of entrepreneurial capabilities and founding of enterprises;

ix) Improvement in the business climate and furtherance of legalization; and

$\mathrm{x}$ Improvement of institutional capacity to support the development of MIPYMEs.

82. The MIPYME regulatory framework will be modernized, in order to facilitate the founding and operation of these enterprises. GRUN has proceeded to strengthen the legal and information network in order to reduce entry barriers and obstacles to market performance, while promoting clear rules that stimulate company growth and guarantee compliance with their rights and obligations as an important actor in the country's development.

\section{Energy and mining policy}

\section{Energy}

83. The GRUN energy policy in essence consists of expanding the supply of renewable resources and changing the energy generation matrix. The Ministry of Energy and Mines (MEM) actively supports the development of energy generation projects based on renewable energy, with the goal of changing the energy matrix in the medium and long term. These projects may be implemented by private, state or joint enterprises.

84. The following projects are part of the Expansion and Generation Plan, under scenario A: wind energy - Amayo (40 MW), which began operations in February 2009. Geothermal - San Jacinto-Tizate (under execution and expected to deliver the first $24 \mathrm{MW}$ in the second semester of 2011, with another 48 MW to follow in the first semester of 2012; El Hoyo-Monte Galán and Managua-Chiltepe, both in the exploration phase and expected to begin operations during the first semester of 2014 and 2015, respectively; the awarding of a concession for the exploration of the Casita-San Cristóbal geothermal area, scheduled to begin operation in the 2013-16 period (20 MW, $40 \mathrm{MW}$ and $40 \mathrm{MW}$, respectively); bidding processes are currently underway for the geothermal areas at Apoyo, Ometepe and Mombacho, to begin operating in the first semester of 2016, the second semester of 2016 and the first semester of 2017, respectively. Hydroelectricity - the hydroelectric projects at Tumarín (180 MW), for which a specific law was passed by the National Assembly on 1 July 2009 and which is projected to begin producing electricity during the second semester of 2013; at Larreynaga (17 MW), to be developed by the Nicaraguan Electricity Company (ENEL) with the civil works being tendered through CABEI, with generation probable during the second semester of 2012; at Boboké (70 MW), to start operation in the second semester of 2014; at Salto Y-Y (25 MW), to initiate operation in the second semester of 2012); and at HidroPantasma (12 $\mathrm{MW}$ ), also to begin operation during the second semester of 2012). 
85. MEM is negotiating the signing of agreements with companies from Brazil, Russia, Iran and Mexico for the development of hydroelectric projects at Brito $(180 \mathrm{MW}$, located in the province of Rivas); COPALAR Bajo (150 MW) and El Carmen (100 MW). The latter are both in the Río Grande de Matagalpa river basin.

86. In sum, the GRUN energy strategy is designed to double Nicaragua's energy generation capacity by 2017 , based on renewable energy.

Table No. 6: EXPANSION OF ELECTRIC GENERATION PLAN 2008-2017

BASE A RECOMMENDED SCENARIO (POWER EXPRESSED IN MW)

\begin{tabular}{|c|c|c|c|c|c|c|c|c|c|c|c|c|c|c|c|c|c|c|c|c|c|c|c|c|c|}
\hline \multirow{3}{*}{ Type } & \multirow{3}{*}{ PROJECTS } & \multirow{3}{*}{ Type } & \multirow{3}{*}{ Investor } & \multicolumn{22}{|c|}{ YEAR } \\
\hline & & & & \multicolumn{2}{|c|}{2007} & \multicolumn{2}{|c|}{2008} & \multicolumn{2}{|c|}{2009} & \multicolumn{2}{|c|}{2010} & \multicolumn{2}{|c|}{2011} & \multicolumn{2}{|c|}{2012} & \multicolumn{2}{|c|}{2013} & \multicolumn{2}{|c|}{2014} & \multicolumn{2}{|c|}{2015} & \multicolumn{2}{|c|}{2016} & \multicolumn{2}{|c|}{2017} \\
\hline & & & & IS & II S & IS & IIS & IS & II S & IS & IIS & IS & IIS & IS & II S & IS & II S & IS & II S & IS & IIS & IS & II S & IS & II S \\
\hline Thermal & Albanisa (Bunker) * 1 & Thermal & ALBANISA & & & & 54 & 37 & 73 & 36 & & & & & & & & & & & & & & & \\
\hline \multicolumn{2}{|r|}{ TOTAL THERMAL } & & 200 & & & & 54 & 37 & 73 & 36 & & & & & & & & & & & & & & & \\
\hline Wind & Amayo & Wind & $\begin{array}{l}\text { GRUPO } \\
\text { AMAYO }\end{array}$ & & & & & 40 & & & & & & & & & & & & & & & & & \\
\hline \multicolumn{2}{|r|}{ TOTAL WIND } & & 40 & & & & & 40 & & & & & & & & & & & & & & & & & \\
\hline Geo & San Jacinto * & Geo & POLARIS & & & & & & & & & & 24 & 48 & & & & & & & & & & & \\
\hline Geo & Casitas * & Geo & MIXED & & & & & & & & & & & & & 20 & & & & 40 & & & 40 & & \\
\hline Geo & EI Hoyo I * & Geo & GEONICA & & & & & & & & & & & & & & & 40 & & & & & & & \\
\hline Geo & Chiltepe * & Geo & GEONICA & & & & & & & & & & & & & & & & & 40 & & & & & \\
\hline Geo & APOYO * & Geo & Undefined & & & & & & & & & & & & & & & & & & & 40 & & & \\
\hline Geo & OMETEPE * & Geo & Undefined & & & & & & & & & & & & & & & & & & & & 30 & & \\
\hline Geo & МОМВАСНО * & Geo & Undefined & & & & & & & & & & & & & & & & & & & & & 40 & \\
\hline \multicolumn{2}{|r|}{ TOTAL GEO } & & 362 & & & & & & & & & & 24 & 48 & & 20 & & 40 & & 80 & & 40 & 70 & 40 & \\
\hline Hydro & Boboke *2 & Hydro & $\begin{array}{l}\text { MIXED } \\
\text { (BOT) }\end{array}$ & & & & & & & & & & & & & & & & 70 & & & & & & \\
\hline Hydro & Hydro-Pantasma (run-of. & Hydro & $\begin{array}{l}\text { FCC - } \\
\text { SARET }\end{array}$ & & & & & & & & & & & & 12 & & & & & & & & & & \\
\hline Hydro & Larreynaga (run-of-the-ri & Hydro & ENEL & & & & & & & & & & & & 17 & & & & & & & & & & \\
\hline Hydro & Tumarín * & Hydro & $\begin{array}{c}\text { MIXED } \\
\text { (BOT) }\end{array}$ & & & & & & & & & & & & & & 160 & & & & & & & & \\
\hline Thermal & Coal (PNI Conversion) * & Thermal & $\begin{array}{l}\text { PRIVATE } \\
\text { OR STATE }\end{array}$ & & & & & & & & & 0 & & 0 & & & & & & & & & & & \\
\hline Hydro & Salto Y-Y (run-of-the-rive & Hydro & $\begin{array}{l}\text { CÍA. } \\
\text { CERVEC. } \\
\text { NIC. }\end{array}$ & & & & & & & & & & & & 25 & & & & & & & & & & \\
\hline \multicolumn{2}{|r|}{ TOTAL HYDRO } & & 284 & & & & & & & & & & & & 54 & & 160 & & 70 & & & & & & \\
\hline \multicolumn{2}{|r|}{ TOTAL } & 886 & 886.0 & 0 & 0 & 0 & 54 & 77 & 73 & 36 & 0 & 0 & 24 & 48 & 54 & 20 & 160 & 40 & 70 & 80 & 0 & 40 & 70 & 40 & 0 \\
\hline \multicolumn{2}{|c|}{ CUMULATIVE TOTAL } & & & & & & 54 & & 204 & & 240 & & 264 & & 366 & & 546 & & 656 & & 736 & & 846 & & 886 \\
\hline
\end{tabular}

* These projects represent solid power commitments

Notes:

1 According to the Energy Stability Law

2 In the "B" and "C" base scenarios, the Brito and Copalar Bajo Hydroelectric projects are presented as alternative projects to Boboké. 
87. Expansion of the electricity transmission grid. The funds needed to strengthen and expand the national electricity transmission grid, a requirement of the Central American Electrical Interconnected System (SIEPAC) have been obtained. This ensures that by late 2010 Nicaragua will be in a position to buy and sell electricity on the regional electricity market. The National Electricity Transmission Company (ENATREL) has built $142 \mathrm{~km}$ of transmission lines from Matiguás (Matagalpa) to Siuna (North Atlantic Autonomous Region, RAAN), the interconnection from Bluefields to El Bluff (South Atlantic Autonomous Region, RAAS), and an $18 \mathrm{~km}$ transmission line (138,000 volts) from Masaya to Granada. In addition, it has rehabilitated the Nandaime substation and continued work to strengthen the National Transmission System (SNT), replacing power transformers at the substations in Villanueva, Las Banderas, Rivas and Chinandega.

88. Continuation of rural electrification projects. The government will continue to develop rural electrification projects in the different communities in the country. These are financed both with external funds (donations and loans) and budget allocations. Significant resources were obtained from IADB, the World Bank, CABEI, the Netherlands, GTZ, SDC, UNDP and ACDI, among others. For the year 2009 the national budget contains an investment of C\$ 204.502 million in rural electrification projects, intended to benefit 230 communities and 74,661 persons living in 12,525 houses. Some $526 \mathrm{~km}$ of distribution lines will be laid. Currently a new electrification project for both urban and rural areas is in the formulation stage. It is designed to significantly increase electrical service coverage. Further, small hydroelectricity plants are being built in isolated areas, including the accompanying electrical networks. Generation and distribution concessions are granted to local companies.

89. Energy savings and efficiency actions. In order to comply with Presidential Decree No. 22008 titled "Planning of Energy Use", a total of 20 energy audits have taken place in the government sector, as have 25 of the 30 audits scheduled for the industry and commercial sectors. The Decree announces measures for the efficient and rational use of energy at executive branch agencies for the purpose of reducing energy consumption by at least $20 \%$.

90. Reduction of distribution losses. To contribute further to the viability of the electricity sector and its development, GRUN promoted passage in the National Assembly of the Distribution and Responsible Use of Electrical Energy (Law 661 of 28 July 2008). This has contributed to gradually bringing down losses related to distribution to $23 \%$ as of this past July. Starting in 2009 , the government is supporting the distribution companies as they implement a pilot program to improve electricity metering and other services in low-income urban neighborhoods.

91. Regulatory framework. The regulating entity will continue to authorize monthly electricity rate adjustments, if justified. To that end a formula will be applied (published on 21 December 2007 in La Gaceta, official parliamentary record, no. 246). This formula takes into account variations and avoids accumulated losses. A Protocol of Understanding was signed with the distributors (DISSUR and DISNORTE), which was agreed to by the National Assembly (Decree no. 29-2008, published on 27 July 2008 in La Gaceta, no. 122). Among other things, the distributing companies committed themselves to invest a minimum of US\$ 33.7 million in the distribution system over the next 4 years; both parties will suspended their legal actions (an arbitration process begun by the National Energy Institute, INE, and a complaint brought by the distributors before the World Bank 
Multilateral Investment Guarantee Agency (MIGA). A mechanism was implemented that conciliated matured debts between the government and the distributors, and allowed the government to take over $16 \%$ of shares in equity capital, thus gaining a seat on the companies' Board of Directors.

92. Actions in the hydrocarbons sector. To ensure the supply of hydrocarbons required by Nicaragua, a Reciprocal Assistance and Cooperation Agreement has been entered into with Venezuela. The Agreement includes the construction of an oil refinery in the Pacific region, the rehabilitation of storage capacity at Piedras Blancas and the construction of a fuel oil reception and storage terminal with capacity for 200,000 barrels at Corinto. The latter is currently functioning. There is also a contact for the supply of 27,000 barrels of oil per day. Along the same lines, exploration for oil is being pursued vigorously, and 4 concession contracts for exploration on the continental platform of the Nicaraguan Caribbean have been negotiated. Similar activities are being monitored offshore in the Pacific Ocean, with the aim of determining the existence of hydrocarbons and their eventual use.

93. Promote the development of agricultural energy and biofuels. MEM is promoting biomass programs as well as the use of biofuels as renewable energy sources that can be used to partially make up for the consumption of hydrocarbons, on condition that food security is not negatively affected.

\section{Mining}

94. The Ministry of Energy and Mines is fostering the following measures: i) a review of the legal framework as concerns mining, for the purpose of proposing reforms to the Special Law on Mine Exploration and Exploitation; ii) increase knowledge of mineral wealth in the country by carrying out geological studies; iii) improve the registry, inscription and legalization of artisan miners; iv) promote the transformation of artisan miner collectives into small and medium mining companies; and v) promote joint investments with mining companies in the electricity generation using renewable resources.

95. Geological research on minerals. Carry out geological research and mapping of potential mineral sites.

96. Transformation of artisan mining into small mining companies: i) identify, organize, reorganize and train individual artisan miners as well as those organized in collectives; ii) transform artisan mining collectives into small and medium mining companies, including the introduction of modern types of association and technology.

\section{Tourism}

97. Tourism in Nicaragua is evolving, as are policies keyed to furthering this activity. In this context, GRUN is promoting significant transformations concerning infrastructure, in order to stimulate economic growth. It is also important to maintain levels of political and social stability so as to minimize the perception of risk among potential visitors. Thus Nicaragua may be attractive as an opportunity for internal and foreign direct investment, which will have an effect on the growth of the tourism industry. The government has a policy of offering incentives to small tourism projects, 
and an intensive policy of positioning the country in the world economy, to which end the promotion of tourism is essential. Tourism has the potential generate a multiplier effect in economic activities, generate employment and promote consumption, all of which contribute to the overall NHDP goal of fighting poverty.

98. The Government of Reconciliation and National Unity is taking action to meet expectations in the sector. Indeed, even amidst the international financial and economic crisis, the type of relaxation tourism and attractive prices available in Nicaragua can be turned to best advantage. The strategy being proposed includes defining touristic products and positioning the country, a review of the legal framework, improvements in customs procedures, prioritizing the Caribbean Coast, promoting tourism MIPYMES and developing specific projects to benefit the sector.

99. Positioning the image of Nicaragua as a country attractive to tourists has been largely overlooked in the past. This has hampered that the country's attractions be better known, both domestically and internationally. However, remedying this situation requires resources and an appropriate marketing strategy. Measures are being taken, in coordination with the private sector and local governments, to increase the flow of tourists, the average time of stay and average amount spent daily. To that effect, the supply of tourist destinations, citizen safety and investment opportunities in the country are being increased. In this context a specific policy to develop tourism on the Caribbean coast is being developed, working closely with local governments.

100. The adjustment of the legal framework is taking place with the aim of developing tourism in a sustainable and safe manner, adapting it to the various stages of tourism development. Legal initiatives are promoted to endow tourism with a stable and permanent juridical framework that ensures security for investors, tourists and tourism MIPYMES ${ }^{8}$. In addition, inclusion and access for the entire sector is promoted by designing tools for use by micro-, small and medium companies involved in tourism, allowing them to benefit from the incentives and benefits established in the various pieces of legislation.

101. The Caribbean Coast is given priority due to its potential and because the sector is strategic to reducing poverty in the two autonomous regions. The inclusion of the Nicaraguan Caribbean Coast to the regional destination brand "the Caribbean", recognized by tourists worldwide, will allow Nicaragua to achieve the objectives pursued by its strategy. This implies seeking out tourism development poles in the region, carrying out specific projects, obtaining financing for infrastructure such as the extension and improvement of ports, airports (such as is occurring in Bilwi) and road construction, as well as facilitating the development of services infrastructure through the MIPYME.

102. An important element in the tourism strategy is the improvement of entry points. Customs areas and procedures are being modernized to speed up admittance to the country by various means, including free visas and granting of residency, while encouraging airlines and cruise ships to call at

\footnotetext{
${ }^{8}$ Law of Retired Pensioners: seeks to attract foreign retirees to come live in Nicaragua, thus generating consumption, jobs, taxes and currency. - Coastal Law: consensus was reached on a way to regulate coastal areas, ensuring sustainable and adequate development and magnifying the tourism potential of this valuable asset. - Law on Incentives for the Tourism Industry: facilitates inclusion and access by the entire sector to tools for use by tourism MIPYMES, favoring them via incentives and other benefits.
} 
Nicaraguan (airports, with the aim of having Nicaragua included to the already existing tourist routes in Central America and thus facilitate access from important markets.

\section{Telecommunications and postal services}

103. A factor fundamental to the success of the NHDP is the identification of the potentialities and deficiencies that exist in the different parts of the Nicaraguan geography as regards telecommunications and postal services. Investments in communications are an imperative, as these ensure the growth of other economic, social, political and cultural sectors in the country. The actions taken and investments made in the development of telecommunications and postal services must prioritize the most neglected areas, in order to reduce the degrees of productive and social inequity, as well as geographic isolation and lack of access to communications. In particular, public investments in communications by the government would increase overall quality, as it would contribute to ensure that the public resources earmarked for the development and use of infrastructure have the greatest possible impact.

104. GRUN will continue to take actions to foster a telecommunications market that functions efficiently and contributes to promote the competitiveness of the economy and the growth of micro-, small and medium enterprises, while simultaneously benefiting end consumers.

\section{Goals for the telecommunications sector and postal services}

105. With the aim of reversing the situation of social inequity, GRUN is working through the Nicaraguan Telecommunications and Postal Institute (TELCOR) to develop projects that will benefit those population groups least favored during the past decade. The projects are geared toward benefiting people living in isolated communities and whose incomes are very low, in order to narrow the digital gap for citizens traditionally without access to communications and computers, while strengthening the education sector.

i) By late 2009, Nicaragua will have a detailed analysis of the telecommunications sector that allows for determining current conditions as concerns competition, conditions under which services are provided to users and the current telecommunication networks. This will make it possible to define a sectoral policy that ensures universal access to telecommunications.

ii) In the course of the year 2009 the installation of Internet presence points, call centers and cell phone coverage will be concluded in 104 municipal capitals that did not have this service when GRUN came into office. It is estimated that 1,165,000 Nicaraguans will benefit. By the time the project concludes, all 153 municipal capitals without exception will have access to Internet and cell phone coverage.

iii) By the end of the third quarter of 2009, one hundred technological centers endowed with computers connected to the Nicaragua Educational Intranet will have been installed at public schools. Guided by the Secretariat for Communications, Citizenship and Social Well-Being of the Presidency, these centers will contribute to improve the learning process of students and strengthen teacher training.

iv) During 2009-2012, approximately 400 technological centers will be installed throughout Nicaragua. 
v) During 2009-2010, at least one public telephone will be installed in 347 neglected communities with populations over 400 persons, for coverage of $90 \%$ of these communities. It is expected that the first 60 communities enjoy this benefit by late 2009. By end-2011, coverage of communities with more than 400 inhabitants will be total.

vi) During 2009-2010, it is expected that 42 rural communities in RAAN will benefit from the installation of a renewable energy electricity generation plant for strictly local use. This will be accompanied by telecommunications systems, computer equipment and electrification of community facilities.

106. Concerning postal services, it is expected to achieve the following goals:

i) In 2009 there began the implementation of the Comprehensive Postal Sector Reform and Development Plan, which was prepared during the second semester of 2008 and is scheduled to conclude in 2010.

ii) By late 2009, Nicaragua will have an analysis of the current situation of the Universal Postal System (SPU). The goal is to ensure a quality postal service for the entire population, and to issue a law and enabling regulations that establish competitive and fair exploitation of the market by private operators and the public postal system (Correos de Nicaragua).

iii) In 2010 a sectoral policy will be in place that establishes guidelines for the performance of the Nicaraguan state as it complies with its SPU obligations, without thereby limiting the right of private operators to the commercial exploitation of the national postal market.

iv) By late 2011 there will be a modernized public postal system operating (Correos de Nicaragua), with the capability of providing a range of services strategic to the country's development. It will thus become a fundamental pillar in support of the development of all economic and social sectors.

107. In order to achieve the goals described in the foregoing, GRUN intends to carry out the actions listed below and thus put into practice its sectoral policy:

i) Formulate a new Telecommunications Sector Policy, proposing objectives, designing strategies and establishing short, medium and long-term goals that are congruent with the National Human Development Plan.

ii) Propose the modernization of the regulating entity, facilitator and proponent of telecommunications in Nicaragua. TELCOR is formulating a modern telecommunications bill for the sector, including enabling regulations, in order to transform telecommunications into an effective instrument in Nicaragua's development.

iii) Identify and prepare conditions for the use of frequency bands that offer the most advantages regarding coverage and quality of service with the least cost in terms of infrastructure deployment. This will translate into an increase in the supply of services at a lower cost to users.

iv) Facilitate conditions for the productive and social use of the infrastructure and telecommunications services by installing portals to provide electronic services in all 
provincial capitals and government agency delegations in the territory, including onestop investment windows or taxpayer registration offices. Even more important, a conceptual framework for municipal e-government is to be implemented.

v) Expand the ENATREL network so all provincial capitals are connected to the grid. Thus data can be transmitted at fair and reasonable prices, while increasing the supply of these services.

108. To further develop the postal sector, GRUN is implementing a Comprehensive Postal Sector Reform and Development Plan, in cooperation with the Universal Postal Union (UPU) and the Postal Union of the Americas, Spain and Portugal (UPAEP). The aim is to modernize and develop the sector by means of the following actions:

i) Set up a Universal Postal Service (SPU). To that end several studies are being carried out to determine the quantitative and qualitative features of the supply and demand in the country's postal services market, as well as deciding which postal services to include in the Universal Postal service.

ii) Modernize the current legislation by means of a new law and its enabling regulations, based on the abovementioned studies.

iii) Modernize the services currently provided by the public postal operator (Correos de Nicaragua). A specific and direct plan will be drawn up, based on a strategic, medium-term plan, including pertinent actions and the projects required for restructuring and updating its operations.

iv) Prepare a study to identify the logistical support the public postal operator may be able to provide state institutions with, for the purpose of reducing the costs of logistical services at these agencies and determining the benefits to be obtained.

\section{Trade policy}

109. One of the main objectives of the international trade policy is to regulate Nicaragua's trade relations with the rest of the world, guided by the notion of fair and competitive trade. Under that premise, Nicaragua has insisted at various international trade forums on the need to incorporate the idea of fair trade to the world market, understood as a real acknowledgement of the asymmetries between the economies of the countries and the correction of distortions on world markets.

110. In this context, Nicaragua will continue to propose to industrialized countries the elimination of subsidies and internal assistance for goods and services of commercial interest, as well as special and differentiated treatment for developing countries, in particular those that have small and vulnerable economies, such as Nicaragua itself. GRUN has also expressed that the WTO Doha Round negotiations constitute a fundamental instrument for the country's development strategy.

111. Within Nicaragua, the government will guarantee a stable and predictable rate of exchange, the free use of hard currency, the free convertibility of currencies and a tariff policy congruent with its commercial interests, including respect for the international commitments acquired. 


\section{Private investment promotion policy}

112. The general policy to stimulate private investment is based on three points, as follows:

i) macroeconomic stability;

ii) responsible fiscal policy;

iii) respect for private property; and

iv) appropriate incentives to stimulate direct foreign investment.

113. The government has taken important steps in these directions. It has signed a three-year agreement with the IMF that guarantees the flows of external resources to finance investments in infrastructure. Cooperation agreements have been renewed with the main donors, and progress has been made concerning commercial agreements.

114. A legal framework intended to strengthen the arbitration system and property rights is being devised. Investments are being made in infrastructure and citizen security to fight illicit activities and create the propitious business climate required by national and foreign direct investment.

115. The private sector (in particular large businesses), has been taken into account within this overall framework, as evidenced by the incentives provided through the investments law, fiscal policy and coordination with the government. In 2007, a coordination mechanism (roundtable) was established with the large business sector, headed by the President of Nicaragua, for the purpose of maintaining an ongoing dialogue between large producers and the government. To date this mechanism has served to facilitate the resolution of the difficulties faced by the sector, and to foster a common agenda favorable to the country's economic development.

116. The coordination roundtable has led to time-saving measures by reducing the bureaucracy and eliminating unnecessary procedures and requirements in business management and development. Perspectives concerning investments may in fact improve, as the mechanism is useful for clarifying situations and dissipating fears that are essentially political, economic and social in nature. It also generates a link that improves relations with the other branches of government, in order to advance with the passage of laws and solutions to problems regarding property and retardation of justice. Further, a program is underway to capitalize small rural producers and small and medium urban enterprises.

\subsection{Fostering well-being and social equity}

117. The Government of Reconciliation and National Unity is widening the focus regarding social policy. In its overall social strategy, GRUN prioritizes five areas leading in several directions that contribute to reduce poverty and encourage economic growth: i) food strategy; ii) education strategies and policies; iii) health strategies and policies; iv) drinking water and sanitation strategies and policies; and v) labor policy. These are the most salient and representative areas of the government's social policy. This in no way limits the creation of other programs that favor specific situations that may arise in the course of implementing the NHDP. Indeed, this Plan is subject to constant updating, according to prevailing conditions and the needs of the Nicaraguan population. 


\section{Food strategy}

118. The food strategy was conceived of as a way to expeditiously tackle the problem of malnutrition among small farmer families and the urban poor, with income-generating activities to follow in a later stage. The policies, actions and programs underway are intended to restore the productive capabilities of the poor, increase employment and income, and reduce the emigration of small farmers.

119. This includes specific food programs introduced to the education system. In 2007 GRUN launched the Hambre Cero program, designed to benefit 75,000 rural families over a five-year period. This is being done through a partially reimbursable transfer mechanism that provides means of production to these families, with the adult woman in the household being the program's main partner. The strategy includes other programs as well, such as the extension of the Pound-for-Pound program and the microfinance program Usura Cero.

\section{Education strategy and policies}

120. The Government of Reconciliation and National Unity conceives of education as the fundamental strategic pillar for attaining sustainable human development in Nicaragua. Since January 2007 a policy is being implemented that is based on the principles of equity and quality of education. These principles reflect an effort to concentrate resources on facilitating access to education and providing a learning process in accordance with the needs of individuals, families, communities and the country.

121. The main lines of the GRUN education policy are as follows: (i) More Education, which consists of diminishing illiteracy among the population under fifteen years of age while extending education coverage at all levels (pre-school, primary, secondary, special, teacher training and technical); ii) Better Education, which means transforming the education curriculum and training teachers; iii) Other Education, geared toward transforming values in education and the education system; iv) Participatory and Decentralized Education Management, whereby the participation of parents, educators, students, civil society organizations, municipal governments, communications media and international NGOs is promoted in the formulation and administration of education policies; and v) All Educations, which coordinates the various subsystems and components of the education system into a comprehensive whole that allows for an educational continuum from cradle to grave.

122. The More Education policy in essence means continuing the struggle against illiteracy begun on 23 March 1980. The National Literacy Campaign "From Martí to Fidel” was organized and implemented starting in June 2007 and ended two years later, in June 2009. It was based on the Cuban method Yo, Sí Puedo (Yes, I Can). It is worth highlighting the participation and collaboration of the Citizen Power Councils in the reduction of illiteracy from $22.8 \%$ to $4.06 \%$ among the population over 15 years of age. As a result, Nicaragua has been declared Territory Free of Illiteracy by UNESCO. Now that the promise to reduce illiteracy among the population under 15 years of age has been fulfilled, the next task is the full enrolment of those that have recently learned to read and write. This will take place via a broad-based post-literacy campaign program, based on the Cuban 
model Yo Sí Puedo Seguir (Yes, I Can Continue). In parallel with these activities, GRUN intends to continue implementing its permanent literacy program among those who are still illiterate, a number estimated in June 2009 at 121,811 persons over 15 years of age.

123. The Better Education policy has fundamentally meant transforming the Basic National Curriculum and the formulation and launching of the National Teacher Education and Training System. The curricular transformation process has proceeded according to the following itinerary: during 2007 a National Curriculum Consultation process was carried out, in which 17,500 persons were interviewed nationwide, among teachers, parents, and civil, cultural and political organizations, with discussion centering on what is to be taught and learned in schools; during 2008, and based on the result of the Consultation, a new and Nicaraguan concept of Basic and Middle Education Curriculum was prepared by teachers and persons involved with the Study Programs, Education Nuclei, Educational Training, Evaluation and Programming Workshops, Classrooms and Pedagogical Training and Accompaniment Network; starting in February 2009 the new Regular Education Curriculum began to be implemented, and for the first time in the history of Nicaraguan education there began a process of preparing Non-Regular Education Curricula. Starting in 2010, the two subsystems of the New Nicaraguan Education System will have an entirely new curriculum.

124. The Other Education policy refers to the process of substituting the former values based on which children had to pay the school for their education, for an ethical, moral and social framework that promotes citizen, family, environmental, economic and patriotic values and relates these to child health and rights. Reflecting the knowledge promoted in the new curricula for Regular and Non-Regular Education, the Pro-Values Program is being implemented starting in 2009, by means of which at all education centers in the country every month a different set of values is promoted (i.e. in May, family values; in June, environmental values; in September, patriotic values, and so on).

125. The Participatory and Decentralized Education Management policy is also related to the new way of educating children and administering education at national and local level. According to this policy, education is a responsibility of the state, in particular as regards ensuring the right to education. It is also, however, everyone's task. Thus in 2007 the National Curriculum Consultation took place; starting in 2008 the process of local contextualization of what is taught and learned at schools is carried out every month at the Educational Training, Evaluation and Programming Workshops; and starting in 2009 the Ten-Year Education Plan will begin to be developed in all 153 of the country's municipalities, with full citizen participation. Further, the Education Cabinets at community, municipal and provincial level provide information, analysis and recommendations on how to improve education in their localities.

126. The All Educations policy is geared toward coordinating basic and middle education with other levels as set forth in the General Education Law (higher education, technical education, extraschool education and the Regional Autonomous Education System, SEAR), in the context of the preparation and foundation of a genuinely Nicaraguan education system, for the first time in history.

127. As concerns higher education, GRUN has reached consensus with the universities on strategic actions to improve quality and access to higher education, along four strategic lines: (i) improve the quality and relevance of public higher education by contributing to the improvement 
and updating of the curriculum at undergraduate and postgraduate levels, as well as scientific research and technological innovation that augments the contribution made by universities to the solution of national problems and the eradication of poverty; (ii) strengthen the institutional framework and coordination of higher education with the various sectors in society (i.e. production and services); (iii) create a culture of social accountability, by means of a transparent administration of resources and broad-based dissemination of results, including the contributions made by universities to solving the country's economic, productive, social and cultural problems, above all those that reproduce the vicious circles of exclusion and poverty among the majority; and (iv) strengthen higher education on the Caribbean coast by supporting academic and scientific development, the establishment of a curriculum, improving the quality of education, promoting national and regional cultures and intensifying autonomy.

\section{Health strategy and policies}

128. The Government of Reconciliation and National Unity considers that health, much like education, is a fundamental factor and a human right. An investment in human education that furthers the existence of a population with a higher quality of life and greater capacity to contribute to the country's productive process is a contribution to the full exercise of human rights. The GRUN health policy focuses on restoring the rights of Nicaraguans to a healthy life by means of preventive health and the availability of comprehensive services (promotion, prevention, assistance and rehabilitation). These must be free of charge and of good quality, adjusted to the multiethnic, cultural, religious and social realities in the country and accepted by all Nicaraguans. Health care for the insured is described in the section on social security (paragraphs 133-143).

129. An essential objective in the field of health is to ensure universal and free access to quality health services. The main actions are geared towards the promotion of health, preventive health and comprehensive health care in case of illness. This is being made possible by organizing the network of services according to the capabilities and complexities at each type of health establishment, with priority being given to the first health care level, while executing an investment program in hospitals and health care centers. However, the increase in coverage of services in the sector concentrates on marginalized rural and urban areas. Immediate and sustainable programs are underway to overcome the most felt difficulties as expressed by the population, such as discourteous personal relations, poor quality of care, payment for medications, delays of surgery and obstacles to getting appointments with specialists. In addition to changing all of the foregoing, priority is given to care for children less than five years of age, adolescents and pregnant women.

130. In order to deal with these priorities the Ministry of Health (MINSA) is promoting plans and programs based on interaction with other state institutions and broad-based mobilization and participation by the people. This translates into a democratization of the management of ministry policy, ensuring the elimination of barriers that hinder access to health services. Thus the delivery of public and private services is harmonized under the leadership on MINSA, in order to meet the objective of preserving health and supervising the quality of the services being provided and strengthening the overall effort of society at large to fight epidemics and deal with natural disasters.

131. The new Family and Community Health Model is decentralized and converts health into a personalized service. This model seeks to change the centralized culture according to which 
government officials wait for people to come to health facilities to seek care. The development model invites the family and the community to work together with the authorities to deal with the factors that influence health-related processes and illness. With this practice in mind, services are fostered regarding promotion, prevention, epidemic control and health protection, in an effort to benefit the entire population.

132. There follows a description of the main policy actions to be carried out and from which the sector objectives, indicators and goals are derived:

i) Avoid people falling ill, promoting the idea that "a healthy people is a happy people":

$\circ$ Nine nationwide campaigns to be undertaken each year with support from the Citizen Power Councils and benefiting the population in general, aimed at controlling epidemics and avoiding that persons fall ill or have accidents (one Summer Citizen Power Campaign, one Citizen Power Vaccination Campaign, five Citizen Power Anti-Epidemic Campaigns, one Citizen Power Dog Vaccination Campaign and one Citizen Power Campaign to Prevent Accidents Caused by Fireworks).

- Physical activity is promoted, as are sports and recreation and healthy dietary habits among boys, girls and adolescents nationwide, in order to foster a culture of healthy eating habits.

- Traffic accident prevention is promoted among the population at large, to diminish traffic deaths.

- Community programs are promoted to educate people as concerns health and nutrition. These are keyed in particular to the mothers of children less than six years of age, and aim to improve their health situation.

- Childbirth shelters for pregnant women living in rural areas are functioning and guarantee childbirth under safe conditions, thus reducing maternal mortality.

ii) Provide quality medical care and free medication:

- Outpatient care is provided to any citizen anywhere in the country who requires it.

- Hospital care is provided to anyone among the population who requires it.

- Laboratory examinations are carried out for patients who visit doctors and/or are hospitalized at any MINSA health unit in the country.

- Medications are provided free of charge to patients who visit MINSA health units, ensuring health care to the entire population.

iii) Fight against maternal mortality.

○ Potential risks and complications are among pregnant women are detected in a timely fashion, with the aim of reducing subsequent difficulties, aftereffects and maternal deaths (family planning, early detection of pregnancy, four prenatal controls).

- Childbirth is guaranteed to be safe for pregnant women who come to a MINSA hospital on their own or are referred to one. 
iv) Fight against child mortality.

- The growth and development of children less than one year of age is monitored, and their adequate growth is promoted. In addition, children under one year of age are vaccinated against tuberculosis, diphtheria, whooping cough, tetanus, influenza, hepatitis B, polio, rotavirus (diarrhea), measles, rubella and mumps.

v) The lists of persons awaiting surgery and of persons waiting specialized external care are shortened.

- The number of scheduled and emergency surgeries is increased.

- Surgery quality improves by using modern, low-risk techniques.

- Medical care is provided to the poor population who has difficulties regarding access through the use of national and international health brigades, with the aim of improving their health situation.

vi) In order to bring health services to poor or extremely poor populations, as well as those with greatest difficulties regarding access:

○ The Family and Community Health Model is implemented, with health care being provided to the entire population in the area of influence of the health units.

○ The family and community health teams are organized. They are made up of health brigade members and community leaders.

- Hours during which medical care is available to the population are extended.

- The health care provided to persons insured by INSS at MINSA Social Security Medical Clinics is expanded.

vii) The health care model is regionalized in the North and South Atlantic

Autonomous Regions (RAAN) and (RAAS).

- Health care is provided to the Caribbean population using norms adjusted to their social, cultural and political features.

- Professional medical staff specializing in comprehensive medicine will be available in the RAAS and RAAN. They are graduates of the Latin American School of Medicine in Cuba.

viii) Popular and traditional medicine is revived, as are other types of non-western medicine.

- Health care is provided to the Caribbean population using norms adjusted to their social, cultural and political features.

- Professional medical staff specializing in comprehensive medicine work in the RAAS and RAAN. They are graduates of the Latin American School of Medicine in Cuba.

ix) Comprehensive development of human resources in the health sector.

- The availability of doctors, nurses or other health technicians in all provinces and autonomous regions in the country.

- The technical and scientific level of knowledge among health service doctors is reinforced.

$\mathrm{x}$ Better use is made of external resources. 
- Foreign cooperation is aligned and harmonized with national policies and plans.

- Social integration processes in the field of health are strengthened in Central America and the Caribbean.

\section{Social Security}

133. Social security in Nicaragua is financially structured upon a common fund, at whose base a pension policy has been drawn up. The fund is fed mainly by the contributions made by employees throughout over the course of their working lives and those of their employers, as established by law.

134. The fundamental principles that underpin the Social Security system are:

i) Universality, through the protection provided indiscriminately to all persons at all stages of their lives.

ii) Solidarity, by protecting those least favored and based on the participation of all those who pay into the system.

iii) Equity, meaning equal opportunity, access, treatment and guarantee of receiving benefits; and

iv) Comprehensiveness, by ensuring that all social security needs forming part of the system are covered.

135. Taking into account that social security is an important pillar of the NHDP social strategy, the Government of Reconciliation and National Unity is working on a more broad-based proposal according to which the costs of changing the system are not borne by the pensioners. The viability of a mixed model is under study, but under no circumstances will the reform place the benefits of those currently covered at risk.

136. Regardless of the model that is ultimately adopted, GRUN is taking actions to guarantee there are social security services available for active and retired workers. Responsibility for rescuing the system over the medium and long term determines the limits of the current system. The expansion of benefits, coverage and adjustment of pensions need not be at the expense of a deterioration of future pensions, including alternatives to improve the system's financial position and re-establish the balance between contributions and benefits, while respecting the rights acquired by workers that are not yet of retirement age.

137. The government has established as one of its top priorities concerning Social Security to ensure that health services are provided without exclusion to all persons covered by INSS. Services will continue to be delivered through the private sector, while strengthening public health institutions.

138. The Government of Reconciliation and National Unity guarantees universal access to health services to those insured by INSS by purchasing services from public and private providers. This system provides care for approximately 1 million persons (the insured person, spouse and children under 12 years of age). Most of this population lives in León, Chinandega and Managua. 
139. INSS has three types of contracts: pre-payment for outpatient or hospital care; post-payment of a fixed sum for complementary services; and payment for high-cost medical services.

140. Currently health care services are made available through contracts with 21 health providers nationwide. In 2007 and 2008 contracts were rescinded with 14 such providers because they lacked adequate infrastructure and medical equipment with which to deliver acceptable health care to the insured and pensioners.

141. Starting in 2007 a gradual negotiation process has been underway concerning the delivery of prepaid services through health service providers, for the purpose of covering all illnesses and health services available in the country. By late 2008 the list of illnesses previously considered to be "offcoverage" had been eliminated, and today all those insured have the right to receive attention regardless of their illness. In addition, services included in the prepayment contract were expanded to include all laboratory exams available in Nicaragua, as well as computerized axial tomography, magnetic resonance and all diagnostic and therapeutic ultrasound equipment.

142. In addition, INSS has introduced preventive services at workplaces, in order to identify women at risk of cervical cancer, breast cancer and the early detection of patients with chronic diseases.

\section{Drinking water and sanitation strategy and policies}

143. The drinking water sector has been devoid of the long-term policies and investments necessary to expand coverage, improve quality, and contribute to the improvement of the population's health. This is a sector that experiences a high coefficient of non-technical and technical losses, the latter in large part due to an obsolete network that has been affected over time by tremors and earthquakes, but also lack of maintenance. The final disposal of untreated industrial wastewater is problematic, to which must be added a low level of solid waste collection and disposal, and the excessive use of agrochemicals. ${ }^{9}$

144. The fundamental principles guiding the drinking water and sanitation policy are inclusion, sustainability, participatory joint responsibility, decentralization, equity and work with the municipalities. This implies the application of double targeting by allocating resources to infrastructure projects aimed at reducing gaps in coverage, with emphasis on the poorest communities in the country. The solution to problems in the sector requires raising awareness, organizing citizens and encouraging their participation, as well as adherence to the principles of human development.

145. The aforementioned principles mean that the main policy guidelines are geared towards:

i) strengthening the administration, regulation and organization of the sector;

ii) mobilize donor resources in an organized and systematic manner, under the program modality;

\footnotetext{
${ }^{9}$ It is estimated that $37 \%$ of the population living in poverty, and $60 \%$ of those in extreme poverty, have no access to toilets or latrines. Sewage system coverage is low (35.1\%), and of the volume of wastewater collected by the different networks only $42 \%$ are treated.
} 
iii) promote proper management of water resources;

iv) provide adequate maintenance to the systems, equipment and infrastructure;

v) encourage and promote citizen, entrepreneurial and social responsibility towards the sector; and

vi) promote the development and monitoring of water quality and stimulate the social, environmental and financial sustainability of the strategy.

146. In rural areas the policy is keyed to seeking a model capable of including entire communities more efficiently, improving the setting and generating citizen capacity to participate actively in projects around water and sanitation issues. An investment program is underway with a medium and long-term vision, intended to restore and expand the water infrastructure. It includes the installation of alternative systems, such as mini-aqueducts in their various construction modalities. Likewise, a technical accompaniment and citizen participation program has been established for purposes of decision-making, identification, implementation and maintenance of water and sanitation works. Thus the population becomes part of the solution to the problem.

147. In urban areas, the main policies are intended to strengthen institutional capacity to achieve more efficient administration of water resources and cultivate more solidarity in the behavior on the part of citizens. In this context, the quality and coverage of drinking water and sanitation are a function of policies designed to rehabilitate the networks and storm sewers that are part of the damaged sewage system; the implementation of a plan to control pollution from industries and the quality of wastewater flowing into the receiving rivers, lakes and lagoons, as well as the maintenance of systems and promotion of social, entrepreneurial and citizen joint responsibility. This includes an intensive policy to monitor the quality of water and effluents, the protection of water sources and the education of new generations. This is strategic to the plan's success.

\section{Housing policy}

148. Among the circumstances that affects the standard of living of the population living in poverty is that of not having their own home, or having one that is extremely precarious. ${ }^{10}$ The lack of a comprehensive long-term housing policy, extremely limited public investment in the sector, credit restrictions in an incipient housing market and the cost factor are all serious constraints to finding a solution the housing problem in Nicaragua.

149. The Government of Reconciliation and National Unity has established an overall policy framework in order to provide an element of social interest to housing programs. Resources and mechanisms to be allocated are framed according to the following guidelines:

i) granting of subsidies;

ii) creation of an insured mortgage fund;

iii) creation of a credit fund;

iv) creation of a construction materials bank;

\footnotetext{
${ }^{10}$ According to the Population Census (III) and Housing (IV) Census taken in 2005, it is estimated that the housing deficit is of 957,000 units. It is necessary to build 349,000 new houses to cover the needs of 48,000 families with no house and replace another 300,000 that are in a state of total disrepair. Partial improvements are needed at another 609,000 houses in poor condition.
} 
v) training of a workforce as contribution by program beneficiaries; and

vi) program to legalize property rights.

150. A subsidy has been deemed the most effective mechanism to ensure that the social interest housing program being promoted by the government proves viable. The policy contemplates that the subsidies are to be granted according to a definition that takes into account the concepts of "lowincome families" and "cost of resources". In order to further its program, GRUN has defined two types of subsidies, namely direct and with interest rates. The former will be granted for both new houses and house improvements, and consider the income of the beneficiary family. ${ }^{11}$ The subsidy with an interest rate attached is defined as the amount granted by the government for a ten-year period in order to ensure a lower interest rate on mortgage loans and that the monthly payments are adjusted to the capacity make said payments.

151. As concerns financing mechanisms, GRUN is promoting three financing schemes: i) the Insured Mortgage Fund, which consists of a guarantee fund specializing in insuring mortgage funds granted by the financial system to families of moderate or medium income, so they can buy a home; ii) a Social Housing Credit Fund through which the government can provide direct financing to social sectors or territories of special interest; and iii) the construction materials bank, which in a direct, progressive and supervised manner finances construction materials for low-income families for home construction and improvement.

152. In addition, GRUN has defined the following policy actions:

i) Introduce a reform of the Urban and Rural Housing Institute (INVUR) and Social Housing Fund (FOSOVI) legal framework to the National Assembly. The reform includes the modernization of the concept of social interest housing, the expansion of criteria for the eligibility of beneficiaries, the regulation of tax incentives in the sector and the redefinition of roles at auxiliary entities.

ii) Promote reforms of regulations at the Bank Superintendency to allow for an expansion of access to mortgage credit by low-income families.

iii) Strengthen planning, regulation and control capabilities at the mayor's offices. This includes an environmental impact assessment, so as to ensure safe urban development in the municipalities.

iv) Support poor families in the legalization of urban and rural housing through the delivery of subsidies and the provision of juridical security and favorable conditions that make them eligible to receive credits and/or subsidies for the construction or improvement of homes.

v) Establish effective coordination between the various government entities (INETER, INVUR, and DGI) and the Supreme Court of Justice in order to expedite procedures leading to cadastral certifications and registry at the Land Registry.

vi) Promote the supply of urbanized land, in coordination with the mayor's offices and landowners.

\footnotetext{
11 For low-income families (those earning less than US\$ 200 a month), the subsidy is of US\$ 900 for home improvements and US\$ 1,850 for the building of a new home. For those in the middle-income bracket (US\$ 500 a month) the subsidy is of US\$ 600 for home improvements and US\$1,500 for the building of a new home.
} 
vii) Grant direct subsidies for the construction and/or improvement of housing. These are fixed subsidies, granted and disbursed by the government in a single payment to families in order to help them collect the amount money needed for the total cost of their home.

\section{Labor policy}

153. The labor policy established in Nicaragua since 1990 did not include a government policy to protect worker's rights. The imperfections of the system and the lack of an adequate legal framework created an adverse setting for the development of an efficient labor market. Today wages are inadequate in real terms, and working conditions carry implicit a high degree of risk for workers.

154. The labor policy has for its foundation the aim of "restoration, oversight and promotion of labor rights" among workers. One of its components is a salary policy, which in turn has for its main element the issue of minimum wages. These are regulated by the Minimum Wage Law, which stipulates that these must be negotiated every six months by unions, employers and the government, based on inflation and productivity indicators. However, given the low wages paid during the past three governments, the readjustments have reflected the need to give these indicators a social and juridical combination, including the recovery of the large gap that exists between wages and the cost of the basic goods basket. The minimum wage policy will continue to be based on the permanent search for tripartite consensus between employees, employers and the government.

155. The Government of Reconciliation and National Unity is reviewing and building a labor policy that is adjusted to the principles that govern its NHDP. Increased state participation in the conduct of the economy does not imply the generation of employment at government agencies in order to reduce unemployment. However, it opens spaces that generate work opportunities in the small producer private sector; the improvement of labor conditions; strengthening of the labor policy regulatory framework; and the protection of worker's rights vis-à-vis arbitrary actions taken by employers in the course of labor relations.

156. GRUN has established three dimensions of advocacy in order to achieve its objectives of employment, safety and job protection and compensation. The first dimension is based on policies such as the restoration of productive capabilities among small and medium producers living in poverty and the public investment program, which has a direct impact on generating employment. The second dimension is based on the reforms to the legal framework regulating the labor market, institutional strengthening, citizen participation and legal advisory services. The third dimension deals with social security policies, mechanisms to enhance productivity, and company compensation in acknowledgement of worker skills in the form of training, scholarships and other worker stimulus mechanisms.

157. The authorities that regulate and manage labor policy have made progress in the formulation of a labor policy proposal. This National Dignified Work Plan has been the object of noteworthy citizen participation at mayor's offices, unions and employers organizations, all of whom are interested in having their interests, preferences and constitutional rights taken into account. Further, steps have been taken toward institutional strengthening by means of a reform to the legal 
framework of the General Directorate of Occupational Health and Safety, which allows the Ministry of Labor greater capability to exert influence as concerns safe working conditions.

\subsection{Steps toward good public management}

158. In 2007 the government began a process of transformation in order to achieve its good public management objectives. Its strategies revolve around:

i) transparency and probity;

ii) citizen security;

iii) guarantee of the right to property;

iv) decentralization and municipal development; and

v) strengthening of the state and public administration.

159. Among the specific actions the government has carried out to improve good public management are the following:

(i) Establishment of a direct relation between the state and society by means of citizen participation through the exercise of direct democracy at the Citizen Power Councils and Cabinets found among the different agents that make up the country's institutional framework.

(ii) Development of a national reconciliation and unity model based on direct democracy and which promotes the inclusion of citizens in the process of establishing themselves as the builders and direct beneficiaries of said process.

(iii) Continue the process of state modernization and simplification, strengthening its leadership role, decentralizing the institutions, and avoiding overlapping and doubling of functions, while seeking efficiency and savings in public spending.

(iv) Strengthen the active role of the municipalities in order to improve service delivery to the people and ensure the effective struggle against poverty.

(v) Encourage the process of harmonization and joint work between the branches of government. This is an important condition for achieving human development that takes into account the cultural, economic, social and political dimensions.

\section{Citizen participation}

160. The people organized in citizen-based democracy will have the power to be the protagonists of their own history as they make the decisions that affect their economic, political, social and cultural life. Direct democracy is exercised through the Community Councils, Neighborhood and District Congresses; Municipal Congresses, Provincial Congresses and a National Congress. The ideas, needs, demands and positions of the people are made manifest in these spaces and are taken into account by the President of Nicaragua when making decisions. 


\section{Direct democracy}

161. Nicaragua will become a democracy in which the people participate in a real and effective manner. The people are an integral part in the process of decision-making, management and evaluation of government policy, based on widespread participation by the different sectors of society and consultations with the various associations, such as small and medium industry, coffeegrowers, large entrepreneurs, political actors and civil society.

162. It is through the people, at all levels, that demands can be brought before those that guide and implement the country's policies and actions. Plans, programs and projects are a responsibility not only of the state but also of the citizens. This will be achieved through the various forums of participation, which may be in a neighborhood, community, rural district, municipality, province or autonomous region.

\section{Transparency and probity}

163. The head-on struggle against corruption is very important and constitutes one of the government's firm commitments. The actions being taken in this sphere are preventive in nature. It is of practical interest to honor the public function and activity of government officials. The government has begun a process intended to eliminate the notion of the state as booty, and has scrapped excessively high salaries for public officials. ${ }^{12}$ It is a requirement that officials must make a declaration of probity before taking a post, as a move to avoid the misappropriation of public funds. Society has oversight regarding the use made of the budget and an Access to Public Information Law has been passed, by means of which citizens can oversee what their leaders are doing.

164. Central government institutions and autonomous entities must be open to providing access to public information. The government ensures that the Access to Public Information Law is being applied. This requires not only political will, but also economic resources. Therefore the most sensitive institutions have been singled out, which are those that manage funds for which they are accountable to the people. For GRUN it is a goal to achieve that in the short term the Law be implemented fully at all state institutions, joint private/public ventures, companies that receive state subsidies, as well as private entities that administrate, manage or receive public resources, fiscal or any other benefits, concessions or advantages, as stipulated in article 1 of the aforementioned law.

165. The government is providing the Office of the Comptrollers General (CGR) with conditions and resources with which to strengthen its economic framework and technical capacity. This is one of the priorities that will strengthen Nicaragua as a nation, given that the CGR is an instrument that allows for exercising honest administration of state assets and resources by means of a systematic articulation of mechanisms that make effective oversight viable. A new organic law for the CGR is currently at the National Assembly for consideration. It includes mechanisms for external financial, operative or management audits at entities or of persons under their competence; the evaluation of operative systems; the organization and functioning of internal audits; evaluation of internal audit operation and management systems; evaluation of audits carried out by other persons or entities at

\footnotetext{
${ }^{12}$ In prior administrations, high-level public officials in Nicaragua had the highest salaries in Central America, notwithstanding its ranking as one of the very poorest countries on the continent.
} 
state agencies; evaluation of compliance with goals, legality, efficiency and economic effectiveness; and declarations of administrative, civil or criminal responsibility.

166. For the purpose of expanding coverage of controls and the effectiveness of the work done by the CGR, an institutional modernization program is being carried out. This program includes the improvement of administrative processes, the redefinition of functions, the definition of an organizational structure, training of employees and the updating of the information and communications technology at the CGR computer center. Progress has been made in the determination of the applications needed to optimize processes, mainly as regards audits and subsequent external control. Public officials are being trained so they take ownership of and work harmoniously with the juridical framework as concerns controls.

\section{Citizen security}

167. Citizen security in its broadest sense is conditioned by multiple internal and external factors. Essentially, it is understood to mean the right of each person, whether Nicaraguan or foreign, and who finds him/herself anywhere in the national territory, to live without threat to his/her physical integrity, assets or civic rights. Factors that undermine citizen security are usually related to poverty, unemployment and education, all of which in turn define the country's level of development. The problem of poverty is a direct outcome of the unjust distribution of wealth, unequal opportunities, social exclusion and the passive role of the state. Taken together, these propitiate citizen insecurity in many countries. It is further the case that high levels of poverty and unemployment tend to encourage higher rates of alcoholism, drug addiction, domestic violence, and interruption of the education cycle. This too reduces the possibility of improving citizen security.

168. Citizen security is the product of the political and social history of each country. In Central America, and particularly in Nicaragua, there are still signs of the war of intervention that took place in the eighties. Therefore there are still many weapons in the hands of civilians and the culture of non-violence and alternative ways of conflict resolution are only recently becoming better known and practiced. Linked to the foregoing, as well as to emigration as a solution to the problems of poverty and unemployment, youth gangs emerged which constitute a serious threat to citizen security. Nicaragua is not impervious to this phenomenon. Drug traffickers and organized crime take advantage of these weaknesses and they come to constitute a factor of insecurity in many countries in the region.

169. The government has identified two dimensions of citizen security, in its effort to manage the security situation. One is quantitative, and contains an analysis of indicators in areas such as poverty, illiteracy, alcoholism, violence, drug addiction and health problems; the other is qualitative and considers issues such as human dignity, participation in community affairs, restitution and respect for rights, and the promotion of a positive use of spare time by youths and adults. Based on these premises, and considering that the subject and actor of citizen security is the population itself, it is necessary to foster actions that increase the effectiveness of preventive measures, while the results of structural measures against poverty and unemployment take effect.

170. Institutional strengthening will be an important part of the Citizen Security Program. The government is adjusting its work agenda at those institutions linked to this priority (MIFAMILIA, 
JUVENTUD; DEPORTES, MINED, MINSA), the mayor's offices, the National Police, Ministry of Home Affairs and Ministry of Transport and Infrastructure. In particular, it is necessary to strengthen and deepen relations between state institutions and the community, while improving inter-institutional coordination to work on short and medium-term actions and conclude with a state policy regarding citizen security.

\section{Access and quality in delivering justice}

171. During the past few years there have been major transformations that have changed the face of justice administration in the country. The significant development of the judicial branch infrastructure in the past few years, the creation of the Public Ministry, the role of the Office of the Human Rights Ombudsman, the thoroughgoing reform of the Criminal Procedures Code (CPP) and the efforts to achieve greater independence through the judicial career, the Criminal Code, the creation of a special unit on Coexistence and Citizen Security - as a new concept in security rooted in the family and communities in the territories - all constitute undeniable progress that indicate that in Nicaragua a dynamic and unstoppable process of change is underway.

172. In order to advance in an organized manner with the achievement of objectives such as improved access to and quality of justice, a Justice Sectoral Plan has been drawn up. Said Plan was formulated by the judicial branch, the Public Ministry, the Ministry of Home Affairs (National Prison System, Migration and Aliens Service, Civil Inspector Corps, Technical Division), the National Police General Directorate, the Office of the Comptrollers General, the Office of the State Prosecutor, and the Office of the Human Rights Ombudsman. This effort represents a very active agreement to seek consensus on and articulate an agenda aimed at improving the delivery of justice services to the population.

173. To improve the justice services infrastructure in order to expand access is an objective to be worked on immediately. As determined by the country's economic capabilities, the government works to strengthen and expand the functions and competencies of the Directorate for Alternative Conflict Resolution, in order to promote the use of alternative means of solving conflicts and reducing costs in the sector. Further, public defense services will be strengthened, and the Citizen Power Community Councils will be mobilized as another alternative means of solving conflicts in the communities. Along the same lines, it will be necessary to improve and expand the services provided by the Public Ministry, as well as to increase knowledge among the population on the role of the Office of the State Prosecutor and extend its coverage nationwide. The strengthening of capacities in the specialty of National Police judicial assistance and the improvement of the prison system infrastructure to ensure acceptable conditions for persons deprived of liberty will also be important to achieving the objectives being put forth.

174. Institutional strengthening will be indispensable to improving the efficiency and efficacy of the justice service. Programs are being implemented to strengthen regular services offices, judge's chambers, notifications offices and oversight of criminal proceedings by the competent CPP entities. Likewise, progress is being made to increase the efficacy of jurisdictional actions under the aegis of the Public Ministry, and efforts are underway to involve the Office of the Human Rights Ombudsman in the expansion, promotion and respect for human rights. Conditions at prisons are being improved, as is the infrastructure needed to adequately manage detentions at border-crossings. 
This implies strengthening the capabilities and means of the Directorate of Migration and Aliens Service. Likewise, processes and procedures in the services offered by the Office of the State Prosecutor must be improved in order to institutionally respond to demand, with particular emphasis on the stability and legality of property, which is a priority in the Justice Plan mentioned earlier.

\section{Strengthening the state and capacity building for responsible public administration}

175. The government recognizes the state as society's instrument by which to promote, guide and regulate economic development with equity and social justice. No country has ever developed without state guidance in taking an active and proactive role concerning the difficulties faced by the nation. In the case of Nicaragua, with its serious structural problems, the state must play a leading role, together with the population, in the socioeconomic, cultural and political development of the country.

176. The model to be implemented by the Government of Reconciliation and National Unity will be one that is committed to Human Development. It is a model in which the state is strengthened in its regulatory and democratizing role, while remaining flexible, decentralized, strong and simplified, with no overlapping of functions. The state must have for its purpose to bring its public sector structures close to the citizens, and in so doing make them strong, effective and efficient. The public sector must move swiftly to take decisions and provide services, concentrating its objectives on the struggle against poverty. Finally, the state must be strengthened continuously through the full participation of citizens by means of direct democracy.

\section{Harmonization among the branches of government}

177. The Government of Reconciliation and National Unity will promote mechanisms such as a permanent dialogue between the executive branch and the other branches of government, thus ensuring their integration to the struggle against poverty and corruption. With the legislative branch the idea is to speed up and pass laws that promote human development, private investment and state participation as an active partner of private enterprises. As for the judicial branch, the goals are to improve justice administration, overcome the hurdles that cause retardation of justice and bolster confidence among national and foreign investors.

\section{Decentralization and municipal strengthening}

178. The development objective is to achieve greater efficiency and efficacy in the production and delivery of local public services and the management of human development in the municipalities. Decentralization seeks to establish stronger linkages with the citizens, granting then more decisionmaking power by means of improved public administration at each level, determining responsibility for the various competencies and carrying out fiscal and tax transfers between levels of government in a harmonious manner. It is with this objective in mind that the strategy for the National Decentralization and Local Development Plan is being prepared, and focuses on contributing to fighting poverty and fostering economic growth with equity.

179. In order to put the proposal into practice citizens will be directly involved in negotiating the decentralization policies and strategies with each sector. This line of action will lead to the design of 
a system with instruments intended to strengthen the decentralization processes and guarantee these are operative and accompanied by technical assistance and monitoring, particularly in the municipalities and autonomous regions. Direct linkage between citizens and the processes of negotiation and decision-making regarding investments and municipal public resources will be promoted by preparing training and management instruments.

180. The government benefits micro-enterprises and small agricultural producers living in conditions of poverty in a sustainable manner. The goal is to inject dynamism into the local economy through the direct allocation of resources, economic promotion, financing and productive investment. The establishment of a Local Economic Fund is being promoted as a complement to the sectoral productive sector, implementing mechanisms and instruments for sectoral and territorial coordination and the promotion and management of the local economy. The government is also making an effort at improving the efficiency of public spending and the local taxation systems through a process of fiscal decentralization the aim of which is to optimize the output achieved by budget transfers to the municipalities.

\section{Security regarding property rights}

181. The Government of Reconciliation and National Unity has for its economic development strategy to guarantee security regarding property rights, as it is clear that juridical insecurity causes instability in several sectors that are key to economic development. Institutions such as the Ministry of Finance and Public Credit (MHCP), the Nicaraguan Institute of Territorial Studies (INETER), the Office of the State Prosecutor (PGR), the Property Intendancy and the regional governments on the Caribbean coast will work toward to determine an appropriate juridical framework and will implement a plan for the streamlining, certification and titling in order to put a definitive end to conflicts generated by land tenure and use. The activities being implemented are in order to advance toward improved juridical security are as follows:

(i) Review and conclusion of a policy framework regarding land.

(ii) Demarcation of land, protected areas and indigenous lands.

(iii) Develop a short-term plan to legalize urban and rural properties nationwide.

(iv) Modernization of the cadastre and property registry systems.

(v) Implementation of a property registry system.

182. The fundamental aim of the NHDP is to reduce poverty and promote solid economic growth. This requires that security regarding property rights is evident at all levels of development - for small and medium producers, large entrepreneurs, and national as well as foreign private investors. The outcome is better governance and the construction of a government based on solid, participatory institutions with direct democracy, and which increases confidence both internally and abroad.

183. In accordance with the foregoing, GRUN has advanced in an effective manner to solve conflicts stemming from land ownership issue and the titling of properties. It has been a priority for the President of Nicaragua to solve legal conflicts regarding property and problems regarding property titles among those sectors with acquired rights. In response to the population's demands, the government in 2007 granted 3,339 property titles nationwide, an increase of 58\% over the year before. It is foreseen that in 2008 some 10,500 titles will be issued for urban and rural properties. 


\subsection{Environmental sustainability and forestry development}

184. In Nicaragua the irrational behavior of social and economic actors in the use of natural resources and the environment have led to the overexploitation of the former and degradation of the latter. Growth in productive activity and population growth have not been accompanied by measures to keep the environment sustainable and protect natural resources as the vital elements they are in the conservation of life itself. If the current trend continues unchecked, by the year 2050 the agricultural frontier will have reached the Caribbean coast, and the pollution of the environment by wastewater, pesticides, industrial discharges and solid waste will dramatically reduce the country's water resources potential.

185. The Government of Reconciliation and National Unity promotes sustainable development based on the protection and restoration of the environment. This is one of the principles of the NHDP. Thus the overall objective of the environmental plan is to contribute to human development based on citizen power, a return to the ancestral cultural values of respect for natural resources and the revival of lost habitats by means of education and training that emphasize values such as responsibility, solidarity and equity in the safekeeping of the country's natural heritage.

186. Nicaraguan environmental policies are based on governing technical principles and reflect aspects of the Constitution, ${ }^{13}$ the General Environmental and Natural Resources Law, and a number of other laws, regulations and national and international agreements. Currently there are sectoral and specific policies that complete the overall framework of environmental policies. A process is underway to complete and implement the specific policies framework by means of the formulation of national policies in water sources conservation; protection and development of coastal resources; rational use of water for agricultural production, based on reservoirs; conservation and management of protected areas and biodiversity; forest protection and development; ${ }^{14}$ a national reforestation campaign; sustainable land use; control and reduction of pollution; sustainable solid waste management; adaptation and mitigation measures vis-à-vis climate change; and environmental education for all Nicaraguans. ${ }^{15}$

\subsection{GRUN policy on natural and man-made disasters}

187. Nicaragua, due to its geological make-up and geographic location on the Central American isthmus has repeatedly been subject to a variety of natural phenomena, which often end up as emergencies or disasters that physically, socially and economically affect the country and its potential development for decades, as significant resources are invested in rehabilitation and reconstruction. Human beings and their irrational practices in the use of natural resources; the excessive use of chemicals in agriculture; the lack of adequate policies in soil use; the failure to

\footnotetext{
${ }^{13}$ See article 60, Constitution of Nicaragua.

${ }^{14}$ In terms of forest development it is thought that the agroforestry potential of Nicaragua is of around $72.8 \%$, with $20.6 \%$ in agriculture/livestock; $43.9 \%$ in forests; and $28.9 \%$ in agroforestry and pastureland. It is estimated that the participation of the forest sector in GDP is only $1.3 \%$. The rate of deforestation is of 70,000 ha per year (1948 to 2000 ). At this pace, within 50 years there will be no more forests in Nicaragua.

${ }^{15}$ See National Human Development Plan.
} 
follow the regulations that govern the various processes, above all in the field of construction, are all factors that deepen the already high levels of vulnerability to which the country is exposed.

188. Throughout Nicaraguan history many natural phenomena have occurred and caused emergencies or disasters. Natural phenomena include earthquakes, tsunamis, volcanic eruptions, hurricanes, landslides, draughts and floods. Examples of man-made disasters are infrastructure and forest fires; spillage of chemical substances; and those originating from technology. Taken together, these have caused great loss of human and animal life, environmental degradation and impairment of materials of high economic value.

189. The urgent need to reduce the levels of damage caused by natural phenomena or human activity inevitably implies diminishing social, natural, structural and economic vulnerabilities, among others, which afflict the population and the country. To that end it is necessary to have a cross-cutting issue in the NHDP, namely integrated risk management strategies and policies. These must act upon the causes of risk, mitigating any possible impact and preparing conditions for a response. Such a transformation will create safer conditions for society, the environment and the economy, while gradually propitiating scenarios of secure and sustainable development in the national, territorial and sectoral spheres.

190. It is necessary to define the causes and factors that generate risk, and therefore take intersectoral and multidisciplinary actions to strengthen national poverty reduction initiatives and facilitate access to social services by the vulnerable population, thus contributing to the full development of Nicaraguan society.

\section{Objective}

191. The overriding objective is to reduce the risks occasioned by natural and man-made phenomena that affect the security of persons, their assets and those of the country, by fostering a culture and practice of prevention among the population and all social actors in the life of the nation. In addition, to incorporate risk management to institutional and territorial development plans, implement mitigation programs and strengthen the country's response capacity when faced by disaster, whatever its origin.

\section{Disaster prevention, mitigation and relief strategy}

192. The strategy to be formulated with the active participation of the citizens is based on the following guidelines:

i) Create organizational conditions for planning, training, raising awareness and commitment on the part of all institutional and social actors, in strict adherence to laws governing the matter.

ii) Contribute to the insertion of integrated risk management to all processes in the economic and social life of the nation, and in particular to institutional, sectoral and territorial plans. Integrated risk management involves prevention, mitigation, preparation, response, rehabilitation and reconstruction.

iii) Promote a culture of prevention among the population and all social and institutional sectors of the country, while strengthening local capacity in the various stages of risk management. 
iv) Improve the efficacy of the National System for Disaster Prevention, Mitigation and Relief (SINAPRED) through the training of human resources and securing of the financial, material and technological resources needed to guarantee efficient risk management.

v) Coordinate environmental and risk management, for the purpose of guiding efforts that reduce vulnerability and mitigate the impact of disasters, whatever their origin. Every effort must be made to take measures in order to adapt to climate change and implement risk transfer policies.

\subsection{Caribbean Coast Development Strategy}

193. The development of the Caribbean coast is an integral part of the NHDP and constitutes one of the most important pillars in the poverty reduction strategy. Priorities targeted at this region are determined by the overall policies that serve as referent for all sectors and regions, as well as by specific policies that reflect autonomous, cultural and potential particularities from an economic perspective. ${ }^{16}$ The inhabitants of the autonomous regions have expressed their wish participate in national progress and Nicaraguan democracy, but also that they intend to be the authors of their own history, from the perspective of their identity and the priorities they have set to overcome the urgent needs that afflict them. This sentiment has been clearly expressed in the UNDP Caribbean Coast Human Development Report. ${ }^{17}$

194. During the first stage of the Caribbean Coast Development Strategy (CCDS) an effort was made to overcome the emergency situation caused by Hurricane Felix in September 2007. It is estimated that the losses caused exceeded 7\% of GDP for 2006, according to a preliminary evaluation issued by the Economic Commission for Latin America and the Caribbean (ECLAC). ${ }^{18}$ According to this report, most of the damage took place in the productive sector, including impairment of natural resources. ${ }^{19}$ In the medium term it is proposed to carry out a reconstruction program to cover housing, schools, health centers and means of communications (roads, wharves), so as to return to the levels of activity existing before the Hurricane. Provisional installations to continue the school year, care for persons living in shelters, and other temporary measures must be overcome in order to move on to a definitive phase. The government has already begun restoration of the main means of access to the most affected communities, and is providing productive and other inputs to replace lost food harvests, in the framework of the Hambre Cero program.

\section{Development objective}

195. The main development objective is to work towards achieving an economic, political and social reality that restores the rights of the inhabitants of the Caribbean coast and the Upper Wangki-

\footnotetext{
${ }^{16}$ The Atlantic Coast in figures: $46 \%$ of Nicaraguan territory; $72 \%$ of the forested area; $95 \%$ of the watersheds drain into the Caribbean; $70 \%$ of fishery production; $23 \%$ of the agricultural area; and $60 \%$ of mining resources. In addition, the Atlantic Coast contains $45,000 \mathrm{~km}^{2}$ of the Continental platform, with excellent potential for the exploitation if hydrocarbons, and some $700 \mathrm{~km}$ of coastline on the Caribbean Sea.

${ }^{17}$ UNDP Human Development Report, 2005: The Autonomous Regions of the Caribbean Coast.

18 ECLAC. Impact of Hurricane Felix on the North Atlantic Autonomous Region and the Torrential Rains in Northwestern Nicaragua, 13 December 2007.

${ }^{19}$ In sectoral terms the impact caused in the RAAN was $72.6 \%$ in damages to the productive sector (agriculture, livestock, fishery and livestock) and $27 \%$ in social sectors, mainly housing. ECLAC. Impact of Hurricane Felix on the North Atlantic Autonomous Region and the Torrential Rains in Northwestern Nicaragua, 13 December 2007.
} 
Bocay river, with basic but good quality human services, equitable and fair productive opportunities, and support from autonomous citizen participation, thus contributing to reduce poverty and improve human development on the Caribbean coast by 2020.

\section{Specific objectives}

196. To lay the foundation for sustainable and equitable human development, with concrete benefits, basic but good quality human services, equitable and fair productive opportunities, supported by strengthened autonomous institutions and autonomous, dynamic and coordinated citizen participation as a result of the first stage (2009-2012).

\section{Goals and results expected by 2012}

Goal: The socioeconomic well-being of the population living on the Nicaraguan Caribbean coast improves, by means of:

a) A drop in the illiteracy rate from $38 \%$ in 2008 to $10 \%$ in 2012 .

b) A drop in the mortality rate from $21 \%$ in 2008 to $10 \%$ in 2012.

c) An increase in the number of families with access to drinking water, from $40 \%$ in 2008 to $60 \%$ in 2012 .

d) A reduction in extreme poverty from $37 \%$ of the population in 2008 to $30 \%$ in 2012 .

Goal: An equitable and sustainable economic transformation, in which humans and nature live in harmony

a) Increase of productivity among the poorest sectors of the population, from $16 \%$ in 2008 to $32 \%$ in 2012 .

b) Increase in access to electrical services among the poorest families, from $25 \%$ in 2008 to $50 \%$ in 2012 .

c) Improvement in the communications and transport infrastructure by at least $40 \%$ in 2012.

Goal: The autonomous institutions are strengthened and lead human development on the Caribbean coast

a) The regional governments and the territorial governments in the Upper Coco and Bocay areas formulate and implement expanded planning and multi-annual budgets that are aligned and in harmony with the Nicaraguan Caribbean Coast Development Plan (100\% by 2012).

b) One hundred percent of donor and national budget resources are aligned to the Plan. Starting with C\$ 50 million, there is to be an increase of at least C\$ 150 million per year.

c) Eight key sectors (health, education, environment, natural resources, tourism, transport and infrastructure, fishery, forestry, agrosylvopastoral systems) have regionalized their administration and management at the regional councils and governments, from $0 \%$ in 2008 to $100 \%$ in 2012 .

\section{Expected results:}


a) Improvement of the socioeconomic well-being of the population living on the Nicaraguan Caribbean coast.

b) An equitable and sustainable economic transformation, in which humans and nature live in harmony.

c) The autonomous institutions are strengthened and lead human development on the Caribbean coast

\section{Pillars and programs}

The CCDS is based on three main pillars upon which rests the foundation for a sustainable and equitable human development model, with concrete benefits, good quality basic services and equitable and fair productive opportunities, with support from the autonomous institutions and citizen participation.

Pillar 1: Socioeconomic well-being of the population living on the Nicaraguan Caribbean coast

Pillar 2: Equitable and sustainable economic transformation, humans and nature live in harmony

Pillar 3: Autonomous institutions are strengthened and lead human development on the Nicaraguan Caribbean coast

197. GRUN has prepared programs for each of these pillars. They are listed

immediately below. For a detailed description of these programs, see section 5.7.7 of the NHDP.

Pillar 1: Socioeconomic well-being of the population living on the Nicaraguan Caribbean coast

1) Mother Earth Program

2) Food Sovereignty Program

3) Cultural and Sporting Identity Revitalization Program

4) Autonomous Regional Education Program

5) Regional Health Program

6) Access to Water and Sanitation Program

7) Community Coexistence Program

Pillar 2: Equitable and sustainable economic transformation, humans and nature live in harmony

1) Environmental Protection Program

2) Economic Infrastructure Program

3) Agro-Industrial Development Program

4) Fishery Development Program

5) Tourism Development Program

6) Access to Water and Sanitation Program 
7) Community Coexistence Program

\section{Pillar 3: Autonomous institutions are strengthened and lead human development on the Nicaraguan Caribbean coast}

1) Program to Strengthen Territorial Autonomous Institutions and Regional Public Administration

2) Program to Strengthen Citizen Participation Capacity on the Caribbean Coast and Upper WangkiBocay.

\section{CHAPTER V. NHPD STRATEGIC FRAMEWORK AND GOALS}

198. In order to quantify and provide follow-up on fulfillment of the strategic objectives contained in the National Human Development Plan (NHPD), a Directive Matrix has been designed that displays the major efforts the Government has been and will continue fostering in order to fulfill historic and current commitments acquired with the people of Nicaragua.

199. In general terms, the Directive Matrix focuses on six perspectives with strategic objectives, results indicators and goals through 2011 that are related to macroeconomic and financial stability, restitution of rights that generate social welfare and equity, strengthening of a production strategy for economic growth, environmental protection, and the development of the Caribbean Coast, with the support of good public management. In addition, an Action Furtherance Matrix has been prepared that reflects the major achievements from 2007 to July 2009 for each of the results indicators and goals (see Annex 4, Action Furtherance Matrix).

200. Both matrixes facilitate the mobilization of financial resources, clearly identifying government priorities to fight and reduce extreme poverty and hunger in the country. Their construction has implied a broadly interactive and ongoing process among government institutions and the Planning Division of the Secretariat of the Presidency (SEPRES), with the necessary input from the Nicaragua Central Bank (BCN), the Ministry of Finance and Public Credit (MHCP) and the National Public Investment System (SNIP-SEPRES), as well as technical suggestions from World Bank experts.

201. For practical purposes, a limited number of relevant indicators have been selected, and these are aligned with strategic NHDP objectives expressed operationally in government institution plans. Baseline figures for these indicators are from 2007 and will be measured during the 2009-2011 period; they are representative and most are easily measured, ensuring that follow-up and evaluation will occur, based on cumulative experience, the model and mechanisms in operation, and using the platform installed as part of the Government of Reconciliation and National Unity Information System (SIGRUN).

202. The financial framework used by institutions to calculate goals was based on projections made for the 2009-2011 period, during the second and third review of the Economic and Financial Program agreed upon with the IMF, the overall and sector-based budget projections prepared by the MHCP, and the Public Investment Program formulated by SNIP-SEPRES. 
203. This financial framework presents a very restricted scenario, due to the impact of the international financial crisis which, in the 2009-2011 period, will generate cumulative losses of US\$997.1 million in the government's expenditure budget, US\$980.7 million in regular revenues and US\$403.1 million in grants and loans, multiplying the budget gap by almost four times (from US\$109.6 million forecast in the medium-term budget framework before the crisis to US\$402.4 million with the crisis). This will generate a net gap increase of approximately US\$292.8 million (see Table 8, Resource Gaps of the Central Government 2009 - 2011, in Chapter VI, Budget Framework and Financial Strategy).

204. At sector level, this cumulative loss impacts mainly government social spending, despite efforts made to protect it. The result is a reduction of US\$555.2 million, representing $55.7 \%$ of total cumulative losses (US\$997.1 million) for 2009-2011. Inevitably, the institutions that were most affected in this adjustment process are in the sectors that provide goods and services directly to the population, such as health care, education, social interest housing and community services. Together, these sectors absorbed $92.5 \%$ (US\$513.7 million) of the total reduction in social spending (US\$555.2 million). At sector level, education goals lost US\$244.7 million, health lost US\$165.1 million, and housing construction / improvement and community services US\$103.9 million (see Table 9, Central Government Social Spending 2009 - 2011).

\subsection{Perspectives, strategic objectives, results indicators and goals}

205. The Directive Matrix has been designed in the context of a profound international financial and economic crisis that severely impacts the Nicaragua's fiscal situation. This is a critical factor for the sustainability of the projections made. Nevertheless, although there may be changes in the fulfillment of goals as planned for each year, the framework of priorities that were re-established for this stage of the crisis will remain in effect.

206. It is worth noting that in 2009 a process was begun to align the results indicators and annual goals with institutional strategic objectives. However, a key element to achieving these goals is the procurement of new technical assistance and external financial resources beyond those already allocated.

\subsection{Reduce extreme poverty and chronic child malnutrition}

\section{Fight extreme poverty}

207. According to the Living Standards Measurement Survey (LSMS) conducted in 2005, 17.2\% of Nicaraguans lived in conditions of extreme poverty, with that year's National Development $\operatorname{Plan}^{20}$ anticipating an $11.5 \%$ reduction by 2010 , based on the following assumptions: i) that the economy would grow over the long term at rates higher than 5\% annually; ii) that the budget would include significant increases in social spending; iii) that the efficiency of public policies would improve; and iv) that donor support would be aligned, harmonized and based on mutual responsibility. This obviously has not happened.

\footnotetext{
${ }^{20}$ National Development Plan, Government of Nicaragua. November 2005.
} 
208. Although the results show significant progress starting in 2007 , especially in social policy, the international economic and financial crisis, the increase in oil prices and the food crisis have slowed the pace of progress. The impact of these worldwide crises on the economy and fiscal balance (see chapter VI, above) even threatens to reverse the achievements attained. In this new and difficult context, the slow economic growth being forecast forces the deceleration of goals to reduce extreme poverty. It is projected that the percentage of the population living in conditions of extreme poverty will be reduced to $16.2 \%$ by $2011 .^{21}$ In the context of the international financial and economic crisis, it would in fact be an achievement if this indicator does not deteriorate and perhaps even experiences slight progress.

\section{Reduce chronic child malnutrition}

209. The government has given special priority to food sovereignty and security; thus it is expected that chronic malnutrition will be reduced in coming years. The government has been fostering prioritized programs in the production and economic sector, such as the Food Production Program; the Zero Usury Micro-credit Program; the School Snack and Garden Program (education sector); and the National Program for the Eradication of Chronic Child Malnutrition (health sector). These programs include the following interventions at national level:

- Comprehensive Child Care: Aimed at children under five years of age, through the components of child health, growth and development surveillance and development (VPCD), immunizations, vitamin A and ferrous sulfate supplements, as well as the integrated management of childhood illness at institutional and community levels.

- Comprehensive Care for Women. In addition to prenatal, birthing and postpartum components, it includes the detection, prevention and treatment of anemia as well as the promotion of exclusive breastfeeding until the age of six months, with breastfeeding continuing until the infant is two years of age.

- $\quad$ Community Health and Nutrition Program (PROCOSAN). A community strategy based on personalized counseling for changes in dietary behaviors along with family health and nutrition promotion actions. The program targets children under two years of age that live in poor rural communities with difficulty in accessing health facilities.

National Micronutrient Program. A food supplementation and fortification component, coupled with information, education and communication.

- National Breastfeeding Program. Measures to promote protect and maintain natural breastfeeding, as this contributes to improving the nutritional status of milk-fed infants.

\footnotetext{
${ }^{21}$ This estimate was made by using the regression method, with support from WB experts and based on studies conducted by this institution which conclude that the elasticity of reduction of extreme poverty, given growth in per capita income, is -2.4. In other words, with a $1.0 \%$ growth in per capita income, the rate of extreme poverty would decrease $2.4 \%$. If this is applied to the initial extreme poverty population of $17.2 \%$, with a growth in per capita income of $1.8 \%$ for 2007 , it is anticipated that extreme poverty will decrease by $4.32 \%$ of that universe, reaching $16.4 \%$. Following the same method for subsequent years and using the same per capita growth hypothesis, the population living in extreme poverty in 2011 will be $16.2 \%$.
} 
210. Other health and nutrition sector interventions are developed by the Ministry of the Family, Adolescents and Children through the AMOR Program, which ensures the care of children under six of mothers that work in rural areas and towns, providing them with comprehensive care to improve educational, nutritional and health conditions in Urban and Community Child Development Centers and Base Houses.

211. Along these same lines, the Ministry of Agriculture and Forestry (MAGFOR) implements the Vulnerable Groups Assistance Program, which is directed at pregnant women, breastfeeding mothers, and children less than two years of age, in order to improve their health and nutrition conditions. Its activities include the distribution of complementary food rations in Base Houses and Health Posts on a quarterly basis.

\subsection{Macroeconomic and Financial Perspectives}

\section{Macroeconomic stability to support human development priorities}

212. Macroeconomic stability will be measured through real GDP growth, per capita GDP and the inflation rate. The goals for these had to be revised downward in view of the variations in oil and food prices and the impact of the international financial and economic crisis, which significantly affected the outlook for economic growth.

213. It is anticipated that the economy will contract by about $1.0 \%$ in 2009 , instead of the $4.5 \%$ growth estimated in the October 2008 NHDP. It is forecast that in 2011 growth will be of $2.5 \%$. Several years will pass before the country recovers the GDP level forecast for 2009 prior to the international economic crisis. In line with this slower growth, it is estimated that per capita GDP will begin recovery in 2011 (by $1.2 \%$ ), after decreasing in both 2009 and 2010. The inflation rate has been adjusted downward to $2-3 \%$ and $6 \%$ for 2009 and 2011, respectively, down from the previous estimates of $11.7 \%$ and $8 \%$.

\section{Efficient and sustainable public finances to fight poverty}

214. The efficiency and sustainability of public finances will be estimated by the level of execution of public spending relative to the updated budget, which is expected to climb to $95 \%$ in 2011. Similarly, it is estimated that the proportion of primary spending in the non-financial public sector directed at fighting poverty will remain at an average of $43 \%$ throughout the $2009-2011$ period; and that the percentage of primary spending in the non-financial public sector directed at the Public Investment Program will increase from $17.9 \%$ in 2007 to $19.8 \%$ in 2011.

\section{Foreign cooperation aligned with national priorities}

215. Foreign cooperation is key to complementing national efforts and resources in order to generate well-being among Nicaraguan families. In the framework of strategic management of official development aid during 2009-2011, it is expected that the average annual support to be received from the donor community will be US\$546.3 million. 


\subsection{Social welfare and equity perspectives}

\section{Food Security}

216. Given its importance for the generation of food, the indicator "Number of poor rural and urban families capitalized through the Production Package" has been selected. This is a component of the Food Production Program which began operations in June 2007, benefiting 12,217 families that year. The total target is 75,000 families over the five-year period from 2007 to 2011 .

\section{Quality education for all}

217. Consistent with the priority of ensuring free quality education which overcomes the historic performance gaps in the education sector, the reduction of illiteracy is a major national challenge in which there has been progress at a pace unprecedented in the history of Nicaragua, with a low illiteracy rate of $3.0 \%$ being anticipated by 2011. The "From Martí to Fidel" National Literacy Campaign has decreased illiteracy to $4.1 \%$, supported by the mobilization of different sectors and social movements. On July 19, 2009 Nicaragua was declared a territory free of illiteracy.

218. In line with the reconstruction of the educational system, systematic follow-up will be provided on school attendance, retention and grade promotion. Through linked and differentiated efforts between regular and alternative education, it is anticipated that by 2011, school retention will be $89.5 \%$ in preschool, $91.5 \%$ in primary school and $88 \%$ in secondary school. The percentage for grade promotion in primary and secondary schools will be $90 \%$ and $86.5 \%$, respectively, and the net schooling rate for primary school will be $88.5 \%$ in 2011.

\section{Restitution of the human right to health}

219. The National Health Policy has defined its priorities as care for women, particularly during pregnancy, birth and the postpartum period; care for children under one year of age; and the elimination of barriers that prevent access to health services.

220. The maternal mortality rate was 94 per 100,000 live births registered in 2006, and decreased to 80 in 2007. The development of interventions by the Ministry of Health to strengthen the process of surveillance, ongoing monitoring and the reduction of maternal mortality has been key to this significant achievement. These interventions include: the implementation of the Family and Community Health Model and the Plan for Eradication of Maternal Mortality, establishing alliances with the community network (including Maternity Houses) and implementing strategies to decrease maternal morbidity and mortality; identifying the risks for pregnant women in a timely fashion in order to reduce complications, aftereffects and deaths, serving the demand for prenatal care, birthing plans and postpartum care; providing timely quality care for all women that seek care for complications; ensuring family planning services; providing surveillance and monitoring of micronutrient supplementation; and offering services for the detection, prevention and treatment of anemia and other deficiencies. It is anticipated that the maternal mortality rate of 67 per 100,000 live births attained in 2008 will be maintained, decreasing to 62.8 in 2010 and to 55 in 2011. 
221. In keeping with the health policy to fight infant mortality, it is anticipated that the rate of mortality will decrease on a consistent basis, and maintain a sustained downward trend, from 27 per 1,000 live births in 2009 to 26 in 2010 and 25 in 2011. To this end, maximum efficiency is ensured in Comprehensive Care for Children, developing the components of infant health, Growth and Development Surveillance and Development (VPCD), of children under one year of age (promoting their proper and healthy growth and development); in quality Integrated Management of Childhood Illness, immunizations (against tuberculosis, diphtheria - whooping cough - tetanus - influenza hepatitis B, polio, and measles / mumps / rubella), application of the rotavirus-diarrhea vaccine, promoting food and nutrition security actions (strengthening and expanding the community-based health and nutritional education strategy); follow-up on the minimum expected weight according to new growth standard (WHO) and surveillance of perinatal and infant mortality.

222. Furthermore, outpatient medical care is provided for the entire population that seeks it throughout the country; medications are guaranteed free of charge; routine and specialized laboratory examinations are provided for patients visiting health units and hospitals anywhere in the country.

\section{Restitution of the right of children to live a decent and happy life (AMOR Program)}

223. Derived from the National Social Welfare System, the AMOR Program works to restore the right of children to live a decent and happy life, providing them with education, health care, security, sports, art, recreation and joy.

224. Part of this commitment is the restitution of the rights of children and adolescents to live under normal conditions, in family and without running the risks of street life. This involves providing comprehensive attention to those exposed to risks and found in the streets of the various towns, or Managua. They are ensured the right to education and a permanent place in the schools. Each year 5,000 children and adolescents are taken off of the streets and 3,000 of these are enrolled in public schools.

225. To restore the right of children and adolescents to a decent life without child labor, every year 3,000 children and adolescents whose labor is exploited under the worst conditions will be sponsored by the AMOR Program and incorporated and retained in school. The care of children whose mothers work is guaranteed, providing them with holistic attention to improve their educational, nutritional and health conditions. Each year, 4,300 children under six years of age receive holistic attention in Child Development Centers and care will be provided for 87,027 children in Community Child Development Centers and Base Houses.

226. The right of children to grow up with the love and care of a family also is being restored, as well as the right to specialized care for those with disabilities. Children and adolescents of migrant parents, whose mothers are deprived of liberty or in situations of sexual exploitation, are also given attention. 


\section{Access to drinking water and sanitation}

227. Consistent with the human right to regular access to drinking water, the government is working to bring water to historically marginalized households. Priority is given to investments in water and sanitation. Key goals defined for this are effective coverage of drinking water in urban areas, raising it from $65 \%$ in 2007 to $86 \%$ in 2011 and increasing coverage by sanitary sewerage systems from $36.5 \%$ to $48 \%$ in 2011 .

228. In addition, follow-up is provided on the nominal coverage indicators to measure drinking water service and wastewater treatment in urban areas as well as water and sanitation coverage in rural areas of the country. The coverage of drinking water in rural areas will increase from $56.3 \%$ in 2007 to $64.1 \%$ in 2011 ; and from $73.2 \%$ to $81.0 \%$ in 2011 for sanitation, through ecological latrine construction projects.

229. Emphasizing the importance of the sector, a presidential mandate elevated the human right of access to drinking water and sanitation to the category of a roundtable, which was established in June 2009 and has the mission of updating the Sectoral Drinking Water and Sanitation Strategy, based on the proposals for urban and rural water and sanitation strategies developed by the national water authority (ENACAL) and the Social Investment Emergency Fund (FISE). This will result in a new Urban and Rural Water and Sanitation Strategy that prioritizes the equitable well-being of citizens in harmony with the proper use and good management of the resource. Consultation will be conducted on this proposal with Citizen Power Councils, international donors, the private sector, and social and labor movements.

\subsection{Production Perspective}

\section{Increase in the generation of electrical energy for the people and the economy}

230. The government is fostering a Generation Expansion Plan that reflects a gradual change of the energy matrix. New power generation plants are scheduled to come on line, as others are withdrawn because they are unsuitable for continued operation based on technical criteria. This is reflected in the goals for 2009 and 2010, in which an additional energy production capacity of $320 \mathrm{MWe}$ will be accumulated (total additional capacity to the National Energy System from 2007 to 2011 is of 344 MWe).

\section{Additional expansion of the electrical energy transmission grid}

231. Between 2009 and 2011, the government will install 153.9 kilometers of new 138 and 230kilovolt $(\mathrm{KV})$ transmission lines for the expansion of the transmission system and the connection of new sub-stations to the current transmission grid.

232. Parallel to this effort, transformers with additional power of 760 megavolt-amperes (MVA) will be supplied and installed during 2009-2011, distributed in the existing and new sub-stations in 
order to receive greater amounts of energy generated from the plants and to cover the increased demand for power and energy.

233. Rural electrification will continue to increase during 2009-2011, bringing energy service to 37,549 households, especially in isolated areas. Small hydroelectric plants will be built, solar panels will be installed and concessions for generation and distribution will be promoted among local companies.

\section{Improvement of the road network to expand access to basic services and markets}

234. Efforts will be focused on road-building, in order to facilitate access to basic services, stimulate production and access to markets. The Road Maintenance Fund (FOMAV) will provide maintenance on trunk roads while the Ministry of Transportation and Infrastructure (MTI) has scheduled improvements of all-weather roads and the building of new roads in productive zones using gravel or cement blocks.

\section{Increase agricultural production}

235. It is expected that the country will experience an increase in agricultural production beginning with the 2009/2010 and 2010/2011 production cycles as a result of the production support programs implemented by the government: greater use of certified seeds and fertilizers, technical assistance, transfer of technologies and financing of small and medium scale farmers. The increase in trade with ALBA countries will also have an impact, especially with Venezuela.

236. Nevertheless, due to the environmental - climatic vulnerability of the country, the total area of staple food crops lost in the 2007/2008 agricultural cycle reached approximately 80,000 ha, equivalent to $9.7 \%$ of the total area planted. In the 2008/2009 cycle, the loss of 95,000 ha was reported, equivalent to $12.1 \%$ of the total area planted. These losses were caused by climate irregularities (particularly the impact of Hurricane Felix in September 2007) and damages caused by rodents, insects and plant diseases.

237. In the industrial sector, based on a projection that assumes the decrease of industrial and agricultural sector exports in 2009, the government foresees growth beginning in 2010 and 2011 with the reactivation of the agricultural sector and the onset of support projects for micro-, small and medium enterprises, especially in manufacturing activities. Under this scenario, it is assumed there is a reactivation of the global economy.

\subsection{Natural disasters and environmental perspectives}

\section{Environment}

238. The National Reforestation and Natural Resources Restoration Crusade is the institutionalized government effort to recover the water sources, forest and soils needed strengthen natural livelihoods and fight poverty. 
239. It is estimated that the annual loss of forest cover in Nicaragua is of 70,000 ha; at this pace, forests will have disappeared in less than 40 years time. This situation is aggravated by the physical damage to the environment caused by Hurricane Felix. It is anticipated that the tendency toward deforestation will slow to approximately 19,000 ha annually between 2009 and 2011 and that the areas with vegetation coverage will increase.

\section{Control and reduction of pollution}

240. The economy of Nicaragua is developing under pressure to increase production, to achieve efficiency in the production processes and in services while also decreasing the negative impact on the environment. In this context, plans for environmental management are instruments by which to continuously apply a comprehensive environmental protection strategy to processes, products and services, increasing eco-efficiency and reducing risks to human health and the environment. To this end, the number of registered companies that implement environmental management plans to reduce pollution will continue to increase in a sustained manner.

\section{Natural disaster prevention, mitigation and relief}

241. Nicaragua constantly receives the impact of different natural phenomena that cause disasters, both for the population and for its economy. Therefore, the government is developing a culture of disaster prevention, accompanied by the application of technical advances to reduce the impact of natural disasters in the country. Early Warning Systems will be expanded and integrated to the most vulnerable areas of the country.

242. In addition to preparation work with the population, a key element in the development of a disaster prevention, mitigation and relief culture, is the government's organization of Municipal Committees (COMUPRED) in all the municipalities of the country and its strengthening of the capacities for planning and raising awareness in the institutions and municipalities, in order to deal with natural disasters in the best way possible, providing improved care and a more efficient response to the families affected.

\subsection{Development of the Caribbean coast}

243. The objective of the Caribbean Coast Development Strategy is to develop an economic, political and social reality that restores the rights of the inhabitants of the autonomous regions of the Caribbean to receive quality basic human services and equitable and fair opportunities for production, supported by dynamic and coordinated autonomous citizen power. The outcome will be an increase in the social and economic well-being of the population, achieving an economic transformation that is equitable, sustainable and harmonious for both human beings and nature, and strengthening autonomous institutions to lead human development in the Caribbean region, with an emphasis on the following aspects:

\section{Reduction of illiteracy}

244. A literacy campaign is underway on the Caribbean Coast with a bilingual intercultural approach that addresses the needs of the population of the autonomous regions, fostering the 
development of the mother tongue and the learning of Spanish as a second language. There are educational materials that are appropriate to the setting in the Miskito, Mayangna and English languages. Monolingual teachers will be trained for the management of the bilingual intercultural programs and mapping and a school census will be conducted for the Caribbean regions. It is expected that this will reduce the illiteracy rate for people 10 years of age and older from $28.6 \%$ in 2007 to $1.2 \%$ in 2011.

\section{Secure property rights}

245. A priority task for the government is to address and resolve property conflicts in high risk areas, as a factor in the social and political stability of the country. The Property Administration Office is working on demarcation and titling of the territories of the indigenous communities in strict observance of the culture, traditions and customs of the inhabitants. It is anticipated that the process of demarcation and titling of indigenous and Afro-descendent territories and complementary areas will be finalized in the short term.

\section{Equitable and sustainable economic transformation, in which humans and nature live in harmony}

246. One of the core elements for establishing the basis of a model of development with equity on the Caribbean coast is to achieve economic transformation that is equitable, sustainable and harmonious for both humans and nature through the productive rehabilitation of thousands of families who live in the indigenous and Afro-descendent territories and in the most impoverished municipalities, and by increasing access of the population to electricity services.

247. It is anticipated that by 2001 some 10,000 families living in the indigenous and Afrodescendent territories will have been the subjects of productive rehabilitation. A seed bank and processing facility are to be set up, and a strategy formulated for the processing of rice and the management of beans and corn, among other projects. In addition, an increase of up to $40.0 \%$ is planned for access to electricity services through the development of rural electrification programs, the construction of small hydroelectric plants, micro-turbines and unconventional energy systems, as well as the development of research leading to the generation of renewable and environmentallyfriendly energy.

\section{Strengthened autonomous institutional development}

248. The strengthening of institutions in the Autonomous Regions of the Caribbean Coast of Nicaragua (RAAN and RAAS) should not be understood as only a training process and the supply of material and technical resources to existing institutions, but also must take into account those aspects of institutional strengthening that contribute to good governance, strengthening the capacities of the leaders and professionals, fostering mechanisms for dialogue, accountability, conflict resolution and the coordination of actions and policies among different levels of government. Furthermore, these elements contribute to a more dynamic execution of regional, municipal and community plans to improve the public administration of regional autonomy. 
249. Implementation is now underway of the Development Strategy and Plan to Strengthen the North Atlantic Autonomous Government (GRAAN) which is the basic instrument for developing conditions and capacities needed for leadership and improvement of conditions allowing for human development. Also being implemented is Caribbean Coast Development Plan. A task that is yet to be carried out is the formulation and implementation of the Institutional Strengthening Strategy and Plan for the municipality of Rosita and the South Atlantic Autonomous Government (GRAAS). In addition, the Results-based Integrated Management System will be implemented in both regions.

\subsection{Actions for good public management}

\section{Transparency and integrity in public management}

250. In the direct democracy model that the government fosters, the right to access understandable and timely public information is restored for effective exercise of citizen power. For this purpose, the government has since 2008 been establishing offices at government institutions to provide public information to the citizenry, in physical form and/or through their web pages. The goal is to increase the number of institutions with such offices from eight in 2008 to 48 in 2011.

\section{Strengthening public management}

251. The strengthening of public administration will improve and consolidate what already exists at central government level, as it is aimed at supporting the effective establishment of the public policies set forth in the NHDP. One of the priorities of the government is the modernization of the financial administration in order to comprehensively improve processes for public management. To accomplish this, the government has prepared a Plan for Modernization of the Financial Administration Systems (PMSAF) which establishes actions to strengthen the financial administration of the budget, accounting, treasury and public credit, the related public operations functions, public investment, procurement and contracting, internal auditing and the modernization of the Integrated Financial, Administrative and Auditing Management System (SIGFA).

252. The development of PMSAF has been based on the internal assessment of the different systems, which has made it possible to identify the major constraints and challenges for modernization of public finances. Three aspects are highlighted in the assessment: (i) the current SIGFA only encompasses the central government, (ii) the need to gradually expand the coverage of the SIGFA to the public sector in general; and (iii) the need to modernize the SIGFA technological platform. These aspects reflect priority actions to be addressed by PMSAF in the medium and long term.

253. The integration of administrative processes will enable the entities that use the financial administration systems to comprehensively manage their administrative procedures, minimizing the duplication of processes and improving the efficiency of the administrative processes. The modernization of financial administration will thus provide user entities with tools for improving the quality of the services provided in a timely and transparent fashion. The PMSAF will carry out a series of actions aimed at defining a new conceptual model for financial and administrative management in order to modernize public administration and to improve the quality of public spending. An important aspect of the conceptual model will be the strengthening of the Medium- 
Term Budget Framework (MTBF) as a planning instrument that supports the objective of sustainability of public finances and contributes to the evaluation of the results of the public policies contained in the NHDP.

254. It is anticipated that, over the long term, modernization of the SIGFA technological platform will expand coverage of the financial information system to decentralized and autonomous entities. In the medium term, progress will be made in the consolidation of the central government, providing reliable and timely financial information, optimizing decision-making regarding the results of execution of public resources at all levels, from executing units to the consolidation of the public sector. For citizens in general, the system will provide reliable and timely information concerning the use of public resources, thus strengthening accountability processes and state - citizen relations.

\section{Citizen security}

255. The strategies defined by the government to attain good public administration include citizen security, understood as a multi-factor phenomenon, and not merely as a crime-related issue. Thus the strategy includes programs against domestic violence, control and reintegration of youth gangs and a frontal struggle against criminal activity in general, anticipating that deceleration of crime will be the result. By calculating the percentage of deceleration of crime compared to the demographic crime index, follow-up will be provided on the evolution of this strategy; with hopes for a downward trend in indicators to be measured every two years.

256. Other indicators linked to the process that also will be subject to follow-up and evaluation are: the number of young people at social risk that are incorporated into recreational activities; the number of volunteer promoters involved in the struggle against domestic violence; the number of promoters working to stop the use of firearms; the number of training sessions at schools on prevention of domestic and sexual violence; and the number of prisoners permanently incorporated into school instruction, vocational activities, and cultural and recreational activities.

\section{Secure property rights}

257. The legalization of urban and rural property is a priority, especially for the traditionally excluded population (farmers, homemakers, those demanding land, disarmed combatants). The legalization of property will contribute to improving physical property planning in Nicaragua.

258. The indicator "Property titles issued by the government" will provide an accounting of the total number of property documents issued and to be issued (2007-2011), including urban titles, rural titles, certificates of good standing under Laws 85, 86 and 88, and certificates of compliance. Between 2007 and 2008, accelerated progress was made in solving many cases. As of 2011, the tendency is toward a decrease in the pace of property conflict resolution, as more cases are solved. 
259. There follows the NHDP Directive Matrix.

\section{Directive Matrix: Perspectives, Strategic Objectives, Results Indicators and Goals}

\begin{tabular}{|c|c|c|c|c|c|c|c|}
\hline \multirow{2}{*}{$\begin{array}{l}\text { Perspective / } \\
\text { Strategic Objective }\end{array}$} & \multirow{2}{*}{ Results Indicator } & \multirow{2}{*}{$\begin{array}{l}\text { Baseline } \\
2007\end{array}$} & \multicolumn{4}{|c|}{ GOALS } & \multirow{2}{*}{$\begin{array}{l}\text { Institution } \\
\text { Responsible }\end{array}$} \\
\hline & & & 2008 & 2009 & 2010 & 2011 & \\
\hline \multicolumn{8}{|c|}{ FIGHT EXTREME POVERTY } \\
\hline $\begin{array}{l}\text { 1) Reduce extreme } \\
\text { poverty. }\end{array}$ & $\begin{array}{l}\text { \% reduction in extreme } \\
\text { povety }^{1 /}\end{array}$ & 17.2 & - & - & - & 16.2 & GRUN/INIDE \\
\hline \multicolumn{8}{|c|}{ MACROECONOMIC AND FINANCIAL PERSPECTIVES } \\
\hline \multirow{3}{*}{$\begin{array}{l}\text { 1) Establish } \\
\text { macroeconomic } \\
\text { stability that supports } \\
\text { the human } \\
\text { development } \\
\text { priorities. }\end{array}$} & Real GDP growth rate & 3.2 & 3.2 & -1.0 & 1.0 & 2.5 & $\mathrm{BCN}$ \\
\hline & \begin{tabular}{|l|}
$\begin{array}{l}\text { Real per capita GDP } \\
\text { growth rate }\end{array}$ \\
gl
\end{tabular} & 1.8 & 1.9 & -2.3 & -0.3 & 1.2 & $\mathrm{BCN}$ \\
\hline & Inflation rate & 11.1 & 19.8 & 4.0 & 5.0 & 5.9 & $\mathrm{BCN}$ \\
\hline \multirow{3}{*}{$\begin{array}{l}\text { 2) Ensure the fisca } \\
\text { effort necessary to } \\
\text { fight poverty througl } \\
\text { efficient } \\
\text { sustainable an } \\
\text { finances. }\end{array}$} & $\begin{array}{l}\% \text { execution of public } \\
\text { expenditures relative to } \\
\text { the updated budget }^{3 / 4 /}\end{array}$ & 93.3 & 94.9 & 95.0 & 95.0 & 95.0 & MHCP \\
\hline & \begin{tabular}{|l|}
$\%$ of non-financial \\
public sector primary \\
expenditures directed at \\
the Public Investment \\
Program
\end{tabular} & $17.9^{5 /}$ & $17.1^{5 /}$ & 20.4 & 19.6 & 19.8 & $\mathrm{SNIP} / \mathrm{BCN}$ \\
\hline & $\begin{array}{l}\% \text { of non-financial } \\
\text { public sector primary } \\
\text { expenditures directed at } \\
\text { fighting poverty } \\
\end{array}$ & 47.9 & 46.2 & 42.9 & 42.9 & 43.2 & SEPRES \\
\hline $\begin{array}{l}\text { 3) Align international } \\
\text { cooperation with } \\
\text { national priorities. }\end{array}$ & $\begin{array}{l}\begin{array}{lr}\text { Amount of } & \text { external } \\
\text { resources } & \text { disbursed } \\
\text { (millions of dollars) }\end{array}\end{array}$ & 630.7 & 417.8 & 560.8 & 556.7 & 521.5 & $\begin{array}{l}\text { BCN-SREC- } \\
\text { MINREX }\end{array}$ \\
\hline \multicolumn{8}{|c|}{ SOCIAL WELFARE AND EQUITY PERSPECTIVES } \\
\hline \multicolumn{8}{|l|}{ Food Security } \\
\hline $\begin{array}{lr}\text { 1) Increase food } \\
\text { production } & \text { for } \\
\text { consumption by } & \text { the } \\
\text { population. } & \end{array}$ & $\begin{array}{l}\text { Number of poor rural } \\
\text { and urban families } \\
\text { capitalized through the } \\
\text { Production Package } \\
\text { Cumulative number of } \\
\text { families that receive the } \\
\text { Production Package }\end{array}$ & 12,217 & 31,576 & 47,486 & 62,486 & 75,000 & MAGFOR \\
\hline \multicolumn{8}{|c|}{ Quality Education for All } \\
\hline \multirow{5}{*}{$\begin{array}{l}\text { 2) Increase the } \\
\text { average number of } \\
\text { years of schooling. }\end{array}$} & \begin{tabular}{|l|l|}
$\begin{array}{l}\text { Net rate of primary } \\
\text { schooling }\end{array}$ \\
\end{tabular} & 86.5 & 87.2 & 88.0 & 88.0 & 88.5 & MINED \\
\hline & $\%$ of preschool retention & 86.0 & 87.4 & 88.0 & 89.0 & 89.5 & MINED \\
\hline & $\begin{array}{l}\% \text { of primary school } \\
\text { retention }\end{array}$ & 87.6 & 89.6 & 90.5 & 91.0 & 91.5 & MINED \\
\hline & $\begin{array}{l}\% \text { of secondary school } \\
\text { retention }\end{array}$ & 83.0 & 84.4 & 85.8 & 87.0 & 88.0 & MINED \\
\hline & $\begin{array}{l}\text { \% of grade promotion in } \\
\text { primary school }\end{array}$ & 86.4 & 87.6 & 88.0 & 89.0 & 90.0 & MINED \\
\hline
\end{tabular}




\begin{tabular}{|c|c|c|c|c|c|c|c|}
\hline \multirow{3}{*}{$\begin{array}{c}\text { Perspective / } \\
\text { Strategic Objective }\end{array}$} & \multirow{2}{*}{ Results Indicator } & \multirow{2}{*}{$\begin{array}{l}\text { Baseline } \\
2007\end{array}$} & \multicolumn{4}{|c|}{ GOALS } & \multirow{2}{*}{$\begin{array}{l}\text { Institution } \\
\text { Responsible }\end{array}$} \\
\hline & & & 2008 & 2009 & 2010 & 2011 & \\
\hline & $\begin{array}{l}\% \text { of grade promotion in } \\
\text { secondary school }\end{array}$ & 86.1 & 85.3 & 85.5 & 86.0 & 86.5 & MINED \\
\hline 3) Reduce illiteracy. & $\begin{array}{l}\text { Illiteracy rate among } \\
\text { persons } 10 \text { years of age } \\
\text { or older }(22.0 \% \text { in } 2005 \\
\text { Census) } \\
\end{array}$ & 20.2 & 7.5 & 5.0 & 4.0 & 3.0 & MINED \\
\hline \multicolumn{8}{|c|}{ Restitution of the Human Right to Health } \\
\hline \multirow{2}{*}{$\begin{array}{lr}\text { 4) Ensure } & \text { universal } \\
\text { and free } & \text { access to } \\
\text { quality } & \text { health } \\
\text { services. } & \end{array}$} & $\begin{array}{l}\text { Maternal mortality rate } \\
\text { per } 100,000 \text { live births }\end{array}$ & 80.0 & 67.0 & 67.0 & 62.8 & 55.0 & MINSA \\
\hline & $\begin{array}{l}\text { Infant mortality rate per } \\
\text { thousand live births }\end{array}$ & 29.0 & 28.0 & 27.0 & 26.0 & 25.0 & MINSA \\
\hline \multicolumn{8}{|c|}{ Restitution of the Right of Children to Live a Decent and Happy Childhood (AMOR Program) } \\
\hline $\begin{array}{l}\text { 5) Restore to children } \\
\text { and adolescents the } \\
\text { right to live under } \\
\text { normal family } \\
\text { conditions, withou } \\
\text { running the risks of the } \\
\text { streets and to have } \\
\text { decent life withou } \\
\text { child labor. }\end{array}$ & $\begin{array}{l}\text { Number of children and } \\
\text { adolescents on the } \\
\text { streets, exposed to risks } \\
\text { and the worst forms of } \\
\text { child labor, who are } \\
\text { incorporated to school. }\end{array}$ & - & 6,000 & 8,000 & 8,000 & 8,000 & MIFAM \\
\hline $\begin{array}{l}\text { 6) Ensure the care of } \\
\text { children of working } \\
\text { mothers, providing } \\
\text { them } \\
\text { comprehensive care to } \\
\text { improver thein } \\
\text { educational, nutritiona } \\
\text { and health conditions. }\end{array}$ & $\begin{array}{l}\text { Number of children } \\
\text { under six years of age } \\
\text { receiving } \\
\text { comprehensive care at } \\
\text { Child Development } \\
\text { Centers (CDI). }\end{array}$ & - & 84,307 & 90,048 & 96,132 & 96,990 & MIFAM \\
\hline \multicolumn{8}{|c|}{ Access to Drinking Water and Sanitation } \\
\hline \multirow{2}{*}{$\begin{array}{l}\text { 7) Provide national } \\
\text { coverage of drinking } \\
\text { water. }\end{array}$} & $\begin{array}{l}\% \text { of effective coverage } \\
\text { of drinking water in } \\
\text { urban areas }\end{array}$ & 72.0 & 77.0 & 80.0 & 82.0 & 86.0 & ENACAL \\
\hline & $\begin{array}{l}\% \text { of effective coverage } \\
\text { of drinking water in rural } \\
\text { areas }\end{array}$ & 56.3 & 57.9 & 59.4 & 62.1 & 64.1 & FISE \\
\hline \multirow{2}{*}{$\begin{array}{l}\text { 8) Provide national } \\
\text { coverage of sanitary } \\
\text { sewerage. }\end{array}$} & $\begin{array}{l}\% \text { of access by the urban } \\
\text { population to sewerage } \\
\text { service }\end{array}$ & 36.5 & 37.0 & 38.0 & 43.0 & 48.0 & ENACAL \\
\hline & $\begin{array}{l}\% \text { of sanitation coverage } \\
\text { of the population in rural } \\
\text { areas }\end{array}$ & 73.2 & 74.8 & 76.3 & 79.0 & 81.0 & FISE \\
\hline \multicolumn{8}{|c|}{ PRODUCTION PERSPECTIVE } \\
\hline $\begin{array}{l}\text { 1) Increase the } \\
\text { generation } \\
\text { electricity for the } \\
\text { people and the } \\
\text { economy. }\end{array}$ & $\begin{array}{l}\text { Number of additional } \\
\text { MW of energy capacity } \\
\text { produced }^{6 /} \\
\text { Cumulative number of } \\
\text { additional MW of energy } \\
\text { capacity produced }^{6 /}\end{array}$ & 60 & 120 & 280 & 320 & 344 & MEM \\
\hline
\end{tabular}




\begin{tabular}{|c|c|c|c|c|c|c|c|}
\hline \multirow{2}{*}{$\begin{array}{c}\text { Perspective / } \\
\text { Strategic Objective }\end{array}$} & \multirow{2}{*}{ Results Indicator } & \multirow{2}{*}{$\begin{array}{l}\text { Baseline } \\
2007\end{array}$} & \multicolumn{4}{|c|}{ GOALS } & \multirow{2}{*}{$\begin{array}{l}\text { Institution } \\
\text { Responsible }\end{array}$} \\
\hline & & & 2008 & 2009 & 2010 & 2011 & \\
\hline \multirow{3}{*}{$\begin{array}{l}\text { 2) Increase the } \\
\text { expansion of the } \\
\text { electrical energy } \\
\text { transmission grid. }\end{array}$} & $\begin{array}{|lr|}\text { Number of } & \text { new } \\
\text { kilometers } & \text { of } \\
\text { transmission lines } & \\
\end{array}$ & - & 141.8 & 16.1 & 14.5 & 123.3 & ENATREL \\
\hline & $\begin{array}{l}\text { Number of additional } \\
\text { megavolt-amperes } \\
\text { (MVA) for increased } \\
\text { transformation capacity }\end{array}$ & - & 26.3 & 40.0 & 175.0 & 545.0 & ENATREL \\
\hline & $\begin{array}{|lll|}\begin{array}{l}\text { Number of } \\
\text { households } \\
\text { electricity }\end{array} & & \text { rural } \\
\end{array}$ & 9,102 & 11,423 & 10,227 & 9,148 & 18,174 & MEM \\
\hline \multirow{2}{*}{$\begin{array}{l}\text { 3) Improve roads to } \\
\text { expand access to } \\
\text { basic services and to } \\
\text { the market. }\end{array}$} & \begin{tabular}{|l|}
$\begin{array}{l}\text { Number of new } \\
\text { kilometers of secondary } \\
\text { roads }\end{array}$ \\
\end{tabular} & 19.5 & 20.4 & 80 & 146 & 124 & MTI \\
\hline & $\begin{array}{l}\text { Number of rehabilitated } \\
\text { kilometers of secondary } \\
\text { roads }\end{array}$ & 82.5 & 102.4 & 27 & 56 & 48 & MTI \\
\hline \multirow{3}{*}{$\begin{array}{l}\text { 4) Increase } \\
\text { agricultural } \\
\text { production }\end{array}$} & 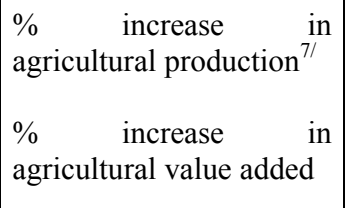 & -3.2 & -1.5 & 10.4 & 0.9 & 10.5 & $\begin{array}{l}\text { MAGFOR/ } \\
\text { BCN }\end{array}$ \\
\hline & $\begin{array}{l}\% \text { increase in yields of } \\
\text { corn and beans }\end{array}$ & -5 & -2 & 15 & 3 & 1 & MAGFOR \\
\hline & $\begin{array}{l}\% \text { increase of industrial } \\
\text { value added }\end{array}$ & 7.4 & 2.2 & -1.5 & 0.5 & 2.4 & $\mathrm{MIFIC} / \mathrm{BCN}$ \\
\hline \multicolumn{8}{|c|}{ NATURAL DISASTERS AND ENVIRONMENTAL PERSPECTIVE } \\
\hline \multicolumn{8}{|l|}{ Environment } \\
\hline $\begin{array}{l}\text { 1) Ensure forests for } \\
\text { the future. }\end{array}$ & $\begin{array}{|lrr|}\text { Number } & \text { of } & \text { hectares } \\
\text { reforested } & \text { in } & \text { the } \\
\text { framework } & \text { of } & \text { the } \\
\text { National } & \text { Reforestation } \\
\text { Campaign } & & \\
\end{array}$ & 14,713 & 10,451 & 20,287 & 19,860 & 16,000 & $\begin{array}{l}\text { INAFOR } \\
\text { MARENA }\end{array}$ \\
\hline $\begin{array}{l}\text { 2) Control and reduce } \\
\text { pollution. }\end{array}$ & \begin{tabular}{|l|} 
Number of registered \\
companies implementing \\
environmental \\
management programs to \\
reduce pollution \\
\end{tabular} & 137 & 158 & 209 & 220 & 240 & MARENA \\
\hline \multicolumn{8}{|c|}{ Natural Disaster Prevention, Attention and Mitigation } \\
\hline $\begin{array}{l}\text { 3) Reduce the impact } \\
\text { of natural disasters on } \\
\text { the country. }\end{array}$ & $\begin{array}{l}\text { Number of early warning } \\
\text { systems (EWS) for } \\
\text { tsunamis, earthquakes } \\
\text { volcanic eruptions, floods } \\
\text { landslides and volcanid } \\
\text { mudflows in the mos } \\
\text { vulnerable sites in the } \\
\text { country }\end{array}$ & 2 & 5 & 10 & 13 & 15 & INETER \\
\hline $\begin{array}{l}\text { 4) Consolidate } \\
\text { planning } r \text { and } \\
\text { organizational } \\
\text { processes with a risk } \\
\text { management }\end{array}$ & $\begin{array}{|lr|}\% \text { of } & \text { Municipal } \\
\text { Committees } & \text { for Disaster } \\
\text { Prevention, } & \text { Mitigation } \\
\text { and Relief } & \text { (COMU- } \\
\text { PRED) organized }\end{array}$ & 60 & 80 & 85 & 95 & 100 & SINAPRED \\
\hline
\end{tabular}




\begin{tabular}{|c|c|c|c|c|c|c|c|}
\hline \multirow{3}{*}{$\begin{array}{l}\text { Perspective / } \\
\text { Strategic Objective } \\
\text { approach to address } \\
\text { the needs of families } \\
\text { affected by natural } \\
\text { disasters. }\end{array}$} & \multirow{2}{*}{ Results Indicator } & \multirow{2}{*}{$\begin{array}{l}\text { Baseline } \\
2007\end{array}$} & \multicolumn{4}{|c|}{ GOALS } & \multirow{2}{*}{$\begin{array}{l}\text { Institution } \\
\text { Responsible }\end{array}$} \\
\hline & & & 2008 & 2009 & 2010 & 2011 & \\
\hline & $\begin{array}{l}\% \text { of families affected by } \\
\text { natural disasters that } \\
\text { receive solidary attention }\end{array}$ & 80 & 90 & 95 & 100 & 100 & SINAPRED \\
\hline \multicolumn{8}{|c|}{ DEVELOPMENT OF THE CARIBBEAN COAST } \\
\hline 1) Reduce illiteracy. & $\begin{array}{l}\text { Illiteracy rate for people } \\
\text { that are } 10 \text { years of age } \\
\text { or older }\end{array}$ & 28.6 & 20.4 & 6.4 & 3.8 & 1.2 & MINED \\
\hline $\begin{array}{l}\text { 2) Assure the right to } \\
\text { property }\end{array}$ & $\begin{array}{|lr|}\text { Number of indigenous } \\
\text { and Afro-descendent } \\
\text { territories } r \text { and } \\
\text { complementary areas } \\
\text { demarcated and titled } \\
\end{array}$ & 5 & 2 & 3 & - & - & $\begin{array}{l}\text { Property } \\
\text { Adminis- } \\
\text { tration Office/ } \\
\text { SDCC }\end{array}$ \\
\hline \multirow[b]{2}{*}{$\begin{array}{l}\text { 3) Develop economi } \\
\text { transformation that } \\
\text { equitable, sustainabl } \\
\text { and harmoniou } \\
\text { between human being } \\
\text { and nature. }\end{array}$} & $\begin{array}{l}\% \text { increase in access to } \\
\text { electricity services }\end{array}$ & - & 25.0 & 35.0 & & 40.0 & SDCC \\
\hline & $\begin{array}{|lr|}\text { Number of families } \\
\text { productively } \\
\text { rehabilitated living in } \\
\text { indigenous and Afro- } \\
\text { descendent territories } \\
\text { and the r most } \\
\text { impoverished } & \\
\text { municipalities } & \\
\end{array}$ & 4,135 & 3,125 & - & - & 2,740 & SDCC \\
\hline $\begin{array}{l}\text { 4) Strengthen } \\
\text { autonomous } \\
\text { institutional } \\
\text { development. }\end{array}$ & $\begin{array}{l}\text { Formulation an } \\
\text { implementation } \\
\text { expanded multi-yea } \\
\text { planning and budget that } \mathrm{i} \\
80 \% \text { aligned and it } \\
\text { harmony with th } \\
\text { Development Plan of th } \\
\text { Caribbean Coast by 2011 }\end{array}$ & $\begin{array}{c}\text { Allocation of } \\
\text { task by } \\
\text { MHCP-AN }\end{array}$ & $\begin{array}{c}\text { Regional } \\
\text { MPMM } \\
\text { formulated }\end{array}$ & $\begin{array}{c}\text { Regional } \\
\text { MPMM } \\
\text { formulated } \\
\text { that } \\
\text { integrates a } \\
\text { least two } \\
\text { sectors to b } \\
\text { regiona- } \\
\text { lized }\end{array}$ & & $\begin{array}{c}\text { Regional } \\
\text { MPMM } \\
\text { formulated } \\
\text { that } \\
\text { integrates } \\
\text { at least } \\
\text { four } \\
\text { sectors to } \\
\text { be regiona- } \\
\text { lized } \\
\end{array}$ & SDCC \\
\hline \multicolumn{8}{|c|}{ ACTIONS FOR GOOD PUBLIC ADMINISTRATION } \\
\hline $\begin{array}{lr}\text { 1) } & \text { Foster } \\
\text { transparency } & \text { and } \\
\text { integrity in } & \text { public } \\
\text { administration. } & \\
\end{array}$ & \begin{tabular}{|l|l|} 
Number of State \\
institutions that have \\
offices that provide \\
public information to \\
citizens
\end{tabular} & - & 8 & 15 & 30 & 48 & SEPRES \\
\hline \multirow{3}{*}{$\begin{array}{l}\text { 2) Strengthen public } \\
\text { administration. }\end{array}$} & $\begin{array}{l}\text { Number of accredited } \\
\text { public servants }\end{array}$ & 7,620 & 3,500 & 2,500 & 2,500 & 2,000 & $\begin{array}{l}\text { MHCP/ } \\
\text { DGFUP }\end{array}$ \\
\hline & \begin{tabular}{|l|} 
Budgetary entities \\
implementing MTBF
\end{tabular} & 18 & 25 & 33 & 45 & & МHCP \\
\hline & Audit of PGR & $\begin{array}{l}2006 \text { Audit } \\
\text { of PGR } \\
\text { presented }\end{array}$ & $\begin{array}{c}2007 \\
\text { Audit of } \\
\text { PGR } \\
\text { presented }\end{array}$ & \begin{tabular}{|c|}
2008 \\
Audit of \\
PGR is \\
presented
\end{tabular} & $\begin{array}{c}2009 \\
\text { Audit of } \\
\text { PGR is } \\
\text { presented }\end{array}$ & $\begin{array}{c}2010 \\
\text { Audit of } \\
\text { PGR is } \\
\text { presented }\end{array}$ & CGR/MHCP \\
\hline
\end{tabular}




\begin{tabular}{|c|c|c|c|c|c|c|c|}
\hline \multirow{4}{*}{$\begin{array}{c}\text { Perspective / } \\
\text { Strategic Objective }\end{array}$} & \multirow{2}{*}{ Results Indicator } & \multirow{2}{*}{$\begin{array}{l}\text { Baseline } \\
2007\end{array}$} & \multicolumn{4}{|c|}{ GOALS } & \multirow{2}{*}{$\begin{array}{l}\text { Institution } \\
\text { Responsible }\end{array}$} \\
\hline & & & 2008 & 2009 & 2010 & 2011 & \\
\hline & $\begin{array}{l}\text { Number of entities and } \\
\text { organizations of the } \\
\text { central public } \\
\text { administration that } \\
\text { publish key phases of the } \\
\text { contracting procedures in } \\
\text { ther portal: } \\
\text { www.nicaraguacompra.g } \\
\text { ob.ni }\end{array}$ & 14 & 32 & 50 & 60 & 70 & $\begin{array}{l}\mathrm{MHCP} / \\
\mathrm{DGCE}\end{array}$ \\
\hline & $\begin{array}{l}\% \text { of non-financial } \\
\text { public sector institutions } \\
\text { that maintain the } \\
\text { SIGRUN up-to-date to } \\
\text { support presidential } \\
\text { decision-making }\end{array}$ & - & 17.8 & 80.3 & 92.8 & 100 & SEPRES \\
\hline $\begin{array}{l}\text { 3) Ensure citizen } \\
\text { security. }\end{array}$ & $\begin{array}{l}\% \text { of deceleration of the } \\
\text { crime rate relative to the } \\
\text { demographic crime index }\end{array}$ & 11.0 & 6.0 & 6.0 & 5.0 & 5.0 & $\begin{array}{l}\text { National } \\
\text { Police } \\
\text { /MINGOB }\end{array}$ \\
\hline \multirow{2}{*}{$\begin{array}{l}\text { 4) Ensure the right to } \\
\text { property. }\end{array}$} & $\begin{array}{l}\text { Number of property titles } \\
\text { issued by the } \\
\text { government }\end{array}$ & 8,904 & 19,355 & 19,000 & 19,000 & 14,500 & $\begin{array}{l}\text { Property } \\
\text { Adminis- } \\
\text { tration Office } \\
\end{array}$ \\
\hline & $\begin{array}{l}\text { Number of beneficiaries } \\
\text { with property documents } \\
\text { issued }\end{array}$ & 40,068 & 87,097 & 90,013 & 90,000 & 69,750 & $\begin{array}{l}\text { Property } \\
\text { Adminis- } \\
\text { tration Office }\end{array}$ \\
\hline
\end{tabular}

1/: Sources: the rate for the base year of 2007 is calculated according to the consumption method for measuring the level of extreme poverty in the 2005 Living Standards Measurement Survey (LSMS-05). This estimate was made by using the regression method, with support from WB experts and based on studies conducted by this institution which conclude that the elasticity of reduction of extreme poverty, given growth in per capita income, is -2.4. In other words, with a $1.0 \%$ growth in per capita income, the rate of extreme poverty would decrease $2.4 \%$. If this is applied to the initial extreme poverty population of $17.2 \%$, with a growth in per capita income of $1.8 \%$ for 2007 , it is anticipated that extreme poverty will decrease by $4.32 \%$ of that universe, reaching $16.4 \%$. Following the same method for subsequent years and using the same per capita growth hypothesis, the population living in extreme poverty in 2011 will be $16.2 \%$.

2/: These rates differ from the per capita GDP growth rates published by the BCN because those are based on nominal GDP and the figures presented in this framework are based on real GDP, which harmonizes the behavior of the annual variation rate of the real GDP and the variation rate of the annual per capita GDP.

3/: The updated budget is understood to be the Expenditure Budget of the Central Government, updated with the latest reforms and modifications at the time the indicator is calculated.

4/: This calculation will take into account the level of fulfillment of the schedule of external resources, understood as loans and grants.

5/: Only gross capital formation is included in this calculation.

6/: Due to the inclusion of the power contribution made by the Hugo Chávez plants that came on line in 2007 with an effective capacity of $45 \mathrm{MWe}$, a figure that differs from the information in Table 6 "2008-2017 Generation Expansion Plan".

7/: Source: MAGFOR and MIFIC, based on the real variation of gross production (base year for prices: 1994) and the BCN. 


\section{CHAPTER VI. IMPACT OF THE INTERNATIONAL ECONOMIC CRISIS, BUDGET FRAMEWORK AND FINANCING STRATEGY}

260. The public sector budget framework expresses government capability to operate the state by efficiently allocating resources obtained through various routes, in the context the international economic and financial crisis. This crisis is the major reason for the need to update the NHDP summary and its impact is described in section 6.1. In this setting, the government seeks a budgetary balance that enables it to face a high degree of rigidity due to legally required expenditures, the resistance to paying taxes by sectors benefiting from preferential tax policies, and its social commitment to reduce poverty.

261. In the struggle to maintain fiscal discipline in a framework of low inflation, the Government of Reconciliation and National Unity has introduced structural reforms to reduce the costs of public administration. Nevertheless, the public sector as a whole still faces significant financial imbalances which force it to constantly take corrective measures to maintain the fiscal balance at manageable levels. This process attempts to reduce the quasi-fiscal losses of the Central Bank, the operational deficits of public enterprises, and the persistent central government deficit. In this same context, the effects of social security on the public sector budget are also of great concern.

262. In this context, the budget framework and the financial strategy in the updated NHDP summary contain a factor for macro-stability and a factor for sector-wide growth according to the priorities established by the poverty reduction strategy. The stability factor is related to the capacity of the Nicaragua Central Bank to guarantee a level of international reserves consistent with the monetary base and availability to assist commercial banks in addressing the international financial crisis, if necessary. It is also important to maintain inflation at one-digit rates. Stability regarding the rate of exchange is a central objective. Therefore, the Central Bank has sought contingency financing mechanisms to create conditions of trust and stability in the system ${ }^{22 .}$ The macro-stability factor is addressed in the section on monetary policy.

263. This chapter addresses the changes in the budget framework that are necessary due to the magnitude of the effects of the international economic and financial crisis on public sector revenue. To provide a comprehensive analysis, the effects on the production structure of the country have been calculated, followed by an assessment of the effects on the revenue structure of the central government, given its high elasticity in the economy. Also, an analysis was conducted of the decrease in external resources due to extra-economic factors not associated with the international financial crisis. The second step involved evaluation of the expenditure policy of the government, forcing a new order of priorities and a financial strategy to close the resources gap and the resulting fiscal gap for the 2009-2011 period. The timely results of the second and third reviews of the Economic and Financial Program (EFP) conducted by the IMF and the government (July to September 2009) made it possible to quantify the financial effects of the crisis and other internal factors on the government's income and expenditure budget.

\footnotetext{
22 In April 2009, the Board of Directors of CABEI approved a contingency loan for US\$200 million; US\$100 million of this will be at the disposal of the Deposit Guaranty Fund (FOGADE), if necessary.
} 


\subsection{Impact of the international economic crisis and changes in the macroeconomic context}

264. The macroeconomic context envisioned during the preparation of the EFP in 2007, with which the Sandinista Front began its new administration, has changed substantially as a result of various adverse factors. As mentioned throughout this document, the government had to face an historic increase in the price of oil on the international market which raised the inflation rate to two digits in 2008, affecting the costs of production and infrastructure projects, thereby decelerating the economic growth rate.

265. In 2009 , the economy was much more fragile, in the face of the international economic and financial crisis that affects the developed economies. The effect has been more direct and profound in volume as opposed to prices, the reverse of what had occurred in the previous period. This time, the economic base for taxes has deteriorated at an accelerated rate due to several mechanisms through which the financial crisis is transmitted. Thus, the economy, which was expected to grow at an average annual rate of $5.0 \%$ during 2009-2011, is now expected to grow by an average annual rate of $0.8 \%$ for this period, with an estimated drop of $1.0 \%$ for 2009 . Foreign trade, consumption, family remittances and direct foreign investment have been affected more than expected as the crisis is prolonged and does not have an easy solution. This has also severely decreased the volume of revenue collected by the government. This lower volume of taxes is the response of an economy that is smaller than was thought before the onset of the international economic and financial crisis.

266. The loss of productive dynamism in the Nicaraguan economy has led to a prolonged recession that will dominate the next three years and will last for many more years after that in relation to the goals that were projected before the crisis. It is estimated, in nominal terms, that the loss of the gross domestic product for the 2009-2011 period alone will be of approximately US $\$ 4.8$ billion, with the average growth rate decreasing from a projected $5.0 \%$ for $2009-11$ before the crisis to an annual average $0.8 \%$ in the new context. The contraction of foreign demand, the lower credit capacity of international markets and the effect of unemployment on the economies affected directly by this phenomenon have generated and will continue to generate a contraction of liquidity in the national economy of unprecedented dimensions.

267. In nominal terms, the losses estimated for the 2009-2011 period as concerns primary activities are US $\$ 897$ million, US $\$ 1.073$ billion for secondary activities, and US\$2.375 billion for tertiary activities. It is estimated that public and private consumption will contract by US\$5.192 billion due to decreased demand for internal and imported goods and services; gross public and private investment will fall by US $\$ 2.509$ billion; losses in exports are expected to reach US $\$ 1.999$ billion and will be a US $\$ 4.884$ billion decrease in imports. The cumulative loss in nominal GDP is estimated at US\$4.8 billion for 2009 to 2011, which represents $75.6 \%$ of the GDP obtained in 2008 and is 3.23 times exports for 2008 .

268. The impact of the international economic and financial crisis is such that nominal GDP projected for 2011 is barely $88.9 \%$ of the nominal GDP projected for 2009 before the crisis and is $75 \%$ of nominal GDP projected for 2011 before the crisis. This is evident in the cumulative growth rate for 2009-2011 which was $15.3 \%$ before the crisis. Now the cumulative growth rate will only be $2.5 \%$, resulting in a cumulative loss in economic growth of $-12.8 \%$. This means that it will first take many years to regain that $12.8 \%$ of cumulative loss in economic growth before recovering the nominal GDP levels projected for 2011 prior to the crisis (see Table 7). 


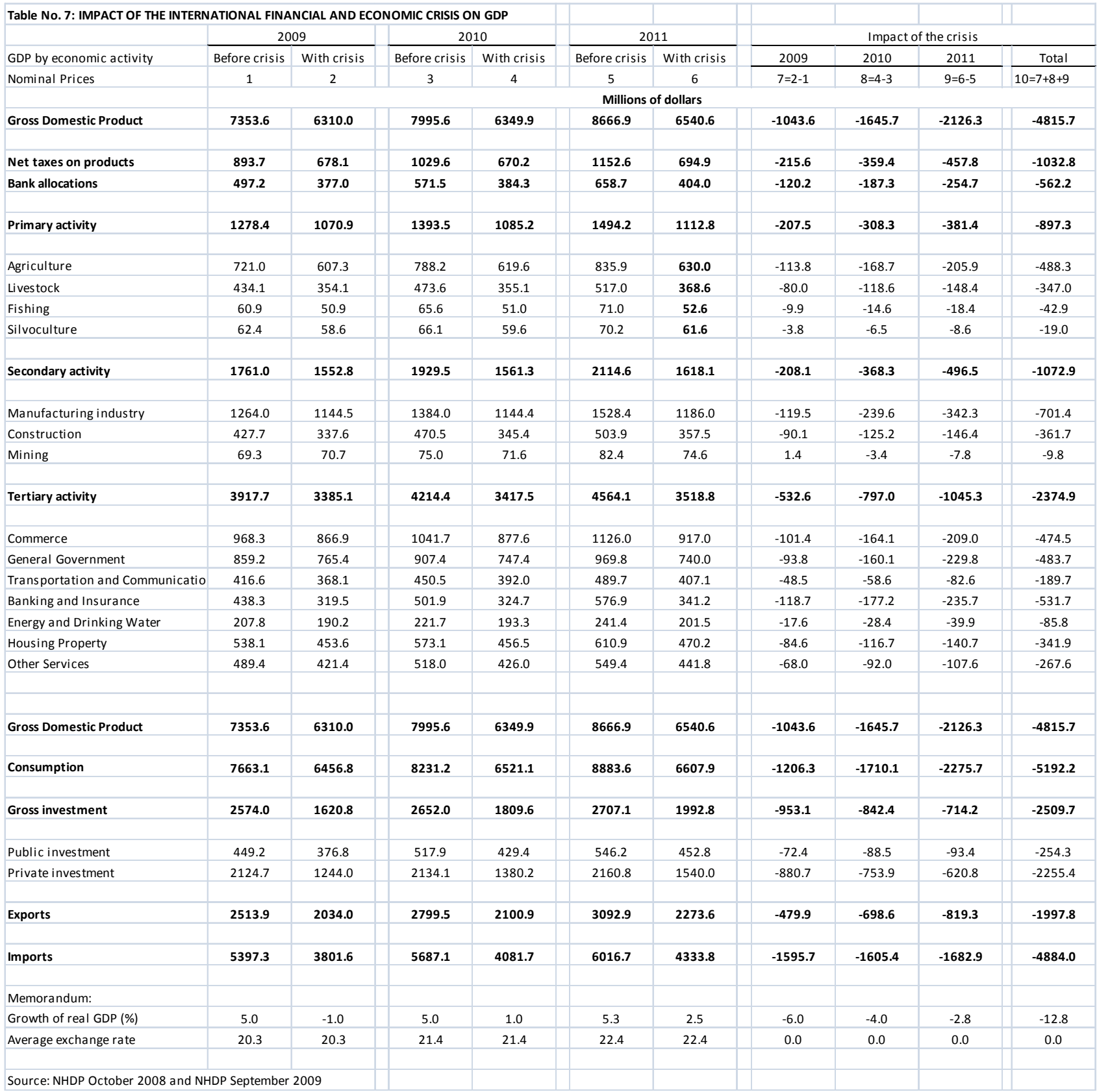

\subsection{Budget framework 2009-2011}

269. The budget framework agreed upon by the government and the IMF and contained in the 2007 EFP, was adjusted in all regards due to the international economic and financial crisis and other extra-economic factors that contributed to the deterioration of public finances. This review has included the adjusted outlooks for the international economy, particularly those factors that most affect the Nicaraguan economy; the evaluation of performance and trends in the economy from 2007 to June 2009, including an evaluation of the impact of the international economic and financial crisis; the budgetary reforms introduced at the beginning of the year; the crisis program implemented by the government at the beginning of 2009; the second budgetary reform; and the projected third budgetary reform. A new macroeconomic framework and financial profile for the 
EFP have emerged from the above, as part of the second and third reviews of the program conducted by GRUN and the IMF. With this input, the government has reformulated the fiscal framework for 2009-2011 and has defined a strategy to close the budgetary gap caused by these changes, as discussed in this chapter.

270. The structure of the budget framework that served as the basis for the goals of GRUN's social programs was affected by three major factors. The first relates to the drop in fiscal revenue as an effect of the decrease in the economic base and the increase in tax arrears due to lack of liquidity in the private sector. The second factor is the increase in costs with inflation above the rates projected, reducing the buying power of income and increasing the cost of consumption and of investment projects. The third factor is associated with decreased spending as a consequence of the drop in tax revenue, the suspension of budgetary support by the BSG, and delayed disbursements from some multilateral organizations, mainly affecting social expenditures and investment in infrastructure.

271. The budgetary evaluation has revealed that revenue for the central government will decrease by more than $21.5 \%$ of GDP for the 2009 to 2011 period. It is estimated the income of the central government will decrease by US\$1.3838 billion as a result of effects associated with the international economic and financial crisis and extra-economic internal factors. This abrupt drop in revenue forced GRUN to take new measures to maintain fiscal discipline that is consistent with the goals for inflation and to close gaps, while causing the least damage possible to social programs. Both political aspects and financial strategy have been subjects of the EFP review that the IMF and the government have conducted.

272. The budget line most affected by the international economic and financial situation is tax revenues. Lower volumes of imports and private consumption, essential sources of indirect taxes, will cause severe decreases in the collection of these taxes. Less economic activity and employment will halt the previously rising trend in income tax revenue collection. It is estimated that the government tax revenue will decrease US\$897.4 million for the period as a result of the crisis. The high elasticity of taxes relative to the GDP growth rate makes it so this income falls at the same rate.

273. The combination of these factors has reduced the external supply of resources by $6.2 \%$ of the GDP, including loans and grants to finance social programs and public investment. It is estimated that the decrease in external resources for the 2009-2011 period will be US\$403.1 million, compared to the budget framework projected before the crisis. Of these resources, it is anticipated that donations will fall US\$388.1 million, of which US\$188.4 million were free availability funds. The pace of loan disbursements remains manageable; this is due mainly to the accumulation of loans yet to be disbursed, rather than new assistance from donors.

\subsection{Financial strategy: closing the gap}

274. The Government of Reconciliation and National Unity has determined that it is not possible to adjust public spending on an equal basis with the forecast reduction of income. However, it will be necessary to make the corresponding adjustments due to the decrease in external resources that are generally tied to projects. As the outside restriction on obtaining liquid resources prevents compensating for the fall in tax revenue, the government has taken a series of measures to reduce spending, revise tax policy and take on internal debt. 
275. Nevertheless, the government wishes to persevere in negotiations with international organizations in order to mitigate the effects of this crisis. This is in line with internal market constraints for providing the liquidity needed by the government to cover the gap, but also due to the onerous nature of this type of indebtedness, which GRUN does not wish to incur. However, as a temporary measure, the government may place treasury bonds at up to $21.2 \%$ of the amount of the reduction of tax revenue. The remainder must come from a reduction in spending, of which $37.0 \%$ will be associated with the decrease in foreign grants and loans. The rest will be covered by fiscal containment measures on lower priority spending. Despite the above, spending will continue to reflect great dependency on external resources. It is estimated that this coefficient will be approximately $23.6 \%$ for this period.

276. At the specific level of central government spending for 2009 to 2011 , there will be an automatic adjustment due to the reduction in external resources. It is estimated that the spending allocated to gross capital formation will be reduced by US\$265.9 million, which is explained by the decrease of US\$320.3 million in external loans and grants tied to projects; the difference corresponds to adjustments in capital spending that is not related to infrastructure. Ordinary spending also will be affected by those external liquid resources directed at social programs and other ordinary spending categories, including the donations from the Budget Support Group (BSG). The net decrease of these resources, including loans and grants, will be US\$82.7 million, which will almost account for the $15.6 \%$ total drop in ordinary spending. The above reflects the serious vulnerability of Nicaragua's budget framework due to its acute dependency on foreign savings.

277. The government also will take measures to reduce ordinary spending not associated with social programs. It should be clarified that there is an automatic spending adjustment linked to the level of income, defined by the Constitution or by specific legal provisions for certain sectors. The abrupt drop in income altered the way in which transfers to municipalities, universities, the Supreme Court of Justice and others are calculated. It is estimated that ordinary and capital transfers will be reduced by US\$377.4 million compared to the original program. GRUN also has scheduled complementary measures to reduce operating expenditures and decelerate the salary burden through a freeze on hiring for open positions and lower salary increases. As a result of these measures, current government expenditures will also be lower than the amount calculated before the crisis, with an estimated reduction of US\$531.3 million.

278. In the execution of the GRUN economic program during 2008 it is important to highlight the renegotiation of the internal debt associated with the banking crisis and the issuance of bonds by the $\mathrm{BCN}$, which made it possible to free up US\$43 million from the national budget for that same year, and allocate resources to increase spending on social programs, energy, transportation, reconstruction of infrastructure and other areas. The renegotiation extended the financing term for this debt to 20 years and reduced the interest rate from 8.3 to $5.0 \%$ during the first 10 years and to $5.5 \%$ for the remaining 10 years. Thus, the government will make smaller payments internal debt service payments for the 2009-2011 period. It is calculated that this amortization level constitutes a reduction of US\$67.9 million compared to the figure forecast in the EFP and NHDP before the international economic crisis.

279. This combination of measures will enable the government to ensure the stability of the economy, reduce impact on the social sectors and remain within the margins of a sustainable fiscal debt during this period of crisis. The government has determined that this budget scenario will improve with the availability of extraordinary financing for developing countries and poor countries 
affected by the crisis, as announced by international bodies and the Group of 20 (G-20). In this context, the IMF granted Nicaragua US\$164.3 million (equivalent to SDR105.1 million ${ }^{23}$ ) as part of the multilateral financial support fostered by the G-20 in order to strengthen the international reserves of the member countries. At the request of Nicaragua, the Inter-American Development Bank (IADB) is seeking disbursement mechanisms for US\$300.0 million over and above the offer that this body made for the same purpose, and the World Bank has announced increases in cooperation for production and social programs, which all depend upon bureaucratic procedures. To the extent that these resources become available, the fiscal gap can be covered without resorting to excessive internal debt, while invigorating the Public Investment Program and protecting social spending (see Table 8).

Table No. 8- NICARAGUA: Central Government Resource Gap 2009-2011

\begin{tabular}{|c|c|c|c|c|c|c|c|c|c|c|}
\hline \multirow{3}{*}{ Source and Uses } & \multicolumn{2}{|c|}{2009} & \multicolumn{2}{|c|}{2010} & \multicolumn{2}{|c|}{2011} & \multicolumn{4}{|c|}{ Resource Gap ${ }^{1}$} \\
\hline & $\begin{array}{c}\text { Budget } \\
\text { Before/Crisis }\end{array}$ & $\begin{array}{c}\text { Budget } \\
\text { with/Crisis }\end{array}$ & $\begin{array}{c}\text { Budget } \\
\text { Before/Crisis }\end{array}$ & $\begin{array}{c}\text { Budget } \\
\text { with/Crisis }\end{array}$ & $\begin{array}{c}\text { Budget } \\
\text { Before/Crisis }\end{array}$ & $\begin{array}{c}\text { Budget } \\
\text { with/Crisis }\end{array}$ & 2009 & 2010 & 2011 & Total \\
\hline & 1 & 2 & 3 & 4 & 5 & 6 & $7=2-1$ & $8=4-3$ & $9=6-5$ & $10=7+8+9$ \\
\hline & \multicolumn{10}{|c|}{ Millions of dollars } \\
\hline TOTAL INCOME & $\underline{1,880.3}$ & $\underline{1,578.8}$ & $\underline{2,045.7}$ & $\underline{1,558.7}$ & $\underline{2,207.8}$ & $\underline{1,612.5}$ & $\underline{-301.4}$ & -487.0 & $\underline{-595.3}$ & $\underline{-1,383.8}$ \\
\hline (in relation to GDP) & $\underline{25.6}$ & $\underline{25.0}$ & $\underline{25.6}$ & $\underline{24.5}$ & $\underline{25.5}$ & $\underline{24.6}$ & $\underline{-4.8}$ & $\underline{-7.7}$ & $\underline{-9.1}$ & $\underline{-21.5}$ \\
\hline Current income & $\underline{1,384.8}$ & $\underline{1,132.2}$ & $\underline{1,503.2}$ & $\underline{1,180.5}$ & $\underline{1,629.4}$ & $\underline{1,223.9}$ & $\underline{-252.5}$ & $\underline{-322.7}$ & -405.5 & $\underline{-980.7}$ \\
\hline (in relation to GDP) & $\underline{18.8}$ & $\underline{17.9}$ & $\underline{18.8}$ & $\underline{18.6}$ & $\underline{18.8}$ & $\underline{18.6}$ & -4.0 & $\underline{-5.1}$ & $\underline{-6.2}$ & $\underline{-15.3}$ \\
\hline Tax revenue & $1,273.2$ & $1,041.5$ & $1,382.1$ & $1,088.8$ & $1,500.5$ & $1,128.1$ & -231.7 & -293.3 & -372.5 & -897.4 \\
\hline Non-tax revenue & 95.4 & 82.3 & 104.4 & 83.6 & 111.6 & 87.0 & -13.1 & -20.8 & -24.6 & -58.5 \\
\hline Property tax revenue & 10.0 & 2.3 & 10.8 & 2.3 & 11.7 & 2.4 & -7.8 & -8.6 & -9.4 & -25.7 \\
\hline Current transfers & 6.2 & 6.2 & 5.8 & 5.8 & 5.6 & 6.5 & 0.0 & 0.0 & 0.9 & 0.9 \\
\hline$\underline{\text { External income }}$ & $\underline{495.5}$ & $\underline{446.6}$ & $\underline{542.5}$ & $\underline{378.2}$ & $\underline{578.5}$ & $\underline{388.6}$ & -48.9 & $\underline{-164.3}$ & $\underline{-189.9}$ & -403.1 \\
\hline Loans & 248.3 & 280.0 & 253.2 & 234.5 & 271.2 & 243.2 & 31.7 & -18.7 & -28.0 & -15.0 \\
\hline Liquid & 40.0 & 91.8 & 40.0 & 63.5 & 39.6 & 70.0 & 51.8 & 23.5 & 30.4 & 105.7 \\
\hline Tied & 208.3 & 188.2 & 213.2 & 171.0 & 231.6 & 173.2 & -20.1 & -42.2 & -58.4 & -120.7 \\
\hline Grants & 247.2 & 166.6 & 289.3 & 143.6 & 307.2 & 145.4 & -80.6 & -145.6 & -161.8 & -388.1 \\
\hline Liquid & 63.0 & 0.0 & 63.0 & 0.0 & 62.4 & 0.0 & -63.0 & -63.0 & -62.4 & -188.4 \\
\hline Tied & 184.2 & 166.6 & 226.3 & 143.6 & 244.8 & 145.4 & -17.6 & -82.6 & -99.4 & -199.6 \\
\hline TOTAL EXPENDITURES & $\underline{1,910.3}$ & $\underline{1,696.8}$ & $\underline{2,075.7}$ & $\underline{1,688.1}$ & $\underline{2,257.4}$ & $\underline{1,767.5}$ & $\underline{-213.4}$ & $\underline{-387.6}$ & -489.9 & $\underline{-1,090.9}$ \\
\hline (in relation to GDP) & $\underline{26.0}$ & $\underline{26.9}$ & $\underline{26.0}$ & $\underline{26.6}$ & $\underline{26.0}$ & $\underline{26.9}$ & $\underline{-3.4}$ & $\underline{-6.1}$ & $\underline{-7.5}$ & $\underline{-16.9}$ \\
\hline Above the line expenditures & $\underline{1,674.2}$ & $\underline{1,531.7}$ & $\underline{1,819.9}$ & $\underline{1,453.0}$ & $\underline{2,018.1}$ & $\underline{1,530.5}$ & $\underline{-142.5}$ & $\underline{-366.9}$ & -487.6 & $\underline{-997.1}$ \\
\hline (in relation to GDP) & $\underline{22.8}$ & $\underline{24.3}$ & $\underline{22.8}$ & $\underline{22.9}$ & $\underline{23.3}$ & $\underline{23.3}$ & $\underline{-2.3}$ & $\underline{-5.8}$ & -7.4 & $\underline{-15.5}$ \\
\hline Current expenditures & $1,216.4$ & $1,154.0$ & $1,283.0$ & $1,086.5$ & $1,427.3$ & $1,154.9$ & -62.4 & -196.5 & -272.4 & -531.3 \\
\hline Salaries and wages & 439.7 & 429.2 & 471.3 & 427.2 & 504.3 & 437.5 & -10.5 & -44.1 & -66.8 & -121.4 \\
\hline Goods and services & 290.3 & 252.8 & 297.4 & 223.1 & 363.7 & 259.9 & -37.6 & -74.4 & -103.8 & -215.7 \\
\hline Interest & 90.2 & 89.5 & 96.3 & 90.3 & 95.6 & 94.2 & -0.7 & -6.0 & -1.3 & -7.9 \\
\hline Transfers & 396.2 & 382.5 & 417.9 & 345.9 & 463.7 & 363.2 & -13.7 & -72.0 & -100.5 & -186.2 \\
\hline Capital expenditures & 457.8 & 377.7 & 536.9 & 366.5 & 590.8 & 375.6 & -80.1 & -170.4 & -215.2 & -465.7 \\
\hline Fixed capital formation & 209.9 & 187.2 & 268.9 & 165.7 & 310.9 & 171.0 & -22.7 & -103.2 & -140.0 & -265.9 \\
\hline Transfers & 234.9 & 188.6 & 268.0 & 199.6 & 279.9 & 203.4 & -46.3 & -68.4 & -76.4 & -191.2 \\
\hline Others & 13.0 & 1.9 & 0.0 & 1.2 & 0.0 & 1.2 & -11.1 & 1.2 & 1.2 & -8.7 \\
\hline Debt payment & 179.8 & 165.3 & 206.0 & 185.2 & 204.2 & 185.3 & -14.5 & -20.8 & -18.9 & -54.3 \\
\hline Foreign & 45.2 & 46.4 & 47.1 & 47.5 & 34.2 & 43.3 & 1.2 & 0.4 & 9.1 & 10.7 \\
\hline Domestic & 134.6 & 118.8 & 159.0 & 137.7 & 170.0 & 142.0 & -15.7 & -21.3 & -28.0 & -65.0 \\
\hline Transfers to $\mathrm{BCN}$ & 48.9 & -0.2 & 49.7 & 49.9 & 35.1 & 51.8 & -49.1 & 0.2 & 16.7 & -32.2 \\
\hline Others & 7.4 & 0.1 & 0.0 & 0.0 & 0.0 & 0.0 & -7.3 & 0.0 & 0.0 & -7.3 \\
\hline FISCAL GAP $^{2}$ & $\underline{-30.0}$ & $\underline{-118.0}$ & $\underline{-30.0}$ & $\underline{-129.4}$ & $\underline{-49.6}$ & $\underline{-155.0}$ & $\underline{-88.0}$ & $\underline{-99.4}$ & $\underline{-105.4}$ & $\underline{-292.8}$ \\
\hline (in relation to GDP) & $\underline{-0.4}$ & $\underline{-1.9}$ & $\underline{-0.4}$ & $\underline{-2.0}$ & $\underline{-0.6}$ & $\underline{-2.4}$ & $\underline{-1.4}$ & $\underline{-1.6}$ & $\underline{-1.6}$ & $\underline{-4.6}$ \\
\hline Placement of Treasury Bonds & 30.0 & 118.0 & 30.0 & 129.4 & 49.6 & 155.0 & 88.0 & 99.4 & 105.4 & 292.8 \\
\hline \multicolumn{11}{|l|}{ Memorandum: } \\
\hline Real GDP growth (\%) & 5.0 & -1.0 & 5.0 & 1.0 & 5.3 & 2.5 & -6.0 & -4.0 & -2.8 & -12.8 \\
\hline Nominal GDP (Millions C\$) & $149,278.0$ & $128,092.3$ & $171,105.0$ & $135,887.6$ & $194,139.0$ & $147,104.8$ & $-21,185.7$ & $-35,217.4$ & $-47,034.2$ & $-103,437.3$ \\
\hline Nominal GDP (Millions US\$) & $7,353.6$ & $6,310.0$ & $7,995.6$ & $6,349.9$ & $8,666.9$ & $6,567.2$ & $-1,043.6$ & $-1,645.7$ & $-2,099.7$ & $-4,789.0$ \\
\hline Average exchange rate & 20.3 & 20.3 & 21.4 & 21.4 & 22.4 & 22.4 & 0.0 & 0.0 & 0.0 & 0.0 \\
\hline
\end{tabular}

\footnotetext{
${ }^{23}$ Special Drawing Rights (SDR) are reserve assets created by the IMF and are comprised of a basket of international currencies including the U.S. dollar, the euro, the pound sterling and the Japanese yen.
} 


\subsection{Prioritized sectors}

\section{Social expenditures}

280. Despite GRUN efforts, social expenditures have been affected to an undesirable extent, although it is anticipated that they will remain at the same proportion relative to GDP and total budget expenditures. During 2009-2011, it is estimated that social spending will decrease by $8.6 \%$ of GDP (US\$555.2 million) relative to the resources projected in the EFP framework and the NHDP. The government has prioritized the programs that are most important to the population living in poverty, such as food programs, transportation subsidies, electricity and other social services. Nevertheless, the burden of the adjustment has fallen on the education, health and housing sectors, given the volume of resources that these areas absorb from the budget. This situation would have been worse had the government not programmed cuts in the complementary operations spending equivalent to $6.9 \%$ of GDP (US\$441.8 million) and issued treasury bonds on the market for $4.6 \%$ of GDP (US\$292.8 million).

281. It should be mentioned that the affect of the budget crisis on each sector depends upon the structure of its financing. Sectors that are highly dependent on external funding are more vulnerable to decreases of international liquidity and its effects on the supply of concessionary resources, or in the face of internal factors that cause the suspension of foreign cooperation. The government does not have the savings capacity to replace these resources. By contrast, those sectors that depend upon internal financing are more flexible and have more room to maneuver to readjust funding to areas of greater priority during the crisis. Nevertheless, it is clear that sectors (institutions) that traditionally absorb the greatest budgetary allocation are those that will suffer most from the adjustments.

282. The concentration of resources in certain sectors makes them more vulnerable when there are spending cuts. For example, it is estimated that education (MINED), health (MINSA) and infrastructure (MTI) traditionally absorb $40.0 \%$ of the expenditure budget. A review of their dependence on resources shows that these three sectors demand $47.5 \%$ of all external resources that are budgeted each year for the central government. This explains in great part why these sectors are the most affected by the automatic spending adjustment.

283. The above is confirmed in the budget analysis that was conducted to define the NHDP financial strategy for 2009-2011. Effectively, funds available for the education and health sectors, which dominate social spending, will be reduced by US\$409.8 million, or $73.8 \%$ of the total adjustment of social spending. It is estimated that $42.1 \%$ is to be allocated for construction of schools and health centers, given their high participation in the budget and the concentration of external resources in these areas, which include budget support resources. This deficiency of resources in sectors closely identified with poverty reduction holds priority over any eventual unexpected flow of resources in this scenario (see Table 9). 
Table No. 9.- NICARAGUA: 2009-2011 Social Expenditures of the Central Government

\begin{tabular}{|c|c|c|c|c|c|c|c|c|c|c|}
\hline \multirow{3}{*}{ Prioritized Sectors } & \multicolumn{2}{|c|}{2009} & \multicolumn{2}{|c|}{2010} & \multicolumn{2}{|c|}{2011} & \multicolumn{4}{|c|}{ Resource Gap } \\
\hline & $\begin{array}{c}\text { Budget } \\
\text { Before/Crisi }\end{array}$ & $\begin{array}{c}\begin{array}{c}\text { Budget } \\
\text { with/Crisis }\end{array} \\
\end{array}$ & $\begin{array}{c}\text { Budget } \\
\text { Before/Crisi }\end{array}$ & $\begin{array}{c}\text { Budget } \\
\text { with/Crisis }\end{array}$ & $\begin{array}{c}\text { Budget } \\
\text { Before/Crisi }\end{array}$ & $\begin{array}{c}\text { Budget } \\
\text { with/Crisis }\end{array}$ & 2009 & 2010 & 2011 & Total \\
\hline & 1 & 2 & 3 & 4 & 5 & 6 & $7=2-1$ & $8=4-3$ & $9=6-5$ & $1=7+8+9$ \\
\hline & \multicolumn{10}{|c|}{ Millions of dollars } \\
\hline${ }_{\text {Total Central Government Expenditures }}^{1}$ & $\underline{1,674.2}$ & $1,531.7$ & $\underline{1,819.9}$ & $\underline{1,453.0}$ & $\underline{2,018.1}$ & $\underline{1,530.5}$ & $\underline{-142.5}$ & $\underline{-366.9}$ & -487.6 & -997.1 \\
\hline (As a percentage of GDP) & 22.8 & 24.3 & 22.8 & 22.9 & 23.3 & 23.3 & -2.3 & -5.8 & -7.4 & -15.5 \\
\hline$\underline{\text { Social Expenditures }}$ & 911.7 & $\underline{834.1}$ & $1,025.9$ & $\underline{819.1}$ & $\underline{1,120.8}$ & $\underline{850.0}$ & $\underline{-77.6}$ & -206.8 & -270.8 & $\underline{-555.2}$ \\
\hline (As a percentage of GDP) & 12.4 & 13.2 & 12.8 & 12.9 & 12.9 & 12.9 & $\underline{-1.2}$ & $\underline{-3.3}$ & -4.1 & $\underline{-8.6}$ \\
\hline Education $^{2}$ & 389.9 & 356.7 & 446.7 & 356.7 & 502.4 & 381.0 & -33.2 & -90.1 & -121.4 & -244.7 \\
\hline Health & 266.6 & 243.9 & 302.5 & 241.5 & 337.2 & 255.8 & -22.7 & -61.0 & -81.4 & -165.1 \\
\hline Social service and assistance & 17.9 & 16.4 & 16.2 & 12.9 & 14.5 & 11.0 & -1.5 & -3.3 & -3.5 & -8.3 \\
\hline Housing and community services & 167.0 & 152.8 & 194.0 & 154.9 & 209.3 & 158.8 & -14.2 & -39.1 & -50.6 & -103.9 \\
\hline Production $^{3}$ & 18.7 & 17.1 & 19.1 & 15.3 & 19.1 & 14.5 & -1.6 & -3.9 & -4.6 & -10.1 \\
\hline Transportation (subsidy) & 7.4 & 6.8 & 7.4 & 5.9 & 7.5 & 5.7 & -0.6 & -1.5 & -1.8 & -3.9 \\
\hline Electric energy (subsidy) & 11.1 & 10.1 & 7.4 & 5.9 & 3.7 & 2.8 & -0.9 & -1.5 & -0.9 & -3.3 \\
\hline Drinking water (transfers) ${ }^{4}$ & 12.6 & 11.6 & 12.4 & 9.9 & 6.2 & 4.7 & -1.1 & -2.5 & -1.5 & -5.1 \\
\hline Regional governments and councils ${ }^{5}$ & 15.9 & 14.5 & 15.5 & 12.3 & 16.0 & 12.1 & -1.3 & -3.1 & -3.9 & -8.3 \\
\hline Other social services ${ }^{6}$ & 22.4 & 20.5 & 20.9 & 16.7 & 19.5 & 14.7 & -1.9 & -4.2 & -4.7 & -10.9 \\
\hline$\underline{\text { Complementary Expenditures }}^{7}$ & 762.6 & $\underline{697.6}$ & 794.0 & $\underline{633.9}$ & $\underline{897.3}$ & $\underline{680.4}$ & $\underline{-64.9}$ & $\underline{-160.1}$ & -216.8 & -441.8 \\
\hline (As a percentage of GDP) & 10.4 & 11.1 & 9.9 & 10.0 & 10.4 & 10.4 & -1.0 & -2.5 & -3.3 & -6.9 \\
\hline \multicolumn{11}{|l|}{ Memorandum: } \\
\hline GDP millions of dollars & 7,353.6 & $6,310.0$ & $7,995.6$ & $6,349.9$ & $8,666.9$ & $6,567.2$ & $-1,043.6$ & $-1,645.7$ & $-2,099.7$ & $-4,789.0$ \\
\hline Social Expenditures / Total Expenditures & 54.5 & 54.5 & 56.4 & 56.4 & 55.5 & 55.5 & 0.0 & 0.0 & 0.0 & 0.0 \\
\hline
\end{tabular}

\section{Gross capital formation}

284. Given the high correlation of capital investment to economic growth and employment, the government has prioritized investment in infrastructure. Since the 2009 crisis program was put into place, the government has prioritized a critical mass of projects that have assured financing and are underway, in order to apply administrative attention and accelerate the implementation of these projects. With the prolongation of the crisis, this initiative will be extended and expanded until 2011 , in order to contribute to reduce the deceleration of the economy.

285. It should be clear that expectations before the crisis included resources to initiate new projects with great economic and social potential. However, the world economic situation has affected this type of funding and has lowered donor interest in large programs. Given the international economic and financial crisis, donors are directing their efforts at projects with a smaller scale and greater focus on generation of employment and social services. Preferential resources for highly-indebted poor countries are scarce and the increase in the costs of projects also has had an impact on lower levels of public investment, particularly as it relates to gross capital formation.

286. In this context, GRUN has prioritized investment in infrastructure directly linked to production and the expansion of basic services. The critical mass of prioritized investment is US $\$ 1.448$ billion, excluding capital expenditures not associated with gross capital formation. This new prioritization is US $\$ 663.0$ million less than the amount originally projected in the medium-term budget framework presented in 2008. Of these resources, $77.3 \%$ correspond to the central government. 
287. The sector-based prioritization shows that the government, even while facing a decrease in resources, will allocate $74.8 \%$ of the resources available to the production and social sectors, including autonomous entities. The latest estimates indicate that the public sector will be able to allocate US\$498.1 million to the social sector, between the central government and autonomous entities, including investment in drinking water, health care, education and housing. This represents $34.4 \%$ of all resources for 2009-2011. For production, which includes investment in highways, roads and electricity, the government has projected expenditures of US\$584.7 million, or $40.4 \%$ of the total available. Nevertheless, together these two sectors will receive US\$578.5 million less than originally projected, between central government and autonomous entities (see Table 10).

Table No. 10.- NICARAGUA: Resource Gap for Gross Capital Formation

\begin{tabular}{|c|c|c|c|c|c|c|c|c|c|}
\hline \multirow{2}{*}{ Description } & \multicolumn{2}{|c|}{2009} & \multicolumn{2}{|c|}{2010} & \multicolumn{2}{|c|}{2011} & \multicolumn{2}{|c|}{ 2009-2011 } & \multirow[b]{2}{*}{ Total } \\
\hline & Before/Cris is & With/Crisis & Before/Cris is & With/Cris is & Before/Cris is & With/Cris is & Before/Cris is & With/Cris is & \\
\hline & \multicolumn{9}{|c|}{ Millions of dollars } \\
\hline$\underline{\text { Total investment }}$ & $\underline{559.1}$ & $\underline{458.5}$ & $\underline{745.8}$ & $\underline{496.0}$ & $\underline{806.1}$ & $\underline{493.5}$ & $\underline{2,111.0}$ & $\underline{1,448.0}$ & $\underline{-663.0}$ \\
\hline (In relation to GDP) & $\underline{7.6}$ & $\underline{7.3}$ & $\underline{9.3}$ & $\underline{7.8}$ & $\underline{9.3}$ & $\underline{7.5}$ & 26.2 & 22.6 & -3.6 \\
\hline Central Government & $\underline{457.8}$ & $\underline{377.7}$ & $\underline{536.9}$ & $\underline{366.5}$ & $\underline{590.8}$ & $\underline{375.6}$ & $\underline{1,585.6}$ & $\underline{1,119.8}$ & -465.7 \\
\hline (In relation to GDP) & $\underline{6.2}$ & $\underline{6.0}$ & $\underline{6.7}$ & $\underline{5.8}$ & $\underline{6.8}$ & $\underline{5.7}$ & 19.8 & 17.5 & -2.3 \\
\hline Social & 125.8 & 104.6 & 205.7 & 102.3 & 220.9 & 121.6 & 552.3 & 328.4 & -223.9 \\
\hline Education & 47.5 & 42.5 & 78.6 & 40.8 & 95.3 & 44.0 & 221.3 & 127.3 & -94.1 \\
\hline Health & 38.5 & 29.2 & 62.3 & 29.4 & 86.1 & 49.7 & 186.9 & 108.3 & -78.6 \\
\hline Drinking water and sanitation & 28.2 & 22.2 & 46.4 & 17.9 & 19.8 & 15.6 & 94.4 & 55.7 & -38.7 \\
\hline Housing & 11.6 & 10.7 & 18.4 & 14.2 & 19.7 & 12.3 & 49.7 & 37.2 & -12.5 \\
\hline Production & 182.8 & 152.4 & 200.6 & 142.1 & 200.1 & 131.6 & 583.6 & 426.2 & -157.4 \\
\hline Transportation \& communication & 152.2 & 127.3 & 175.0 & 122.4 & 176.9 & 110.4 & 504.1 & 360.0 & -144.1 \\
\hline Energy & 16.8 & 20.5 & 14.7 & 16.5 & 13.4 & 13.2 & 45.0 & 50.2 & 5.2 \\
\hline Others & 13.8 & 4.7 & 10.9 & 3.2 & 9.9 & 8.1 & 34.6 & 16.0 & -18.6 \\
\hline $\begin{array}{l}\text { Other infrastructure } \\
\text { Of which: }\end{array}$ & 149.2 & 120.7 & 130.6 & 122.1 & 169.8 & 122.4 & 449.6 & 365.2 & -84.4 \\
\hline Municipal transfers & 86.1 & 74.7 & 103.9 & 89.7 & 112.8 & 94.0 & 302.8 & 258.5 & -44.3 \\
\hline Autonomous Entities & $\underline{101.2}$ & $\underline{80.7}$ & $\underline{208.9}$ & $\underline{129.5}$ & $\underline{215.3}$ & $\underline{117.9}$ & $\underline{525.4}$ & $\underline{328.2}$ & $\underline{-197.2}$ \\
\hline Social & 65.8 & 53.4 & 77.4 & 58.0 & 103.1 & 58.3 & 246.3 & 169.7 & -76.6 \\
\hline Drinking water and sanitation & 65.8 & 53.4 & 77.4 & 58.0 & 103.1 & 58.3 & 246.3 & 169.7 & -76.6 \\
\hline Production & 35.4 & 27.3 & 131.4 & 71.5 & 112.3 & 59.7 & 279.1 & 158.5 & -120.6 \\
\hline Transportation \& communication & 6.8 & 5.0 & 10.1 & 4.3 & 9.8 & 4.2 & 26.7 & 13.5 & -13.2 \\
\hline Energy & 28.6 & 22.3 & 121.4 & 67.2 & 102.4 & 55.5 & 252.4 & 145.0 & -107.4 \\
\hline \multicolumn{10}{|l|}{ Memorandum: } \\
\hline GDP in millions of dollars & $7,353.6$ & $6,310.0$ & $7,995.6$ & $6,349.9$ & $8,666.9$ & $6,567.2$ & $\cdots$ & $\ldots$ & $\cdots$ \\
\hline Average exchange rate & 20.3 & 20.3 & 21.4 & 21.4 & 22.4 & 22.4 & $\ldots$ & $\ldots$ & $\ldots$ \\
\hline
\end{tabular}

Source: SEPRES/SNIP 


\subsection{Financial support: external resources program}

288. The GRUN 2009-2011 crisis strategy is financially supported through a program of disbursements agreed upon with the international community ${ }^{24}$. GRUN has considered the situation regarding the stock of resources pending disbursement, the advanced negotiations for new resources, and the special programs that the multilateral organizations have established for countries affected by the financial crisis. Given the HIPC status of the country, the government has excluded the possibility of acquiring non-concessionary external debt. Furthermore, to develop a disbursement program, GRUN has taken into account the risks of insecurity carried by some resources, as these are conditioned by political parameters demanded by the sources, and it has expressed the need for those resources and is in dialogue with the pertinent agencies, within the spirit of the Paris Agreement and the framework of national sovereignty.

289. GRUN has determined that, given the profound nature of the deceleration of the economy, external resources will be the replacement route that will buffer the impact of the financial crisis on the social sectors. However, GRUN recognizes that, in addition to the effects of the crisis, there are other factors, of a different nature, that may drive the country more urgently toward procuring additional external resources. Thus, GRUN has advised the international community of this possibility in the context of the review of the program with the IMF and the World Bank and through other routes, in an effort to accelerate the support offered by governments and organizations to those countries that are most vulnerable to the world financial and economic crisis.

290. Given the above, the government believes that the next disbursement program should be considered as a baseline scenario that will change as new financing is negotiated and becomes available. The government is accelerating the procurement of rapid disbursement resources, with flexible allocation, and in line with the objectives of the crisis program. The criteria for allocation are identified with the budgetary gaps calculated for each sector and by the urgency of unemployment and the need for social protection of the population with few resources.

291. External support during 2009-2011 will be concentrated mainly among multilateral sources in resources tied to specific purposes, and in loans. This program reflects the lack of resources for budget support, the tendency of donors to award mostly grants tied to projects, and the fragmentation of foreign cooperation. GRUN has estimated the critical mass of external resources at US\$1.6567 billion, signifying $25.6 \%$ of GDP. Eighty-two percent of these resources are tied to the Public Investment Program, amounting to US\$1.3562 billion (20.9 \% of GDP). Some 75.3\% (US\$1.2481 million) of all cooperation comes from multilateral sources and, of that, $75.0 \%$ will be disbursed by the IADB, the World Bank and CABEI. Loans are most prevalent in the structure of the program $(65.3 \%)$, a situation fostered by a lesser flow of donated resources to social projects and budget support. Liquid resources only represent $13.7 \%$ of the total provided by the World Bank and the IADB (see Table 11).

\footnotetext{
${ }^{24}$ The baseline disbursement scenario was agreed upon for the 2009-2011 period in the framework of the second and third reviews of the PRGF with the IMF.
} 
Table No.11.- NICARAGUA: External Financing to the Public Sector-Base Scenario (Disbursement Program)

\begin{tabular}{|c|c|c|c|c|c|c|c|c|c|c|}
\hline \multirow[b]{2}{*}{ Source } & \multicolumn{2}{|c|}{2009} & \multicolumn{2}{|c|}{2010} & \multicolumn{2}{|c|}{2011} & \multicolumn{2}{|c|}{ Annual Average } & \multicolumn{2}{|c|}{ Total 2009-2011 } \\
\hline & $\begin{array}{l}\text { US\$ } \\
\text { Mill. }\end{array}$ & $\begin{array}{c}\% \\
\text { GDP }\end{array}$ & $\begin{array}{l}\text { US\$ } \\
\text { Mill. }\end{array}$ & $\begin{array}{c}\% \\
\text { GDP }\end{array}$ & $\begin{array}{l}\text { US\$ } \\
\text { Mill. }\end{array}$ & $\begin{array}{c}\% \\
\text { GDP }\end{array}$ & $\begin{array}{l}\text { US\$ } \\
\text { Mill. }\end{array}$ & $\begin{array}{c}\% \\
\text { GDP }\end{array}$ & $\begin{array}{l}\text { US\$ } \\
\text { Mill. }\end{array}$ & $\begin{array}{c}\% \\
\text { GDP }\end{array}$ \\
\hline TOTAL RESOURCES & $\underline{560.8}$ & $\underline{8.9}$ & $\underline{556.7}$ & $\underline{8.8}$ & $\underline{521.5}$ & 7.9 & $\underline{546.3}$ & $\underline{8.5}$ & $\underline{1,656.7}$ & $\underline{25.6}$ \\
\hline Multilateral & 430.2 & 6.8 & 431.0 & 6.8 & 373.3 & 5.6 & 411.5 & 6.4 & $1,248.1$ & 19.2 \\
\hline Bilateral & 130.6 & 2.1 & 125.7 & 2.0 & 148.2 & 2.3 & 134.8 & 2.1 & 408.5 & 6.3 \\
\hline Loans & 378.5 & 6.0 & 366.2 & 5.8 & 325.5 & 5.0 & 356.7 & 5.6 & $1,082.0$ & 16.7 \\
\hline Grants & 182.3 & 2.9 & 190.5 & 3.0 & 196.0 & 3.0 & 189.6 & 3.0 & 574.7 & 8.9 \\
\hline Liquid Resources & $\underline{91.6}$ & $\underline{1.5}$ & $\underline{63.7}$ & $\underline{1.0}$ & $\underline{69.9}$ & $\underline{1.1}$ & $\underline{75.1}$ & $\underline{1.2}$ & $\underline{227.7}$ & $\underline{3.5}$ \\
\hline IADB & 53.3 & 0.8 & 33.7 & 0.5 & 34.9 & 0.5 & 40.6 & 0.6 & 123.3 & 1.9 \\
\hline World Bank-PRSC (IDA) & 38.3 & 0.6 & 30.0 & 0.5 & 35.0 & 0.5 & 34.4 & 0.5 & 104.4 & 1.6 \\
\hline Balance of payments support & $\underline{36.1}$ & $\underline{0.6}$ & $\underline{35.6}$ & $\underline{0.6}$ & $\underline{0.0}$ & $\underline{0.0}$ & $\underline{23.9}$ & $\underline{0.4}$ & $\underline{72.8}$ & $\underline{1.1}$ \\
\hline OPEC & 0.0 & 0.0 & 0.0 & 0.0 & 0.0 & 0.0 & 0.0 & 0.0 & 0.0 & 0.0 \\
\hline IADB (grants) & 0.5 & 0.0 & 0.4 & 0.0 & 0.0 & 0.0 & 0.3 & 0.0 & 0.9 & 0.0 \\
\hline IMF & 35.6 & 0.6 & 35.2 & 0.6 & 0.0 & 0.0 & 23.6 & 0.4 & 71.9 & 1.1 \\
\hline Tied to projects (PIP) & $\underline{433.1}$ & $\underline{6.9}$ & $\underline{457.4}$ & $\underline{7.2}$ & $\underline{451.6}$ & $\underline{6.9}$ & $\underline{447.4}$ & $\underline{7.0}$ & $\underline{1,356.2}$ & $\underline{20.9}$ \\
\hline IADB & 125.9 & 2.0 & 158.0 & 2.5 & 140.1 & 2.1 & 141.3 & 2.2 & 428.5 & 6.6 \\
\hline World Bank & 72.5 & 1.1 & 67.0 & 1.1 & 60.6 & 0.9 & 66.7 & 1.0 & 202.3 & 3.1 \\
\hline CABEI & 22.4 & 0.4 & 23.3 & 0.4 & 31.7 & 0.5 & 25.8 & 0.4 & 78.1 & 1.2 \\
\hline Spain & 25.6 & 0.4 & 25.4 & 0.4 & 23.6 & 0.4 & 24.9 & 0.4 & 75.4 & 1.2 \\
\hline Japan & 10.2 & 0.2 & 9.6 & 0.2 & 18.6 & 0.3 & 12.8 & 0.2 & 38.7 & 0.6 \\
\hline Canada & 10.3 & 0.2 & 8.1 & 0.1 & 7.9 & 0.1 & 8.8 & 0.1 & 26.6 & 0.4 \\
\hline Denmark & 14.0 & 0.2 & 9.2 & 0.1 & 10.3 & 0.2 & 11.2 & 0.2 & 33.9 & 0.5 \\
\hline Germany & 13.8 & 0.2 & 12.9 & 0.2 & 11.9 & 0.2 & 12.9 & 0.2 & 39.0 & 0.6 \\
\hline South Korea & 15.7 & 0.2 & 1.8 & 0.0 & 6.0 & 0.1 & 7.8 & 0.1 & 23.8 & 0.4 \\
\hline Nordic Funds & 0.0 & 0.0 & 52.8 & 0.8 & 40.0 & 0.6 & 30.9 & 0.5 & 93.6 & 1.4 \\
\hline European Union & 13.3 & 0.2 & 12.5 & 0.2 & 11.5 & 0.2 & 12.4 & 0.2 & 37.7 & 0.6 \\
\hline Others & 109.4 & 1.7 & 76.8 & 1.2 & 89.4 & 1.4 & 91.9 & 1.4 & 278.5 & 4.3 \\
\hline \multicolumn{11}{|l|}{ Memorandum: } \\
\hline Central Government & 354.1 & 5.6 & 315.3 & 5.0 & 318.3 & 4.8 & 329.2 & 5.1 & 998.3 & 15.4 \\
\hline Public enterprises & 79.0 & 1.3 & 142.1 & 2.2 & 133.3 & 2.0 & 118.1 & 1.8 & 357.9 & 5.5 \\
\hline Loans & 251.3 & 4.0 & 267.3 & 4.2 & 255.8 & 3.9 & 258.1 & 4.0 & 782.6 & 12.1 \\
\hline Grants & 181.8 & 2.9 & 190.1 & 3.0 & 195.8 & 3.0 & 189.2 & 3.0 & 573.6 & 8.9 \\
\hline GDP in millions of dollars & $6,310.0$ &.. & $6,349.9$ &.. & $6,567.2$ &.. & $6,409.0$ &.. &.. &.. \\
\hline
\end{tabular}

Source: $\mathrm{MHCP} / \mathrm{BCN}$ 


\section{CHAPTER VII. RISKS AND THREATS}

292. The Government of Reconciliation and National Unity recognizes that, along the road of struggle against poverty, injustice and corruption and in favor of overall human development, there are risks and threats that lie in wait and may ambush these noble objectives. However, the major strength of this government is the energy, will and courage of the Nicaraguan people in confronting any adversary, as they have done in the past. Moreover, the consensus on policy actions and on reconciliation will become a strength during difficult moments in the life of the nation. The country has abundant natural resources, great expanses of land, an enviable geographic position that enables it to feed people and to do so at the level they deserve. Nicaragua also enjoys the solidarity of friendly countries and the international community in general. This will contribute to reducing the risks that threaten the good performance of the NHDP.

293. The government is committed to the priority of protecting the poorest sectors when adverse factors threaten their health, education, food, and their very lives. Contingency plans will be available for each sector and on a macroeconomic level to reduce the impact of problems that menace the NHDP. The government will take the measures necessary to keep its program on course and to prevent social, political or economic collapse.

294. The global financial crisis and the associated recession can be translated into a reduced capacity to demand products from countries in the global south, heightened interest rates that make international financing more expensive, and increasing unemployment, especially among emigrants, which reduces family remittances.

295. Another risk is the world food crisis, which has the strongest repercussions on low-income countries. The food crisis originates mainly from three sources: i) the impact of the worldwide increase in oil prices on inputs, energy, transportation and thus food production; ii) the policy of industrialized countries to foster the use of food to produce bio-fuels (biodiesel and ethanol) as a response to the high price of oil; and iii) the growing demand for commodities futures contracts as a speculative activity in the major stock exchanges, in response to the weak dollar, further increasing the price of food. This also affects the price of oil due to the same speculative rationale.

296. In addition to these problems, non-compliance by the industrialized nations with the Doha agreements, which establish the elimination of protectionist barriers and agricultural subsidies for their farmers, has put the agricultural production of the low income countries at a disadvantage. This is also true for non-compliance with the Kyoto Protocol and its measures against the emission of greenhouse gases. Such non-compliance by industrialized countries has generated climate changes that negatively affect the production of food and the ecosystems of the planet as a whole.

297. In view of these difficulties, the Government of Reconciliation and National Unity promoted meetings of Central American countries, Mexico and ALBA member countries in May 2008, two at the ministerial level and another at the presidential level, in order to analyze the world food crisis and seek ways to solve it. The results of the Presidential Summit indicate that "Currently, agricultural activity faces great challenges, such as climate variability and the food crisis, which demand recognition of the importance of establishing sustainable production systems with clean production technologies to reduce and mitigate risks. A barrier to fair trade is the policy of subsidizing agricultural production which is maintained by developed countries (the European Union, the United States and Japan) and which surpasses US\$327 billion annually, representing 
$34 \%$ of the agricultural income of those countries; it is reported that it represents $21 \%$ of the income of farmers in the U.S, 35\% of the income of European farmers and 59\% the income of Japanese farmers. This situation seriously distorts international trade in agricultural products."

298. The current international economic order and the economic policies that are adverse to food and agricultural sustainability in developing countries have led to the present crisis in food prices and availability. Agricultural production in these countries should be used to meet the right to food of people everywhere, through comprehensive policies to support poor farmers.

299. The more frequent recurrence of natural disasters has become an annual threat to the population, production and the environment. The problems caused by the El Niño and La Niña maritime currents, floods, droughts and other difficulties are magnified when the population resides in high risk areas, when they occur in productive zones, or when neither the population nor the government are organized to face the emergencies that these phenomena give rise to. It is necessary to be prepared for natural disasters and the food crisis affecting humanity. Beyond the risk to human life, this also has an impact on the economy through damages to infrastructure, on families due to impairment of their homes and harvests, and on the government because it must obtain resources to address reconstruction in the areas affected. Such a situation would make implementing the NHDP more difficult.

300. A latent risk every year is the delay or suspension of foreign cooperation. The failure to acknowledge the Nicaraguan political reality, which is made manifest through partisan vigor and energy, has generated conflicts that may indeed occur in young democracies. However, this often leads to conditions being placed on aid based on performance criteria that are difficult to comply with as they run counter to the country's Constitution and legal framework, or because, in the judgment of the donor, the government does not make progress in certain areas. Many times, proposed laws are taken hostage by political adversaries to generate a process of negotiation, but the laws are ultimately passed. In the process, however, donors have delayed disbursements until the results are known. This behavior seriously affects the implementation of the NHDP and creates uncertainty in the country.

301. The Government of Reconstruction and National Unity has diversified its sources of external financing. The Bolivarian Alternative for the Americas (ALBA) represents a union of countries that are struggling to consolidate Latin American and Caribbean independence and sovereignty through several means, including addressing the degree of dependence upon conditioned multilateral and bilateral foreign cooperation. Furthermore, cooperation agreements have been established with Brazil, Iran, Taiwan and other friendly countries in Asia and Europe, and regional cooperation and Central American integration have been strengthened. This is also the idea behind enhancing and providing incentives for direct foreign investment. All of the above seek to restart the economy in a sustainable fashion, leading to the gradual reduction of dependence on external cooperation.

302. Political conflicts around electoral processes are always a risk to the constitutionality of public policies and, therefore, the country's development plans. During political campaigns, the population and the private business sector generally have lower expectations regarding decisions on savings or investment; however, this returns to normal once the electoral results are known. This scenario changes when there are prolonged acute conflicts and political uncertainty becomes a negative economic factor. 
303. Electoral processes in Nicaragua are progressing and will be strengthened in the medium term, by means of the modernization of its legal framework. Although Nicaragua is a young democracy, it has already carried out five presidential and legislative electoral processes since 1984 with good success. The branches of government work to reduce the threats of electoral conflicts. The executive branch is providing continuity to a series of policies and reforms taken from the previous National Development Plan in order to reduce transition costs. Within this context, the quest for reconciliation and unity among all Nicaraguans becomes one of the major instruments for ensuring the nation's political stability.

304. Inflating the programming of resources in support of the NHDP is a significant risk and should be avoided, as the future cannot be built on false expectations. Frequently, political enthusiasm ends up contaminating technical viability as concerns implementation, which is reflected in an inflated financial program. Based on this, false expectations are created among the population and disappointment carries with it a high political cost in loss of credibility for the government and its program.

305. To prevent the above situation, the government is including only resources that are truly available for execution in its financial programming. Moreover, only those resources that are in the final stages of negotiation are included in the projections for the medium term. In other words, whenever there are clear commitments from the donors to make effective disbursements in the future.

306. Finally, but no less important, are the risks reflected by the institutional capacity for implementing the NHDP. Experience reveals there are institutional and other types of difficulties in when it comes to full execution of resources budgeted. Leaving aside the problems of financial overprogramming, it is clear that this is a problem that goes beyond the government's sphere, as the projects and works are executed and built by the private sector, while the most important resources come from foreign cooperation, with disbursements mostly being made during the second half of the year, which has repercussions on the execution of the Public Investment Program. Thus, it is important to understand the country's real capacity for the construction of projects, as a sudden spike in public and private investment could run into serious bottlenecks concerning project implementation and the flow of foreign cooperation. 


\section{CHAPTER VIII. IMPLEMENTATION, FOLLOW-UP AND EVALUATION}

307. The responsibility for the implementation of the NHDP, and of its associated plans, is assumed by each of the respective government institutions, individually and in the context of sectorwide action. However, it is essential that various factors work together for there to be effective execution. These include: regular review of the impact of the international crisis on the country and on the NHDP; proper programming for the fulfillment of goals; the timing of resources that finance the NHDP, including the forecasting and timely fulfillment of conditions that govern the disbursements of international cooperation, all key elements in the efficient action of budgetary mechanisms; the creation of awareness and popular mobilization in support of the government's efforts and the contribution of the municipal governments, and social, production and business organizations and movements. This will provide appropriate feedback and help create awareness that national development is a task for everyone.

\subsection{National Planning System}

308. GRUN has proposed to have the complete design for the National Planning System (SNP) finished by January 2010. This system will provide institutional support for the implementation of the NHDP and other plans and should begin operations during the first quarter of 2010. However, several overall and specific planning instruments already have been developed and are contributing to the implementation of the NHDP. These instruments make it possible to visualize the implementation phases in a medium-term context.

309. In-depth sector-based dialogue has begun in order to clarify and develop inter-sectoral relationships and synergies for the effective implementation of the NHDP. Examples of this include the operation of the National Social Welfare System (SNBS), the Rural and Agricultural Public Sector (SPAR), the education sector, the health sector, and the environmental, natural resources and disaster prevention sector.

310. By presidential mandate, at the end of 2007 GRUN fostered the formulation of the 2008 Citizen Action Plan in which, for the first time, a government used inputs from the territory when formulating the budget in its substantive programs as well as the Public Investment Program. This serves as one of the major instruments of citizen power, so people have the information and knowledge that enable them to monitor and verify the commitments made by the government, enabling them to exercise decision-making power through social auditing. In 2009, 52 results-based operational institutional plans have been designed that are consistent with the NHDP. These plans take into account the context of crisis and are developed using simple language, in order to facilitate communication with people from a perspective of rights restitution.

311. The quality of the Public Investment Program (PIP) has also been enhanced. Following successive current expenditure "clean-ups" from its books in 2007 and 2008, the PIP in 2009 prioritized gross capital formation, in line with the goals for economic growth. Moreover, its execution has improved, with an historic record of $90.9 \%$ in 2008.

312. On the financial - budget side, as part of the instruments supporting the NHDP, progress has been made in aligning the Medium-Term Budget Framework (MTBF) as the financial expression of the NHDP and from which the annual budget is derived. This MTBF must ensure total consistency with the Economic and Financial Program (EFP), which establishes budget ceilings that are 
consistent with the goals for inflation. In addition, there is a Prioritized Budget to Fight Poverty, a specific mechanism to strictly measure the programs directed at poverty reduction.

\subsection{Follow-up and evaluation}

313. In the SNP framework, follow-up is understood to go beyond oversight of fulfillment of the goals. Rather, follow-up is seen as an instrument that generates information and knowledge for making timely and appropriate decisions. Thus there is follow-up on the physical and financial execution of the strategic goals, results and impact. However, quantitative and qualitative follow-up is required on the entire context, recognizing that there are factors that are beyond the control of authorities and that may affect the Plan, such as the international economic and financial crisis, environmental vulnerability and risks, and so on. Based on this perspective, the government prioritizes follow-up on compliance with policies, on reforms to be translated into laws, on the performance of international cooperation and the frameworks of commitments agreed upon, and on the quantitative goals that are expressed to provide direction in the Plan.

314. In order to provide follow-up on results and impact, progress continues to be made on strengthening the National Statistics System (details below) and, also, in strengthening and establishing an operational relationship among various entities that generate government financial information: the Integrated Financial Management and Auditing System (SIGFA-MHCP), the Debt Management and Financial Analysis System (SIGADE-MHCP/BCN), the Official Development Cooperation Information System for Nicaragua (SYSODA-MINREX) and the Projects Bank of the National Public Investment System (BP-SNIP/SEPRES).

315. Between 2008 and 2009, a qualitative leap was made in follow-up on short-term execution (strategic goals, inputs and process) through: i) the formation of two national commissions to follow-up on institutional plans and on the PIP, in which execution is reviewed and actions are defined to facilitate the attainment of the proposed goals. In addition, this is bearing fruit in the strengthening of human capacity, providing exchanges of best experiences and the challenges faced in the construction of the new model of development. ii) The operation of the Information System of the Government of Reconciliation and National Unity (SIGRUN), an information platform that automates the 52 institutional operating plans with a follow-up system that generates early warnings, facilitating timely decision-making. This system consolidates a monthly report on fulfillment of the institutional operating plans, identifying the areas where there are gaps in fulfillment which are then re-examined so that measures can be taken to address these by means of a weekly review. iii) A qualitative leap has also been made in the follow-up to the Public Investment Program (PIP), with the Physical - Financial System for Follow-up by Contract, which generates information for weekly follow-up on the execution of the PIP.

316. Institutional strengthening is crucial to ensuring that the implementation of the programs adheres to the implementation calendar. The capacity for physical and budgetary execution is linked to the speed at which the NHDP goals have been programmed. Thus, implementation will not be efficient if there continue to be inherited institutional weaknesses that lead to low execution levels. If these problems persist, the strategic lines of the plan will only be that. Therefore, there is an urgent need to strengthen the planning units in each institution as well as the Planning Division of the Secretariat of the Presidency of the Republic. 


\subsection{Strengthening the national statistics system}

317. The government has prioritized the strengthening and modernization of the National Development Information Institute (INIDE) and the incorporation of the National Statistics System (SEN). The generation of quality statistics in a timely fashion is essential for good public administration, making policy decisions at the proper time, and the knowledge of the country by the international community. INIDE will be strengthened by updating its legal framework, adjustments to its structure, the modernization of processes, development of capacities and financial sustainability. Two lines of action will be developed in 2009: (a) incorporate a system for ongoing production of information on indicators related to employment, income and poverty as well as the standard of living of the population, based on an integrated system of household surveys; (b) make progress in the review and improvement of statistical and administrative records of the institutions which, complementing the information from available surveys and census, provide input to different component systems of the National Statistics System.

318. The integration of the National Statistics System includes actions directed at the generation of the regulating and technical framework. This work is progressing in the definition of mechanisms and instruments for the integration and planning of the System. Communications links will be developed among the sectors by connecting the databases and developing capacities, and through the instrumental assistance of INIDE as governing institution. The implementation of the National Statistics System includes analysis of the gender variable, which will cut across all sub-systems, including the census, survey and special research system.

319. The SEN will be established through the implementation of the following systems: the Statistics Information System with gender breakdown; the Statistics Yearbook; the Vital Statistics System and Yearbook; statistical indicators for international and regional commitments, such as the Millennium Development Goals and Central American Integration; the Statistical Information System for Children and Adolescents; the Information System on Indicators by Sector; and the Presidential Information System. These are all to be complemented with information from the household surveys. 


\section{CHAPTER IX. AGENDA}

320. The Government of Reconciliation and National Unity will continue to seek consensus among Nicaraguans to implement its medium- and long-term economic and social strategy, linked to the citizen power model. This document reflects a basic strategy to deal with the international financial crisis and lay the foundation for a more stable and prosperous period in which to achieve the goals and objectives of the National Human Development Plan. The international community may use this document for the purposes of its financial strategy in Nicaragua during the period covered, in the understanding that the government will work toward a complete revision of the NHDP during the second semester of 2009.

321. The review of the Economic and Financial Program (EFP) agreed upon with the IMF is a work in progress. A technical mission from that body has worked with GRUN Economic Cabinet during several months in 2009 to evaluate economic performance and review the medium-term outlooks (Review Two and Three of the EFP). The levels of public spending consistent with inflation goals and prioritized expenditures to fight poverty were taken from this effort. The flows of external cooperation are also updated, incorporating new contingency agreements attained in 2009, and eliminating the all cooperation with serious delays in disbursement delays, as described in Chapter VI.

322. GRUN will continue to strengthen the follow-up, monitoring and evaluation system of the National Human Development Plan, to continually improve the information needed for good public management.

323. It is important to initiate the process of formulating the national budget for 2010. This task is conducted by sector and implies determining amounts by institution, a wage policy, levels of subsidies, transfers, and the amounts of foreign debt that are to be incurred in order to finance the Public Investment Program. This will provide a basis for review of the 2010-2012 medium-term budget.

324. Discussion is to continue at the coordination roundtables with the donor community via the three already existing roundtables: National Dialogue and Governance; Macroeconomy; and Updating of the NHDP.

325. The dialogue with the farming, professional and union sectors aimed at aligning actions to the priorities of the Updated Summary of the 2009-2011 NHDP will continue.

326. In 2011 it will be critical to measure poverty levels nationwide, in order to redirect and intensify social policies. The food production programs, the literacy program, the health campaigns and the entire context for the anti-poverty strategy must be evaluated after five years of implementation.

327. An overall review of the NHDP is to take place in 2010, while simultaneously formulating and initiating the implementation of the GRUN National Planning and Information System.

328. In 2010 the design and formulation of national consensus will begin around the long-term strategy that will map the road Nicaragua is to travel over the longer term $(2011-2021)$. 
Table No. 12: Working Assumptions

\begin{tabular}{|c|c|c|c|c|c|c|c|c|c|c|c|c|c|c|c|}
\hline \multirow[b]{2}{*}{ Years } & \multicolumn{2}{|c|}{ Real GDP } & \multicolumn{2}{|c|}{ Nominal GDP } & \multirow{2}{*}{$\begin{array}{l}\text { GDP } \\
\text { Deflator }\end{array}$} & \multicolumn{2}{|c|}{ Inflation rate } & \multirow{2}{*}{$\begin{array}{c}\text { Nominal } \\
\text { devaluation }\end{array}$} & \multicolumn{2}{|c|}{ Exchange Rate } & \multirow{2}{*}{$\begin{array}{c}\text { GDP } \\
\text { Millions of US \$ }\end{array}$} & \multicolumn{2}{|c|}{ Per capita GDP } & \multicolumn{2}{|l|}{ Población } \\
\hline & Millions of $C \$$ & Rates & Millions of $\mathrm{C} \$$ & Rates & & Average & Cumulative & & Average & End-of-year & & Dollars/person. & Rates & Thousands of peopl & Rates \\
\hline 1994 & $20,008.4$ & & $20,008.4$ & & & 7.78 & 12.41 & & 6.723 & 7.1117 & $2,976.2$ & 653.1 & & $4,557.2$ & \\
\hline 1995 & $21,191.3$ & 5.9 & $24,029.3$ & 20.1 & 13.4 & 10.94 & 11.12 & 12.00 & 7.530 & 7.9651 & $3,191.3$ & 685.2 & 4.9 & $4,657.7$ & 2.2 \\
\hline 1996 & $22,535.7$ & 6.3 & $28,008.7$ & 16.6 & 9.6 & 11.62 & 12.10 & 12.03 & 8.435 & 8.9236 & $3,320.3$ & 698.7 & 2.0 & $4,752.4$ & 2.0 \\
\hline 1997 & $23,429.6$ & 4.0 & $31,967.1$ & 14.1 & 9.8 & 9.22 & 7.25 & 12.00 & 9.450 & 9.9944 & $3,382.8$ & 698.4 & $(0.0)$ & $4,843.9$ & 1.9 \\
\hline 1998 & $24,299.2$ & 3.7 & $37,804.5$ & 18.3 & 14.0 & 13.04 & 18.46 & 12.00 & 10.580 & 11.1938 & $3,573.2$ & 724.5 & 3.7 & $4,932.1$ & 1.8 \\
\hline 1999 & $26,008.9$ & 7.0 & $44,197.8$ & 16.9 & 9.2 & 11.21 & 7.19 & 10.05 & 11.809 & 12.3182 & $3,742.7$ & 746.0 & 3.0 & $5,016.9$ & 1.7 \\
\hline 2000 & $27,075.7$ & 4.1 & $49,952.0$ & 13.0 & 8.6 & 11.55 & 9.87 & 6.00 & 12.684 & 13.0573 & $3,938.1$ & 772.5 & 3.5 & $5,098.0$ & 1.6 \\
\hline 2001 & $27,877.4$ & 3.0 & $55,155.3$ & 10.4 & 7.2 & 7.35 & 4.65 & 6.00 & 13.445 & 13.8408 & $4,102.4$ & 792.9 & 2.6 & $5,173.9$ & 1.5 \\
\hline 2002 & $28,087.5$ & 0.8 & $57,376.3$ & 4.0 & 3.2 & 3.75 & 3.87 & 6.00 & 14.251 & 14.6712 & $4,026.0$ & 767.6 & (3.2) & $5,244.7$ & 1.4 \\
\hline 2003 & $28,795.5$ & 2.5 & $61,958.5$ & 8.0 & 5.3 & 5.30 & 6.48 & 6.00 & 15.106 & 15.5515 & $4,101.5$ & 772.0 & 0.6 & $5,312.7$ & 1.3 \\
\hline 2004 & $30,325.2$ & 5.3 & $71,155.6$ & 14.8 & 9.1 & 8.47 & 9.26 & 5.00 & 15.937 & 16.3291 & $4,464.7$ & 829.8 & 7.5 & $5,380.5$ & 1.3 \\
\hline 2005 & $31,623.9$ & 4.3 & $81,524.4$ & 14.6 & 9.9 & 9.60 & 9.58 & 5.00 & 16.733 & 17.1455 & $4,872.0$ & 893.9 & 7.7 & $5,450.4$ & 1.3 \\
\hline $2006^{a /}$ & $32,858.2$ & 3.9 & $93,016.6$ & 14.1 & 9.8 & 9.14 & 9.45 & 5.00 & 17.570 & 18.0028 & $5,294.1$ & 958.6 & 7.2 & $5,522.6$ & 1.3 \\
\hline $2007^{\mathrm{b} /}$ & $33,893.4$ & 3.2 & $104,982.8$ & 12.9 & 9.4 & 11.13 & 16.88 & 5.00 & 18.449 & 18.9030 & $5,690.6$ & $1,017.0$ & 6.1 & $5,595.5$ & 1.3 \\
\hline $2008^{\mathrm{cl}}$ & $34,986.8$ & 3.2 & $123,307.3$ & 17.5 & 13.8 & 19.83 & 13.77 & 5.00 & 19.372 & 19.8481 & $6,365.3$ & $1,122.8$ & 10.4 & $5,668.9$ & 1.3 \\
\hline $2009^{c /}$ & $34,641.6$ & $(1.0)$ & $128,092.3$ & 3.9 & 4.9 & 4.04 & 2.60 & 5.00 & 20.339 & 20.8405 & $6,297.7$ & $1,096.7$ & (2.3) & $5,742.3$ & 1.3 \\
\hline $2010^{c /}$ & $34,993.7$ & 1.0 & $135,887.6$ & 6.1 & 5.0 & 5.04 & 5.00 & 5.00 & 21.356 & 21.8825 & $6,362.8$ & $1,094.1$ & $(0.2)$ & $5,815.5$ & 1.3 \\
\hline $2011^{c /}$ & $35,860.3$ & 2.5 & $147,104.8$ & 8.3 & 5.6 & 5.92 & 6.00 & 5.00 & 22.424 & 22.9767 & $6,560.1$ & $1,114.0$ & 1.8 & $5,888.9$ & 1.3 \\
\hline
\end{tabular}

$\mathrm{b} /$ : Estimate

cl: Projected

Note: Population data incorporates results of 2005 census and the 2006/2007 DHS.

8/7/2009 9:22 
Table No. 13

Nicaragua: Macroeconomic indicators

\begin{tabular}{|c|c|c|c|c|c|c|c|c|}
\hline \multirow[b]{2}{*}{ Items } & \multicolumn{3}{|c|}{ Averages } & \multirow[b]{2}{*}{2007} & \multirow[b]{2}{*}{2008} & \multicolumn{3}{|c|}{ Projections } \\
\hline & $\begin{array}{c}1994- \\
1996\end{array}$ & $\begin{array}{c}1997- \\
2001\end{array}$ & $\begin{array}{c}2002- \\
2006\end{array}$ & & & 2009 & 2010 & 2011 \\
\hline
\end{tabular}

\section{Economic growth and inflation}

Real GDP (growth rates)

Per capita GDP (in US\$)

Per capita GDP (growth rates)

Inflation, at end of period

Inflation, annual average

GDP deflator

\section{Balance of payments and foreign trade}

Current account ( $\%$ of GDP)

Trade Balance in goods (\% of GDP)

FOB exports of merchandise (in millions US\$)

FOB imports of merchandise (in millions US\$)

Net from free trade zone (in millions US\$)1/

Fiscal Program (\% GDP)

Current income from combined public sector ${ }^{2 /}$

Total expenditures of the combined public sector

Interest

Overall deficit of Central Bank

Balance of the combined public sector a/d

Donations

Balance of the combined public sector $d / d$

\section{Monetary sector}

Balance of gross international reserves (in millions US\$)

Balance of net international reserves (in millions US\$)

GIR / imports CIF

GIR / monetary base

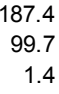

(26.1)

(14.1)

422.3

901.8

28.8

$(22.1)$
$(23.3)$
585.6
$1,547.2$
79.0

(15.4)

(25.3)

769.1

$2,113.0$

180.8

(17.6)

(30.9)

1,224.8

$3,310.7$

304.5

(23.8)

(34.7)

$1,488.7$

$4,017.5$

284.2

(15.0)

(24.9)

1,340.1

$3,190.3$

263.6

(18.2)

(27.2)

$1,412.0$

$3,424.2$

261.0

(17.9)

$1,531.7$

$3,608.2$

289.2

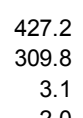

656.6 485.6
25.9

29.0

1.5

0.3

(3.1)

0.9

1,018.6

3.7

2.1

\section{Financial balance}

$$
\begin{gathered}
\text { Savings }=\text { Investment } \\
\text { National savings } \\
\text { Private sector } \\
\text { Public sector } \\
\text { Foreign savings }
\end{gathered}
$$

\section{Investment (\% GDP)}

Private sector

Public sector

Memorandum (in millions of $\mathrm{C} \$$ )

GDP (in 1994 prices)

$21,245.1$

$24,015.5$

$25,738.2$

Nominal GDP (current córdobas)

Nominal GDP (in millions of US\$)

Average exchange rate $C \$ x$ US\$
22.7

(3.3)

(2.9)

(0.4)

26.0

15.0

8.0

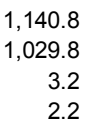

34.3

10.6

9.5

23.7

$(0.4)$
22.5

1/ Exports minus free trade zone imports

2/ Includes Central Bank

Note: The growth rate of the real variable for the 1994-96 period is an average of those observed in 1995 and 1996.

Source: BCN. 
Table 14

Gross domestic product by economic activity

(millions of 1994 córdobas)

\begin{tabular}{|c|c|c|c|c|c|c|c|c|c|c|c|c|}
\hline Categories & 2006 & 2007 & 2008 & 2009 & 2010 & 2011 & 2006 & 2007 & 2008 & 2009 & 2010 & 2011 \\
\hline & & & & & & & & --Growth & ates -- & & & \\
\hline Gross Domestic Product & $32,858.2$ & $33,893.4$ & $34,986.8$ & $34,641.6$ & $34,993.7$ & $35,877.9$ & 3.9 & 3.2 & 3.2 & (1.0) & 1.0 & 2.5 \\
\hline Net taxes on products & $2,923.5$ & $3,052.8$ & $3,169.7$ & $2,905.4$ & $2,920.8$ & $3,029.5$ & 3.6 & 4.4 & 3.8 & (8.3) & 0.5 & 3.7 \\
\hline Bank Allocations & 986.6 & $1,208.5$ & $1,225.5$ & $1,198.5$ & $1,226.1$ & $1,273.9$ & 11.4 & 22.5 & 1.4 & (2.2) & 2.3 & 3.9 \\
\hline Primary Activity & $6,614.5$ & $6,459.0$ & $6,782.6$ & $6,773.4$ & $6,880.6$ & $6,975.7$ & 3.4 & (2.4) & 5.0 & $(0.1)$ & 1.6 & 1.4 \\
\hline Agriculture & $3,373.1$ & $3,041.8$ & $3,331.5$ & $3,333.5$ & $3,413.7$ & $3,423.7$ & 4.4 & $(9.8)$ & 9.5 & 0.1 & 2.4 & 0.3 \\
\hline Livestock & $2,304.3$ & $2,451.4$ & $2,478.0$ & $2,450.1$ & $2,465.8$ & $2,529.9$ & 2.6 & 6.4 & 1.1 & (1.1) & 0.6 & 2.6 \\
\hline Fishing & 522.2 & 540.4 & 538.2 & 546.2 & 548.6 & 559.6 & 1.6 & 3.5 & $(0.4)$ & 1.5 & 0.4 & 2.0 \\
\hline Silvoculture & 415.0 & 425.4 & 434.9 & 443.6 & 452.5 & 462.4 & 2.0 & 2.5 & 2.2 & 2.0 & 2.0 & 2.2 \\
\hline Secondary Activity & $7,909.1$ & $8,318.1$ & $8,421.0$ & $8,269.6$ & $8,271.8$ & $8,470.4$ & 4.3 & 5.2 & 1.2 & (1.8) & 0.0 & 2.4 \\
\hline Manufacturing Industry & $6,289.5$ & $6,755.2$ & $6,904.0$ & $6,802.9$ & $6,769.7$ & $6,931.4$ & 6.5 & 7.4 & 2.2 & $(1.5)$ & $(0.5)$ & 2.4 \\
\hline Construction & $1,312.9$ & $1,278.8$ & $1,243.3$ & $1,200.4$ & $1,231.7$ & $1,260.5$ & (3.2) & (2.6) & $(2.8)$ & (3.4) & 2.6 & 2.3 \\
\hline Mining & 306.7 & 284.1 & 273.8 & 266.3 & 270.4 & 278.5 & (3.4) & (7.4) & (3.6) & (2.7) & 1.5 & 3.0 \\
\hline Tertiary Activity & $16,397.6$ & $17,272.0$ & $17,839.0$ & $17,891.7$ & $18,146.6$ & $18,676.3$ & 4.4 & 5.3 & 3.3 & 0.3 & 1.4 & 2.9 \\
\hline Commerce & $5,442.9$ & $5,696.3$ & $5,881.6$ & $5,776.1$ & $5,853.5$ & $6,029.3$ & 3.9 & 4.7 & 3.3 & $(1.8)$ & 1.3 & 3.0 \\
\hline General Government & $2,037.4$ & $2,099.1$ & $2,202.9$ & $2,259.8$ & $2,270.3$ & $2,362.4$ & 6.2 & 3.0 & 4.9 & 2.6 & 0.5 & 4.1 \\
\hline Transportation and Communications & $2,404.9$ & $2,584.1$ & $2,676.6$ & $2,731.4$ & $2,792.1$ & $2,868.1$ & 4.4 & 7.5 & 3.6 & 2.0 & 2.2 & 2.7 \\
\hline Banking and insurance & $1,151.9$ & $1,344.6$ & $1,380.9$ & $1,336.7$ & $1,363.4$ & $1,415.8$ & 10.3 & 16.7 & 2.7 & $(3.2)$ & 2.0 & 3.8 \\
\hline Energy and Drinking Water & 717.4 & 733.5 & 757.2 & 775.0 & 790.7 & 814.0 & 2.7 & 2.3 & 3.2 & 2.4 & 2.0 & 3.0 \\
\hline Housing Property & $2,138.5$ & $2,215.6$ & $2,274.3$ & $2,301.6$ & $2,324.6$ & $2,366.5$ & 3.2 & 3.6 & 2.7 & 1.2 & 1.0 & 1.8 \\
\hline Other Services & $2,504.7$ & $2,598.8$ & $2,665.5$ & $2,711.0$ & $2,752.0$ & $2,820.2$ & 2.9 & 3.8 & 2.6 & 1.7 & 1.5 & 2.5 \\
\hline
\end{tabular}


Table 15

Gross domestic product by economic activity

(millions of córdobas)

\begin{tabular}{|c|c|c|c|c|c|c|c|c|c|c|c|c|}
\hline Categories & 2006 & 2007 & 2008 & 2009 & 2010 & 2011 & 2006 & 2007 & 2008 & 2009 & 2010 & 2011 \\
\hline & & & & & & & & --Growt| & ates -- & & & \\
\hline Gross Domestic Product & $93,016.6$ & $104,982.8$ & $123,307.3$ & $128,092.3$ & $135,887.6$ & $146,508.9$ & 14.1 & 12.9 & 17.5 & 3.9 & 6.1 & 7.8 \\
\hline Net taxes on products & $11,528.1$ & $13,289.2$ & $14,791.9$ & $13,765.4$ & $14,343.1$ & $15,564.7$ & 18.1 & 15.3 & 11.3 & (6.9) & 4.2 & 8.5 \\
\hline Bank Allocations & $4,426.3$ & $6,190.0$ & $7,521.1$ & $7,652.9$ & $8,223.2$ & $9,049.5$ & 21.6 & 39.8 & 21.5 & 1.8 & 7.5 & 10.0 \\
\hline Primary Activity & $15,429.7$ & $17,181.4$ & $21,048.8$ & $21,739.7$ & $23,222.7$ & $24,927.3$ & 12.7 & 11.4 & 22.5 & 3.3 & 6.8 & 7.3 \\
\hline Agriculture & $8,702.4$ & $9,460.2$ & $11,960.7$ & $12,327.4$ & $13,258.4$ & $14,111.2$ & 13.9 & 8.7 & 26.4 & 3.1 & 7.6 & 6.4 \\
\hline Livestock & $5,135.1$ & $5,878.2$ & $6,987.5$ & $7,188.2$ & $7,598.5$ & $8,257.5$ & 12.4 & 14.5 & 18.9 & 2.9 & 5.7 & 8.7 \\
\hline Fishing & 849.0 & 937.5 & 979.4 & $1,034.2$ & $1,091.0$ & $1,178.7$ & 8.0 & 10.4 & 4.5 & 5.6 & 5.5 & 8.0 \\
\hline Silvoculture & 743.2 & 905.5 & $1,121.2$ & $1,189.8$ & $1,274.7$ & $1,379.9$ & 6.9 & 21.8 & 23.8 & 6.1 & 7.1 & 8.2 \\
\hline Secondary Activity & $21,500.0$ & $24,383.0$ & $29,197.0$ & $31,522.8$ & $33,411.1$ & $36,245.9$ & 13.7 & 13.4 & 19.7 & 8.0 & 6.0 & 8.5 \\
\hline Manufacturing Industry & $15,073.4$ & $17,428.3$ & $20,938.4$ & $23,234.2$ & $24,489.3$ & $26,567.0$ & 12.8 & 15.6 & 20.1 & 11.0 & 5.4 & 8.5 \\
\hline Construction & $5,342.8$ & $5,816.9$ & $6,839.8$ & $6,852.9$ & 7,390.6 & $8,008.3$ & 14.8 & 8.9 & 17.6 & 0.2 & 7.8 & 8.4 \\
\hline Mining & $1,083.8$ & $1,137.9$ & $1,418.8$ & $1,435.8$ & $1,531.3$ & $1,670.5$ & 20.4 & 5.0 & 24.7 & 1.2 & 6.7 & 9.1 \\
\hline Tertiary Activity & $48,985.1$ & $56,319.2$ & $65,790.7$ & $68,717.3$ & $73,133.8$ & $78,820.6$ & 14.5 & 15.0 & 16.8 & 4.4 & 6.4 & 7.8 \\
\hline Commerce & $12,631.2$ & $14,445.7$ & $16,997.4$ & $17,598.4$ & $18,781.4$ & $20,540.4$ & 12.2 & 14.4 & 17.7 & 3.5 & 6.7 & 9.4 \\
\hline General Government & $10,895.3$ & $12,415.6$ & $15,303.5$ & $15,537.8$ & $15,994.0$ & $16,576.8$ & 19.6 & 14.0 & 23.3 & 1.5 & 2.9 & 3.6 \\
\hline Transportation and Communications & $5,022.7$ & $5,907.6$ & $6,592.9$ & $7,471.6$ & $8,387.8$ & $9,119.1$ & 13.5 & 17.6 & 11.6 & 13.3 & 12.3 & 8.7 \\
\hline Banking and insurance & $4,254.8$ & $5,575.5$ & $6,440.0$ & $6,485.9$ & $6,948.7$ & $7,642.6$ & 19.2 & 31.0 & 15.5 & 0.7 & 7.1 & 10.0 \\
\hline Energy and Drinking Water & $2,712.6$ & $2,970.7$ & $3,625.5$ & $3,861.6$ & $4,137.6$ & $4,513.8$ & 20.3 & 9.5 & 22.0 & 6.5 & 7.1 & 9.1 \\
\hline Housing Property & $6,988.8$ & $7,794.0$ & $8,745.3$ & $9,208.0$ & $9,768.4$ & $10,532.7$ & 9.7 & 11.5 & 12.2 & 5.3 & 6.1 & 7.8 \\
\hline Other Services & $6,479.6$ & $7,210.0$ & $8,086.0$ & $8,553.9$ & $9,115.8$ & 9,895.2 & 11.5 & 11.3 & 12.1 & 5.8 & 6.6 & 8.5 \\
\hline
\end{tabular}

SGIE-DO

8/27/2009 11:00 


\section{Table 16}

\section{Gross domestic product: Expenditure Focus}

(millions of 1994 córdobas)

\begin{tabular}{|c|c|c|c|c|c|c|c|c|c|c|c|c|}
\hline Categories & 2006 & 2007 & 2008 & 2009 & 2010 & 2011 & 2006 & 2007 & 2008 & 2009 & 2010 & 2011 \\
\hline & & & & & & & \multicolumn{6}{|c|}{-- Growth rates -- } \\
\hline GROSS DOMESTIC PRODUCT & $32,858.2$ & $33,893.4$ & $34,986.8$ & $34,641.6$ & $34,993.7$ & $35,877.9$ & 3.9 & 3.2 & 3.2 & $(1.0)$ & 1.0 & 2.5 \\
\hline 1. Consumption & $30,482.5$ & $31,720.7$ & $32,959.5$ & $33,136.4$ & $33,728.4$ & $35,115.6$ & 4.0 & 4.1 & 3.9 & 0.5 & 1.8 & 4.1 \\
\hline Public Consumption & $4,488.4$ & $4,659.1$ & $4,865.7$ & $4,504.3$ & $4,321.3$ & $4,435.1$ & 8.6 & 3.8 & 4.4 & (7.4) & (4.1) & 2.6 \\
\hline Private Consumption & $25,994.2$ & $27,061.6$ & $28,093.8$ & $28,632.1$ & $29,407.1$ & $30,680.5$ & 3.3 & 4.1 & 3.8 & 1.9 & 2.7 & 4.3 \\
\hline 2. Gross Investment & $7,848.5$ & $8,699.3$ & $10,111.7$ & $8,757.7$ & $9,042.9$ & $9,063.1$ & (1.5) & 10.8 & 16.2 & $(13.4)$ & 3.3 & 0.2 \\
\hline Fixed investment & $7,534.7$ & $8,129.3$ & $8,796.3$ & $8,045.4$ & $8,363.3$ & $8,778.4$ & 3.5 & 7.9 & 8.2 & (8.5) & 4.0 & 5.0 \\
\hline Construction & $3,234.7$ & $3,150.6$ & $3,063.0$ & $2,957.5$ & $3,034.6$ & $3,105.5$ & (3.2) & (2.6) & $(2.8)$ & (3.4) & 2.6 & 2.3 \\
\hline Buildings & $2,378.0$ & $2,275.2$ & $2,197.2$ & $2,061.1$ & $2,029.3$ & $2,061.2$ & 7.8 & $(4.3)$ & (3.4) & (6.2) & $(1.5)$ & 1.6 \\
\hline Civil engineering works & 856.7 & 875.4 & 865.8 & 896.4 & $1,005.3$ & $1,044.3$ & $(24.5)$ & 2.2 & (1.1) & 3.5 & 12.2 & 3.9 \\
\hline Machinery and equipment & $3,590.1$ & $4,232.0$ & $4,936.5$ & $4,282.2$ & $4,480.9$ & $4,772.6$ & 11.2 & 17.9 & 16.6 & $(13.3)$ & 4.6 & 6.5 \\
\hline Other Investments & 709.9 & 746.7 & 796.7 & 805.7 & 847.8 & 900.4 & 0.4 & 5.2 & 6.7 & 1.1 & 5.2 & 6.2 \\
\hline Inventory change & 313.9 & 570.0 & $1,315.5$ & 712.3 & 679.5 & 284.7 & - & - & - & - & - & - \\
\hline Public Investment & $1,133.3$ & $1,186.2$ & $1,217.8$ & $1,268.4$ & $1,454.4$ & $1,522.0$ & $(25.4)$ & 4.7 & 2.7 & 4.2 & 14.7 & 4.7 \\
\hline Fixed investment & $1,133.3$ & $1,186.2$ & $1,217.8$ & $1,268.4$ & $1,454.4$ & $1,522.0$ & $(25.4)$ & 4.7 & 2.7 & 4.2 & 14.7 & 4.7 \\
\hline Construction & 965.3 & $1,008.0$ & $1,009.0$ & $1,048.1$ & $1,198.7$ & $1,249.4$ & $(26.7)$ & 4.4 & 0.1 & 3.9 & 14.4 & 4.2 \\
\hline Buildings & 263.8 & 288.8 & 302.2 & 313.9 & 359.0 & 374.1 & $(21.6)$ & 9.5 & 4.6 & 3.9 & 14.4 & 4.2 \\
\hline Civil engineering works & 701.6 & 719.2 & 706.9 & 734.2 & 839.8 & 875.3 & $(28.4)$ & 2.5 & $(1.7)$ & 3.9 & 14.4 & 4.2 \\
\hline Machinery and equipment & 167.3 & 177.5 & 208.1 & 219.6 & 254.9 & 271.8 & (17.0) & 6.1 & 17.2 & 5.5 & 16.1 & 6.7 \\
\hline Other Investments & 0.7 & 0.7 & 0.7 & 0.7 & 0.7 & 0.7 & $(0.5)$ & (1.7) & 1.9 & 0.2 & 0.7 & 0.9 \\
\hline Inventory change & - & - & - & - & - & - & - & - & - & 1.0 & 2.0 & 3.0 \\
\hline Private Investment & $6,715.2$ & $7,513.1$ & $8,893.9$ & $7,489.3$ & $7,588.5$ & $7,541.1$ & 4.1 & 11.9 & 18.4 & $(15.8)$ & 1.3 & $(0.6)$ \\
\hline Fixed investment & $6,401.3$ & $6,943.1$ & $7,578.4$ & $6,777.0$ & $6,909.0$ & $7,256.4$ & 11.2 & 8.5 & 9.2 & $(10.6)$ & 1.9 & 5.0 \\
\hline Construction & $2,269.3$ & $2,142.6$ & $2,054.0$ & $1,909.4$ & $1,835.9$ & $1,856.1$ & 12.0 & $(5.6)$ & $(4.1)$ & $(7.0)$ & (3.8) & 1.1 \\
\hline Buildings & $2,114.2$ & $1,986.4$ & $1,895.1$ & $1,747.2$ & $1,670.4$ & $1,687.1$ & 13.0 & $(6.0)$ & (4.6) & $(7.8)$ & (4.4) & 1.0 \\
\hline Civil engineering works & 155.1 & 156.2 & 158.9 & 162.1 & 165.5 & 169.0 & 0.1 & 0.7 & 1.8 & 2.0 & 2.1 & 2.1 \\
\hline Machinery and equipment & $3,422.8$ & $4,054.6$ & $4,728.5$ & $4,062.6$ & $4,226.1$ & $4,500.7$ & 13.1 & 18.5 & 16.6 & $(14.1)$ & 4.0 & 6.5 \\
\hline Other Investments & 709.2 & 746.0 & 796.0 & 805.0 & 847.1 & 899.6 & 0.4 & 5.2 & 6.7 & 1.1 & 5.2 & 6.2 \\
\hline Inventory change & 313.9 & 570.0 & $1,315.5$ & 712.3 & 679.5 & 284.7 & - & - & - & - & - & - \\
\hline 3. Exports & $10,883.9$ & $11,863.8$ & $12,175.4$ & $11,743.2$ & $11,876.5$ & $12,375.3$ & 12.6 & 9.0 & 2.6 & (3.6) & 1.1 & 4.2 \\
\hline 4. Imports & $16,356.8$ & $18,390.3$ & $20,259.9$ & $18,995.7$ & $19,654.1$ & $20,676.1$ & 6.8 & 12.4 & 10.2 & $(6.2)$ & 3.5 & 5.2 \\
\hline
\end{tabular}


Table 17

Gross domestic product: Expenditure Focus (millions of córdobas)

\begin{tabular}{|c|c|c|c|c|c|c|c|c|c|c|c|c|}
\hline Categories & 2006 & 2007 & 2008 & 2009 & 2010 & 2011 & 2006 & 2007 & 2008 & 2009 & 2010 & 2011 \\
\hline & & & & & & & \multicolumn{6}{|c|}{-- Growth rates -- } \\
\hline GROSS DOMESTIC PRODUCT & $93,016.6$ & $104,982.8$ & $123,307.3$ & $128,092.3$ & $135,887.6$ & $146,508.9$ & 14.1 & 12.9 & 17.5 & 3.9 & 6.1 & 7.8 \\
\hline 1. Consumption & $92,810.3$ & $105,784.9$ & $127,859.5$ & $131,072.1$ & $139,551.6$ & $148,017.8$ & 14.3 & 14.0 & 20.9 & 2.5 & 6.5 & 6.1 \\
\hline Public Consumption & $18,348.1$ & $20,546.7$ & $25,289.0$ & $24,406.8$ & $24,501.1$ & $25,536.3$ & 20.1 & 12.0 & 23.1 & $(3.5)$ & 0.4 & 4.2 \\
\hline Private Consumption & $74,462.2$ & $85,238.3$ & $102,570.5$ & $106,665.2$ & $115,050.5$ & $122,481.5$ & 13.0 & 14.5 & 20.3 & 4.0 & 7.9 & 6.5 \\
\hline 2. Gross Investment & $28,054.3$ & $34,891.2$ & $42,290.1$ & $32,902.8$ & $38,725.3$ & $44,639.5$ & 14.4 & 24.4 & 21.2 & (22.2) & 17.7 & 15.3 \\
\hline Fixed investment & $27,119.5$ & $31,825.1$ & $38,392.9$ & $33,558.0$ & $37,009.1$ & $40,781.9$ & 16.9 & 17.4 & 20.6 & (12.6) & 10.3 & 10.2 \\
\hline Construction & $14,279.8$ & $15,551.8$ & $18,275.1$ & $18,316.5$ & $19,752.3$ & $21,404.6$ & 16.5 & 8.9 & 17.5 & 0.2 & 7.8 & 8.4 \\
\hline Buildings & $11,015.1$ & $11,632.7$ & $13,414.2$ & $13,072.9$ & $13,486.5$ & $14,502.4$ & 26.6 & 5.6 & 15.3 & (2.5) & 3.2 & 7.5 \\
\hline Civil engineering works & $3,264.7$ & $3,919.1$ & $4,860.8$ & $5,243.6$ & $6,265.7$ & $6,902.2$ & $(8.1)$ & 20.0 & 24.0 & 7.9 & 19.5 & 10.2 \\
\hline Machinery and equipment & $10,741.3$ & $13,694.8$ & $17,098.0$ & $12,627.8$ & $14,227.7$ & $15,999.8$ & 18.2 & 27.5 & 24.9 & $(26.1)$ & 12.7 & 12.5 \\
\hline Other Investments & $2,098.4$ & $2,578.5$ & $3,019.8$ & $2,613.7$ & $3,029.2$ & $3,377.5$ & 13.3 & 22.9 & 17.1 & (13.5) & 15.9 & 11.5 \\
\hline Inventory change & 934.8 & $3,066.1$ & $3,897.2$ & $(655.2)$ & $1,716.2$ & $3,857.6$ & & & & & & \\
\hline Public Investment & $4,706.5$ & $5,659.4$ & $7,077.7$ & $7,649.0$ & $9,188.5$ & $10,143.6$ & $(8.9)$ & 20.2 & 25.1 & 8.1 & 20.1 & 10.4 \\
\hline Fixed investment & $4,706.5$ & $5,659.4$ & $7,077.7$ & $7,649.0$ & $9,188.5$ & $10,143.6$ & (8.9) & 20.2 & 25.1 & 8.1 & 20.1 & 10.4 \\
\hline Construction & $4,200.5$ & $5,084.1$ & $6,358.5$ & $6,871.8$ & $8,255.2$ & $9,113.3$ & (8.7) & 21.0 & 25.1 & 8.1 & 20.1 & 10.4 \\
\hline Buildings & $1,114.8$ & $1,349.3$ & $1,687.5$ & $1,823.8$ & $2,190.9$ & $2,418.7$ & $(8.6)$ & 21.0 & 25.1 & 8.1 & 20.1 & 10.4 \\
\hline Civil engineering works & $3,085.7$ & $3,734.8$ & $4,671.0$ & $5,048.0$ & $6,064.3$ & $6,694.7$ & (8.7) & 21.0 & 25.1 & 8.1 & 20.1 & 10.4 \\
\hline Machinery and equipment & 504.4 & 573.8 & 717.6 & 775.5 & 931.6 & $1,028.5$ & $(11.1)$ & 13.7 & 25.1 & 8.1 & 20.1 & 10.4 \\
\hline Other Investments & 1.5 & 1.6 & 1.6 & 1.6 & 1.7 & 1.8 & 1.0 & 3.7 & 4.1 & $(0.6)$ & 3.5 & 3.9 \\
\hline Inventory change & - & - & - & - & - & - & & & & & & \\
\hline Private Investment & $23,347.8$ & $29,231.8$ & $35,212.4$ & $25,253.8$ & $29,536.8$ & $34,495.9$ & 20.6 & 25.2 & 20.5 & $(28.3)$ & 17.0 & 16.8 \\
\hline Fixed investment & $22,413.0$ & $26,165.7$ & $31,315.2$ & $25,909.0$ & $27,820.6$ & $30,638.4$ & 24.3 & 16.7 & 19.7 & $(17.3)$ & 7.4 & 10.1 \\
\hline Construction & $10,079.3$ & $10,467.7$ & $11,916.6$ & $11,444.7$ & $11,497.1$ & $12,291.3$ & 31.7 & 3.9 & 13.8 & $(4.0)$ & 0.5 & 6.9 \\
\hline Buildings & $9,900.3$ & $10,283.4$ & $11,726.7$ & $11,249.1$ & $11,295.6$ & $12,083.8$ & 32.4 & 3.9 & 14.0 & $(4.1)$ & 0.4 & 7.0 \\
\hline Civil engineering works & 179.0 & 184.4 & 189.9 & 195.6 & 201.5 & 207.5 & 3.0 & 3.0 & 3.0 & 3.0 & 3.0 & 3.0 \\
\hline Machinery and equipment & $10,236.8$ & $13,121.0$ & $16,380.4$ & $11,852.3$ & $13,296.0$ & $14,971.3$ & 20.1 & 28.2 & 24.8 & $(27.6)$ & 12.2 & 12.6 \\
\hline Other Investments & $2,096.9$ & $2,577.0$ & $3,018.2$ & $2,612.0$ & $3,027.5$ & $3,375.8$ & 13.4 & 22.9 & 17.1 & (13.5) & 15.9 & 11.5 \\
\hline Inventory change & 934.8 & $3,066.1$ & $3,897.2$ & $(655.2)$ & $1,716.2$ & $3,857.6$ & - & - & - & - & - & - \\
\hline 3. Exports & $29,553.3$ & $35,516.9$ & $42,719.9$ & $41,289.4$ & $44,958.8$ & $50,929.7$ & 25.2 & 20.2 & 20.3 & (3.3) & 8.9 & 13.3 \\
\hline 4. Imports & $57,401.2$ & $71,210.3$ & $89,562.3$ & $77,172.0$ & $87,348.1$ & $97,078.0$ & 20.1 & 24.1 & 25.8 & (13.8) & 13.2 & 11.1 \\
\hline
\end{tabular}


Consolidated Operations of the Non-Financial Public Sector

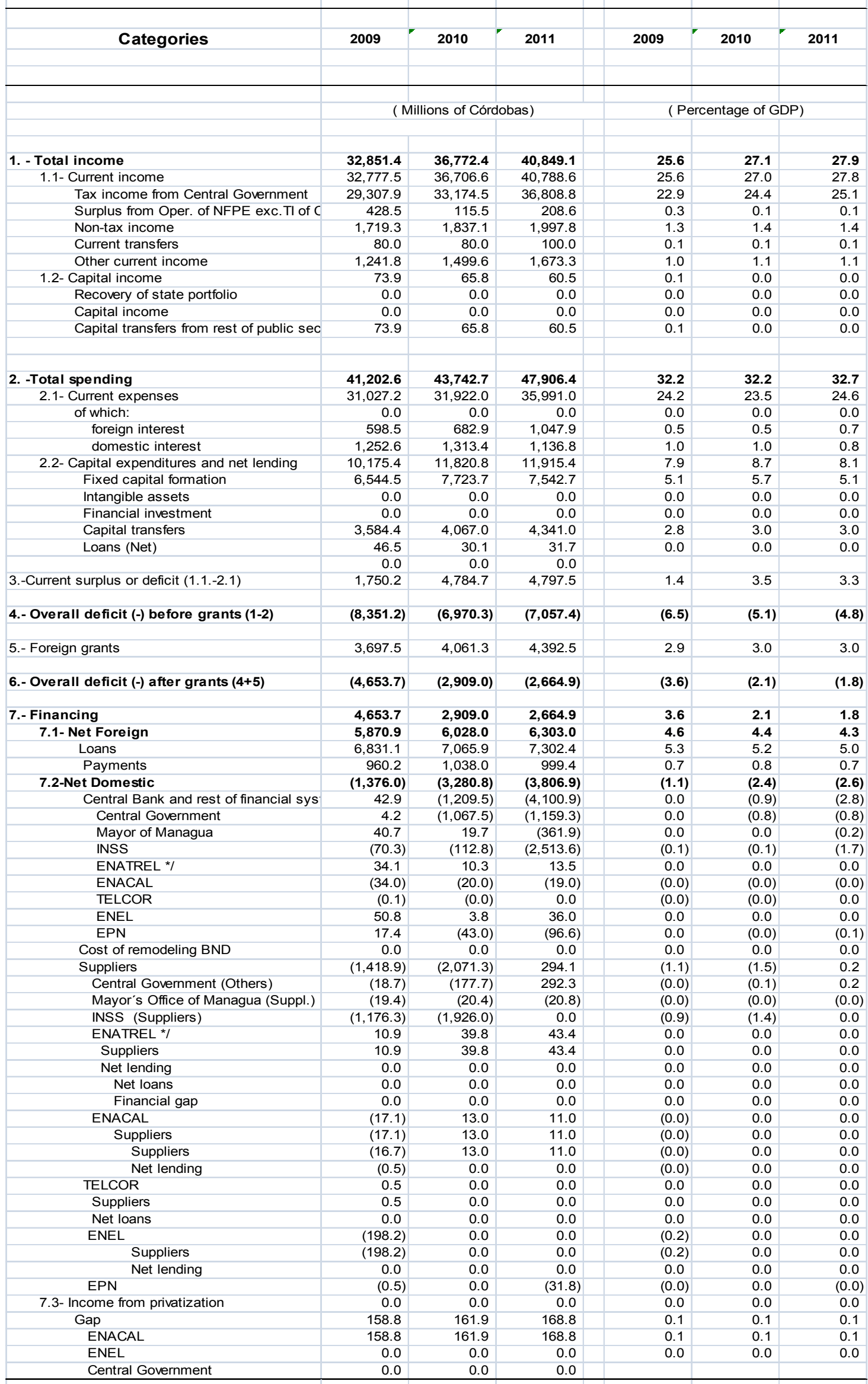

* : From 2001 to 2006 ENTRESA, starting in 2007 ENATREL

CInternational Monetary Fund. Not for Redistribution 


\begin{tabular}{|c|c|c|c|c|}
\hline \multicolumn{5}{|c|}{ Table No. 19 - Nicaragua: Foreign financing available } \\
\hline Categories & 2008 & 2009 & 2010 & 2011 \\
\hline Total foreign resources & 417.8 & 560.8 & 556.7 & 521.5 \\
\hline Liquid resources & 30.7 & 92.1 & 64.0 & 69.9 \\
\hline Budgetary support & 30.0 & 91.6 & 63.6 & 69.9 \\
\hline Loans & 0.0 & 91.6 & 63.6 & 69.9 \\
\hline Grants & 30.0 & 0.0 & 0.0 & 0.0 \\
\hline Balance of payment support & 0.7 & 0.5 & 0.4 & 0.0 \\
\hline Loans & 0.0 & 0.0 & 0.0 & \\
\hline Grants & 0.7 & 0.5 & 0.4 & \\
\hline Resources for Public Investment & 358.2 & 433.1 & 457.4 & 451.6 \\
\hline Loans & 190.6 & 251.3 & 267.2 & 255.7 \\
\hline Central Government & 134.0 & 187.9 & 171.4 & 173.0 \\
\hline Public Enterprises & 33.1 & 55.9 & 95.8 & 82.7 \\
\hline $\mathrm{FNI}$ & 6.5 & 6.1 & 0.0 & \\
\hline Rest of non-consolidated NFPS & 17.0 & 1.4 & 0.0 & \\
\hline Grants & 167.6 & 181.8 & 190.2 & 195.9 \\
\hline Central Government & 153.5 & 166.3 & 143.9 & 145.2 \\
\hline Public Enterprises & 14.1 & 15.5 & 46.2 & 50.6 \\
\hline Central Bank & 0.0 & 0.0 & 0.0 & \\
\hline Rest of non-consolidated NFPS & 0.0 & 0.0 & 0.0 & \\
\hline IMF Resources & 28.9 & 35.6 & 35.2 & 0.0 \\
\hline \multicolumn{5}{|c|}{${ }^{1}$ Refers to ENEL, ENACAL, EPN, ENATREL and Mayor's Office of Managı } \\
\hline Source: $\mathrm{BCN}, \mathrm{MHCP}$ & & & & \\
\hline
\end{tabular}


Table No. 20:

CENTRAL GOVERNMENT OPERATIONS

YEARS 2009 - 2011

(Thousands of Córdobas)

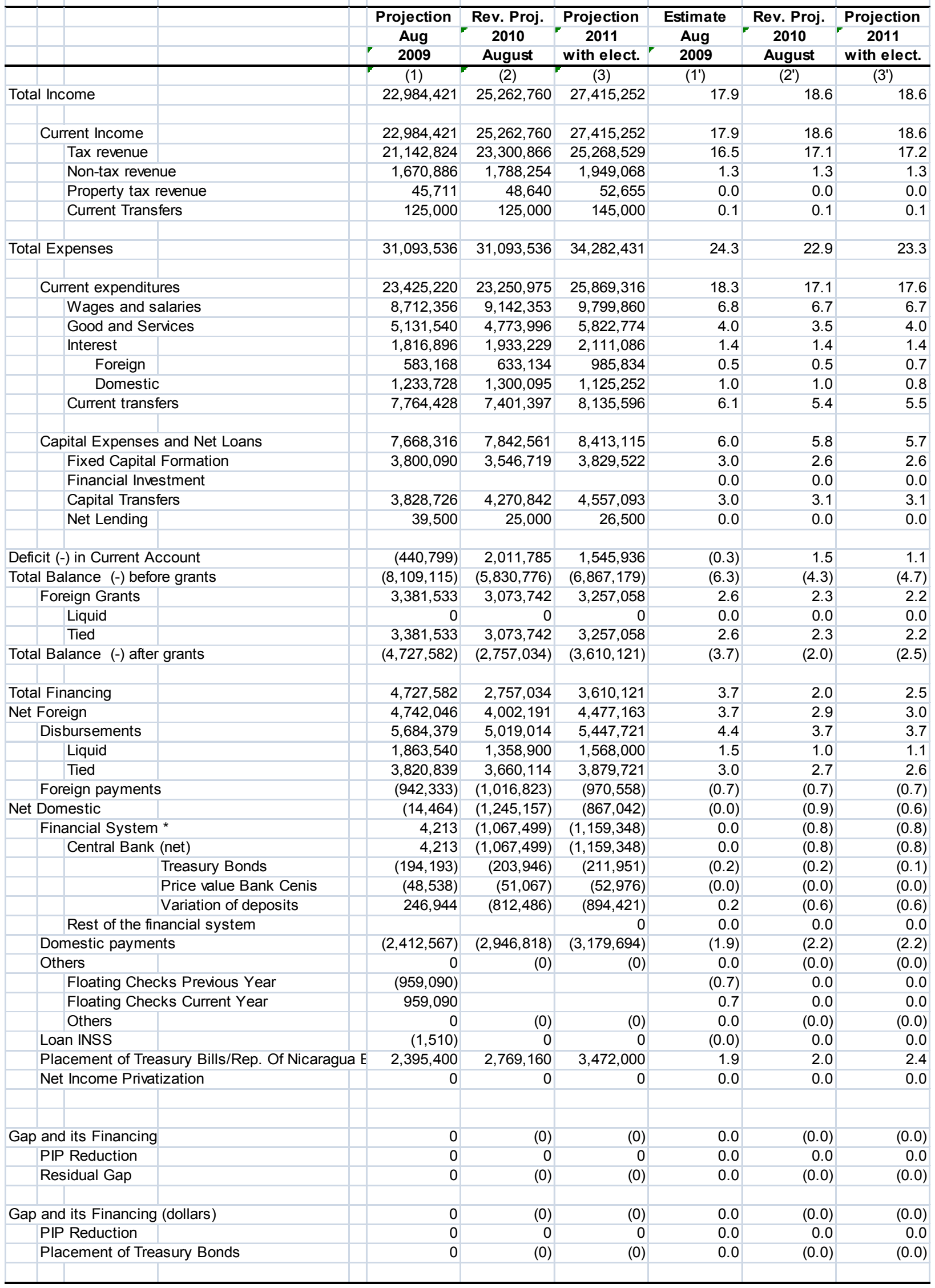


Table No. 21:

Central Government

Ordinary Income 2009-2011

Thousands of Córdobas

\begin{tabular}{|c|c|c|c|c|c|c|}
\hline \multicolumn{7}{|l|}{ Inousanas or Coraopas } \\
\hline & $\begin{array}{c}\text { Proj. } \\
\text { August }\end{array}$ & $\begin{array}{c}\text { Rev. Proj. } \\
\text { August }\end{array}$ & Projection & $\begin{array}{c}\text { Proj. } \\
\text { August }\end{array}$ & $\begin{array}{c}\text { Rev. Proj. } \\
\text { August }\end{array}$ & Projection \\
\hline & 2009 & 2010 & 2011 & 2009 & 2010 & 2011 \\
\hline & & With CT & With CT & & & \\
\hline & $(1)$ & $(2)$ & (3) & $\left(1^{\prime}\right)$ & $\left(2^{\prime}\right)$ & $\left(3^{\prime}\right)$ \\
\hline Total Collections & $22,984,421$ & $25,262,760$ & $27,415,252$ & 17.9 & 18.6 & 18.6 \\
\hline Current Income & $22,984,421$ & $25,262,760$ & $27,415,252$ & 17.9 & 18.6 & 18.6 \\
\hline Tax Revenue & $21,142,824$ & $23,300,866$ & $25,268,529$ & 16.5 & 17.1 & 17.2 \\
\hline On Income & $7,507,547$ & $9,096,474$ & $9,854,678$ & 5.9 & 6.7 & 6.7 \\
\hline Income tax & $7,507,547$ & $9,096,474$ & $9,854,678$ & 5.9 & 6.7 & 6.7 \\
\hline On Production, Consumption and Int. Trans. & $7,614,126$ & $8,095,779$ & $8,791,530$ & 5.9 & 6.0 & 6.0 \\
\hline Value Added Tax (VAT) & $3,425,231$ & $3,633,691$ & $3,933,659$ & 2.7 & 2.7 & 2.7 \\
\hline Selective Consumption Tax (SCT) & $4,160,975$ & $4,432,468$ & $4,825,806$ & 3.2 & 3.3 & 3.3 \\
\hline Rum and Alcohol & 147,632 & 159,721 & 172,906 & 0.1 & 0.1 & 0.1 \\
\hline Beer & 575,564 & 619,823 & 670,987 & 0.4 & 0.5 & 0.5 \\
\hline Cigarettes & 195,348 & 210,155 & 227,503 & 0.2 & 0.2 & 0.2 \\
\hline Carbonated beverages & 199,574 & 211,719 & 229,196 & 0.2 & 0.2 & 0.2 \\
\hline Oil derivatives & $2,070,811$ & $2,257,244$ & $2,443,574$ & 1.6 & 1.7 & 1.7 \\
\hline Other Selective Consumption & 73,929 & 78,428 & 84,902 & 0.1 & 0.1 & 0.1 \\
\hline Selective Consumption Tax on Imports & 898,117 & 895,378 & 996,738 & 0.7 & 0.7 & 0.7 \\
\hline Fiscal Stamp Tax (FST) & 27,920 & 29,620 & 32,065 & 0.0 & 0.0 & 0.0 \\
\hline & & & & & 0.0 & \\
\hline Taxes on Foreign Trade & $6,021,151$ & $6,108,613$ & $6,622,321$ & 4.7 & 4.5 & 4.5 \\
\hline Import Customs Duties (ICD) & 888,516 & $1,071,146$ & $1,200,276$ & 0.7 & 0.8 & 0.8 \\
\hline Value Added Tax on Imports & $5,093,064$ & $4,993,962$ & $5,372,721$ & 4.0 & 3.7 & 3.7 \\
\hline $35 \%$ on Goods and Services from Hond. and Colombia & 39,571 & 43,505 & 49,324 & 0.0 & 0.0 & 0.0 \\
\hline Non-tax Income & $1,670,886$ & $1,788,254$ & $1,949,068$ & 1.3 & 1.3 & 1.3 \\
\hline Rates & 42,767 & 47,568 & 50,925 & 0.0 & 0.0 & 0.0 \\
\hline Import Services & 41,494 & 46,218 & 49,463 & 0.0 & 0.0 & 0.0 \\
\hline Other Services of the Forestry Sector & 1,273 & 1,350 & 1,462 & 0.0 & 0.0 & 0.0 \\
\hline Duties & 183,547 & 195,963 & 212,109 & 0.1 & 0.1 & 0.1 \\
\hline Consular Duties & 62,162 & 65,947 & 71,362 & 0.0 & 0.0 & 0.0 \\
\hline Surface Duty (Mining Exploration) & 28,724 & 30,472 & 32,987 & 0.0 & 0.0 & 0.0 \\
\hline Exploitation Permit (Mining Sector) & 61,390 & 61,691 & 66,783 & 0.0 & 0.0 & 0.0 \\
\hline Geothermal Surface Resource Permit & 703 & 745 & 807 & 0.0 & 0.0 & 0.0 \\
\hline Exploitation of Geothermal Resource Permit & 6,347 & 6,734 & 7,290 & 0.0 & 0.0 & 0.0 \\
\hline Duties for Use of Fishing Resources & 5,642 & 10,664 & 11,544 & 0.0 & 0.0 & 0.0 \\
\hline Forestry Sector Use Permit & 14,868 & 15,773 & 17,075 & 0.0 & 0.0 & 0.0 \\
\hline Concession Fees for the Forestry Sector & 316 & 335 & 362 & 0.0 & 0.0 & 0.0 \\
\hline Concession Fees for Fishing Sector & 3,395 & 3,602 & 3,899 & 0.0 & 0.0 & 0.0 \\
\hline Fines & 25,775 & 27,447 & 31,171 & 0.0 & 0.0 & 0.0 \\
\hline Fines on the Forestry Sector & 774 & 821 & 889 & 0.0 & 0.0 & 0.0 \\
\hline Fines for surface and mining exploitation permit & 166 & 48 & 52 & 0.0 & 0.0 & 0.0 \\
\hline Fines for Traffic infractions & 1,336 & 1,417 & 1,534 & 0.0 & 0.0 & 0.0 \\
\hline Fines for Fishing Sector & 185 & 196 & 212 & 0.0 & 0.0 & 0.0 \\
\hline Other Fees & 23,314 & 24,965 & 28,484 & 0.0 & 0.0 & 0.0 \\
\hline Other Non-Tax Income & $1,418,797$ & $1,517,276$ & $1,654,863$ & 1.1 & 1.1 & 1.1 \\
\hline Profit from Exchange Rate differences & 63,506 & 67,371 & 72,933 & 0.0 & 0.0 & 0.0 \\
\hline Other Non-Tax Income & 195,307 & 208,727 & 227,763 & 0.2 & 0.2 & 0.2 \\
\hline Special Tax for FOMAV & 537,431 & 587,633 & 640,346 & 0.4 & 0.4 & 0.4 \\
\hline Specific Purpose Income & 622,553 & 653,545 & 713,821 & 0.5 & 0.5 & 0.5 \\
\hline Property Income & 45,711 & 48,640 & 52,655 & 0.0 & 0.0 & 0.0 \\
\hline Interest obtained from Loans & 21,986 & 23,324 & 25,249 & 0.0 & 0.0 & 0.0 \\
\hline Interest from Domestic Loans & 21,986 & 23,324 & 25,249 & 0.0 & 0.0 & 0.0 \\
\hline Interest Obtained on Deposits & 23,725 & 25,316 & 27,406 & 0.0 & 0.0 & 0.0 \\
\hline Interest on Domestic Deposits & 23,725 & 25,316 & 27,406 & 0.0 & 0.0 & 0.0 \\
\hline & & & & & & \\
\hline Current Transfers & 125,000 & 125,000 & 145,000 & 0.1 & 0.1 & 0.1 \\
\hline From the Public Sector & 125,000 & 125,000 & 145,000 & 0.1 & 0.1 & 0.1 \\
\hline From Non-Business Autonomous Entities & 105,000 & 105,000 & 120,000 & 0.1 & 0.1 & 0.1 \\
\hline From Non-Financial Public Enterprises & 20,000 & 20,000 & 25,000 & 0.0 & 0.0 & 0.0 \\
\hline Capital Income & & & & & & \\
\hline
\end{tabular}


Table No. 22:

CENTRAL GOVERNMENT

REVISED PROJECTED EXPENDITURES 2009-2011

Thousands of Córdobas

\begin{tabular}{|c|c|c|c|c|c|c|c|c|}
\hline & & & & & With Elect. & & & With Elect. \\
\hline & & & Projection & Rev. Proj. & Projection & Rev. Proj. & Rev. Proj. & Projection \\
\hline \multicolumn{2}{|c|}{ Category } & & August & 2010 & 2011 & 2009 & 2010 & 2011 \\
\hline & & & 2009 & August & & August & August & \\
\hline & & & (1) & (2) & (3) & $\left(1^{\prime}\right)$ & $\left(2^{\prime}\right)$ & $\left(3^{\prime}\right)$ \\
\hline \multicolumn{3}{|c|}{ Current Expenditures } & $23,425,220$ & $23,250,975$ & $25,869,316$ & 18.3 & 17.1 & 17.6 \\
\hline & & & & & & & & \\
\hline & \multicolumn{2}{|c|}{ Consumption Expenditures } & $13,843,896$ & $13,916,349$ & $15,622,634$ & 10.8 & 10.2 & 10.6 \\
\hline & & & & & & & & \\
\hline & \multicolumn{2}{|r|}{ Remuneration } & $8,712,356$ & $9,142,353$ & $9,799,860$ & 6.8 & 6.7 & 6.7 \\
\hline & \multicolumn{2}{|r|}{ Good and Services } & $5,131,540$ & $4,773,996$ & $5,822,774$ & 4.0 & 3.5 & 4.0 \\
\hline & & & & & & & & \\
\hline & \multicolumn{2}{|c|}{ Current Transfers } & $7,764,428$ & $7,401,397$ & $8,135,596$ & 6.1 & 5.4 & 5.5 \\
\hline & \multirow{2}{*}{\multicolumn{2}{|c|}{ To Private Sector }} & & & & & & \\
\hline & & & $1,593,895$ & $1,325,585$ & $1,632,327$ & 1.2 & 1.0 & 1.1 \\
\hline & \multicolumn{2}{|r|}{ To Public Sector } & $6,089,705$ & $5,994,761$ & $6,417,356$ & 4.8 & 4.4 & 4.4 \\
\hline & \multicolumn{2}{|r|}{ To External Sector } & 80,828 & 81,051 & 85,914 & 0.1 & 0.1 & 0.1 \\
\hline & & & & & & & & \\
\hline & \multicolumn{2}{|c|}{ Interest on the Public Debt } & $1,816,896$ & $1,933,229$ & $2,111,086$ & 1.4 & 1.4 & 1.4 \\
\hline & \multicolumn{2}{|c|}{ Domestic } & $1,233,728$ & $1,300,095$ & $1,125,252$ & 1.0 & 1.0 & 0.8 \\
\hline & \multicolumn{2}{|r|}{ Foreign } & 583,168 & 633,134 & 985,834 & 0.5 & 0.5 & 0.7 \\
\hline \multicolumn{3}{|c|}{ Capital Expenditures } & $7,668,316$ & $7,842,561$ & $8,413,115$ & 6.0 & 5.8 & 5.7 \\
\hline & & & & & & & & \\
\hline & \multicolumn{2}{|c|}{ Direct Investment } & $3,800,090$ & $3,546,719$ & $3,829,522$ & 3.0 & 2.6 & 2.6 \\
\hline & & & & & & & & \\
\hline & \multicolumn{2}{|r|}{ Real Investment } & $3,800,090$ & $3,546,719$ & $3,829,522$ & 3.0 & 2.6 & 2.6 \\
\hline & & & & & & & & \\
\hline & & Machinery and Equipment & 551,147 & 553,742 & 586,967 & 0.4 & 0.4 & 0.4 \\
\hline & & Works and Construction & $3,248,943$ & $2,992,977$ & $3,242,555$ & 2.5 & 2.2 & 2.2 \\
\hline & & & & & & & & \\
\hline & \multicolumn{2}{|c|}{ Financial Investment } & 39,500 & 25,000 & 26,500 & 0.0 & 0.0 & 0.0 \\
\hline & & & & & & & & \\
\hline & & Real Estate Acquisition & 0 & 0 & 0 & & & 0.0 \\
\hline & & Net Lending & 39,500 & 25,000 & 26,500 & 0.0 & 0.0 & 0.0 \\
\hline & & & & & & & & \\
\hline & \multicolumn{2}{|c|}{ Indirect Investment } & $3,828,726$ & $4,270,842$ & $4,557,093$ & 3.0 & 3.1 & 3.1 \\
\hline & & & & & & & & \\
\hline & \multicolumn{2}{|r|}{ In Private Sector } & 163,816 & 327,490 & 347,139 & 0.1 & 0.2 & 0.2 \\
\hline & \multicolumn{2}{|r|}{ In Public Sector } & $3,664,910$ & $3,943,352$ & $4,209,953$ & 2.9 & 2.9 & 2.9 \\
\hline & \multirow{2}{*}{\multicolumn{2}{|c|}{ In External Sector }} & 0 & 0 & 0 & & & 0.0 \\
\hline & & & 0 & & 0 & & & \\
\hline \multicolumn{3}{|c|}{ TOTAL EXPENDITURES } & $31,093,536$ & $31,093,536$ & $34,282,431$ & 24.3 & 22.9 & 23.3 \\
\hline & & & & & & & & \\
\hline & Payı & ments on the Public Debt & $3,599,141$ & $4,218,654$ & $4,415,179$ & 2.8 & 3.1 & 3.0 \\
\hline & & Domestic & $2,656,808$ & $3,201,831$ & $3,444,621$ & 2.1 & 2.4 & 2.3 \\
\hline & & Foreign & 942,333 & $1,016,823$ & 970,558 & 0.7 & 0.7 & 0.7 \\
\hline & TAL & EXPENDITURES + PAYMENTS & $34,692,677$ & $35,312,190$ & $38,697,610$ & 27.1 & 26.0 & 26.3 \\
\hline & & & & & & & & \\
\hline
\end{tabular}

CInternational Monetary Fund. Not for Redistribution 
Table No. 23:

CENTRAL GOVERNMENT

EXPENDITURES BY TRANSFER 2007-2011

Thousands of Córdobas

\begin{tabular}{|c|c|c|c|c|c|c|c|c|}
\hline & & & & & With Elect. & & & With Elect. \\
\hline & & & Projection & Rev. Proj. & Projection & Rev. Proj. & Rev. Proj. & Projection \\
\hline \multicolumn{2}{|c|}{ Category } & & August & 2010 & 2011 & 2009 & 2010 & 2011 \\
\hline & & & 2009 & August & & August & August & \\
\hline & & & (1) & (2) & (3) & $\left(1^{\prime}\right)$ & $\left(2^{\prime}\right)$ & $\left(3^{\prime}\right)$ \\
\hline \multicolumn{2}{|c|}{ Current Transfers } & & $7,764,428$ & $7,401,397$ & $8,135,596$ & 6.06 & 5.45 & 5.53 \\
\hline & & & & & & & & \\
\hline \multicolumn{2}{|r|}{ Private Sector } & & $1,593,895$ & $1,325,585$ & $1,632,327$ & 1.24 & 0.98 & 1.11 \\
\hline \multicolumn{3}{|c|}{ Worker Benefits } & 353,476 & 353,476 & 374,685 & 0.28 & 0.26 & 0.25 \\
\hline \multicolumn{3}{|c|}{ Pensions and Retirement } & 62,184 & 61,784 & 65,491 & 0.05 & 0.05 & 0.04 \\
\hline \multicolumn{3}{|c|}{ Scholarships and Registrations } & 238,492 & 210,992 & 223,652 & 0.19 & 0.16 & 0.15 \\
\hline \multicolumn{3}{|c|}{ MOH voucher } & 61,301 & 60,210 & 63,823 & 0.05 & 0.04 & 0.04 \\
\hline \multicolumn{3}{|c|}{ MED Voucher } & 18,971 & 16,753 & 17,758 & 0.01 & 0.01 & 0.01 \\
\hline \multicolumn{3}{|c|}{ MED Subsidized Schools } & 79,026 & 79,026 & 83,768 & 0.06 & 0.06 & 0.06 \\
\hline \multicolumn{3}{|c|}{ Contribution to Political Parties } & 115,458 & 63,157 & 274,153 & 0.09 & 0.05 & 0.19 \\
\hline & Remainder & & 449,214 & 264,414 & 300,279 & 0.35 & 0.19 & 0.20 \\
\hline & \multicolumn{2}{|c|}{ Allocation for Workers Compensation } & 0 & 0 & 0 & 0.00 & 0.00 & 0.00 \\
\hline & \multirow{2}{*}{\multicolumn{2}{|c|}{$\begin{array}{l}\text { Urban Collective Transp. Coop. } \\
\text { Electric Rate Subsidy }\end{array}$}} & 120,000 & 120,000 & 127,200 & 0.09 & 0.09 & 0.09 \\
\hline & & & 95,773 & 95,773 & 101,519 & 0.07 & 0.07 & 0.07 \\
\hline \multicolumn{2}{|r|}{ Public Sector } & & $6,089,705$ & $5,994,761$ & $6,417,356$ & 4.75 & 4.41 & 4.36 \\
\hline \multicolumn{3}{|c|}{ Municipalities } & 483,222 & 577,879 & 626,512 & 0.38 & 0.43 & 0.43 \\
\hline & Universities & & $1,848,795$ & $1,715,612$ & $1,906,946$ & 1.44 & 1.26 & 1.30 \\
\hline & \multicolumn{2}{|c|}{ Employer Contrib. } & 992,645 & $1,111,762$ & $1,178,468$ & 0.77 & 0.82 & 0.80 \\
\hline & CIPS & & 32,856 & 31,856 & 33,767 & 0.03 & 0.02 & 0.02 \\
\hline & \multicolumn{2}{|c|}{ Decentralization of MED } & 0 & 0 & 0 & 0.00 & 0.00 & 0.00 \\
\hline & \multicolumn{2}{|c|}{ Regional Govts and Councils } & 145,074 & 141,398 & 149,882 & 0.11 & 0.10 & 0.10 \\
\hline & INATEC & & 24,770 & 27,002 & 28,622 & 0.02 & 0.02 & 0.02 \\
\hline & \multicolumn{2}{|c|}{ Rubén Darío National Theatre } & 10,333 & 9,833 & 10,423 & 0.01 & 0.01 & 0.01 \\
\hline & INTA & & 164,231 & 160,631 & 170,269 & 0.13 & 0.12 & 0.12 \\
\hline & DGI & & 260,413 & 258,578 & 274,093 & 0.20 & 0.19 & 0.19 \\
\hline & DGSA & & 199,064 & 196,064 & 207,828 & 0.16 & 0.14 & 0.14 \\
\hline & ENEL & & 0 & 0 & 0 & 0.00 & 0.00 & 0.00 \\
\hline & ENACAL & & 57,650 & 42,000 & 44,520 & 0.05 & 0.03 & 0.03 \\
\hline & FOMAV & & 536,933 & 584,767 & 640,346 & 0.42 & 0.43 & 0.44 \\
\hline & \multicolumn{2}{|c|}{ Rest of Public Sector } & $1,333,719$ & $1,137,379$ & $1,145,681$ & 1.04 & 0.84 & 0.78 \\
\hline \multicolumn{2}{|r|}{ External Sector } & & 80,828 & 81,051 & 85,914 & 0.06 & 0.06 & 0.06 \\
\hline & & & 0 & & & & & \\
\hline Cap & ital Transfers & & $3,828,726$ & $4,270,842$ & $4,557,093$ & 2.99 & 3.14 & 3.10 \\
\hline & & & & & & & & \\
\hline & Private Sector & & 163,816 & 327,490 & 347,139 & 0.13 & 0.24 & 0.24 \\
\hline & Remainder & & 163,816 & 327,490 & 347,139 & 0.13 & 0.24 & 0.24 \\
\hline & Public Sector & & $3,664,910$ & $3,943,352$ & $4,209,953$ & 2.86 & 2.90 & 2.86 \\
\hline & ENACAL & & 161,392 & 141,277 & 149,754 & 0.13 & 0.10 & 0.10 \\
\hline & ENATREL & & 82,940 & 62,551 & 66,304 & 0.06 & 0.05 & 0.05 \\
\hline & Universities & & 202,611 & 150,000 & 150,000 & 0.16 & 0.11 & 0.10 \\
\hline & Municipalities & & $1,476,632$ & $1,752,828$ & $1,900,341$ & 1.15 & 1.29 & 1.29 \\
\hline & Regional Gov & ernments & 124,992 & 123,254 & 130,649 & 0.10 & 0.09 & 0.09 \\
\hline & Remainder & & $1,616,343$ & $1,713,442$ & $1,812,906$ & 1.26 & 1.26 & 1.23 \\
\hline & & & & & & & & \\
\hline & External Sector & & & & & 0.00 & 0.00 & 0.00 \\
\hline
\end{tabular}

(C) International Monetary Fund. Not for Redistribution 
Table No. 24:

CENTRAL GOVERNMENT

PROJECTION 2009 - 2011

TOTAL EXPENDITURES

Thousands of Córdobas

\begin{tabular}{|c|c|c|c|c|c|c|c|}
\hline & & Mod. Budget & Projection & Projection & Mod. Budget & Projection & Projection \\
\hline \multicolumn{2}{|r|}{ Institution } & 2009 & 2010 & 2011 & 2009 & 2010 & 2011 \\
\hline & & & & \multicolumn{4}{|c|}{ Percentage GDP } \\
\hline \multicolumn{2}{|c|}{ TOTAL MINISTRIES } & $20,536,204$ & $19,896,468$ & $22,141,911$ & 16.03 & 14.64 & 15.05 \\
\hline \multicolumn{2}{|r|}{ Branches of Government and other Institutions } & $2,246,268$ & $2,155,770$ & $3,239,391$ & 1.75 & 1.59 & 2.20 \\
\hline \multicolumn{2}{|r|}{ National Assembly } & 418,191 & 397,023 & 420,527 & 0.33 & 0.29 & 0.29 \\
\hline \multicolumn{2}{|r|}{ Supreme Court } & $1,244,128$ & $1,243,741$ & $1,371,298$ & 0.97 & 0.92 & 0.93 \\
\hline \multicolumn{2}{|r|}{ Supreme Electoral Council } & 417,086 & 359,509 & $1,297,470$ & 0.33 & 0.26 & 0.88 \\
\hline & Elections & 230,000 & 177,423 & $1,104,605$ & 0.18 & 0.13 & 0.75 \\
\hline & Remainder & 187,086 & 182,086 & 192,865 & 0.15 & 0.13 & 0.13 \\
\hline \multicolumn{2}{|r|}{ Comptroller General of the Republic } & 166,863 & 155,497 & 150,096 & 0.13 & 0.11 & 0.10 \\
\hline \multicolumn{2}{|r|}{ Presidency and Ministries } & $18,289,936$ & $17,740,698$ & $18,902,520$ & 14.28 & 13.06 & 12.85 \\
\hline \multicolumn{2}{|r|}{ Presidency of the Republic } & 186,620 & 189,654 & 199,405 & 0.15 & 0.14 & 0.14 \\
\hline \multicolumn{2}{|r|}{ Ministry of the Interior } & $1,454,632$ & $1,423,025$ & $1,488,163$ & 1.14 & 1.05 & 1.01 \\
\hline & National Police & $1,101,298$ & $1,090,004$ & $1,132,750$ & 0.86 & 0.80 & 0.77 \\
\hline \multirow{2}{*}{\multicolumn{2}{|c|}{$\begin{array}{l}\text { Remainder } \\
\text { Foreign Ministry }\end{array}$}} & 353,334 & 333,021 & 355,413 & 0.28 & 0.25 & 0.24 \\
\hline & Foreign Ministry & 491,028 & 473,119 & 501,144 & 0.38 & 0.35 & 0.34 \\
\hline \multicolumn{2}{|r|}{ Ministry of Defense } & 854,190 & 822,718 & 869,191 & 0.67 & 0.61 & 0.59 \\
\hline \multicolumn{2}{|r|}{ Army of Nicaragua } & 840,095 & 808,726 & 854,371 & 0.66 & 0.60 & 0.58 \\
\hline & Remainder & 14,095 & 13,992 & 14,820 & 0.01 & 0.01 & 0.01 \\
\hline \multicolumn{2}{|r|}{ Ministry of Finance and Public Credit } & 339,114 & 400,935 & 399,424 & 0.26 & 0.30 & 0.27 \\
\hline \multicolumn{2}{|r|}{ Ministry of Development, Industry and Commerce } & 232,560 & 229,049 & 236,570 & 0.18 & 0.17 & 0.16 \\
\hline & Ministry of Education & $5,241,205$ & $4,915,878$ & $5,361,904$ & 4.09 & 3.62 & 3.64 \\
\hline & Ministry of Agriculture and Forestry & 955,205 & $1,008,355$ & $1,065,324$ & 0.75 & 0.74 & 0.72 \\
\hline & Ministry of Agriculture and Forestry & 668,398 & 780,439 & 842,891 & 0.52 & 0.57 & 0.57 \\
\hline & INTA & 188,281 & 163,148 & 153,831 & 0.15 & 0.12 & 0.10 \\
\hline & INAFOR & 98,526 & 64,768 & 68,602 & 0.08 & 0.05 & 0.05 \\
\hline & Ministry of Transportation and Infrastructure & $2,314,679$ & $2,405,518$ & $2,436,935$ & 1.81 & 1.77 & 1.66 \\
\hline & Ministry of Health & $5,169,714$ & $4,995,174$ & $5,329,419$ & 4.04 & 3.68 & 3.62 \\
\hline & Ministry of Labor & 222,414 & 136,977 & 311,194 & 0.17 & 0.10 & 0.21 \\
\hline & Ministry of Labor & 47,937 & 46,022 & 49,687 & 0.04 & 0.03 & 0.03 \\
\hline & INATEC & 174,477 & 90,955 & 261,507 & 0.14 & 0.07 & 0.18 \\
\hline & Ministry of the Environment and Natural Resources & 122,418 & 116,937 & 123,632 & 0.10 & 0.09 & 0.08 \\
\hline & Ministry of the Family, Adolescents and Children & 280,399 & 239,228 & 213,180 & 0.22 & 0.18 & 0.14 \\
\hline & Ministry of Energy and Mining & 367,682 & 302,509 & 283,170 & 0.29 & 0.22 & 0.19 \\
\hline & Attorney General of the Republic & 58,076 & 81,622 & 83,865 & 0.05 & 0.06 & 0.06 \\
\hline & & & & & 0.00 & 0.00 & 0.00 \\
\hline TOT & TAL ALLOCATIONS AND SUBSIDIES & $8,740,392$ & $9,263,840$ & $10,029,436$ & 6.82 & 6.82 & 6.82 \\
\hline & Nicaraguan Institute for Municipal Development & 98,124 & 60,232 & 69,650 & 0.08 & 0.04 & 0.05 \\
\hline & Institute for Rural Development - IDR & 477,312 & 392,744 & 413,917 & 0.37 & 0.29 & 0.28 \\
\hline & Social Emergency Investment Fund (FISE) & 563,059 & 528,136 & 662,330 & 0.44 & 0.39 & 0.45 \\
\hline & General Revenue Office & 281,537 & 256,142 & 271,513 & 0.22 & 0.19 & 0.18 \\
\hline & General Customs Services Office & 202,814 & 197,064 & 208,887 & 0.16 & 0.15 & 0.14 \\
\hline & Nicaraguan Institute of Territorial Studies & 79,890 & 72,509 & 80,498 & 0.06 & 0.05 & 0.05 \\
\hline & Northern Atlantic Autonomous Regional Governme & 189,759 & 167,792 & 177,254 & 0.15 & 0.12 & 0.12 \\
\hline & Southern Atlantic Autonomous Regional Governme & 100,272 & 96,683 & 102,520 & 0.08 & 0.07 & 0.07 \\
\hline & Road Maintenance Fund (FOMAV) & 537,182 & 587,633 & 640,346 & 0.42 & 0.43 & 0.44 \\
\hline & National Development Information Institute & 35,523 & 34,303 & 36,486 & 0.03 & 0.03 & 0.02 \\
\hline & Nicaraguan Women's Institute & 6,334 & 6,125 & 6,488 & 0.00 & 0.00 & 0.00 \\
\hline & Remainder & $6,168,586$ & $6,864,477$ & $7,359,547$ & 4.82 & 5.05 & 5.00 \\
\hline & & & & & & & \\
\hline$\overline{\text { TOT }}$ & TAL OPERATIONAL EXPENDITURES & $29,276,596$ & $29,160,308$ & $32,171,347$ & 22.86 & 21.46 & 21.87 \\
\hline & & & & & & & \\
\hline & & & & & & & \\
\hline & Interest on the Public Debt & $1,816,895$ & $1,933,229$ & $2,111,086$ & 1.42 & 1.42 & 1.44 \\
\hline & & & & & & & \\
\hline & & & & & & 0.00 & \\
\hline$\overline{\text { TOT }}$ & TAL EXPENDITURES & $31,093,491$ & $31,093,537$ & $34,282,433$ & 24.27 & 22.88 & 23.30 \\
\hline & & & & & & 0 & \\
\hline
\end{tabular}


Table No. 25: CENTRAL GOVERNMENT

PROJECTION 2009 - 2011

TOTAL CURRENT EXPENDITURES

Thousands of Córdobas

\begin{tabular}{|c|c|c|c|c|c|c|c|c|}
\hline & & & & & & & \multicolumn{2}{|c|}{$\%$ GDP } \\
\hline & & & Mod. Budget & Projection & Projection & Mod. Budget & Projection & Projection \\
\hline \multicolumn{2}{|c|}{ Institution } & & 2,009 & 2,010 & 2,011 & 2,009 & 2,010 & 2,011 \\
\hline & & & & & & \multicolumn{3}{|c|}{ Percentage GDP } \\
\hline \multicolumn{3}{|c|}{ TOTAL MINISTRIES } & $16,287,542$ & $15,837,775$ & $17,749,440$ & 12.72 & 11.66 & 12.07 \\
\hline \multicolumn{3}{|c|}{ Branches of Government and other Institutions } & $2,127,289$ & $2,059,759$ & $3,164,677$ & 1.66 & 1.52 & 2.15 \\
\hline \multicolumn{3}{|c|}{ National Assembly } & 407,023 & 397,023 & 420,527 & 0.32 & 0.29 & 0.29 \\
\hline \multicolumn{3}{|c|}{ Supreme Court } & $1,168,844$ & $1,170,691$ & $1,306,298$ & 0.91 & 0.86 & 0.89 \\
\hline \multicolumn{3}{|c|}{ Supreme Electoral Council } & 417,086 & 359,509 & $1,297,470$ & 0.33 & 0.26 & 0.88 \\
\hline & & Elections & 230,000 & 177,423 & $1,104,605$ & 0.18 & 0.13 & 0.75 \\
\hline & & Remainder & 187,086 & 182,086 & 192,865 & 0.15 & 0.13 & 0.13 \\
\hline \multicolumn{3}{|c|}{ Comptroller General of the Republic } & 134,336 & 132,536 & 140,382 & 0.10 & 0.10 & 0.10 \\
\hline \multicolumn{3}{|c|}{ Presidency and Ministries } & $14,160,253$ & $13,778,016$ & $14,584,763$ & 11.05 & 10.14 & 9.91 \\
\hline \multicolumn{3}{|c|}{ Presidency of the Republic } & 177,233 & 170,693 & 181,530 & 0.14 & 0.13 & 0.12 \\
\hline \multicolumn{3}{|c|}{ Ministry of the Interior } & $1,316,266$ & $1,316,011$ & $1,383,579$ & 1.03 & 0.97 & 0.94 \\
\hline & & National Police & $1,000,325$ & $1,001,911$ & $1,049,008$ & 0.78 & 0.74 & 0.71 \\
\hline & & Remainder & 315,941 & 314,100 & 334,571 & 0.25 & 0.23 & 0.23 \\
\hline \multicolumn{3}{|c|}{ Foreign Ministry } & 489,417 & 473,003 & 501,023 & 0.38 & 0.35 & 0.34 \\
\hline \multicolumn{3}{|c|}{ Ministry of Defense } & 834,087 & 802,718 & 849,191 & 0.65 & 0.59 & 0.58 \\
\hline & & Army of Nicaragua & 820,095 & 788,726 & 834,371 & 0.64 & 0.58 & 0.57 \\
\hline & & Remainder & 13,992 & 13,992 & 14,820 & 0.01 & 0.01 & 0.01 \\
\hline \multicolumn{3}{|c|}{ Ministry of Finance and Public Credit } & 298,259 & 280,755 & 287,732 & 0.23 & 0.21 & 0.20 \\
\hline \multicolumn{3}{|c|}{ Ministry of Development, Industry and Commerce } & 170,538 & 167,594 & 177,516 & 0.13 & 0.12 & 0.12 \\
\hline \multicolumn{3}{|c|}{ Ministry of Education } & $4,721,129$ & $4,550,416$ & $4,836,877$ & 3.69 & 3.35 & 3.29 \\
\hline \multicolumn{3}{|c|}{ Ministry of Agriculture and Forestry } & 680,481 & 650,351 & 665,291 & 0.53 & 0.48 & 0.45 \\
\hline & & Ministry of Agriculture and Forestry & 436,299 & 422,435 & 442,858 & 0.34 & 0.31 & 0.30 \\
\hline & & INTA & 164,231 & 163,148 & 153,831 & 0.13 & 0.12 & 0.10 \\
\hline & & INAFOR & 79,951 & 64,768 & 68,602 & 0.06 & 0.05 & 0.05 \\
\hline & Minist & ansportation and Infrastructure & 252,651 & 248,119 & 253,687 & 0.20 & 0.18 & 0.17 \\
\hline & Minist & ealth & $4,629,790$ & $4,575,178$ & $4,874,605$ & 3.61 & 3.37 & 3.31 \\
\hline & Minist & abor & 60,078 & 61,622 & 66,211 & 0.05 & 0.05 & 0.05 \\
\hline & & Ministry of Labor & 46,796 & 46,022 & 49,687 & 0.04 & 0.03 & 0.03 \\
\hline & & INATEC & 13,282 & 15,600 & 16,524 & 0.01 & 0.01 & 0.01 \\
\hline & Minist & e Environment and Natural Resources & 98,710 & 94,056 & 99,624 & 0.08 & 0.07 & 0.07 \\
\hline & Minist & e Family, Adolescents and Children & 259,376 & 198,905 & 210,680 & 0.20 & 0.15 & 0.14 \\
\hline & Minist & nergy and Mining & 114,565 & 109,390 & 115,866 & 0.09 & 0.08 & 0.08 \\
\hline & Attorn & neral of the Republic & 57,673 & 79,205 & 81,351 & 0.05 & 0.06 & 0.06 \\
\hline & & & & & & 0.00 & 0.00 & 0.00 \\
\hline TOTA & AL ALL & ONS AND SUBSIDIES & $5,327,371$ & $5,479,971$ & $6,008,790$ & 4.16 & 4.03 & 4.08 \\
\hline & & Nicaraguan Institute for Municipal Development & 58,147 & 50,104 & 51,676 & 0.05 & 0.04 & 0.04 \\
\hline & & Institute for Rural Development - IDR & 138,413 & 111,557 & 112,860 & 0.11 & 0.08 & 0.08 \\
\hline & & Social Emergency Investment Fund (FISE) & 151,259 & 146,120 & 156,518 & 0.12 & 0.11 & 0.11 \\
\hline & & General Revenue Office & 270,377 & 256,142 & 271,513 & 0.21 & 0.19 & 0.18 \\
\hline & & General Customs Services Office & 199,064 & 197,064 & 208,887 & 0.16 & 0.15 & 0.14 \\
\hline & & Nicaraguan Institute of Territorial Studies & 63,078 & 65,378 & 70,110 & 0.05 & 0.05 & 0.05 \\
\hline & & Northern Atlantic Autonomous Regional Governm & 98,911 & 85,931 & 92,476 & 0.08 & 0.06 & 0.06 \\
\hline & & Southern Atlantic Autonomous Regional Governr & 66,128 & 63,883 & 69,470 & 0.05 & 0.05 & 0.05 \\
\hline & & Road Maintenance Fund (FOMAV) & 536,933 & 587,633 & 640,346 & 0.42 & 0.43 & 0.44 \\
\hline & & National Development Information Institute & 35,523 & 34,303 & 36,486 & 0.03 & 0.03 & 0.02 \\
\hline & & Nicaraguan Women's Institute & 6,248 & 6,125 & 6,488 & 0.00 & 0.00 & 0.00 \\
\hline & & Remainder & $3,703,290$ & $3,875,731$ & $4,291,960$ & 2.89 & 2.85 & 2.92 \\
\hline & & & & & & & & \\
\hline & & & & & & & 0.00 & \\
\hline TOTA & AL OPE & NAL FUNDING & $21,614,913$ & $21,317,746$ & $23,758,230$ & 16.87 & 15.69 & 16.15 \\
\hline
\end{tabular}


Table No. 26:CENTRAL GOVERNMENT

PROJECTION 2009 - 2011

TOTAL CAPITAL EXPENDITURES

Thousands of Córdobas

\begin{tabular}{|l|c|c|c|c|c|c|c|c|c|c|c|c|c|}
\hline & Mod. Budget & Projection & Projection & Mod. Budget & Projection & Projection \\
\hline Institution & 2,009 & 2,010 & 2,011 & 2,009 & 2,010 \\
\hline
\end{tabular}

\section{TOTAL MINISTRIES}

Branches of Government and other Institutions

National Assembly

Supreme Court

Supreme Electoral Council

$$
\text { Elections }
$$

Remainder

Comptroller General of the Republic

\section{Presidency and Ministries}

Presidency of the Republic

Ministry of the Interior

National Police

Remainder

Foreign Ministry

Ministry of Defense

\section{Army of Nicaragua}

Remainder

Ministry of Finance and Public Credit

Ministry of Development, Industry and Commerce

Ministry of Education

Ministry of Agriculture and Forestry

Ministry of Agriculture and Forestry

\section{INTA}

INAFOR

Ministry of Transportation and Infrastructure

Ministry of Health

Ministry of Labor

$$
\text { Ministry of Labor }
$$

INATEC

Ministry of the Environment and Natural Resources

Ministry of the Family, Adolescents and Children

Ministry of Energy and Mining

Attorney General of the Republic

\section{TOTAL ALLOCATIONS AND SUBSIDIES}

Nicaraguan Institute for Municipal Development

Institute for Rural Development - IDR

Social Emergency Investment Fund (FISE)

General Income Office

General Customs Services Office

Nicaraguan Institute of Territorial Studies

Northern Atlantic Autonomous Regional Governme

Southern Atlantic Autonomous Regional Governm

Road Maintenance Fund (FOMAV)

National Development Information Institute

Nicaraguan Women's Institute

Remainder

\begin{tabular}{r|}
$\mathbf{4 , 2 4 8 , 6 6 2}$ \\
$\mathbf{1 1 8 , 9 7 9}$ \\
11,168 \\
75,284 \\
0 \\
0 \\
0
\end{tabular}

32,527

$4,129,683$

9,387

138,366

100,973

37,393

1,611

20,103

20,000

103

40,855

62,022

520,076

274,724

232,099

24,050

18,575

$2,062,028$

539,924

162,336

1,141

161,195

23,708

21,023

253,117

403

$3,413,021$

39,977

338,899

411,800

11,160

3,750

16,812

90,848

34,144

249

0

86

$2,465,296$
$4,058,693$

96,011

73,050

0

0

22,961

$3,962,682$

18,961

107,014

88,093

18,921

116

20,000

20,000

120,180

61,455

365,462

358,004

358,004

0

$2,157,399$

419,996

75,355

0

75,355

22,881

40,323

193,119

2,417

$\mathbf{3}, \mathbf{7 8 3}, \mathbf{8 6 9}$

10,128

281,187

382,016

$$
0
$$

7,131

81,861

32,800

$\begin{array}{r}\mathbf{4 , 3 9 2 , 4 7 1} \\ \mathbf{7 4 , 7} \\ \mathbf{6 5 , 0} \\ \hline \\ \hline\end{array}$

392,471

74,714

3.32

2.99

0.07

0.00

2.99

5,000

0.01

0.05

0.00

0.00

0.00

9,714

$4,317,757$

17,875

104,584

83,742

20,842

121

20,000

20,000

0
111,692

59,054

525,027

400,033

400,033

0

$2,183,248$

454,814

244,983

0

244,983

24,008

2,500

167,304

2,514

0.00

0.00

0.00

0.02

2.92

3.22

0.01

0.11

0.01

0.08

0.06

0.01

0.00

0.00

0.03

\begin{tabular}{l}
0.03 \\
0.00 \\
\hline
\end{tabular}

0.02

0.02

0.01

$\begin{array}{ll}0.00 & 0.00\end{array}$

0.03

0.05

0.09

0.09
0.05

0.41

0.21

0.18

0.18
0.02

0.02
0.01

1.61

0.42

0.13

0.13

0.13

0.02

0.02

0.20

0.00

0.27

0.26

0.26

0.00

0.00

1.59

0.31

0.06

0.00

0.06

0.02

0.03

0.14

0.00

0.00

$4,020,646$

17,974

301,057

2.66

0.00

2.78

0.01

505,812

0.03

0.26

0.21

\begin{tabular}{|l|l|}
\hline 0.32 & 0.28 \\
\hline 0.01 & 0.00 \\
\hline
\end{tabular}

0.00

0.00

0.01

0.01

0.06

0.02

0.00

0.00

0.00

2.20

5.77

5.72 


\section{Table No. 27: Balance of Payments}

(millions of dollars)

\begin{tabular}{|c|c|c|c|c|c|}
\hline \multicolumn{2}{|r|}{ Item } & \multirow[b]{2}{*}{2008} & \multicolumn{3}{|c|}{ Projections } \\
\hline & & & 2009 & 2010 & 2011 \\
\hline \multicolumn{2}{|c|}{ 1.- Current Account } & $(1,512.9)$ & (946.4) & $(1,160.7)$ & $(1,166.8)$ \\
\hline & As percentage of GDP & $-23.8 \%$ & $-15.0 \%$ & $-18.2 \%$ & $-17.9 \%$ \\
\hline \multicolumn{2}{|c|}{ Trade Balance in Goods } & $(2,211.3)$ & $(1,570.5)$ & $(1,732.0)$ & $(1,767.4)$ \\
\hline & Exports & $2,537.6$ & $2,298.2$ & $2,363.7$ & $2,584.8$ \\
\hline & Merchandise & $1,488.7$ & $1,340.1$ & $1,412.0$ & $1,531.7$ \\
\hline & Manufactured goods (FTZ) & $1,015.6$ & 942.0 & 932.5 & $1,033.2$ \\
\hline & Other goods & 33.3 & 16.0 & 19.2 & 19.9 \\
\hline & Imports & $(4,748.9)$ & $(3,868.7)$ & $(4,095.7)$ & $(4,352.2)$ \\
\hline & Merchandise & $(4,017.5)$ & $(3,190.3)$ & $(3,424.2)$ & $(3,608.2)$ \\
\hline & Other goods & $(731.4)$ & $(678.4)$ & (671.5) & $(744.0)$ \\
\hline \multicolumn{2}{|c|}{ Trade Balance in Services } & (209.1) & (193.7) & (252.8) & $(290.6)$ \\
\hline & Income & 399.1 & 410.2 & 413.0 & 430.4 \\
\hline & Expenditures & $(608.2)$ & $(603.9)$ & $(665.8)$ & $(721.0)$ \\
\hline \multirow[t]{2}{*}{ Net income } & & (160.6) & (183.4) & (197.5) & (221.7) \\
\hline & of which: Interest on Public Debt & $(40.5)$ & $(41.5)$ & $(42.4)$ & $(47.5)$ \\
\hline \multicolumn{2}{|c|}{ Private transfers } & $1,068.1$ & $1,001.2$ & $1,021.7$ & $1,112.9$ \\
\hline & of which: Family remittances & 818.1 & 771.2 & 801.7 & 912.9 \\
\hline \multicolumn{2}{|c|}{ 2.- Capital and Financial Account } & $1,534.8$ & 929.5 & $1,195.7$ & $1,163.2$ \\
\hline \multicolumn{2}{|c|}{ Official Capital } & 332.8 & 478.5 & 486.0 & 451.0 \\
\hline & Grants & 198.3 & 182.3 & 190.6 & 195.9 \\
\hline & Loans & 219.5 & 378.5 & 366.1 & 325.6 \\
\hline & Payments & $(75.1)$ & $(80.9)$ & $(70.7)$ & $(70.5)$ \\
\hline & Other & $(9.8)$ & $(1.4)$ & 0.0 & \\
\hline \multicolumn{2}{|c|}{ Private Capital $1 /$} & $1,202.0$ & 451.0 & 709.8 & 712.2 \\
\hline & Direct foreign investment & 626.1 & 513.8 & 562.0 & 577.1 \\
\hline & Portfolio investment & $(0.3)$ & 0.0 & 0.0 & \\
\hline & Capital transfer & 176.7 & 216.1 & 144.0 & 136.2 \\
\hline & Financial System and private flows & 399.5 & $(278.9)$ & 3.7 & $(1.1)$ \\
\hline & Assets & $(64.7)$ & (231.9) & $(33.0)$ & $(43.3)$ \\
\hline & Medium and long-term liabilities & 202.6 & 137.5 & 146.5 & 178.1 \\
\hline & Others & 261.6 & $(184.6)$ & $(109.8)$ & $(135.9)$ \\
\hline \multicolumn{2}{|c|}{ 3.- Balance of payments balance $(1+2)$} & 21.9 & (16.8) & 35.1 & (3.6) \\
\hline & Changes in reserve assets (- increz & $(37.5)$ & $(1.8)$ & $(46.6)$ & $(7.0)$ \\
\hline & Exceptional financing $2 /$ & 15.6 & 18.6 & 11.5 & 10.6 \\
\hline \multicolumn{6}{|c|}{ Memorandum } \\
\hline \multicolumn{2}{|c|}{ GDP in millions of dollars } & $6,365.3$ & 6,297.7 & $6,362.8$ & $6,533.5$ \\
\hline \multicolumn{2}{|c|}{ 1/: Includes errors and omissions } & & & & \\
\hline \multicolumn{3}{|c|}{ 2/: Includes current relief in service of the foreign debt } & & & \\
\hline \multicolumn{2}{|c|}{ Source: BCN / MHCP } & & & & \\
\hline
\end{tabular}

CInternational Monetary Fund. Not for Redistribution 


\section{ANNEX No. 2: ECONOMIC AND SOCIAL MANAGEMENT 2007-2008}

\section{Introduction}

329. The Government of Reconciliation and National Unity (GRUN) took power on January 10, 2007, with a new proposal for government in the face of the neoliberal project that is in crisis in all Latin American countries with devastating effects on the economy of the most vulnerable citizens. It has been demonstrated in Nicaragua and the rest of Latin America that the neoliberal socioeconomic model does not lead to development or poverty reduction, but rather the opposite, to a concentration of wealth and income in financial capital. The government seeks to move from an economic model that has put the market at its center to a new model of Citizen Power that centers on human beings, as the point of departure to reach toward a society with human quality and dignity.

330. The citizen power model puts the human being at the center of the model, emphasizing the recovery of rights, the recovery of values and the recovery of social capacities that foster people's sovereignty, cooperation, solidarity and complementary efforts, and humanitarian foreign aid, with no type of conditionality.

331. As the basis of that model, at the beginning of its administration, the GRUN worked to immediately resolve the problem of daily 12-hour cuts in electrical energy through solidarity from Bolivarian Alternative for the Americas (ALBA) which provided thermal plants. In order to achieve economic stability, the government worked on its own Economic and Financial Program (EFP) to facilitate rapid agreement with the IMF. It established macroeconomic stability as a means to ensure economic function, but mainly as a means to combat poverty; fostering productive capacities of the poorest; implementing a strategy of food security and sovereignty in rural areas; recovering the free nature of health services and education; ending illiteracy in two years; applying a new National Social Welfare System; creating anti-poverty programs, with Zero Hunger, Zero Usury, the seed and urea plan; strengthening small and medium enterprises; and moving toward harmony between human beings and nature in the face of the depredation of the environment.

332. On its first day in office, the revolutionary government decreed a first set of policies to defend the buying power of the poor and to counteract the effects of the neoliberal model, including: free public education and health care, subsidized fares of C\$2.50 for the urban buses of Managua, a subsidized social rate for domestic consumers of electricity who consume less than $150 \mathrm{KWH}$, and a subsidized social rate for water for poor families in poor settlements with consumption of less than six cubic meters.

333. In addition, to counteract the effect of speculative prices on food, it reactivated the dismantled National Basic Foodstuffs Supply Company (ENABAS) to use it and a network of small neighborhood shops to distribute staple foods at prices that are lower than the open market. It also lowered tariffs on imports of chicken and eliminated tariffs on imports of wheat flour, beans, pasta, oat and barley by-products, soy-based preparations and non-refined oils. Other measures to defend against the crisis have included increases in the national thermal energy capacity by $120 \mathrm{MW}$, which has made it possible to resolve the immediate national needs while the energy grid is transformed toward diverse renewable sources. 
334. In order to deal with the effects of the world crisis and to establish a basis for reactivation of the economy, the GRUN, through the program to reactivate production and exports for growth and employment, has added other measures to address critical situations in various current categories of production, prioritizing food for nutritional and food security and sovereignty, exports and intensive work activities. Furthermore, it also emphasizes the mass use of public investment to generate economic activity and to invigorate investments in tourism, agro industry and free trade zones. It has also taken measures to maximize the use of public spending on wealth-generating activities.

335. This report addresses each of the major actions taken by the Government of Reconciliation and National Unity, not only to alleviate the effects of the worldwide financial crisis, but also to change the model of government, offering people greater participation in the different arenas for decision-making.

\section{DEVELOPMENT AND SOCIAL EQUITY}

336. The Government of Reconciliation and National Unity (GRUN) faces a challenge in developing a broader social policy that leads to transformation from the neoliberal model of unprotected social rights to the creation in the Nicaraguan people of an awareness and practice of rights, advancing toward a fair and equitable society with solidarity, based on the recovery of values, the recovery of rights, and the recovery and expansion of the capacities of Nicaraguans.

\section{Free and Quality Health Care}

337. The major challenge found by the GRUN in health care has been the lack of access to health services by large sectors of the population, and it has responded by implementing the policy of free health care, the expansion of high-cost medical services directed at the neediest population with chronic diseases, and the extension of specialized services using surgical medical brigades and mobile medical brigades, enabling it to serve broad sectors of the population, thus contributing to the restoration of the rights of Nicaraguan citizens.

338. The Family and Community Health Model began the process of providing comprehensive health care to the population according to the condition of the individual. As of 2008, achievements include visits to 128,891 families, of which $65 \%$ live in rural areas.

339. Total medical consultations (in hospitals and Health Centers and Posts) have increased from $6,630,743$ in 2006 to $9,899,885$ in 2008; this increase in 2008 represents a $49.3 \%$ increase over the consultations provided in 2006. Prescriptions dispatched also increased, from 10,916,833 in 2006 to $20,443,542$ in 2008 , an increase of $87.3 \%$. Total discharges of patients that were hospitalized increased $19 \%$ in 2008 over the figure for 2006.

340. In addition, there was a $46.5 \%$ increase in access by the public to surgery in 2008 compared to 2006. Misión Milagros attended 770 patients in Cuba and 3,021 patients in Venezuela. Some 37,002 operations were performed in Ophthalmological Centers in Ciudad Sandino, Bluefields and Puerto Cabezas in Nicaragua. 
341. One hundred and fourteen deaths of women (during pregnancy, birth or the postpartum period) were recorded in 2007, while 94 deaths were recorded in 2008, with the implementation of the Maternal Mortality Containment Plan. Increased coverage for prenatal care, attention during birth and postnatal care has a positive impact on this achievement.

342. Deaths of children less than one year of age decreased to 1,308 in 2008 (this number was 1,349 in 2006). Factors that contributed to this achievement included: the Growth and Development Surveillance and Promotion (VPCD) Program's monitoring of children less than one year of age, the National Health Campaigns and immunizations of children less than one year of age.

\section{Child Protection: Amor Program}

343. This program began in 2008 and by the end of that same year, 2,100 of the 25,000 children who live at risk in streets throughout the country had been enrolled in school for the cycle beginning in February 2009, 205 were incorporated into their homes of origin or substitute families, and the network of solidarity homes was strengthened with 380 families willing to welcome a child into their home. Comprehensive care was provided for 4,000 children less than six years of age in 37 Child Development Centers (CDI) throughout the country. Nineteen CDIs have been rebuilt, with reconstruction and equipping of four additional CDIs currently underway. There are 60 units for basic physical medical care in different health centers around the country and work is being done on a community-based rehabilitation strategy. The program identified 1,960 children and adolescents who did not have a birth certificate and 800 were registered. Some 5,974 children and adolescents that work were enrolled in school for the 2009 academic year.

\section{Free and Quality Education}

344. The triumph of the Government of Reconciliation and National Unity in 2007 marked the end of the privatization of education, opening school doors to the entire population and initiating the process of change toward high-quality education that is inclusive and equitable, leading to the transformation of human being and enabling them to emerge from poverty and underdevelopment. This process is being implemented through five educational policies: More Education, Better Education, Another Education, Participatory and Decentralized Educational Management, and All Educations.

345. The "From Martí to Fidel" National Literacy Campaign, begun in 2007, has taught a total of 246,209 citizens to read and write, decreasing the illiteracy rate from $20.2 \%$ reported in January 2007 to $7.5 \%$ at the end of 2008 , surpassing the historic figures of the $1980 \mathrm{~s}(12.5 \%)$.

346. Preschool registration for 2008 was 220,529 children, surpassing the 2007 figure by 5,914 and the 2006 figure by 10,579. Moreover, the proportion of school age children that are registered (net schooling rate) rose from $52.1 \%$ in 2006 to $55.1 \%$ in 2008 . Enrollment in primary school in 2008 was 944,341 children. The net schooling rate (school-age children enrolled in school) in primary school increased in 2008 compared to 2007 , rising from $86.5 \%$ to $87.1 \%$. Secondary school enrollment was 446,868 students in 2008, decreasing by 4,215 students compared to 2007 . Nevertheless, there were 21,150 more students than in 2006. The net schooling rate remained at 
$46 \%$ for 2008 and 2007 , higher than the 2006 rate of $43.6 \%$. School retention was $90.9 \%$ in 2008 , surpassing the figures for 2007 and 2006 which were $83 \%$ and $86 \%$ respectively.

\section{Quality Model: Progress in Curriculum Reform}

347. The Government of Nicaragua, through the Ministry of Education (MINED), began the process of educational change in 2007, with the Great National Curriculum Consultation which considered the opinion of 17,500 people throughout the country, including parents as well as civic, cultural and political organizations, regarding what should be taught and learned in the schools.

348. In 2008, based on the results of the consultation, curriculum documents were formulated for the sub-systems of preschool, primary and secondary education, and the new Nicaraguan concept of the Regular Basic and Secondary Education sub-system, comprised of the Teachers, Curriculum, Educational Nuclei, Educational Planning and Evaluation Workshops (TEPCEs), Classrooms, and the Network for Pedagogical Training and Accompaniment (RED-CAP).

\section{Linkages between the Formal and Non-formal Systems}

349. In order to redesign the Nicaraguan school system, based on recognizing the differences, features and attributes of the various types of formal and non-formal education, and on the need to provide priority attention to the school-age population (three to seventeen years of age) that is not in school and which is historically and statistically hidden from official educational attention, MINED has proposed the creation of two General Divisions, the General Division for Regular Basic and Secondary Education and the General Division for Irregular Basic and Secondary Education, in order to respond to the need to link the formal and non-formal systems.

\section{Regional Autonomous Educational System (SEAR)}

350. A process is underway to make adjustments to primary and secondary education to the reality of the Nicaraguan Caribbean region and its multi-ethnic and multi-cultural characteristics, through the Regional Autonomous Educational System (SEAR) and the Intercultural Bilingual Education Program (PEBI) which is part of SEAR. Most of the schools that implement the PEBI are in three ethnic and linguistic areas: Sumu-Mayangna, Miskito and Creole. These areas are located in the North Atlantic Autonomous Region (RAAN): Waspam, Puerto Cabezas, Siuna, Rosita, Bonanza and Prinzapolka; and in the South Atlantic Autonomous Region (RAAS): Corn Island, Bluefields, Pearl Lagoon and La Desembocadura. The Intercultural Bilingual Education Program has been fundamental to recovering and strengthening the indigenous and Afro-descendant languages and cultures that are the heritage of humanity.

\section{Drinking Water and Sanitation}

351. The investment policy was established for the restoration of the water and sanitation system which was greatly deteriorated, due to the urgency of reducing technical losses and to increase the effective coverage of good quality services, as well as for the protection of the country's water resources. 
352. During this period, execution of the Environmental Sanitation Program for the Lake and City of Managua is underway, with physical advancement of $87 \%$, anticipating the conclusion of the first phase in the first quarter of 2009. The expansion of the drinking water system for the city of Juigalpa was inaugurated, benefiting 68,500 users, and water systems were constructed for six Managua neighborhoods, including the communities of Las Viudas and Jocote Dulce, benefiting 36,834 people. Drinking water and sanitary sewerage systems have been improved in the cities of Estelí, Ocotal, Ciudad Sandino, Boaco, Chinandega, Masaya and Carazo, benefiting 482,500 citizens. The program to optimize the supply systems and improve measurement rates has been completed, contributing to the organization of the sector.

\section{Production and Commercial Strategy}

\section{Agricultural Production}

353. The implementation of the Food Production Program is the major effort fostered by the government, aiming at the reconversion of production and at food and nutritional security. It is directed at rural families and the goal for the first five-year phase from 2007 to 2012 is to capitalize 75,000 peasant families at an average annual cost of approximately US\$30 million and a per-family investment that ranges between US\$1,500 and US\$2,000.

354. Progress in this program is reflected in the benefits received by 32,000 families that have received the Production Package, which represents $43 \%$ of the goal. This has contributed to national production as follows:

- $\quad 2.5$ million liters of cow's milk.

- $\quad 3,200$ liters of goat's milk.

- $\quad 31,400$ suckling pigs.

- $\quad 5.5$ million eggs.

- $\quad 19,500$ quintals of corn.

- $\quad 11,700$ quintals of beans.

355. In addition, the contribution of this program is reflected in the behavior of figures for value added for staple crops which increased $12.8 \%(-18.1 \%$ in 2007$)$. The above was the result of a spike in the harvest from the first planting season, caused by increases in the areas planted in all crops, particularly beans.

356. Also, the Agro-Seeds Program began in 2008, with the objective of providing small scale farmers with improved seeds, urea fertilizer and technical assistance in the form of a credit in order to increase their capacity for the production of food for their own consumption and surpluses for export.

\section{Financing}

357. The amount of credit disbursed through government and private entities rose from C\$542.2 million in 2007 to C $\$ 2.4205$ billion in 2008 as reimbursable financing, representing 4.5 times more than the previous year and thus establishing a policy that fosters capacities for production. 
358. Other funds disbursed in the agricultural sector as "non-reimbursable" include those aimed at the capitalization of small and medium scale farmers, mainly in kind (Food Production Package) and in productive infrastructure for harvest collection, processing and commercialization of agricultural and forestry production.

359.

Eighty-

eight percent of the Food Production Program has been financed by the national budget and the remaining $12 \%$ has been covered by funds from international cooperation: the European Union, the International Fund for Agricultural Development, Sweden, Taiwan and the Bolivarian Alternative for the Americas (ALBA).

360. In 2008, 19,359 production packages were distributed (of these, 1,524 are backyard packages) to women under the "Zero Hunger" Program, and the "Zero Usury" Microcredit Program served 68,221 members, implementing gender perspective practices and improving capacities. This represents an increase of 64,916 members over the achievements of the program's beginnings in 2007.

\section{Small and Medium Enterprises}

361. Small and medium enterprises in the new model cease to be simply justification for seminars and consultation; they are now true instruments of development. Thus, in 2008, there were 160 enterprises that prepared to become formal entities; 88 service and production cooperatives and credit unions were legally constituted; five traditional fishing cooperatives were legally established and 46 cooperatives were organized to work in this same area.

362. There was a total of 3,486 micro- and small enterprises registered as working in the tourism sector; of these, 894 were first-time operations generating 3,577 new jobs. In 2007, 408 new microand small tourism enterprises were registered, generating 2,801 new jobs, for a total of 6,378 new jobs in 2007-2008.

363. Progress was made in the creation of harvest collection and storage centers to support the micro-, small and medium enterprises in Managua, Masaya, Granada, Rivas, León, Chinandega, Matagalpa, Estelí, Boaco, Chontales and Bluefields. Twelve centers were opened in Jinotega that served 9,700 small and medium scale business owners from different production sectors during 2008 .

\section{Free Trade Zones}

364. The National Free Trade Zone Commission attracted investments of US\$96.3 million, some US\$50 million more than in 2007. Furthermore, there has been noteworthy strengthening of the relationships of among all participants in the free trade zone regimen through the installation of a tripartite roundtable comprised of the different union organizations in the free trade zones, the Nicaraguan Textile and Clothing Industry Association (ANITEC), the Nicaraguan Chamber of Private Free Trade Zones (FCNZFP) and the State institutions related to free trade zones. A 
Corporate Social Responsibility Committee was also established, an important instrument for raising the social awareness of the companies within the Free Trade Zone Regimen.

\section{Foreign Investment}

365. Nicaragua shows positive performance in terms of attracting direct foreign investment (DFI). The total figure for 2007-2008 surpasses the total investment for the three previous years. The year 2008, with US\$505.83 million, was the first year in Nicaragua's history in which the country reported annual investment over US\$400 million. This represents more than $42.0 \%$ growth over 2007, with US\$355.28 million.

366. In 2006, Nicaragua held third place for this index at the regional level, including Panama, with 5.4\%. In 2007, it moved to second place with $5.9 \%$. This positive trend in the level of investments relative to the GDP continued during 2008, with 7.0\% (according to preliminary figures), and was mainly led by the telecommunications sector (US\$284.7 million), the free trade zones (US\$213.0 million) and the energy sector (US\$192.0 million) which represent $86.6 \%$ of all investments.

367. Five investment projects represented $61.2 \%$ of the total investments attracted: ENITEL (US\$73.3 billion), the Amayo Wind Power Consortium (US\$69.0 million), ALBANISA (US\$51.0 million), América Móvil (US\$50.0 million) and Inmobiliaria Santo Domingo (US\$38.3 million).

\section{Generation of Employment}

368. Overall, as an effect of the behavior of employment levels, the national open unemployment rate as of July 2008 was $6.1 \%$; it was $6.4 \%$ in July 2007 and $7 \%$ in 2005 . The national overall employment rate was $93.9 \%$ in July 2008 , with no significant difference between employment rates for men and women, or $94.4 \%$ and $93.1 \%$ respectively (INIDE, 2008). New minimum wage levels were established in 2008. This measure benefited 138,864 workers in the formal sector; this number has increased by $12 \%$ and $34 \%$ over 2007 and 2006, respectively.

\section{Electrical Energy}

369. In 2007, the government received an energy system that was in profound crisis from the previous administration, with an energy deficit that affected broad sectors of the citizenry and of private enterprise, due to constant rationing. The situation was reversed almost immediately with the incorporation of generators with an additional capacity of 180 megawatts over the existing 822 megawatts left by the previous government. The GRUN also fostered the formulation of renewable energy projects and the search for financing to resolve the inherited energy crisis and to improve the country's energy grid.

370. This government policy is underway. The installation of an alternative generation plant was scheduled for the first quarter of 2009 and was completed with the installation of a plant based on renewable energy. The Amayo wind plant has 19 aero-generators with the capacity to generate 40 megawatts. This plant is located in the province of Rivas, using the wind potential there to generate 
electricity, and is already connected to the National Interconnected System (SIN) and contributing to the system.

371. Both foreign cooperation and private investment are supporting the implementation of electrical generation projects using renewable sources. The foreign cooperation donor organizations that are providing financial support for these projects are: the United Nations Development Program (UNDP) and Swiss Development Cooperation (SDC) which finance the construction of small hydroelectric plants.

372. Private investment totals US\$5,331,928.00, or the equivalent in córdobas of $\mathrm{C} \$ 108,446,084.00$. Of this amount, C\$88,634,209.00 corresponds to investment in the geothermic sphere by the following companies: Polaris Energy de Nicaragua S.A (PENSA) for the San Jacinto Tizate Project and Geotérmica Nicaragüense (GEONICA) for the El Hoyo - Monte Galán and Managua-Chiltepe Projects. An additional C $\$ 19,811,874.00$ corresponds to wind generation by the Amayo Consortium. In the area of rural electrification, the goal was to provide service to approximately 18,000 rural homes in 2007 and 2008. This was 100\% fulfilled; representing 400 rural communities that now have access to the electrification system.

\section{Public Investment Policy}

373. From the beginning, the Government of Reconstruction and National Unity (GRUN) set out to increase the efficiency, performance and impact of the Public Investment Program (PIP) on economic growth and poverty reduction, placing more emphasis on gross capital formation to increase the social and production infrastructure of the country and to make it more competitive. Thus, the composition of the PIP rose from barely $53 \%$ of capital expenditures in 2006 to $82 \%$ in 2008 , with the expectation that the program will not contain any current expenditure in the 2009 budget.

374. The new strategic approach for public investment policy demanded a more efficient administrative organization. The government began a process to overcome the weakness shown in the public sector at all levels regarding the investment process (formulation, resource management, execution, evaluation and follow-up). The major measures adopted include the creation of a highlevel committee to provide follow-up on the PIP, comprised of the main executing institutions and coordinated by the Presidency of the Republic. The above has contributed, together with the other measures indicated, to an increased level of execution of the PIP, rising from $77 \%$ in 2006 to $91 \%$ in 2008.

375. The following are major achievements in infrastructure:

376. Roads and Highways: During the period, the GRUN prioritized highways and roads that unite production centers to harvest collection and storage centers and these to local markets, areas with potential for tourism and to ports for export, in support of the development of production.

377. Major projects executed during this period include the rehabilitation of the roads between Telica - Malpaisillo (24 km.), Chinandega - El Viejo - El Congo (41.7 km.), Chinandega - Corinto (19.5 km.), Diriamba - Casares; La Virgen - San Juan del Sur (51.25 km.) and Sébaco - Matagalpa 
(27.3 km.); the construction of the road between Guayacán - Jinotega $(4.47 \mathrm{~km}$.) and the improvement of 3,169 kilometers of roadways, prioritizing the network of secondary roads and rural roads. It is important to emphasize highlight the completion of the feasibility study and design for the road between Acoyapa - San Carlos (153 km.); it is anticipated that construction on this will begin in 2009 with an approximate cost of US\$51.0 million.

378. Electrical Energy: The 2007-2008 Public Investment Program for the electrical energy sector for is aimed at changing the energy grid to reduce dependency on oil and to attain more moderate generation costs. A program was initiated to build small hydroelectric plants for use in production in areas outside of the grid: the plants in Río Bravo and Bilampi are complete, and the plants in El Naranjo, Salto Negro, Wapí and Wiwilí are under construction. In terms of energy generation and transmission, two plants with a capacity of 60 megawatts are installed in the Los Brasiles Sub-station and in the Las Brisas Station. Development has begun on a project to install new generator units with an additional 180 megawatts to be located in Masaya, Managua, Tipitapa and Timal. The feasibility study and construction design is finalized for the Larreynaga Hydroelectric Plant which will contribute 17 megawatts to the grid. It is anticipated that construction will begin on this plant in 2009. The Bluefields-El Bluff Electrical Interconnection Project was completed at a cost of US\$2.3 million, and the Granada Sub-station and Transmission Line were completed at a cost of US\$7.3 million. The Matiguás-Siuna Sub-transmission Line was also completed, at a cost of US\$5.7 million. In terms of rural electrification, 488 kilometers of distribution networks were installed for 47,127 residents in the fifteen provinces and two autonomous regions of the country, at a cost of US\$8.1 million.

379. Education and Health: Significant progress was made in the health sector with the construction and rehabilitation of eight Health Posts, 26 Health Centers and nine Maternity Houses throughout the country, as well as the rehabilitation and equipping of the so-called "critical route" for almost all of the hospitals, including the emergency areas, operating rooms and maternity and children's wards. The largest projects include the construction of a maternity and neonatology building in the Rio San Juan Hospital at a cost of US\$0.25 million and the construction and equipping of the Boaco Hospital for the amount of US\$12.5 million. An evaluation of the status of infrastructure in the education sector at the beginning of 2007 revealed that a high percentage needed rehabilitation and expansion to improve service and increase school coverage. During this period, 710 classrooms were repaired, replaced and/or expanded in all municipalities in the country at a cost of US\$16.8 million; and 165 portable classrooms and 150 pre-fabricated classrooms for primary school education were installed at a cost of US\$3.1 million. Thus, progress was made in providing greater security and better hygienic conditions in the schools, initiating a national program to build outside structures and to supply water and sanitary infrastructure.

380. Drinking Water and Sanitation: In this period, the Environmental Sanitation Program for the Lake and City of Managua is being executed, with physical advancement of $87 \%$, anticipating the conclusion of the first phase in the first quarter of 2009; an investment of US\$36.0 million was made in 2007-2008. The expansion of the drinking water system for the city of Juigalpa was inaugurated, benefiting 68,500 users, for a total of US\$16.5 million in the first phase. Water systems were constructed for six neighborhoods in Managua and Ciudad Sandino, including the communities of Las Viudas and Jocote Dulce, benefiting 36,834 people, at a cost of US\$3.3 million. Drinking water and sanitary sewerage systems are improved in the cities of Estelí and Ocotal, at a cost of 
US\$1.7 million. The program to optimize the supply systems and improve the measurement rates has been completed, contributing to the organization of the sector, at a cost of US\$11.5 million.

381. Housing: The GRUN completed the construction of 1,465 houses in both urban and rural areas in 22 municipalities in the country, prioritizing the most socially vulnerable sectors. This represented an investment of US\$7.9 million.

\section{Macroeconomic Program}

382. In the Economic and Financial Program in 2007, the assumptions and outlooks were favorable for economic growth of 4.75\% (2008-2012 period), with efforts to be made for inflation control. Nevertheless, economic growth for 2008 was $3.2 \%$, equal to that of the previous year, as a result of the constant increases in oil and food prices, plus the financial crisis that affected the real economy (decrease in exports and in international prices for raw materials and a contraction of investment) and the negative impact generated by Hurricane Felix.

383. Economic growth in 2008 was dynamic despite the crisis due to the contributions of different sectors as a direct result of the implementation of governmental support policies: agriculture (9.5\%), commerce and services (1.4\%) and, to a lesser degree, the livestock sector and manufacturing industry, while construction (-2.8), fishing and mining showed decreases. Growth in internal demanded solidified into sustained growth of consumption and investment with deceleration of exports. Public consumption showed relative growth as a result of salary policy (adjustments for teachers and doctors) and expenditures related to the municipal elections.

384. Fixed private investment was relatively favorable due to a greater flow into energy and telecommunications, with the latter showing investments totaling US\$453 million, the highest amount in the last five years.

385. Cumulative inflation in 2008 was $13.77 \%$ (16.88\% in 2007), due to increases in food and oil prices that affected domestic prices from January to July, and deflation in December. The supply shocks continued during 2007 and 2008, showing a reduction in the underlying inflation in the last year from $6 \%$ in the first quarter to $3.54 \%$ in the second quarter.

386. The deficit in the current account expanded, due to increases in the prices of oil, food and raw materials and the importation of capital goods (foreign investment in energy), despite the positive dynamic of exports and remittances in the first three quarters.

387. The external gap is $23.2 \%$ of the GDP (17.6\% in 2007), due to the upward path of oil prices, leading to deterioration in the terms of exchange. The shocks in the current account also were associated with the effects of the international financial crisis, which affected inflows of remittances and the exportation of goods, due to the process of economic deceleration in the United States which led to less foreign demand. Capital and financial account flows rose to US\$1.489 billion, which were mostly directed at the private sector through transfers, net loans, commercial credits and direct foreign investment, mainly in energy and telecommunications. 
388. The deficit for the non-financial public sector in 2008 remained the same at $1.8 \%$ of the GDP, according to the original program. The higher capital flows in 2008 compared to the deficit in the current account caused an increase in the accumulation of international reserves of US\$37.5 million. However, there was a decrease of US\$27.4 million in the adjusted net international reserves (ANIR), due to less demand for the monetary base and delays in incoming liquid external resources and budgetary support.

389. The overall balance of the Combined Public Sector (CPS) after grants in 2008 showed a smaller deficit of C\$1,871.9 million compared to the C\$2,339.9 million forecast, due to less capital expenditures and quasi-fiscal losses. Nevertheless, compared to 2007, there was an increase in the CPS after grants, given the expansion of current spending, which was directed at covering the salary demands of prioritized sectors, programs to combat poverty, increases in social security pensions, electoral spending and more activity in the Public Investment Program.

390. The fiscal program in 2008 was affected by less external budgetary support financing (US\$87 million). The tax revenues of the central government were 16\% less than 2007 (and 17\% less than forecast), based on less economic activity in the last quarter, mainly affecting the income tax and the value added tax, and particularly that collected at customs. There was a $1.2 \%$ increase in the domestic value added tax (VAT) due to more refunds, mainly to the energy sector.

391. Total non-financial public sector spending was C $\$ 2.8263$ billion less than anticipated due to fewer capital expenditures. The current expenditures of the central government registered a $27 \%$ increase over 2007 due to salary increases to reduce gaps and the creation of new positions in the education sector (1,500 teachers), the health sector (600 workers), the army and police (500 police officers), with an adjustment of $12 \%$ to $16 \%$, and an adjustment of $6 \%$ for the rest of the public payroll; expenditures for municipal elections; transfers to municipalities (increasing from $7 \%$ to $8 \%$ of tax revenue); expansion of purchases of goods and services due to increased costs generated by higher prices for fuel and public services, together with the transfer of capital expenditure items to current expenditures as part of the process of organizing public spending.

392. Capital expenditures in the non-financial public sector in 2008 were C\$2.82 billion less than anticipated. The process of capital expenditure adjustments is noteworthy, involving the transfer of 1.8 billion to current spending, a reclassification that is not incorporated into the program, with which it is possible to confirm that there was a lower level of capital expenditure under-execution. Despite this methodological problem, execution of the PIP by the central government was $90.9 \%$; however this decreases to $81.4 \%$ when the public companies are incorporated.

\section{Management of Relief in the Framework of the HPIC and MDRI Initiatives}

393. During 2008, Nicaragua obtained total foreign debt relief of US\$59.1 million. Continuity in the management of debt reduction led to a total of US\$6.8064 billion in nominal relief of the formalized debt within the Heavily Indebted Poor Countries Initiative - HIPC and the Multilateral Debt Relief Initiative - MDRI (equivalent to $84 \%$ of the total nominal relief anticipated for Nicaragua under these initiatives). The relief obtained came from commercial creditors that participated in the Operation to Repurchase the External Commercial Debt, particularly the 
Beogradska Banka AD of Serbia (US\$18.2 million) and Bulgargeomin LTD of Bulgaria (US\$14.1 million).

394. The external public debt was US\$3.5115 million as of December 31, 2008, representing 55\% of the GDP (59.5\% in 2007) and $156.5 \%$ of the exports of goods and services (175.8\% in 2007).

\section{7 - 2008 Budgetary Effort to Combat Poverty}

395. The commitment of the GRUN to protect spending on poverty brought the budgetary effort to reduce poverty and hunger during the period analyzed to an annual average of US\$791.3 million (13.2\% of the GDP), US\$254.5 million higher than the annual average executed during the 20022006 period, which was only US\$536.8 million (11.7\% of the GDP). The government guaranteed the financing with resources from the treasury due to the decrease in availability of external resources during this period. Therefore, the fiscal effort to sustain this level of spending is around $50.0 \%$. This means that almost half of the spending on poverty is financed with internal resources, compared with the average of barely $35.0 \%$ that was allocated in the 2002-2006 period.

396. The composition of current expenditures in the period rose to an annual average of US $\$ 417.8$ million (6.9\% of the GDP), doubling the annual average of US\$209.7 million executed for this item from 2002 to 2006 (4.6\% of the GDP). This behavior is explained, to a great extent, by the decision of the government to guarantee free education and health care, as well as by the introduction of new programs to capitalize the poorest families, such as the Food Production Program (Zero Hunger) and Zero Usury, and the expansion of other programs for the development of rural production, such as the Pound for Pound Program.

397. The great dependency on external financing for capital expenditures and the rigidity of disbursements from international cooperation - particularly in the first year of the new administration, as well as the increased cost of projects due to the rise in oil prices, are among the factors that affected the Public Investment Program aimed at combating poverty. Nevertheless, capital spending reached an annual average of US\$373.6 million (6.2\% of the GDP), execution levels that were US\$46.5 million higher than the annual average invested from 2002 to 2006 (US\$327.1 million).

\section{Monetary and Financial Program}

398. The new macroeconomic context and the greater accumulation of reserves in 2007 led to an adjustment in the goal for total Adjusted Net International Reserves (ANIR). At the end of 2008, the ANIR totaled US\$37.4 million, associated with fewer transfers of resources from the central government (due to a US\$86.9 million decrease in external resources for budgetary support) and less demand than anticipated for the monetary base (US\$33.7 million), due to less real demand for money by economic agents in the face of the international financial crisis. This accumulation guaranteed that the level of coverage would remain higher than two times the Gross International Reserves/Monetary Base (GIR/MB).

399. The goal for Net Domestic Assets (NDA) was met satisfactorily, reaching a margin of US\$27.1 million, demonstrating that the monetary and fiscal policies implemented the measures 
necessary for compensating for the lack of external resources, and making clear that the deviation in the ANIR was associated more with the contraction of demand for currency, a variable that is beyond the control of the economic authorities.

400. Open Market Operations (OMO) remained directed at managing short-term liquidity with more active policy, net loans were made in the amount of US\$42 million (programmed at US\$35.9 million), due to higher inflation and delays in the entrance of liquid resources.

\section{Exchange Policy, Balance of Payments and Foreign Trade}

401. In 2008, major actions were directed at seeking new markets for exports. Within the ALBA framework, Nicaragua consolidated an agreement for commercial exchange with Venezuela which has provided greater facility in accessing Nicaraguan exports of agricultural products (black beans, cattle on the hoof and beef).

402. Various actions have been taken on trade agreements: a) Negotiations have continued among the Central American (CA) countries and the European Union (EU) to reach an association agreement in 2009, including a free trade agreement. b) The protocol for the free trade agreement between Panama and Nicaragua was signed in January 2009, with $85 \%$ of the products enjoying immediate tariff exemption. c) The trade agreement signed with Taiwan in 2006 entered into effect on January 1, 2009.

403. Nicaragua signed the modifying protocol to the free trade agreement with Mexico in order to allow the procurement of Mexican textile materials to be used in clothing exports to the United States and vice versa. The signing of the Reciprocal Cooperation Agreement was promoted in the private sector to facilitate commercial and investment exchange, business promotion and the exchange of information about trade legislation. Nicaragua, together with the rest of the countries in Central America, signed the new Central American Uniform Customs Code (CAUCA IV) and its regulations, known as RECAUCA, which facilitate international trade within and outside the region.

404. As part of the anti-inflationary strategy, throughout the year, the government maintained a decrease or temporary elimination of tariffs on the importation of bulk food oils, beans, soy-based products, pastas, oatmeal and barley in order to counteract the price increases for these foods on the international market. Finally, contingencies were issued due to the scarce supply of unhulled rice, yellow corn, butter and corn syrup.

\section{Debt Policy and Foreign Cooperation}

405. The external financing received by the public sector was less than anticipated at US\$417.8 million or US\$284.9 million less than programmed. In addition, the cooperation flows for budgetary support and balance of payments (including International Monetary Fund disbursements) decreased by US\$106.7 million, mainly due to the delays by the National Assembly in approving loans for US\$40 million from the Inter-American Development Bank (IADB) and the World Bank (WB), and the non-disbursement of grants of US\$46.7 million from the members of the Budget Support Group (BSG) that had been reprogrammed for the second half of the year. The lower levels of incoming loan resources (US\$161.0 million) slightly surpassed the grant amounts (US\$123.9 million). 
406. In the context of ALBA, Venezuelan cooperation increased in 2008 compared to 2007, particularly cooperation for electrical energy and oil. This year, this cooperation was US\$457 million, with an emphasis on investments in electricity for an estimated value of US\$98.5 million for the generation of 100 megawatts of electricity. Within the framework of the PETROCARIBE agreement, US\$293 million was received in cooperation, between non-refundable financing (US\$99 million) and loans (US\$194 million), funds that continue to be channeled through Albacaruna. This cooperation is used primarily for the financing of production activities of cooperatives, mainly in the agricultural and livestock sector, electrical energy subsidies and for collective and selective transportation, social infrastructure, food security and other areas.

\section{Development Strategy of the Caribbean Coast}

407. The Development Council of the Caribbean has been strengthened with the ongoing dialogue between regional stakeholders and the central level, also consolidating the autonomous management of the Territorial Government of the Alto Wangki and Bocay with the installation of the Indigenous Territorial Government and the Special Development Regimen for three territories of the Bosawás region, granting them a special allocation of funds from the national budget to strengthen their management.

408. Following its approval, the Autonomous Regions have begun implementing the Development Plan of the Caribbean Coast (PDCC) through a process of strengthening capacities for planning and financial management. Furthermore, the Plan for Regionalization of Health Care was signed and the Coordinating Commission for Regionalization of Education was installed.

\section{The following are the most significant achievements:}

409. Seven indigenous territories have been titled and demarcated, covering 8,903 square kilometers in which 102 Mayagna and Miskito communities reside.

410. More than 63,000 basic grains farmers have been given the means to plant beans, rice and corn. Harvests of 3,500 quintals of beans and 17,000 quintals of rice were processed and commercialized locally, progressing toward food autonomy. Moreover, a total of 7,571 production packages were distributed, representing an investment of more than US\$15 million for poor families, mainly native peoples and Afro-descendants from the Caribbean regions.

411. Medical coverage was expanded, providing an additional 150,271 consultations than in 2007 . The maternal mortality rate decreased compared to 2007, in the RAAS from 262 to 102 and in the RAAN from 250.9 to 190 . Prenatal care coverage increased by more than $5 \%$ and the infant mortality rate decreased from $16.6 \%$ to $8.22 \%$ in the RAAS and from $19.8 \%$ to $15.5 \%$ in the RAAN.

412. In terms of transportation infrastructure, proper maintenance was provided to the Bilwi-Río Blanco road and construction was completed on four bridges on Bilwi-Río Blanco road.

413. The expansion of the National Interconnected Electrical Energy Grid was completed in the sections between Matiguas-Mulukuku-Siuna and Bluefields-El Bluff Rama-Kukra Hill-Pearl 
Lagoon. Electricity service was expanded and improved in four municipalities and energy was ensured for seven indigenous and Afro-descendant territories with community units.

\section{Measures for Good Public Administration}

414. Due to the ongoing dialogue promoted among the different parties in parliament, most of the laws and decrees approved by the plenary have enjoyed a broad political consensus, allowing significant advancement on economic, environmental, social and institutional matters. This ongoing dialogue has ensured that the laws and initiatives approved by the legislature are in accord with the sector-based agendas of the "National Human Development Plan" approved and fostered by the Government of Reconciliation and National Unity.

415. The Ministry of Finance and Public Credit (MHCP) implemented and promoted transparent and austere management to contribute to the improvement of good public administration and access to information about public administration.

\section{Transparent and Austere Public Administration}

416. The link between planning and the budget continued to be developed and the coverage of the Medium-Term Institutional Expenditure Framework rose from 25 institutions in the 2008 formulation to 33 institutions in the 2009 formulation, reflecting the management indicators for each institution. The physical follow-up module in the Integrated Financial Management and Auditing System (SIGFA) will contribute to the implementation of a system to evaluate public spending with product indicators to measure effectiveness and social impact corresponding to the national goals and objectives set forth in the National Human Development Plan and the guidelines of the Poverty Reduction and Growth Facility (PRGF).

417. In the context of the Financial Administration System, the Sub-system for Monthly Cash Programming (MCP) operates in a decentralized fashion in the entities that are financed by the national budget. This has provided the institutional treasury offices with a financial management tool to request their quarterly, monthly and weekly programming of payments from the National Treasury Office, thus modernizing the Treasury Sub-system (SITE) and enabling the National Treasury Office to approve the planning of financial limits and to control the flow of funds that enter and exit the Treasury so that the pace of execution of the current national budget is not interrupted.

418. Through the execution of the State Purchasing and Contracts Efficiency and Transparency Program (PREFTEC), with resources from Loan 1064/SF-NI and Cooperation 2/CL-NI, there is a National Public Contracts Training Center which, for the first time, offered courses to facilitate the implementation of the regulatory instruments approved by this governing body and to train public officials on issues identified in the assessment as opportunities to improve contracting processes.

419. Technical and legal assistance was provided to the central administration agencies, municipalities and the municipal sector under different models, including on site, specific and from a distance. Furthermore, workshops were organized and conducted for the directors of procurement, technical, administrative and advisory units in public sector institutions, municipalities and the municipal sector and to suppliers to the State through the Chamber of Commerce. Regulatory 
instruments were updated and distributed to strengthen mechanisms for internal control and management of purchasing for the public sector and municipalities.

420. This year, the Ministry of Finance and Public Credit (MHCP) improved the efficiency of its administrative and financial management with the incorporation of the Project Execution Units into its organizational structure under the General Financial Administration (DGAF). These include the Public Sector Technical Assistance Credit (PSTAC) Project with World Bank financing, which integrates the components of the Integrated Financial Management and Auditing System (SIGFA), the Civil Service and Administrative Career Project (PRSC), the Office of Fiscal and Economic Affairs (OAFE), the National Public Investment System (SNIP), the National Development Information Institute (INIDE), the Monitoring and Planning Division of the Secretariat of the Presidency (SEPRES) and other components.

421. There is a Public Finance Modernization Plan to identify priority actions that contribute to the modernization of public finances, primarily related to strengthening sub-systems and associated systems that form the Financial Administration System (FAS) of Nicaragua's public sector and to the optimization of critical management processes, executed by the parties defined by Law No. 550, including the following sub-systems: Budget, Treasury, Public Credit and Government Accounting; and their associated systems: Public Investment, Civil Service, and Property and Contracts Administration. In addition, the 2008-2012 Training Plan was developed in the framework of strengthening the MHCP Budget.

\section{Truthful Public Information}

422. The proposed 2009 National Budget, with its annex, the 2009-2012 Medium-Term Budget Framework, the 2008 National Budget, the Report on Liquidation of the 2007 Budget, the Budgetary Execution Report for January/March, January/June and January/September 2008, the Evaluation Report on the Use of Municipal Transfers for 2007 and the first half of 2008, and the Evaluation Report on 2007 Municipal Budgetary Execution are available on the web site of this Ministry to enable citizens, institutions, national and foreign organizations to consult them as needed. This contributes to transparency in public finance management by the GRUN. 


\section{ANNEX No. 3: DETERMINING BUDGET EFFORTS TOFIGHT POVERTY}

423. The criteria introduced to change the content of budgetary efforts to reduce poverty are related to the person, the environment and institutional capacity. These criteria prioritize the policies which directly affect the poor in a structural and relevant manner; the expansion of the real capacity of the country to increase the coverage of services, and the capacity of the State to efficiently carry out the poverty reduction strategy. The new classification of the budgetary effort to reduce poverty seeks the capitalization of the poor, the recovery of their productive potential, and their integration into the economic process, more than the temporary alleviation of their status or prolongation with protectionist policies. In order to facilitate budget operations, this spending has been divided into three levels.

\section{First Level of Impact: Directly improving income redistribution}

424. This type of spending is reinforced in the NHDP by the public policy guidelines which prioritize the allocation of resources to programs that have an immediate impact on the poorest of the population, focusing on actions for those who truly need it. This group of expenditures includes a new generation of national programs to accelerate the eradication of poverty, such as programs that provide infrastructure and supply provisions to restore the right of the poor to access better public health programs and free education. The Food Security and Sovereignty Program which works to capitalize families and impoverished small and medium producers, with a production, participatory and gender approach; the beginning of the National Literacy Program; the Program for More Access to Better Quality Drinking Water, particularly in the impoverished rural areas and the Construction of Social Interest Housing Program are all programs that reflect the political will of the GRUN to make a preferential option to empower the productive capacities of the poorest, so that they can be protagonists and beneficiaries of social and economic development. This level includes the following spending categories:

i.

Expenditures for literacy, preschool education, primary education, adult and special education, including school feeding programs and the provision of educational materials; health services at the primary and secondary level of care, including nutrition and reproductive health programs.

ii.

Programs for the capitalization of families and small, impoverished production units, both in the urban and rural sectors; with financing, improved seed, inputs, training and technical assistance.

iii.

Basic infrastructure which includes the construction, refurbishing and maintenance of streets and rural roads; small ports, bridges and docks - on lakes and rivers - to improve rural productivity and access to markets, and to facilitate attendance in schools and health centers, especially during the rainy season.

iv.

Construction of social interest housing and the supply of water and basic sewage, primarily in rural areas and marginalized urban areas. 
V. Subsidies to low income sectors in order to prevent increases in the cost of transportation and basic services.

vi. Programs to prevent and mitigate damages caused by disasters, designed to cover food security and to support the affected population.

vii. Construction and operation of shelters, homes, feeding centers, and child development centers for the assistance and social protection of the extremely poor, particularly youth and children.

425. Expenditures to support associations and foundations are excluded from this spending group, along with Current Transfers to the Municipalities that cover the operating expenses of the different municipal governments of the country.

\section{Second Level of Impact: Strengthening the capitalization of the poor and increasing their productivity.}

426. The budgetary effort to reduce poverty includes programs for the productive development of small and medium enterprises, including technical assistance and credit to these sectors through the Zero Usury Microcredit Program; the Property Regularization Program; secondary and technical education; rural electrification projects which allow the poor to have access to energy, especially for indigenous communities and those who work in agriculture and livestock production; major trunk roads, secondary paved and unpaved roads, and collector roads. Also included are reforestation, environmental restoration and protection programs. In this sector, the GRUN is promoting the Severe Soil Erosion Protection Strategy in 21 water basin areas of the country, an environmental protection program with national scope.

427. In terms of capital expenditures, investments in ports and airports are excluded from this spending, because the poor have historically been marginalized from these forms of travel; and spending aimed at the modernization of the energy sector is included, despite the certainty that the structural deficiencies in the infrastructure of the country can only be overcome in the medium and long term with significant involvement by private investment.

428. In terms of current expenditures, the services provided by MAGFOR and MIFIC for regulating and organizing the agricultural, forestry, industrial and commercial sectors are excluded; as are programs for the supervision by MAGFOR of agricultural production in general, such as plant health and seed programs, animal health and livestock improvement services, and agrosanitary services.

\section{Third Level of Impact: Increasing the operational efficiency of expenditures in the health, education and social protection sectors.}

429. Spending to fight poverty in this group includes expenditures used to overcome bureaucratic and programming inefficiencies, as well as the difficulties of identifying vulnerable groups which will be beneficiaries of the programs. It also includes spending aimed at strengthening the process of planning, designing, evaluating and providing follow-up on programs and projects that help to 
increase the impact of the services on the sectors identified, in order to improve the well-being of the poor.

430. Expenditures in the NHDP to fight poverty exclude programs that pay for consultants, designs and studies to improve governance, the business climate and local development; as well as those involving strengthening public institutions not related to the sector. 


\begin{tabular}{|c|c|c|c|}
\hline $\begin{array}{c}\text { Perspective / } \\
\text { Strategic } \\
\text { Objective } \\
\end{array}$ & Results Indicator & $\begin{array}{l}\text { Summary of Achievements } \\
(2007-2008-\text { First Half of 2009) }\end{array}$ & $\begin{array}{l}\text { 2009-2011 Furtherance Actions } \\
\text { With implementation ensured through institutional plans and budgets, } \\
\text { with follow-up from the SIGRUN, BP-SNIP and SIGFA }\end{array}$ \\
\hline \multicolumn{4}{|c|}{ COMBAT EXTREME POVERTY AND CHILD MALNUTRITION } \\
\hline \multicolumn{4}{|c|}{ MACROECONOMIC AND FINANCIAL PERSPECTIVE } \\
\hline $\begin{array}{l}\text { 2) Ensure the fiscal } \\
\text { effort necessary to } \\
\text { fight poverty } \\
\text { through efficient } \\
\text { and sustainable } \\
\text { public finances. }\end{array}$ & $\begin{array}{l}\text { Strengthening of tax } \\
\text { management. }\end{array}$ & \begin{tabular}{|l|} 
New Customs Management Information Systems: \\
- In 2008, the United Nations Conference on Trade and \\
Development (UNCTAD) approved technical cooperation \\
and assistance to move from the Automated System for \\
Customs Data (ASYCUDA) ++ to ASYCUDA World. \\
- In 2009, ASYCUDA World was installed as a pilot project \\
in Central Air Customs. \\
- The Risk Management Module was installed in Level One \\
customs offices. \\
- The process began for installing the Meso-American \\
International Transit Module (TIM II).
\end{tabular} & $\begin{array}{l}\text { - Coordinate and continue technical assistance and advice from } \\
\text { international organizations for the gradual installation of the } \\
\text { ASYCUDA World and TIM II in customs offices. } \\
\text { - Install ASYCUDA World in Level One customs offices. } \\
\text { - Complete the installation of TIM II in Level One customs offices. }\end{array}$ \\
\hline
\end{tabular}




\begin{tabular}{|c|c|c|c|}
\hline $\begin{array}{l}\text { Perspective / } \\
\text { Strategic } \\
\text { Objective }\end{array}$ & Results Indicator & $\begin{array}{c}\text { Summary of Achievements } \\
(2007-2008 \text { - First Half of 2009) }\end{array}$ & $\begin{array}{l}\text { 2009-2011 Furtherance Actions } \\
\text { With implementation ensured through institutional plans and budgets, } \\
\text { with follow-up from the SIGRUN, BP-SNIP and SIGFA }\end{array}$ \\
\hline & & $\begin{array}{l}\text { To incorporate the Tax Administration Offices into the Tax } \\
\text { Information System (SIT): } \\
\text { - In 2008, the project to incorporate five Tax Administration } \\
\text { Offices into the SIT was approved. } \\
\text { - In 2009, installation was begun of the SIT in the five Tax } \\
\text { Administration Offices; an assessment was developed for the } \\
\text { implementation of a new Tax Information System; and the } \\
\text { platform for DGI/DGA fiscal and tax information was } \\
\text { installed. }\end{array}$ & $\begin{array}{l}\text { - Complete the incorporation of the five Tax Administration Offices } \\
\text { into SIT. } \\
\text { - Implement the recommendations from the assessment regarding a } \\
\text { new SIT. } \\
\text { - Strengthen joint actions between the General Tax Division (DGI) } \\
\text { and the General Customs Division (DGA) to conclude the process of } \\
\text { exchanging automated information. }\end{array}$ \\
\hline & $\begin{array}{l}\% \text { execution of public } \\
\text { expenditures relative to the } \\
\text { updated budget. }^{1 / 2 /}\end{array}$ & \multirow{2}{*}{$\begin{array}{l}\text { - Maintenance of a responsible spending policy that } \\
\text { contributes to macroeconomic stability without affecting the } \\
\text { GRUN's commitments to social expenditures and the } \\
\text { priority poverty reduction programs. } \\
\text { - Incorporation of the Zero Hunger Program into the budget, } \\
\text { including the Food Production Package and the Improved } \\
\text { Agro-Seeds Program. The Zero Usury Program was also } \\
\text { incorporated. } \\
\text { - Better institutional coordination between the Planning } \\
\text { Division and the Financial Administration and Procurement } \\
\text { Division. } \\
\text { - Truer planning of external resources through coordination } \\
\text { among the MHCP, executing units, and the multilateral and } \\
\text { bilateral organizations. }\end{array}$} & \multirow{2}{*}{$\begin{array}{l}\text { - Ensure and strengthen ongoing follow-up on the execution of plans } \\
\text { and the PIP. } \\
\text { - Strengthen the National Follow-up Commissions on Institutional } \\
\text { Plans and the PIP. } \\
\text { - Improve inter-institutional coordination among the MHCP, } \\
\text { executing institutions and financial organizations in order to raise the } \\
\text { execution of external resources, particularly for those institutions that } \\
\text { have difficulties. } \\
\text { - Ensure intra-institutional coordination among the Divisions of } \\
\text { Planning, Budget, Acquisitions and External Cooperation Units. } \\
\text { - Formulate an external resources budget based on agreements } \\
\text { ratified by the corresponding bodies and according to the true } \\
\text { capacity for execution of each institution. } \\
\text { - Provide more training to the institutions regarding laws, standards } \\
\text { and procedures for the budget, procurement and financial } \\
\text { organizations. }\end{array}$} \\
\hline & $\begin{array}{l}\% \text { of non-financial public } \\
\text { sector primary } \\
\text { expenditures directed at } \\
\text { fighting poverty. }{ }^{2 /}\end{array}$ & & \\
\hline & $\begin{array}{l}\% \text { of non-financial public } \\
\text { sector primary } \\
\text { expenditures directed at the } \\
\text { Public Investment } \\
\text { Program. }\end{array}$ & $\begin{array}{l}\text { - The National Public Investment Program (PIP) Follow-up } \\
\text { Commission was formed to review the Program's execution } \\
\text { and define actions to fulfill the institutional goals. } \\
\text { - Human talent devoted to PIP execution and follow-up is } \\
\text { strengthened through the exchange of best practices and } \\
\text { challenges faced. } \\
\text { - The National Public Investment System installed the } \\
\text { Physical and Financial Project Follow-up System based on } \\
\text { the programming of contracts. This system is an extension of } \\
\text { the SNIP Project Bank, and is intended as a support tool to } \\
\text { facilitate follow-up on national public investment. }\end{array}$ & $\begin{array}{l}\text { - Develop and strengthen the Physical and Financial Project Follow- } \\
\text { up System in the National Public Investment System } \\
\text { (SNIP/SEPRES). } \\
\text { - Strengthen the National Public Investment Program (PIP) Follow- } \\
\text { up Commission. }\end{array}$ \\
\hline
\end{tabular}




\begin{tabular}{|c|c|c|c|}
\hline $\begin{array}{l}\text { Perspective / } \\
\text { Strategic } \\
\text { Objective }\end{array}$ & Results Indicator & $\begin{array}{c}\text { Summary of Achievements } \\
(2007-2008 \text { - First Half of 2009) }\end{array}$ & $\begin{array}{l}\text { 2009-2011 Furtherance Actions } \\
\text { With implementation ensured through institutional plans and budgets, } \\
\text { with follow-up from the SIGRUN, BP-SNIP and SIGFA }\end{array}$ \\
\hline \multicolumn{4}{|c|}{ SOCIAL WELFARE AND EQUITY PERSPECTIVES } \\
\hline \multicolumn{4}{|l|}{ Food Security } \\
\hline $\begin{array}{l}\text { 1) Increase food } \\
\text { production for } \\
\text { consumption by the } \\
\text { population. }\end{array}$ & $\begin{array}{l}\text { Number of poor rural and } \\
\text { urban families capitalized } \\
\text { through the Production } \\
\text { Package }\end{array}$ & $\begin{array}{l}\text { - The Food Security and Sovereignty Law was proposed and } \\
\text { fostered. } \\
\text { - Design and implementation of the Food Production } \\
\text { Program (PPA) which, through the Food Production } \\
\text { Package, has improved the nutritional level of the rural } \\
\text { population with the production of milk, eggs, etc. with } \\
\text { surpluses sold in the communities. } \\
\text { - Since 2007, 33,721 families throughout the country have } \\
\text { benefited from the Production Package. Of these, } 12,217 \\
\text { packages were issued in 2007, 19,359 in } 2008 \text { and } 2,145 \text { in } \\
\text { the first half of 2009. } \\
\text { - Review and restructuring has begun on the Sector-wide } \\
\text { Sustainable Production Rural Development Program } \\
\text { (PRORURAL) to align the priorities regarding food security } \\
\text { and sovereignty. }\end{array}$ & $\begin{array}{l}\text { - Foster the Sector-wide Food Security and Sovereignty Policy and } \\
\text { its instruments within the framework of the Food Security and } \\
\text { Sovereignty Law which establishes observatories for indicators in the } \\
\text { provinces with the greatest vulnerability. } \\
\text { - The National Sector-wide Plan (PRORURAL INCLUSIVE) } \\
\text { establishes the basis for a broader concept than the agricultural, } \\
\text { livestock and forestry production of the original program, with a } \\
\text { gender equity perspective, fostering associations, solidarity and } \\
\text { social cohesion. Specifically, the increase of food for consumption } \\
\text { by the population will occur through the National Food Program. } \\
\text { - Evaluate the results of the Food Production Program to improve } \\
\text { and further its implementation. } \\
\text { - Train the beneficiaries of the program to improve their } \\
\text { administrative capacities and ensure the sustainability of the package } \\
\text { received. }\end{array}$ \\
\hline \multicolumn{4}{|c|}{ Quality Education for All } \\
\hline \multirow[t]{2}{*}{$\begin{array}{l}\text { 2) Increase the } \\
\text { average number of } \\
\text { years of schooling. }\end{array}$} & $\begin{array}{l}\text { Increase in the net rate of } \\
\text { primary schooling. }\end{array}$ & $\begin{array}{l}\text { - Elimination of fees in the public schools, restoring the right } \\
\text { to a free public education to the population. } \\
\text { - National awareness campaign on the need for children, } \\
\text { adolescents and youth to attend school. } \\
\text { - Establishment of the National Curriculum Commission. }\end{array}$ & $\begin{array}{l}\text { - Maintain free public education and improve the quality of } \\
\text { education in all public schools in the country. } \\
\text { - Strengthen the new Overall and Integrated Basic and Secondary } \\
\text { Education System: Equity and Quality; Develop the regular and } \\
\text { irregular sub-systems, develop the curriculum and train teachers. } \\
\text { - Develop differentiated strategies to close gaps in access to } \\
\text { education, including geographical and socio-economic gaps, in order } \\
\text { to diversify the supply of education, organizing available resources } \\
\text { and providing incentives for entering school to those who have not } \\
\text { been able to do so in the past. }\end{array}$ \\
\hline & $\begin{array}{l}\text { Increase in the percentage } \\
\text { of preschool retention. }\end{array}$ & $\begin{array}{l}\text { - Food provided at school to children, going beyond the } \\
\text { previous School Snack Program, increasing the quantity and } \\
\text { the nutritional quality and value of the foods. } \\
\text { - Curricular program serving children from zero to three } \\
\text { years of age. } \\
\text { - Improved conditions in school classrooms. }\end{array}$ & $\begin{array}{l}\text { - Continue providing food at school to approximately one million } \\
\text { preschool and primary school children throughout the country, and } \\
\text { continue to promote school gardens. } \\
\text { - Strengthen the new Overall and Integrated Basic and Secondary } \\
\text { Education System: Equity and Quality; Develop the regular and } \\
\text { irregular sub-systems, develop the curriculum and train teachers. }\end{array}$ \\
\hline
\end{tabular}




\begin{tabular}{|c|c|c|c|}
\hline $\begin{array}{c}\text { Perspective / } \\
\text { Strategic } \\
\text { Objective }\end{array}$ & Results Indicator & $\begin{array}{l}\text { Summary of Achievements } \\
(2007-2008-\text { First Half of 2009) }\end{array}$ & $\begin{array}{l}\text { 2009-2011 Furtherance Actions } \\
\text { With implementation ensured through institutional plans and budgets, } \\
\text { with follow-up from the SIGRUN, BP-SNIP and SIGFA }\end{array}$ \\
\hline & $\begin{array}{l}\text { Increase in the percentage } \\
\text { of primary school } \\
\text { retention. }\end{array}$ & $\begin{array}{l}\text { - Elimination of the policy for fees in the public schools, } \\
\text { both for enrollment as well as in the development of school } \\
\text { activities (examinations and others). } \\
\text { - Food provided at school to children, going beyond the } \\
\text { previous School Snack Program, increasing the quantity and } \\
\text { the nutritional quality and value of the foods. } \\
\text { - Distribution of uniforms, backpacks and school textbooks } \\
\text { in municipalities with the highest poverty rates. } \\
\text { - Improved conditions in school classrooms. } \\
\text { - Great National Curriculum Consultation on Basic and } \\
\text { Secondary Education (2007 and 2008) for the } \\
\text { implementation of the new Basic and Secondary Education } \\
\text { curriculum. } \\
\text { - Implementation of the Overall and Integrated School } \\
\text { Organization and Curriculum Management Model to } \\
\text { improve the quality of basic and secondary education, } \\
\text { applying new plans and programs of study beginning in } \\
\text { February 2009. } \\
\text { - Design and construction of the National Training and } \\
\text { Formation Center for Human Resources in Education, as an } \\
\text { agency that will help to strengthen the quality of teacher } \\
\text { training and, therefore, the quality of education in the } \\
\text { country. }\end{array}$ & $\begin{array}{l}\text { - Continue providing food at school to approximately one million } \\
\text { preschool and primary school children throughout the country, and } \\
\text { continue to promote school gardens. } \\
\text { - Strengthen the new Overall and Integrated Basic and Secondary } \\
\text { Education System: Equity and Quality; Develop the regular and } \\
\text { irregular sub-systems, develop the curriculum and train teachers. } \\
\text { - Develop differentiated strategies to close gaps in access to } \\
\text { education, including geographical and socio-economic gaps, in order } \\
\text { to diversify the supply of education, organizing available resources } \\
\text { and providing incentives for entering school to those who have not } \\
\text { been able to do so in the past. } \\
\text { - Distribute uniforms, backpacks and school textbooks in } \\
\text { municipalities with the highest poverty rates. }\end{array}$ \\
\hline & $\begin{array}{l}\text { Increase in the percentage } \\
\text { of secondary school } \\
\text { retention. }\end{array}$ & $\begin{array}{l}\text { - A policy of no fees in the public schools, both for } \\
\text { enrollment as well as in the development of school activities } \\
\text { (examinations and others). } \\
\text { - Construction of more than } 1,300 \text { classrooms; Distribution } \\
\text { of more than } 200,000 \text { student desks; Distribution of } \\
\text { uniforms, backpacks and school textbooks; Improved } \\
\text { conditions in school classrooms. } \\
\text { - Great National Curriculum Consultation on Basic and } \\
\text { Secondary Education (2007 and 2008) for the } \\
\text { implementation of the new Basic and Secondary Education } \\
\text { curriculum. } \\
\text { - Implementation of the Overall and Integrated School } \\
\text { Organization and Curriculum Management Model to } \\
\text { improve the quality of basic and secondary education, } \\
\text { applying new plans and programs of study beginning in } \\
\text { February } 2009 \text {. } \\
\text { - Design and construction of the National Training and } \\
\text { Formation Center for Human Resources in Education, as an } \\
\text { agency that will help to strengthen the quality of teacher }\end{array}$ & $\begin{array}{l}\text { - Strengthen the new Overall and Integrated Basic and Secondary } \\
\text { Education System: Equity and Quality; Develop the regular and } \\
\text { irregular sub-systems, develop the curriculum and train teachers. } \\
\text { - Develop differentiated strategies to close gaps in access to } \\
\text { education, including geographical and socio-economic gaps, in order } \\
\text { to diversify the supply of education, organizing available resources } \\
\text { and providing incentives for entering school to those who have not } \\
\text { been able to do so in the past. }\end{array}$ \\
\hline
\end{tabular}




\begin{tabular}{|c|c|c|c|}
\hline $\begin{array}{c}\text { Perspective / } \\
\text { Strategic } \\
\text { Objective }\end{array}$ & Results Indicator & $\begin{array}{l}\text { Summary of Achievements } \\
(2007-2008-\text { First Half of 2009) }\end{array}$ & $\begin{array}{l}\text { 2009-2011 Furtherance Actions } \\
\text { With implementation ensured through institutional plans and budgets, } \\
\text { with follow-up from the SIGRUN, BP-SNIP and SIGFA }\end{array}$ \\
\hline & & $\begin{array}{l}\text { training and, therefore, the quality of education in the } \\
\text { country. }\end{array}$ & \\
\hline & $\begin{array}{l}\text { Increase in the percentage } \\
\text { of grade promotion in } \\
\text { primary school. }\end{array}$ & $\begin{array}{l}\text { - Formulation, consultation and implementation of a new } \\
\text { curriculum for basic and secondary education. } \\
\text { - Great National Curriculum Consultation on Basic and } \\
\text { Secondary Education ( } 2007 \text { and 2008) for the } \\
\text { implementation of the new Basic and Secondary Education } \\
\text { curriculum. } \\
\text { - Implementation of the Overall and Integrated School } \\
\text { Organization and Curriculum Management Model to } \\
\text { improve the quality of basic and secondary education, } \\
\text { applying new plans and programs of study beginning in } \\
\text { February } 2009 \text {. } \\
\text { - Design and construction of the National Training and } \\
\text { Formation Center for Human Resources in Education, as an } \\
\text { agency that will help to strengthen the quality of teacher } \\
\text { training and, therefore, the quality of education in the } \\
\text { country. }\end{array}$ & $\begin{array}{l}\text { - Strengthen the new Overall and Integrated Basic and Secondary } \\
\text { Education System: Equity and Quality; Develop the regular and } \\
\text { irregular sub-systems, develop the curriculum and train teachers. } \\
\text { - Develop differentiated strategies to close gaps in access to } \\
\text { education, including geographical and socio-economic gaps, in order } \\
\text { to diversify the supply of education, organizing available resources } \\
\text { and providing incentives for entering school to those who have not } \\
\text { been able to do so in the past. }\end{array}$ \\
\hline
\end{tabular}




\begin{tabular}{|c|c|c|c|}
\hline $\begin{array}{l}\text { Perspective / } \\
\text { Strategic } \\
\text { Objective }\end{array}$ & Results Indicator & $\begin{array}{c}\text { Summary of Achievements } \\
(2007-2008-\text { First Half of 2009) }\end{array}$ & $\begin{array}{l}\text { 2009-2011 Furtherance Actions } \\
\text { With implementation ensured through institutional plans and budgets, } \\
\text { with follow-up from the SIGRUN, BP-SNIP and SIGFA }\end{array}$ \\
\hline $\begin{array}{l}\text { 3) Reduce } \\
\text { illiteracy. }\end{array}$ & $\begin{array}{l}\text { Decrease in the illiteracy } \\
\text { rate among persons } 10 \\
\text { years of age or older } \\
(22.0 \% \text { in } 2005 \text { Census })\end{array}$ & $\begin{array}{l}\text { - Development of the National Literacy Campaign (CNA) } \\
\text { through which illiteracy decreased from } 20.7 \% \text { in } 2007 \text { to } \\
4.1 \% \text { in June } 2009 \text {, the lowest figure in the history of } \\
\text { Nicaragua. Some } 57,631 \text { volunteer facilitators participated } \\
\text { in the CNA; the technical teams in the } 153 \text { municipalities in } \\
\text { Nicaragua were strengthened and consolidated; and } \\
\text { community and religious leaders, students, teachers, } \\
\text { governments, municipal governments, Citizen Power } \\
\text { Councils, the Federation of Secondary Students, Sandinista } \\
\text { Youth, the National Association of Educators of Nicaragua } \\
\text { (ANDEN), state institutions, private enterprise and others } \\
\text { joined the task of teaching literacy. }\end{array}$ & $\begin{array}{l}\text { - Continue the National Literacy Campaign. } \\
\text { - Incorporate children, adolescents and youth that are outside of the } \\
\text { school system to prevent a new increase in illiterate citizens. } \\
\text { - Involve a greater number of people in the adult education circles } \\
\text { under the different models in the Caribbean region. }\end{array}$ \\
\hline \multicolumn{4}{|c|}{ Restitution of the Human Right to Health } \\
\hline $\begin{array}{l}\text { 4) Ensure universal } \\
\text { and free access to } \\
\text { quality health } \\
\text { services. }\end{array}$ & $\begin{array}{l}\text { Reduction in the maternal } \\
\text { mortality rate per } 100,000 \\
\text { live births. }\end{array}$ & $\begin{array}{l}\text { - The Ministry of Health in Nicaragua is developing } \\
\text { interventions to strengthen the process of ongoing } \\
\text { surveillance and monitoring to reduce maternal mortality, } \\
\text { including: } \\
\text {-Implementation of the Family and Community Health } \\
\text { Model (strengthening the process of decentralizing care); the } \\
\text { development of a Plan for Eradication of Maternal Mortality; } \\
\text { Development of Standards of Care and Protocols for } \\
\text { Obstetrical Complications; strengthening of family planning; } \\
\text { strengthening the birth plan with community participation } \\
\text { (census of pregnant women, training to identify danger signs, } \\
\text { transportation brigades and timely referral). } \\
\text { - According to MOH records, the maternal mortality rate } \\
\text { decreased from } 94 \text { in } 2006 \text { to } 80 \text { in } 2007 \text { and to } 67 \text { in } 2008 \text {. }\end{array}$ & $\begin{array}{l}\text { Ensure Comprehensive Care for Women: } \\
\text { - Strengthen the Family and Community Health Model (MO-SAFC), } \\
\text { establish alliances with the community network in the country and } \\
\text { implement strategies to decrease maternal morbidity and mortality. } \\
\text { - Address the demand for prenatal, birth and postpartum care. } \\
\text { - Ensure timely quality care for all women that seek care for } \\
\text { obstetrical complications. } \\
\text { - Incorporate the network of maternity houses into the } \\
\text { Comprehensive Care for Women. } \\
\text { - Guarantee family planning services. } \\
\text { - Provide surveillance and monitoring to micronutrient } \\
\text { supplementation. } \\
\text { - Detect, prevent and treat anemia, vitamin A deficiency and folic } \\
\text { acid deficiency. } \\
\text { - Strengthen and implement Child- and Mother-Friendly Health } \\
\text { Units. }\end{array}$ \\
\hline
\end{tabular}




\begin{tabular}{|c|c|c|c|}
\hline $\begin{array}{l}\text { Perspective / } \\
\text { Strategic } \\
\text { Objective }\end{array}$ & Results Indicator & $\begin{array}{c}\text { Summary of Achievements } \\
(2007-2008-\text { First Half of 2009) }\end{array}$ & $\begin{array}{l}\text { 2009-2011 Furtherance Actions } \\
\text { With implementation ensured through institutional plans and budgets, } \\
\text { with follow-up from the SIGRUN, BP-SNIP and SIGFA }\end{array}$ \\
\hline & $\begin{array}{l}\text { Reduction in the infant } \\
\text { mortality rate per one } \\
\text { thousand live births. }\end{array}$ & $\begin{array}{l}\text { According to the Nicaraguan Demographic and Health } \\
\text { Surveys (DHS) from } 2006 / 2007 \text {, the infant mortality rate } \\
\text { was estimated at } 29 \text { deaths per one thousand live births for } \\
\text { the five-year period prior to the survey; in } 2008 \text {, the rate was } \\
\text { estimated at } 28 \text { deaths per one thousand live births. }\end{array}$ & $\begin{array}{l}\text { Ensure Comprehensive Child Care: } \\
\text { - Growth and Development Surveillance and Promotion. } \\
\text { - Surveillance and Monitoring of Micronutrient Supplementation. - } \\
\text { Follow-up on the Fortified Foods Guarantee and Monitoring System. } \\
\text { - Vitamin A and other supplements. } \\
\text { - Immunizations against tuberculosis, diphtheria - whooping cough - } \\
\text { tetanus - influenza - hepatitis B, polio, and measles - mumps - } \\
\text { rubella. } \\
\text { - Rotavirus vaccine (diarrhea). } \\
\text { - Integrated Management of Childhood Illnesses. } \\
\text { - Personalized counseling for dietary behavior changes. } \\
\text { - Health and nutrition promotion. } \\
\text { - Strengthening of the Community Information System. } \\
\text { - Monitoring of the minimum expected weight according to new } \\
\text { growth standards (WHO). }\end{array}$ \\
\hline \multicolumn{4}{|c|}{ Restitution of the Right of Children to Live a Decent and Happy Childhood (AMOR Program) } \\
\hline $\begin{array}{l}\text { 5) Restore to } \\
\text { children and } \\
\text { adolescents the } \\
\text { right to live under } \\
\text { normal family } \\
\text { conditions, without } \\
\text { running the risks of } \\
\text { the streets and to } \\
\text { have a decent life } \\
\text { without child labor. }\end{array}$ & $\begin{array}{l}\text { Increase in the number of } \\
\text { children and adolescents } \\
\text { on the streets, exposed to } \\
\text { risks and the worst forms } \\
\text { of child labor, who are } \\
\text { now enrolled in school. }\end{array}$ & $\begin{array}{l}\text { Thus far, } 10,670 \text { children and adolescents have been } \\
\text { removed from the streets; of these, } 6,976 \text { are already enrolled } \\
\text { and attending school. }\end{array}$ & $\begin{array}{l}\text { - Provide comprehensive care to those children and adolescents that } \\
\text { are exposed to risk and found on the streets. } \\
\text { - Ensure their enrollment and permanence in school and their } \\
\text { promotion to the next grade level. } \\
\text { - Provide academic reinforcement to those that most need it. } \\
\text { - Ensure their participation in cultural, recreational and sports } \\
\text { activities. } \\
\text { - Raise the awareness of the family so that an adult replaces the child } \\
\text { in the work activity and enrolls the child in school. }\end{array}$ \\
\hline
\end{tabular}




\begin{tabular}{|c|c|c|c|}
\hline $\begin{array}{c}\text { Perspective / } \\
\text { Strategic } \\
\text { Objective } \\
\end{array}$ & Results Indicator & $\begin{array}{c}\text { Summary of Achievements } \\
(2007-2008-\text { First Half of 2009) }\end{array}$ & $\begin{array}{l}\text { 2009-2011 Furtherance Actions } \\
\text { With implementation ensured through institutional plans and budgets, } \\
\text { with follow-up from the SIGRUN, BP-SNIP and SIGFA }\end{array}$ \\
\hline $\begin{array}{l}\text { 6) Ensure the care } \\
\text { of children of } \\
\text { working mothers, } \\
\text { providing them } \\
\text { with } \\
\text { comprehensive } \\
\text { care to improve } \\
\text { their educational, } \\
\text { nutritional and } \\
\text { health conditions. }\end{array}$ & $\begin{array}{l}\text { Increase in the number of } \\
\text { children under six years of } \\
\text { age receiving } \\
\text { comprehensive care at } \\
\text { Child Development } \\
\text { Centers (CDI). }\end{array}$ & $\begin{array}{l}\text { Thus far, comprehensive care has been provided in CDIs to } \\
4,737 \text { children under six years of age who have working } \\
\text { mothers in urban areas; and to } 83,884 \text { children under six } \\
\text { years of age in rural Community CDIs and Base Houses. }\end{array}$ & $\begin{array}{l}\text { - Provide comprehensive care in urban CDIs and Community CDIs } \\
\text { and Base Houses, which includes: } \\
\text { - Providing early stimulation, school readiness and } \\
\text { complementary feeding. } \\
\text { - Monitoring growth and development. } \\
\text { - Provide micronutrient supplementation. }\end{array}$ \\
\hline \multicolumn{4}{|c|}{ Access to Drinking Water and Sanitation } \\
\hline \multirow[t]{2}{*}{$\begin{array}{l}\text { 7) Provide national } \\
\text { coverage of } \\
\text { drinking water. }\end{array}$} & $\begin{array}{l}\text { Increase in the effective } \\
\text { coverage of drinking water } \\
\text { in urban areas. }\end{array}$ & $\begin{array}{l}\text { - Approval of the General Law on National Waters and its } \\
\text { Enabling Regulations (2007). } \\
\text { - Establishment of the Drinking Water and Sanitation Sector } \\
\text { Roundtable, and its respective Technical Commission. } \\
\text { - Investments with priority on the areas where water service } \\
\text { was most interrupted and where there was the greatest } \\
\text { urgency to rehabilitate the network, in areas with the poorest } \\
\text { neighborhoods. } \\
\text { - Infrastructure for water distribution was improved to supply } \\
\text { historic neighborhoods in the capital and other municipalities } \\
\text { where service was irregular and insufficient. }\end{array}$ & $\begin{array}{l}\text { - Formulate and implement the Urban and Rural Water and } \\
\text { Sanitation Strategy. } \\
\text { - Consolidate the Water and Sanitation Sector Roundtable. } \\
\text { - Execute projects to improve the drinking water and sanitation } \\
\text { systems. } \\
\text { - Ensure investments by the sector in the most impoverished } \\
\text { municipalities, communities and neighborhoods of the country. } \\
\text { - Begin projects in the second half of } 2009 \text { to substantially improve } \\
\text { water and sanitation service in Districts V and VI of Managua, } \\
\text { benefiting more than } 30 \text { neighborhoods. } \\
\text { - Execute projects in San Juan del Sur, Granada and Boaco to } \\
\text { improve the drinking water and sanitation systems. } \\
\text { - Initiate the second phase of the drinking water and sanitation } \\
\text { project for Nueva Segovia, Madriz and Estelí. }\end{array}$ \\
\hline & $\begin{array}{l}\text { Increase in the effective } \\
\text { coverage of water in rural } \\
\text { areas. }\end{array}$ & $\begin{array}{l}\text { - Water and Sanitation Strategy for the Rural Sector (October } \\
\text { 2007). } \\
\text { - Reexamination of the Poverty Map, providing special } \\
\text { attention to the allocation of resources to the municipalities } \\
\text { in a state of severe and high poverty over those with medium } \\
\text { and low poverty levels. More than } 60 \% \text { of investments by the } \\
\text { New Social Investment Emergency Fund (FISE) are in } \\
\text { municipalities with severe and high poverty. } \\
\text { - Creation of the Water, Sanitation and Hygiene Office, } \\
\text { strengthening the governance role of the New FISE in the } \\
\text { rural water and sanitation sector. }\end{array}$ & $\begin{array}{l}\text { - Formulate and implement the Urban and Rural Water and } \\
\text { Sanitation Strategy. } \\
\text { - Consolidate the Water and Sanitation Sector Roundtable. } \\
\text { - Strengthen training processes and consolidate regulatory and } \\
\text { methodological efforts. } \\
\text { - Ensure investments by the sector in the most impoverished } \\
\text { municipalities and communities of the country. } \\
\text { - Continue to promote the Community-Guided Projects (CGP) } \\
\text { execution model which promotes empowerment of the community } \\
\text { through the projects while also ensuring their sustainability. } \\
\text { - Execute construction and rehabilitation project for household water } \\
\text { connections. }\end{array}$ \\
\hline
\end{tabular}




\begin{tabular}{|c|c|c|c|}
\hline $\begin{array}{l}\text { Perspective / } \\
\text { Strategic } \\
\text { Objective }\end{array}$ & Results Indicator & $\begin{array}{c}\text { Summary of Achievements } \\
(2007-2008-\text { First Half of 2009) }\end{array}$ & $\begin{array}{l}\text { 2009-2011 Furtherance Actions } \\
\text { With implementation ensured through institutional plans and budgets, } \\
\text { with follow-up from the SIGRUN, BP-SNIP and SIGFA }\end{array}$ \\
\hline \multirow[t]{2}{*}{$\begin{array}{l}\text { 8) Provide national } \\
\text { coverage of } \\
\text { sanitary sewerage. }\end{array}$} & $\begin{array}{l}\text { Increase in access by the } \\
\text { urban population to } \\
\text { sewerage service. }\end{array}$ & $\begin{array}{l}\text { - Initiation of operations of Treatment Plant for Managua and } \\
\text { Ciudad Sandino; and progress on the projects in Granada } \\
\text { (Diriá-Diriomo), Boaco and San Juan del Sur. }\end{array}$ & $\begin{array}{l}\text { - Continue execution of the projects in Boaco, San Juan del Sur and } \\
\text { Granada. } \\
\text { - Continue installing household connections to the sewerage system } \\
\text { as a priority. } \\
\text { - Conduct education and awareness campaigns as part of the } \\
\text { integration of the community and institutions into the care of the } \\
\text { network and its good use so that the treatment plants are not } \\
\text { damaged. }\end{array}$ \\
\hline & $\begin{array}{l}\text { Increase in sanitation } \\
\text { coverage in rural areas }\end{array}$ & $\begin{array}{l}\text { - Construction of } 14,892 \text { latrines, particularly in } \\
\text { municipalities with severe and high poverty. }\end{array}$ & $\begin{array}{l}\text { - Continue investment in the construction of latrines in the poorest } \\
\text { municipalities. }\end{array}$ \\
\hline \multicolumn{4}{|c|}{ PRODUCTION PERSPECTIVE } \\
\hline $\begin{array}{l}\text { 1) Increase the } \\
\text { generation of } \\
\text { electricity for the } \\
\text { people and the } \\
\text { economy. }\end{array}$ & $\begin{array}{l}\text { Number of additional MW } \\
\text { of energy capacity } \\
\text { produced. }\end{array}$ & $\begin{array}{l}\text { Energy rationing was eliminated: } \\
\text { - In 2007, the National Energy Company (ENEL) and the } \\
\text { National Electrical Transmission Company (ENATREL) } \\
\text { installed and initiated commercial operations of } 60 \mathrm{MW} \text { with } \\
\text { the Hugo Chávez Plants } 1 \text { and } 2 \text {; In } 2008 \text {, significant } \\
\text { coordination efforts were made among the Ministry of } \\
\text { Energy and Mines (MEM), ENEL, ENATREL and } \\
\text { ALBANISA to install } 220 \mathrm{MW} \text { of generation based on fuel } \\
\text { oil. Of these, ENEL and ENATREL installed } 60 \mathrm{MW} \text { in the } \\
\text { Ernesto Ché Guevara Plants } 1,2 \text { and 3, which are now in } \\
\text { operation. } \\
\text { - In the first half of } 2009 \text {, ALBANISA initiated the operation } \\
\text { of the } 40 \text { MW Monimbó Plant. } \\
\text { The change in the electrical generation grid was initiated: } \\
\text { - The AMAYO Consortium, with an investment of US } \$ 95.0 \\
\text { million and comprised of private investors, completed } \\
\text { installation and began commercial operations with } 40 \mathrm{MW} \text { of } \\
\text { wind generation in February } 2009 \text {. }\end{array}$ & $\begin{array}{l}\text { Ensure the reliable supply of electrical energy through the increase in } \\
\text { electrical generation potential: } \\
\text { - Update the 2007-2017 Strategic Plan and the Action Plan for } \\
\text { Nicaragua's Energy Sector. } \\
\text { - Continue negotiations among the MEM, ENEL, ENATREL and } \\
\text { ALBANISA to complete the installation of the } 220 \mathrm{MW} \text { planned. Of } \\
\text { these, } 40 \mathrm{MW} \text { is scheduled to go on line in Puerto Sandino in } 2010 \text {. } \\
\text { Continue the change in the electrical generation grid: } \\
\text { - The San Jacinto-Tizate Geothermal Project ( } 72 \mathrm{MW} \text { ) is underway } \\
\text { and } 24 \mathrm{MW} \text { will go on line in the second half of } 2011 \text {, with the } \\
\text { remaining capacity scheduled to be operating in the first half of } \\
2012 \text {. } \\
\text { - The Special Law for the Development of the Tumarín } \\
\text { Hydroelectric Project was approved, and this plant is anticipated to } \\
\text { be in operation in } 2014 . \\
\text { - Awarding of contracts for the construction of works on the } 12 \mathrm{MW} \\
\text { Larreynaga Hydroelectric Plant, which will begin operating in } 2012 \text {. } \\
\text { - Develop the Salto Y-Y (25 MW) and Hydropantasma (12 MW) } \\
\text { Projects, which will begin operating in } 2012 \text {. } \\
\text { - The El Hoyo ( } 40 \text { MW) and Managua-Chiltepe ( } 40 \text { MW) } \\
\text { geothermic areas will be developed. } \\
\text { - A concession was granted through a bidding process for the Casita- } \\
\text { San Cristóbal geothermic areas, with an estimated potential of } 100 \\
\text { MW. }\end{array}$ \\
\hline
\end{tabular}




\begin{tabular}{|c|c|c|c|}
\hline $\begin{array}{l}\text { Perspective / } \\
\text { Strategic } \\
\text { Objective }\end{array}$ & Results Indicator & $\begin{array}{c}\text { Summary of Achievements } \\
(2007-2008-\text { First Half of 2009) }\end{array}$ & $\begin{array}{l}\text { 2009-2011 Furtherance Actions } \\
\text { With implementation ensured through institutional plans and budgets, } \\
\text { with follow-up from the SIGRUN, BP-SNIP and SIGFA }\end{array}$ \\
\hline \multirow{2}{*}{$\begin{array}{l}\text { 2) Increase the } \\
\text { expansion of the } \\
\text { electrical energy } \\
\text { transmission grid. }\end{array}$} & $\begin{array}{l}\text { Increase in the number of } \\
\text { rural households with } \\
\text { electricity. }\end{array}$ & $\begin{array}{l}\text { Electrical coverage was increased in the rural sector: } \\
\text { - In } 2007 \text { and } 2008,20,525 \text { houses received electricity, } \\
\text { benefiting } 123,150 \text { residents in rural areas. } \\
\text { - Extensions of distribution networks were included and } \\
\text { networks were built for small hydroelectric plants, micro- } \\
\text { turbines and individual photovoltaic systems. } \\
\text { - In the first half of } 2009 \text {, electrical service was connected to } \\
\text { meters in } 939 \text { houses and networks and internal installations } \\
\text { were completed, allowing the installation of } 915 \text { additional } \\
\text { meters in that same number of houses. }\end{array}$ & $\begin{array}{l}\text { Continue increasing electrical coverage in the rural sector: } \\
\text { - The government will continue developing rural electrification } \\
\text { projects in the different communities of the country. } \\
\text { - It will also build small hydroelectric plants in isolated areas and the } \\
\text { associated electrical networks, and generation and distribution } \\
\text { concessions will be granted to local enterprises. } \\
\text { - Electrification of isolated areas in the RAAN will continue with } \\
\text { photovoltaic solar panels. }\end{array}$ \\
\hline & $\begin{array}{l}\text { Number of additional } \\
\text { megavolt-amperes (MVA) } \\
\text { for increased } \\
\text { transformation capacity }\end{array}$ & $\begin{array}{l}\text { Expansion, modernization and reinforcement of the national } \\
\text { transmission grid: } \\
\text { - In 2008, new Siuna sub-station, } 6.25 \mathrm{MVA}, 69-24.9 \mathrm{kV} \text {. } \\
\text { - In 2009, change in the transformer from } 5 \text { MVA to } 15 \\
\text { MVA in the Nandaime sub-station. } \\
\text { - New Granada sub-station, } 25 / 40 \text { MVA, } 138 \text { - } 13.8 \mathrm{kV} \text { (40 } \\
\text { MVA). }\end{array}$ & - Contract for the supply of powerful transformers. \\
\hline \multirow[t]{2}{*}{$\begin{array}{l}\text { 3) Improve roads } \\
\text { to expand access to } \\
\text { basic services and } \\
\text { to the market. }\end{array}$} & $\begin{array}{l}\text { Number of new kilometers } \\
\text { of secondary roads. }\end{array}$ & $\begin{array}{l}\text { Generation of wealth was promoted, increasing production } \\
\text { for internal consumption and for export, improving rural } \\
\text { roads (roads and bridges) in order to improve productivity } \\
\text { and access to markets. } \\
\text { - In } 2007,19.46 \text { kilometers were executed. } \\
\text { - In } 200820.43 \text { kilometers were executed. } \\
\text { - In the first half of } 2009,51.09 \text { kilometers were built. }\end{array}$ & $\begin{array}{l}\text { - Continue contracting private national and international construction } \\
\text { companies. }\end{array}$ \\
\hline & $\begin{array}{l}\text { Number of rehabilitated } \\
\text { kilometers of secondary } \\
\text { roads. }\end{array}$ & $\begin{array}{l}\text { - In } 2007,82.52 \text { kilometers were executed. } \\
\text { - In } 2008102.38 \text { kilometers were executed. } \\
\text { - In the first half of } 2009,12.27 \text { kilometers were built. }\end{array}$ & - Contract private national and international construction companies. \\
\hline
\end{tabular}




\begin{tabular}{|c|c|c|c|}
\hline $\begin{array}{l}\text { Perspective / } \\
\text { Strategic } \\
\text { Objective }\end{array}$ & Results Indicator & $\begin{array}{c}\text { Summary of Achievements } \\
(2007-2008-\text { First Half of 2009) }\end{array}$ & $\begin{array}{l}\text { 2009-2011 Furtherance Actions } \\
\text { With implementation ensured through institutional plans and budgets, } \\
\text { with follow-up from the SIGRUN, BP-SNIP and SIGFA }\end{array}$ \\
\hline \multirow[t]{2}{*}{$\begin{array}{l}\text { 4) Increase } \\
\text { agricultural, } \\
\text { livestock and } \\
\text { industrial } \\
\text { production }\end{array}$} & $\begin{array}{l}\% \text { increase in agricultural } \\
\text { production. }{ }^{4 /}\end{array}$ & $\begin{array}{l}\text { Policies were implemented to improve production, } \\
\text { particularly of basic grains, through inputs programs } \\
\text { (certified seed and urea) and the incorporation of new } \\
\text { varieties adapted from seed. During the } 2007-2008 \text { cycle, } \\
94,247 \text { bean, rice and sorghum farmers were attended (first } \\
\text { and second planting seasons) with distribution of } 65,470 \\
\text { quintals of seed. This program is serving } 140,000 \text { farmers in } \\
\text { the } 2008-2009 \text { cycle with } 82,625 \text { quintals of seeds for basic } \\
\text { grains. } \\
\text { In order to increase exports: } \\
\text { - The commercial framework for exchange of goods and } \\
\text { services with ALBA countries was consolidated, opening } \\
\text { new markets with Venezuela, Cuba and Taiwan, among } \\
\text { others, which has had a positive impact. } \\
\text { - The benefits offered by the Generalized System of } \\
\text { Preferences (GSP) of the European Union have been } \\
\text { extended until } 2011 \text {, which will allow Nicaragua to continue } \\
\text { to export to that region. } \\
\text { Major achievements in the Central American Economic } \\
\text { Integration process: } \\
\text { - Signing of the } 2009-2011 \text { Multi-year Central American } \\
\text { Integration Plan. } \\
\text { - The Central American Uniform Customs Code (CAUCA) } \\
\text { and its Regulations (RECAUCA) entered into effect. The } \\
\text { objective of the Code is to standardize customs procedures. } \\
\text { - Implementation of the new online system for procedures, } \\
\text { SIEXPORT, which reduces the number of procedures by } \\
60 \% \text {, and is accessible } 24 \text { a day and } 365 \text { days a year for } \\
\text { export companies from any part of the world. }\end{array}$ & \multirow[t]{2}{*}{$\begin{array}{l}\text { - Establish policies directed at increasing productivity of basic grains } \\
\text { as well as the production of meat, milk and eggs within the } \\
\text { framework of the National Sector Program (PRORURAL } \\
\text { INCLUSIVE) through the National Food Plan. These policies } \\
\text { include the National Seed System, the Cattle Ranching Policy, and } \\
\text { the implementation of agricultural insurance, among others. } \\
\text { - Also provide: } \\
\text { - Access to inputs, equipment, financial services and materials. } \\
\text { - Technological services: technical assistance, extension and } \\
\text { investigation, and local technology markets. } \\
\text { - Food safety and health services. } \\
\text { - Agricultural, livestock and forestry information services. } \\
\text { - Support services for sustainable forestry management. } \\
\text { - Promotion of associations: professional and labor, cooperative } \\
\text { and community. } \\
\text { - Investment in conservation and the restoration of forestry } \\
\text { ecosystems. } \\
\text { - Facilitation of market agro-industrial processing linkages. } \\
\text { - Support to farmers to take advantage of the meat and dairy export } \\
\text { quotas under the different free trade agreements. }\end{array}$} \\
\hline & $\begin{array}{l}\% \text { increase in yields of } \\
\text { corn and beans. }\end{array}$ & $\begin{array}{l}\text { In } 2007 \text {, there was a } 2 \% \text { increase in yields and in } 2008 \text { it was } \\
\text { decreasing with } 5 \% \text {. }\end{array}$ & \\
\hline
\end{tabular}




\begin{tabular}{|c|c|c|c|}
\hline $\begin{array}{l}\text { Perspective / } \\
\text { Strategic } \\
\text { Objective }\end{array}$ & Results Indicator & $\begin{array}{c}\text { Summary of Achievements } \\
(2007-2008-\text { First Half of 2009) }\end{array}$ & $\begin{array}{l}\text { 2009-2011 Furtherance Actions } \\
\text { With implementation ensured through institutional plans and budgets, } \\
\text { with follow-up from the SIGRUN, BP-SNIP and SIGFA }\end{array}$ \\
\hline & $\begin{array}{l}\% \text { increase of industrial } \\
\text { production. } 4 /\end{array}$ & $\begin{array}{l}\text { - In 2008, the National Industrial Development Policy was } \\
\text { approved and its } 2009-2011 \text { Implementation Plan was } \\
\text { formulated. } \\
\text { - The Non-refundable Financial Assistance Fund of C\$5.6 } \\
\text { million is operating to equip industrial microenterprises, and } \\
\text { will benefit } 200 \text { industrial microenterprises and } 10 \text { credit } \\
\text { unions. } \\
\text { - The } 2009-2011 \text { Technological Development Program, the } \\
\text { National Innovation System (SNI) and the Nicaraguan } \\
\text { Technical Innovation Fund (FONITEC) were formulated. } \\
\text { - In the first half of 2009, the Mexican Competitiveness } \\
\text { Institute completed the methodological transfer of the } \\
\text { System of Competitiveness Indicators to the Central } \\
\text { American countries. } \\
\text { - The 2009-2013 National Program for Development of } \\
\text { Micro-, Small and Medium Enterprises (PROMIPYME) is } \\
\text { being formulated. } \\
\text { - More than 7,000 micro-, small and medium enterprise } \\
\text { owners from different economic sectors were assisted in } \\
\text { improving their production quality, marketing and } \\
\text { positioning in national, regional and international markets. }\end{array}$ & $\begin{array}{l}\text { - Seek funds and execute the National Industrial Development } \\
\text { Policy: some of these projects are scheduled to begin execution in } \\
2009 \text { and others in } 2010 \text {. } \\
\text { - Prepare and execute a Plan to Strengthen Human Capital for } \\
\text { Industrial Development, defining actions to be developed in the next } \\
\text { five to ten years. } \\
\text { - Implement the First and Second Phases of Expansion of the } \\
\text { National Program for Development of Micro-, Small and Medium } \\
\text { Enterprises (PROMIPYME). } \\
\text { - Implement a support program for micro-, small and medium } \\
\text { enterprises with a gender perspective (which will be part of } \\
\text { PROMIPYME), which prioritizes activities for organizational } \\
\text { strengthening (cooperatives, networks and other types of } \\
\text { associations) as well as an increase in productivity and marketing. }\end{array}$ \\
\hline \multicolumn{4}{|c|}{ NATURAL DISASTERS AND ENVIRONMENTAL PERSPECTIVE } \\
\hline \multicolumn{4}{|l|}{ Environment } \\
\hline $\begin{array}{l}\text { 1) Ensure forests } \\
\text { for the future. }\end{array}$ & $\begin{array}{l}\text { Number of hectares } \\
\text { reforested in the } \\
\text { framework of the National } \\
\text { Reforestation Campaign }\end{array}$ & $\begin{array}{l}\text { - Formulation, approval and implementation of the National } \\
\text { Reforestation Crusade, to repopulate } 25,164 \text { hectares in } \\
\text { degraded areas of watersheds with the highest risks, } \\
\text { improving the quality of life of } 37,000 \text { families of small and } \\
\text { medium scale farmers from } 49 \text { municipalities in the } \\
\text { provinces of Managua, León, Chinandega, Matagalpa, } \\
\text { Jinotega, Estelí, Madriz, Nueva Segovia, Masaya, Granada, } \\
\text { Carazo, Rivas and Río San Juan, and the indigenous and } \\
\text { Afro-descendant communities of the North and South } \\
\text { Atlantic Autonomous Regions. }\end{array}$ & $\begin{array}{l}\text { - Organize and train the community reforestation brigades, with } \\
\text { special participation by youth, the Citizen Power cabinets and the } \\
\text { native peoples, in the case of community forestry. } \\
\text { - Equip and train the reforestation brigades. } \\
\text { - Produce plants through forestry and community nurseries. } \\
\text { - Plant and care for the trees through community participation. } \\
\text { - Execute the National Community Forestry Strategy. } \\
\text { - Promote participation by the private sector in the planting of trees. } \\
\text { - Provide active support from the public forestry sector for new } \\
\text { projects through carbon credit financing, including the reduction of } \\
\text { emissions due to the prevention of deforestation. } \\
\text { - Expand and execute the National Environmental Fund and the } \\
\text { National Protected Areas Fund. }\end{array}$ \\
\hline
\end{tabular}




\begin{tabular}{|c|c|c|c|}
\hline $\begin{array}{l}\text { Perspective / } \\
\text { Strategic } \\
\text { Objective }\end{array}$ & Results Indicator & $\begin{array}{c}\text { Summary of Achievements } \\
(2007-2008-\text { First Half of 2009) }\end{array}$ & $\begin{array}{l}\text { 2009-2011 Furtherance Actions } \\
\text { With implementation ensured through institutional plans and budgets, } \\
\text { with follow-up from the SIGRUN, BP-SNIP and SIGFA }\end{array}$ \\
\hline $\begin{array}{l}\text { 2) Control and } \\
\text { reduce pollution. }\end{array}$ & $\begin{array}{l}\text { Number of registered } \\
\text { companies implementing } \\
\text { environmental } \\
\text { management programs to } \\
\text { reduce pollution }\end{array}$ & $\begin{array}{l}\text { - Support was provided to initiatives for production } \\
\text { efficiency and the reduction of environmental pollution in the } \\
\text { dairy, tannery, coffee, slaughterhouse and shrimping sectors, } \\
\text { through strict supervision, monitoring and control of } 307 \\
\text { environmental management plans and six manuals on good } \\
\text { environmental practices. }\end{array}$ & $\begin{array}{l}\text { - Conduct inventory of pollutant loads with a focus on watersheds. } \\
\text { - Update the standards of control for wastewater disposal. } \\
\text { - Foster voluntary actions for cleaner production in prioritized } \\
\text { sectors. } \\
\text { - Offer technical support for the development of environmental } \\
\text { management plans. }\end{array}$ \\
\hline \multicolumn{4}{|c|}{ Natural Disaster Prevention, Relief and Mitigation } \\
\hline $\begin{array}{l}\text { 3) Reduce the } \\
\text { impact of natural } \\
\text { disasters on the } \\
\text { country. }\end{array}$ & $\begin{array}{l}\text { Number of early warning } \\
\text { systems (EWS) for } \\
\text { tsunamis, earthquakes, } \\
\text { volcanic eruptions, floods, } \\
\text { landslides and volcanic } \\
\text { mudflows in the most } \\
\text { vulnerable sites in the } \\
\text { country. }\end{array}$ & $\begin{array}{l}\text { - In 2007, two EWS were installed in the area of El Rama, } \\
\text { Bluefields and Kukra Hill, which include limnimetric } \\
\text { stations and the development of local capacities; and in the } \\
\text { Cerro Negro Volcano with eight seismic stations and six } \\
\text { webcams. } \\
\text { - In 2008, three EWS were installed: one for tsunamis in San } \\
\text { Rafael del Sur, comprised of three sirens, two seismic } \\
\text { stations, a threat map and an evacuation plan; another for } \\
\text { volcanic eruptions in the Telica Volcano with six seismic } \\
\text { stations and three webcams; and another for floods in the } \\
\text { urban area of Quilalí. } \\
\text { - In } 2008 \text {, a study was conducted and a flood map was } \\
\text { developed in the watershed of the Río Grande de Matagalpa } \\
\text { and in the urban sector of the municipality of Quilalí. } \\
\text { - In the first half of 2009, a Community EWS was installed } \\
\text { in the Mining Triangle that encompasses the Kahka, Waspuk } \\
\text { and Pis Pis Rivers in the Coco River watershed. This system } \\
\text { includes six limnimeters. }\end{array}$ & $\begin{array}{l}\text { - Seek resources with cooperation for the purchase of equipment. } \\
\text { - Select and evaluate the sites for installation of the Early Warning } \\
\text { Systems. } \\
\text { - Manage the support from the municipal authorities. } \\
\text { - Ensure the acquisition, installation and initiation of operations of } \\
\text { the EWS. } \\
\text { - Ensure the good administration and operation of the EWS. } \\
\text { - Implement a National Disaster Response Fund. }\end{array}$ \\
\hline $\begin{array}{l}\text { 4) Influence the } \\
\text { insertion and } \\
\text { consolidation of } \\
\text { planning and } \\
\text { organizational } \\
\text { processes with a } \\
\text { risk management } \\
\text { approach in } \\
\text { institutional and } \\
\text { sector plans. }\end{array}$ & $\begin{array}{l}\text { Number of Municipal } \\
\text { Committees for Disaster } \\
\text { Prevention, Mitigation and } \\
\text { Relief (COMUPRED) } \\
\text { organized in the } \\
\text { municipalities of } \\
\text { Nicaragua. }\end{array}$ & $\begin{array}{l}\text { - Transmission of a disaster prevention culture, through the } \\
\text { training of } 1,353 \text { teachers and the strengthening of } \\
\text { COMUPRED, training 1,391 people, including delegates } \\
\text { from the National System for Disaster Prevention, Mitigation } \\
\text { and Relief (SINAPRED), the Ministry of the Interior and } \\
\text { authorities from the municipal governments. } \\
\text { - Execution of an earthquake drill, for a earthquake of } 6.7 \\
\text { degrees on the Richter Scale in the city of Managua. } \\
\text { - Development and execution of contingency plans for } \\
\text { different types of threats, such as prevention of forest fires, } \\
\text { intense rain and tsunamis. } \\
\text { - Strengthening the territorial SINAPRED structures, with } \\
\text { the appointment of the Executive Secretariats at the regional, } \\
\text { provincial and municipal levels. } \\
\text { - Development and distribution of } 44 \text { municipal response }\end{array}$ & $\begin{array}{l}\text { - Ensure the inclusion of risk management in municipal planning. } \\
\text { - Maintain the structures and operations of the COMUPRED in all } \\
\text { municipalities of the country. } \\
\text { - Update the } 153 \text { Municipal Response Plans. } \\
\text { - Ensure the supply of resources from international cooperation. }\end{array}$ \\
\hline
\end{tabular}




\begin{tabular}{|c|c|c|c|}
\hline $\begin{array}{l}\text { Perspective / } \\
\text { Strategic } \\
\text { Objective }\end{array}$ & Results Indicator & $\begin{array}{c}\text { Summary of Achievements } \\
(2007-2008-\text { First Half of 2009) }\end{array}$ & $\begin{array}{l}\text { 2009-2011 Furtherance Actions } \\
\text { With implementation ensured through institutional plans and budgets, } \\
\text { with follow-up from the SIGRUN, BP-SNIP and SIGFA }\end{array}$ \\
\hline & & plans. & \\
\hline & $\begin{array}{l}\% \text { of families affected by } \\
\text { natural disasters that } \\
\text { receive solidary attention } \\
\text { (ensure } 100 \% \text { ). }\end{array}$ & $\begin{array}{l}\text { - Relief was provided to } 355,049 \text { people affected by natural } \\
\text { disasters, supplying them with food, provisions and } \\
\text { construction materials. }\end{array}$ & $\begin{array}{l}\text { - Efficiently administer resources for disaster prevention, mitigation } \\
\text { and relief. } \\
\text { - Strengthen the territorial structures of the COMUPRED and } \\
\text { SINAPRED. } \\
\text { - Improve the Damage Assessments and Needs Analyses (DANA) to } \\
\text { attend } 100 \% \text { of the people affected by different natural phenomena. }\end{array}$ \\
\hline \multicolumn{4}{|c|}{ CARIBBEAN COAST PERSPECTIVE } \\
\hline $\begin{array}{l}\text { 1) Reduce } \\
\text { illiteracy. }\end{array}$ & $\begin{array}{l}\text { Decrease in the illiteracy } \\
\text { rate. }\end{array}$ & $\begin{array}{l}\text { - Coordinating commission and three sub-commissions } \\
\text { established to formulate and implement the Plan for } \\
\text { Regionalization of Education. } \\
\text { - The division to link MINED and the Regional Autonomous } \\
\text { Educational Sub-system (SEAR) was created. } \\
\text { - The education sub-delegation was established in Alto } \\
\text { Wangki - Bocay. } \\
\text { - Bonanza and Corn Island were declared Illiteracy-Free } \\
\text { Territories. } \\
\text { - The curriculum from preschool to sixth grade were } \\
\text { redesigned and implemented for intercultural bilingual } \\
\text { education. }\end{array}$ & $\begin{array}{l}\text { - Formulate the Regionalization Plan. } \\
\text { - Declare the urban centers of Siuna, Rama and Bluefields and the } \\
\text { other urban municipalities to be Illiteracy-Free Territories. } \\
\text { - Develop literacy instruction poster card for teaching in different } \\
\text { languages. } \\
\text { - Train monolingual teachers to manage the intercultural bilingual } \\
\text { programs. } \\
\text { - Conduct mapping and school census of the Caribbean region. }\end{array}$ \\
\hline $\begin{array}{l}\text { 2) Assure the right } \\
\text { to property. }\end{array}$ & $\begin{array}{l}\text { Finalization of the process } \\
\text { of demarcation and titling } \\
\text { of indigenous and Afro- } \\
\text { descendant territories and } \\
\text { complementary areas in } \\
2009 .\end{array}$ & $\begin{array}{l}\text { - Since } 2007 \text {, nine indigenous territories have been } \\
\text { demarcated and titled, benefiting } 53,000 \text { inhabitants of } 121 \\
\text { communities located in a total area of } 10,310 \mathrm{~km}^{2} \text { in the } \\
\text { RAAS, the RAAN and the Alto Wanki-Bocay. }\end{array}$ & $\begin{array}{l}\text { - Issue and distribute indigenous land titles in the Nicaraguan } \\
\text { Caribbean region. } \\
\text { - Develop assessments for each area which include conflict } \\
\text { resolution, the mediation process, demarcation and legal clearance. }\end{array}$ \\
\hline
\end{tabular}




\begin{tabular}{|c|c|c|c|}
\hline $\begin{array}{l}\text { Perspective / } \\
\text { Strategic } \\
\text { Objective }\end{array}$ & Results Indicator & $\begin{array}{c}\text { Summary of Achievements } \\
(2007-2008-\text { First Half of 2009) }\end{array}$ & $\begin{array}{l}\text { 2009-2011 Furtherance Actions } \\
\text { With implementation ensured through institutional plans and budgets, } \\
\text { with follow-up from the SIGRUN, BP-SNIP and SIGFA }\end{array}$ \\
\hline \multirow{2}{*}{$\begin{array}{l}\text { 3) Develop } \\
\text { economic } \\
\text { transformation that } \\
\text { is equitable, } \\
\text { sustainable and } \\
\text { harmonious } \\
\text { between human } \\
\text { beings and nature. }\end{array}$} & $\begin{array}{l}\text { Increase in access to } \\
\text { electricity services of } 40 \% \\
\text { by } 2011 .\end{array}$ & $\begin{array}{l}\text { - Development of the Y-Y (25 MW) and Tumarin (160 MW) } \\
\text { hydroelectric plants. } \\
\text { - National Interconnected System in Siuna, Bluff, Kukra Hill } \\
\text { and Pearl Lagoon-Kahkabila, benefiting 20,000 users. } \\
\text { - Generation units in Corn Island, Karawala, Rama Key and } \\
\text { Sahsa for a total of } 185 \mathrm{KW} \text { and } 1600 \text { beneficiaries. } \\
\text { - Expansion of the grid in Kukra Hill-Flor de Pino-Pearl } \\
\text { Lagoon with } 112 \text { kilometers of primary line and } 11 \\
\text { kilometers of secondary line. } \\
\text { - Connection to the electrical grid for pumping drinking } \\
\text { water in Sahsa, Mulukukú, Santa Rita and Siuna. }\end{array}$ & $\begin{array}{l}\text { - Rural Electrification Program. } \\
\text { - Electrical Interconnection Program. } \\
\text { - Construction of hydroelectric plants and micro-turbines. }\end{array}$ \\
\hline & $\begin{array}{l}10,000 \text { families } \\
\text { productively rehabilitated } \\
\text { living in indigenous and } \\
\text { Afro-descendant territories } \\
\text { and the most impoverished } \\
\text { municipalities }\end{array}$ & $\begin{array}{l}\text { - The Food Production Program is being implemented, } \\
\text { benefiting 7,571 families. } \\
\text { - Some 25,000 quintals of rice and bean seed are distributed. } \\
\text { - Some 3,500 quintals of beans and 17,000 quintals of } \\
\text { unhulled rice are harvested and commercialized, } \\
\text { strengthening organized groups of farmers. } \\
\text { - Food assistance was provided to the residents of } \\
\text { communities affected by Hurricane Felix and resources were } \\
\text { sought for rehabilitation of production. } \\
\text { - Some } 6,000 \text { quintals of improved rice seed were collected } \\
\text { from the harvest. }\end{array}$ & $\begin{array}{l}\text { - Establish seed bank in Alto Wangki. } \\
\text { - Formulate a strategy for the processing of rice and the management } \\
\text { of beans and corn. } \\
\text { - Install the Seed Processing Unit in the Experimental Center of the } \\
\text { Nicaraguan Agricultural Technology Institute in Kukra Hill. }\end{array}$ \\
\hline $\begin{array}{l}\text { 4) Strengthen } \\
\text { autonomous } \\
\text { institutional } \\
\text { development to } \\
\text { lead and execute } \\
\text { the Development } \\
\text { Plan for the } \\
\text { Caribbean Coast. }\end{array}$ & $\begin{array}{l}\text { Formulation and } \\
\text { implementation of } \\
\text { expanded multi-year } \\
\text { planning and budget that is } \\
80 \% \text { aligned and in } \\
\text { harmony with the } \\
\text { Development Plan of the } \\
\text { Caribbean Coast by } 2011 .\end{array}$ & $\begin{array}{l}\text { - The Development Strategy for the Caribbean Coast (PDCC) } \\
\text { has been formulated, agreed upon and officially approved. } \\
\text { - The Institutional Strengthening Plan of the RAAN has been } \\
\text { developed and approved and is being implemented. } \\
\text { - The Autonomous Regions are beginning the process of } \\
\text { aligning planning and the Medium-Term Budget Framework } \\
\text { to the PDCC with support from the MHCP and the } \\
\text { Development Secretariat for the Caribbean Coast (SDCC). } \\
\text { - Reference framework for the formulation of the } \\
\text { Institutional Strengthening Strategy and Plan for the RAAS. } \\
\text { - Mapping of resources according to the PDCC core areas } \\
\text { and programs is complete. }\end{array}$ & $\begin{array}{l}\text { - Develop and implement the Institutional Strengthening Strategy } \\
\text { and Plan for Rosita and the territorial governments of the } \\
\text { municipality. } \\
\text { - Implement the Integrated Results-based Management System in the } \\
\text { regions. } \\
\text { - Develop the Institutional Strengthening Plan for the RAAS. }\end{array}$ \\
\hline \multicolumn{4}{|c|}{ ACTIONS FOR GOOD PUBLIC ADMINISTRATION } \\
\hline
\end{tabular}




\begin{tabular}{|c|c|c|c|}
\hline $\begin{array}{l}\text { Perspective / } \\
\text { Strategic } \\
\text { Objective }\end{array}$ & Results Indicator & $\begin{array}{c}\text { Summary of Achievements } \\
(2007-2008 \text { - First Half of 2009) }\end{array}$ & $\begin{array}{l}\text { 2009-2011 Furtherance Actions } \\
\text { With implementation ensured through institutional plans and budgets, } \\
\text { with follow-up from the SIGRUN, BP-SNIP and SIGFA }\end{array}$ \\
\hline $\begin{array}{l}\text { 1) Foster } \\
\text { transparency and } \\
\text { integrity in public } \\
\text { administration. }\end{array}$ & $\begin{array}{l}\text { Number of State } \\
\text { institutions that have } \\
\text { offices that provide public } \\
\text { information to citizens. }\end{array}$ & $\begin{array}{l}\text { - The President of the Republic, through Decree } 117-2007 \text {, } \\
\text { Law } 621 \text {, ordered all government institutions to incorporate } \\
\text { the Offices for Access to Public Information (OAIP), which } \\
\text { is developing under a process that goes beyond the } \\
\text { commitment made. } \\
\text { - Due to financial limitations, the institutions have used } \\
\text { communications resources, the public relations offices and } \\
\text { documentation centers to offer public information to the } \\
\text { population. } \\
\text { - Offices were established with resources allocated } \\
\text { exclusively for that purpose. } \\
\text { - Public information from the institutions has been } \\
\text { incorporated onto their web pages. }\end{array}$ & $\begin{array}{l}\text { - Continue to classify and make information available for } \\
\text { incorporation into the information that can be accessed by the public, } \\
\text { physically in the offices and on the web pages of the institutions. }\end{array}$ \\
\hline $\begin{array}{l}\text { 2) Strengthen } \\
\text { public } \\
\text { administration. }\end{array}$ & $\begin{array}{l}\text { Number of accredited } \\
\text { public servants. }\end{array}$ & $\begin{array}{l}\text { - Regulations for the process have been developed. } \\
\text { - In 2007, 1,761 public servants were accredited and } 4,397 \\
\text { were accredited in } 2008 \text {. } \\
\text { - From the beginning of the accreditation process in } 2005 \text { to } \\
\text { June } 30,2009 \text {, a total of } 12,535 \text { public servants have been } \\
\text { accredited. }\end{array}$ & $\begin{array}{l}\text { - Coordinate institutionally with higher authorities and human } \\
\text { resources divisions to gradually incorporate public servants into the } \\
\text { public administration career. } \\
\text { - Provide technical assistance and training to human resources } \\
\text { management personnel and to union organizations. } \\
\text { - Develop the technical process for accreditation, preparation of the } \\
\text { results report and the issuing of administrative resolutions. }\end{array}$ \\
\hline
\end{tabular}




\begin{tabular}{|c|c|c|c|}
\hline $\begin{array}{l}\text { Perspective / } \\
\text { Strategic } \\
\text { Objective }\end{array}$ & Results Indicator & $\begin{array}{c}\text { Summary of Achievements } \\
(2007-2008-\text { First Half of 2009) }\end{array}$ & $\begin{array}{l}\text { 2009-2011 Furtherance Actions } \\
\text { With implementation ensured through institutional plans and budgets, } \\
\text { with follow-up from the SIGRUN, BP-SNIP and SIGFA }\end{array}$ \\
\hline & $\begin{array}{l}\text { Percentage of non- } \\
\text { financial public sector } \\
\text { institutions that maintain } \\
\text { the SIGRUN up-to-date to } \\
\text { support presidential } \\
\text { decision-making. }\end{array}$ & $\begin{array}{l}\text { - Fifty-two institutional plans have been developed in simple } \\
\text { language for communication with the people from a } \\
\text { perspective of rights restitution, to enable them to exercise } \\
\text { their right for oversight. In addition, the plans take on the } \\
\text { principle that national development does not only depend } \\
\text { upon the government, but also what can be done together by } \\
\text { citizens, unions, social movements, private enterprise and } \\
\text { international cooperation. } \\
\text { - A qualitative leap has been made in the generation of } \\
\text { information with the operation of a platform (the Information } \\
\text { System of the Government of Reconciliation and National } \\
\text { Unity, SIGRUN), installed on the intranet of the Presidency. } \\
\text { This system automates the } 52 \text { plans with a follow-up system } \\
\text { that can generate early warnings, facilitating timely decision- } \\
\text { making. } \\
\text { - This system consolidates a monthly report on fulfillment of } \\
\text { the institutional operating plans, identifying the areas where } \\
\text { there are gaps in fulfillment which are then re-examined so } \\
\text { that measures can be taken to address these by means of a } \\
\text { weekly review. } \\
\text { - Within and among the institutions, decisions are made to } \\
\text { correct the gaps between the planned goals and what has } \\
\text { truly been achieved. This work is initially done by the } \\
\text { planning team and the network of technical staff in the } \\
\text { institutions, and then is later reviewed in the Cabinet of the } \\
\text { Government. }\end{array}$ & $\begin{array}{l}\text { - Design and implement the National Planning System. } \\
\text { - Strengthen follow-up on the execution of plans, budgets and } \\
\text { investments. } \\
\text { - Strengthen the Planning and PIP Follow-up Commissions. }\end{array}$ \\
\hline
\end{tabular}




\begin{tabular}{|c|c|c|c|}
\hline $\begin{array}{c}\text { Perspective / } \\
\text { Strategic } \\
\text { Objective }\end{array}$ & Results Indicator & $\begin{array}{l}\text { Summary of Achievements } \\
(2007-2008-\text { First Half of 2009) }\end{array}$ & $\begin{array}{l}\text { 2009-2011 Furtherance Actions } \\
\text { With implementation ensured through institutional plans and budgets, } \\
\text { with follow-up from the SIGRUN, BP-SNIP and SIGFA }\end{array}$ \\
\hline & $\begin{array}{l}\text { Number of entities and } \\
\text { organizations of the central } \\
\text { public administration that } \\
\text { publish key phases of the } \\
\text { contracting procedures in } \\
\text { the portal: } \\
\text { www.nicaraguacompra.go } \\
\text { b.ni }\end{array}$ & $\begin{array}{l}\text { - The proposed Law on Administrative Contracts in the } \\
\text { Public Sector is before the National Assembly for review and } \\
\text { approval. } \\
\text { - One hundred and twenty-four workshops were conducted, } \\
\text { with participation by } 1,856 \text { trainees. } \\
\text { - Some } 28,746 \text { contracting procedures were published. }\end{array}$ & $\begin{array}{l}\text { - Provide massive training to public servants that work in the } \\
\text { Procurement Units regarding the use of the electronic portal. } \\
\text { - Provide on site advice and technical assistance in the Procurement } \\
\text { Units. } \\
\text { - Conduct workshops on the use of the electronic portal directed at } \\
\text { new officials in the Procurement Units, the private sector } \\
\text { (professional and labor associations, private companies and } \\
\text { individual tradespeople), microenterprises and small businesses, and } \\
\text { others. } \\
\text { - Conduct updating and reinforcement workshops. } \\
\text { - Provide follow-up and monitoring of the quality and timeliness of } \\
\text { the publication of notices. } \\
\text { - Send e-mail notifications or hard copies to the various entities, with } \\
\text { instructions about the publication of procedures or, in some cases, } \\
\text { about completing the missing phases of publication. } \\
\text { - Develop regulations and directives and vacate consultations. }\end{array}$ \\
\hline $\begin{array}{l}\text { 3) Ensure citizen } \\
\text { security. }\end{array}$ & $\begin{array}{l}\% \text { of deceleration of the } \\
\text { crime rate relative to the } \\
\text { demographic crime index. }\end{array}$ & $\begin{array}{l}\text { - The homicide rate per } 100,000 \text { inhabitants decreased from } \\
13.0 \% \text { in } 2006 \text { and } 2007 \text { to } 12.0 \% \text { in } 2008 \text {, placing it among } \\
\text { the lowest in Central America. } \\
\text { - In } 2008 \text {, the crime variation rate per } 100,000 \text { inhabitants } \\
\text { decreased to } 14.7 \% \text { from a level of } 15.7 \% \text { maintained during } \\
2006 \text { and } 2007 \text {. } \\
\text { - Crime has decelerated by } 5.0 \% \text { compared to the } \\
\text { demographic crime index, decreasing to } 6.0 \% \text { in } 2008 \text { from } \\
11.0 \% \text { in } 2007 \text {. }\end{array}$ & $\begin{array}{l}\text { - Convene organized groups to understand the major citizen safety } \\
\text { problems from the community's perspective in order to execute } \\
\text { comprehensive actions and to formulate strategies. } \\
\text { - Design inter-institutional actions for social prevention of crime with } \\
\text { local governments, Citizen Power Cabinets and the police. } \\
\text { - Execute plans and/or actions that decrease the factors that } \\
\text { negatively affect citizen security and life in communities. }\end{array}$ \\
\hline $\begin{array}{l}\text { 4) Ensure the right } \\
\text { to property. }\end{array}$ & $\begin{array}{l}\text { Number of property titles } \\
\text { issued by the government. }\end{array}$ & $\begin{array}{l}\text { - In the period from } 2007 \text { to the first half of } 2009,29,232 \\
\text { property documents have been issued, including urban and } \\
\text { rural titles, certificates of good standing under Laws } 85,86 \\
\text { and } 88 \text {, and certificates of compliance. } \\
\text { - To hasten the processing and solution of property problems, } \\
\text { and with the support of the Citizen Power Cabinets, } \\
\text { coordination is established with government institutions such } \\
\text { as the Office of the Attorney General (PGR), the Nicaraguan } \\
\text { Institute of Territorial Studies (INETER), Public Property } \\
\text { Registries and municipalities. Progress has been made in the } \\
\text { solution of property conflicts, through the implementation of } \\
\text { actions by the PGR, the Verification, Peace and } \\
\text { Reconciliation Commission, and the Citizen Power Cabinets. } \\
\text { - Mediation and inscription of State properties is guaranteed } \\
\text { in coordination with the PGR, INETER, the Central Bank of } \\
\text { Nicaragua (BCN) and the Public Registries of the country, } \\
\text { providing legal security regarding land ownership to the }\end{array}$ & $\begin{array}{l}\text { In order to decrease the insecurity regarding land ownership in } \\
\text { Nicaragua, the following actions will be taken: } \\
\text { - Prioritize and hasten topographic measurement of State properties. } \\
\text { - Establish inter-institutional coordination on working commissions, } \\
\text { comprised of the Property Administration Office, the BCN and the } \\
\text { PGR in order to ensure the process of transferring property from the } \\
\text { extinct banks and from the BCN to the State of Nicaragua. } \\
\text { - Effectively coordinate with the Public Property Registries and the } \\
\text { Central Registries to speed inscriptions of State properties to make it } \\
\text { possible to declare them to be social interest properties for titling. }\end{array}$ \\
\hline
\end{tabular}




\begin{tabular}{|c|c|c|c|}
\hline $\begin{array}{l}\text { Perspective / } \\
\text { Strategic } \\
\text { Objective }\end{array}$ & Results Indicator & $\begin{array}{c}\text { Summary of Achievements } \\
(2007-2008-\text { First Half of 2009) }\end{array}$ & $\begin{array}{l}\text { 2009-2011 Furtherance Actions } \\
\text { With implementation ensured through institutional plans and budgets, } \\
\text { with follow-up from the SIGRUN, BP-SNIP and SIGFA }\end{array}$ \\
\hline & & beneficiaries. & \\
\hline & $\begin{array}{l}\text { Number of beneficiary } \\
\text { families with property } \\
\text { documents issued. }\end{array}$ & $\begin{array}{l}\text { - In the period from } 2007 \text { to the first half of } 2009,149,991 \\
\text { Nicaraguan families received property documents, such as } \\
\text { urban and rural titles, certificates of good standing under } \\
\text { Laws } 85,86 \text { and } 88 \text {, and certificates of compliance, } \\
\text { providing them with legal security and stability in the } \\
\text { ownership of their lots and enabling them to be subjects of } \\
\text { credit to make their land produce and contribute to the socio- } \\
\text { economic development of the country, improving their } \\
\text { family economy and emerging out of poverty. }\end{array}$ & $\begin{array}{l}\text { - Continue implementing actions that ensure property rights and } \\
\text { security at all levels, through effective coordination among } \\
\text { government institutions (PGR, INETER and Public Registries) to } \\
\text { enable the Property Administration Office to issue property titles that } \\
\text { provide legal security and stability to all Nicaraguan families who } \\
\text { are benefitted. }\end{array}$ \\
\hline
\end{tabular}




\section{ACRONYMS}

$\begin{array}{ll}\text { ALBA } & \text { Bolivarian Alternative of the Americas } \\ \text { ANA } & \text { National Water Authority } \\ \text { BCN } & \text { Central Bank of Nicaragua } \\ \text { BSG } & \text { Budget Support Group } \\ \text { CS } & \text { Córdobas } \\ \text { CAFTA } & \text { Central America Free Trade Agreement } \\ \text { CDI } & \text { Community Child Development Centers } \\ \text { CGR } & \text { Comptroller General of the Republic } \\ \text { CIDA } & \text { Canadian International Development Agency } \\ \text { CNRH } & \text { National Council on Water Resources } \\ \text { CNS } & \text { National Sectoral Commissions } \\ \text { COMUPRED } & \text { Municipal Committee for Natural Disaster Prevention, Mitigation and Relief } \\ \text { CONADETI } & \text { National Commission for Territorial Demarcation } \\ \text { CONICYT } & \text { Nicaraguan Council on Science and Technology } \\ \text { CONPES } & \text { National Economic and Social Planning Council } \\ \text { CPP } & \text { Criminal Processing Code } \\ \text { DISNORTE } & \text { Northern Energy Distributor } \\ \text { DISSUR } & \text { Southern Energy Distributor } \\ \text { EDCC } & \text { Development Strategy of the Caribbean Coast } \\ \text { ENABAS } & \text { National Basic Foodstuffs Supply Company } \\ \text { ENACAL } & \text { Nicaraguan Water and Sewage Systems Company } \\ \text { ENATREL } & \text { National Electrical Transmission Company } \\ \text { FAO } & \text { United Nations Food and Agriculture Organization } \\ \text { FOMAV } & \text { Road Maintenance Fund } \\ \text { FOSOVI } & \text { Social Housing Fund } \\ \text { GDP } & \text { Gross Domestic Product } \\ \text { GRAAN } & \text { North Atlantic Autonomous Regional Government } \\ \text { GRAAS } & \text { South Atlantic Autonomous Regional Government } \\ \text { GRUN } & \text { Government of Reconciliation and National Unity } \\ \text { GTZ } & \text { German Technical Cooperation } \\ \text { HIPC } & \text { Heavily Indebted Poor Countries } \\ \text { IADB } & \text { Inter-American Development Bank } \\ \text { IFAD } & \text { International Fund for Agricultural Development } \\ \text { IMF } & \text { International Monetary Fund } \\ \text { INATEC } & \text { National Technological Institute } \\ \text { INETER } & \text { Nicaraguan Institute for Territorial Studies } \\ \text { INIDE } & \text { National Development Information Institute } \\ \text { INPESCA } & \text { Nicaraguan Fishing and Aquaculture Institute } \\ \text { INPYME } & \text { Small and Medium Enterprise Institute } \\ \text { INTUR } & \text { Tourism Institute } \\ \text { INVUR } & \text { Urban and Rural Housing Institute } \\ \text { LAFEX } & \text { Extraordinary Financial Assistance Line } \\ \text { LSMS } & \text { Living Standards Measurement Survey } \\ \text { MAGFOR } & \text { Ministry of Agriculture and Forestry } \\ & \end{array}$




\begin{tabular}{|c|c|}
\hline MCA & Millennium Challenge Account \\
\hline MEM & Ministry of Energy and Mining \\
\hline MHCP & Ministry of Finance and Public Credit \\
\hline MIFAMILIA & Ministry of the Family, Children and Adolescents \\
\hline MIFIC & Ministry of Development, Industry and Commerce \\
\hline MINED & Ministry of Education, Culture and Sports \\
\hline $\mathrm{MOH}$ & Ministry of Health \\
\hline MOSAFC & Family and Community Health Model \\
\hline MTBF & Medium-Term Budget Framework \\
\hline MTI & Ministry of Transportation and Infrastructure \\
\hline MVA & Megavolt-Amperes \\
\hline NHDP & National Human Development Plan \\
\hline PAHO & Pan-American Health Organization \\
\hline PETROCARIBE & Petróleos del Caribe \\
\hline PINE & Comprehensive School Nutrition Program \\
\hline PIP & Public Investment Program \\
\hline PGDH & Attorney General for the Defense of Human Rights \\
\hline PGR & Attorney General of the Republic \\
\hline PGR & General Budget of the Republic \\
\hline PNAIR & National Rural Agroindustry Program \\
\hline PNF & National Forestry Program \\
\hline PROASE & Education Sector Support Program \\
\hline PROCOSAN & Community Health and Nutrition Program \\
\hline PROMIPYME & Program for the Development of Micro-, Small and Medium Enterprise \\
\hline RAAN & North Atlantic Autonomous Region \\
\hline RAAS & South Atlantic Autonomous Region \\
\hline REDD & Reducing Emissions from Deforestation and Forest Degradation \\
\hline RED-CAP & Training and Pedagogical Accompaniment Network \\
\hline SDC & Swiss Development Cooperation \\
\hline SEAR & Autonomous Region Educational System \\
\hline SEN & National Statistical System \\
\hline SEPRES & Secretariat of the Presidency \\
\hline SIEPAC & Central American Electrical Interconnection System \\
\hline SIGADE & Debt Management and Financial Analysis System \\
\hline SIGFA & Integrated Financial Management and Auditing System \\
\hline SIGRUN & Information System of the National Government of Unity and Reconciliation \\
\hline SINAP & National System of Protected Areas \\
\hline SINAPRED & National Disaster Prevention, Mitigation and Relief System \\
\hline SNBS & National Social Welfare System \\
\hline SNIP & National Public Investment System \\
\hline SNT & National Transmission System \\
\hline SPAR & Rural Agriculture Public Sector \\
\hline SPN & National Penitentiary System \\
\hline SYSODA & Information System for Official Aid for Development for Nicaragua \\
\hline TELCOR & Nicaraguan Institute for Telecommunications and Mail \\
\hline TEPCEs & Educational Planning and Evaluation Workshops \\
\hline
\end{tabular}




$\begin{array}{ll}\text { TNC } & \text { The Nature Conservancy } \\ \text { UNDP } & \text { United Nations Development Program } \\ \text { UNESCO } & \text { United Nations Educational, Scientific and Cultural Organization } \\ \text { UNFCCC } & \text { United Nations Framework Convention on Climate Change } \\ \text { UNICEF } & \text { United Nations Children's Fund } \\ \text { UPS } & \text { Universal Postal Service } \\ \text { UPU } & \text { Universal Postal Union } \\ \text { US\$ } & \text { US Dollars } \\ \text { VPCD } & \text { Growth and Development Surveillance and Promotion } \\ \text { WB } & \text { World Bank } \\ \text { WHO } & \text { World Health Organization }\end{array}$

